PNL-10105

\title{
Assessment of Selected Alternative Mitigation Concepts for Hanford Flammable Gas Tanks
}

\author{
C. W. Stewart \\ L. A. Schienbein \\ J. D. Hudson \\ E. J. Eschbach \\ D. L. Lessor
}

September 1994

Prepared for

the U.S. Department of Energy

under Contract DE-AC06-76RLO 1830

Pacific Northwest Laboratory

Richland, Washington 99352 



\section{DISCLAIMER}

This report was prepared as an account of work sponsored by an agency of the United States Government. Neither the United States Government nor any agency thereof, nor any of their employees, make any warranty, express or implied, or assumes any legal liability or responsibility for the accuracy, completeness, or usefulness of any information, apparatus, product, or process disclosed, or represents that its use would not infringe privately owned rights. Reference herein to any specific commercial product, process, or service by trade name, trademark, manufacturer, or otherwise does not necessarily constitute or imply its endorsement, recommendation, or favoring by the United States Government or any agency thereof. The views and opinions of authors expressed herein do not necessarily state or reflect those of the United States Government or any agency thereof. 


\section{DISCLAIMER}

Portions of this document may be illegible in electronic image products. Images are produced from the best available original document. 


\section{Abstract}

This report provides a review and assessment of four selected mitigation concepts: pump jet mixing, sonic vibration, dilution, and heating. Though the relative levels of development of these concepts are quite different, some definite conclusions are made on their comparative feasibility. Key findings of this report are as follows:

- A mixer pump has proven to be a safe and effective active mitigation method in Tank 241SY-101, and we are confident that mixer pumps will effectively mitigate other tanks with comparable waste configurations and properties.

- Low-frequency sonic vibration is also predicted to be effective for mitigation.

- Existing data cannot prove that dilution can mitigate GRE behavior. However, dilution is the only concept of the four that potentially offers passive mitigation.

- Like dilution, heating the waste cannot be proven with available information to mitigate GRE behavior.

The designs, analyses, and data from which these conclusions are derived are presented along with recommendations. 


\section{Executive Summary}

Since 1943, large, steel-lined, underground, concrete storage tanks have been used at Hanford to store waste from the plutonium production process. Several of these tanks have been placed on the flammable gas watch list, because the waste is either known or suspected to be generating, storing, and periodically releasing flammable gases, principally hydrogen and nitrous oxide. While awaiting retrieval operations and ultimate disposal, each tank must be maintained in a safe condition. That is, the accumulation of flammable gases and the potentially hazardous and uncontrolled episodic releases of large volumes of gas must be prevented. The actions to accomplish this constitute mitigation.

Four selected mitigation concepts have been pursued: mixing, sonic vibration, dilution, and heating. Only the mixing pump concept has proceeded through to full-scale, in-tank testing and demonstration in Tank 241-SY-101. (Mitigation efforts were focused on that tank first because it was releasing large quantities of hydrogen, nitrous oxide, ammonia, and other gases during and after gas release events (GREs).

The main performance requirement for mitigation systems is to maintain the average hydrogen concentrations at the exhaust header and in the dome space at less than $25 \%$ of the hydrogen/nitrous oxide/air Lower Flammability Limit (LFL). In addition, dome pressure is to be maintained below atmospheric, and mitigation must not compromise tank integrity. These primary performance requirements were developed in the context of the pressing need to mitigate Tank 241SY-101. However, current plans assume the mitigation of five more tanks for periods of five years or more. This brings into focus several key functional requirements: service life, reliability, operability, maintainability, and transportability, as well as ease of installation, removal, decommissioning, and decontamination. Safety is integral to all of these requirements.

Within the context of evaluating the mitigation concepts, the primary requirement of each mitigation concept is to provide a means (active or passive) for the controlled and safe release of flammable gas. Determining whether a concept meets this requirement for tanks of varying composition is possible only after the gas retention and release mechanisms and the rheological and chemical waste properties that drive them are fully understood. To achieve this understanding, extensive data analysis, theoretical modeling, and waste characterization work have been carried out. Much has been learned, and significant progress has been made in researching and developing the mitigation methods.

Because the four selected mitigation concepts are at such disparate levels of development, it is difficult to compare and make conclusions about them. Only the mixer pump has actually been proven an effective mitigation method in a waste tank. The sonic probe concept is next in level of understanding, although the design of the full-scale prototype is not yet complete. A system has been designed for dilution of Tank 241-SY-101 waste, but the effectiveness of dilution relies on knowledge of waste behavior that is not now available. Heating has not been studied nearly as comprehensively as the other three. Nevertheless, the nature of each of the concepts allows some definite conclusions on their comparative effectiveness. The bases for these conclusions are detailed in specific sections devoted to each concept.

The following are the overall findings of this research:

- The $150 \mathrm{hp}$ mixer pump in Tank 241-SY-101 has proven to be a safe and effective mitigation method for that tank. We are confident that mixer pumps will effectively mitigate other tanks with waste configurations and properties comparable to Tank 241-SY-101. 
- Low-frequency sonic vibration (the current sonic probe design) is predicted by analysis, laboratory testing, and past industrial experience to be safe and effective for mitigation. We recommend a full-scale cold test program, aimed toward a trial in a waste tank, be considered. Ultrasonic (acoustic) mitigation devices are not considered practical due to severe attenuation by the waste at high frequencies.

- Existing data are not sufficient to prove that dilution can mitigate GRE behavior or to predict what dilution ratio is necessary. But, because dilution is the only concept of the four that potentially offers true passive mitigation, we believe that studies related to the effect of dilution on gas retention should be given high priority.

- Like dilution, heating cannot be proven to mitigate GRE behavior with available information, nor can the necessary temperature range be specified. Because other active mitigation methods are already proven or are being actively pursued, it is recommended that research on dilution should have higher priority than heating as a future mitigation method. implications:

In addition, two additional conclusions developed during analysis have important

- $\quad$ Removing a relatively small fraction of waste from a tank (35\% for Tank 241-SY-101) may prevent flammable gas concentrations exceeding the LFL by reducing the volume of potential GREs while providing more dome space for mixing.

- Recent dilution tests on Tank 241-SY-101 core samples indicate that current Westinghouse Hanford Company transfer pipeline requirements can be satisfied with dilutions of $0.4: 1$ rather than $1: 1$ as originally supposed. 


\section{Acknowledgments}

This report required expertise in a wide variety of areas from chemistry to solid mechanics and from system design to hazards analysis. This involved a great number of staff from PNL, WHC, and LANL who are not listed as authors, even though their contributions were vital to the final product. The following list credits this direct assistance:

Dan Reynolds (WHC)

Dan Herting (WHC)

Curt Rieck (WHC)

Bill Kubic (LANL)

Paul Bredt (PNL)

Lenna Mahoney (PNL)

Hank Reid (PNL)

Jim Alzheimer (PNL)

John Friley (PNL)

Jim Colson (PNL)

Mark Friesel (PNL)

Loni Peurrung (PNL)

Harri Kytomaa (MIT)

Mark Hall (WHC)

Scott Cannon (WHC)
Dilution (solubility, equilibrium modeling)

Dilution (aluminate equilibria, prior core sample data)

Dilution (design of dilution/transfer system)

Dilution (Section 5.3.4, hazards analysis)

Dilution (dilution test results on Tank 241-SY-101 waste)

Dilution (App. G, effect of transfer on GRE consequences)

Dilution (TEMPEST modeling of diluent mixing)

Sonic Probe (App. E, TEMPEST model of gas release)

Sonic Probe (App. A, performance model and testing)

Sonic Probe (vibration analysis and performance model)

Sonic Probe (performance model)

Sonic Probe (performance model)

Sonic Probe (gas release and ranging calculation)

Sonic Probe (App. B, attenuation and sound speed theory)

Sonic Probe (design concept and data)

Sonic Probe (hot test results)

We are grateful for many others who contributed to the programs involved. We especially appreciate the assistance rendered by WHC s 222S laboratory staff in performing the dilution tests on 101-SY core samples. Special thanks go to Sheila Bennett who edited the report and to Kathy Moore who assisted with the considerable effort in laying up figures and the logistics of distribution. Finally, we acknowledge the support of the reviewers who took the time to read the draft and participate in the consensus meeting. 


.




\section{Contents}

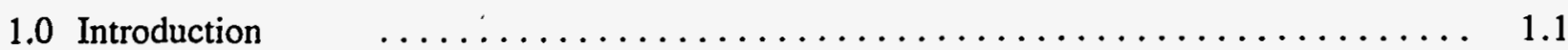

1.1 Unreviewed Safety Question and Tank 241-SY-101 $\ldots \ldots \ldots \ldots \ldots \ldots \ldots$

1.2 Tank Waste Characteristics, Gas Retention and Release (Tank 241-SY-101) _ . 1.2

1.3 Mitigation and Remediation Concepts Working Group $\quad \ldots \ldots \ldots \ldots \ldots \ldots \ldots$

1.4 Goals and Performance Requirements of Mitigation $\quad \ldots \ldots \ldots \ldots \ldots \ldots \ldots$

1.5 Overview of the Mitigation Concepts $\quad \ldots \ldots \ldots \ldots \ldots \ldots \ldots \ldots \ldots \ldots \ldots$

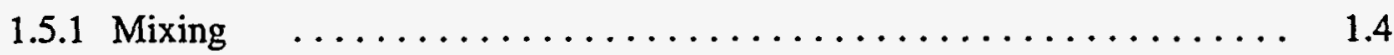

1.5.2 Material yielding by Low-Frequency Sonic Vibration . . . . . . . . 1.5

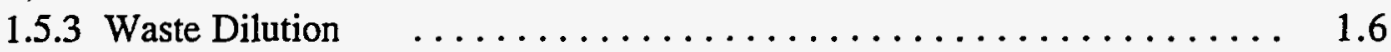



1.6 Potential Deployment in Other Tanks $\quad \ldots \ldots \ldots \ldots \ldots \ldots \ldots \ldots \ldots$

1.6.1 Waste Material Classification $\ldots \ldots \ldots \ldots \ldots \ldots \ldots \ldots \ldots \ldots \ldots$

1.6 .2 Tank Inventory $\ldots \ldots \ldots \ldots \ldots \ldots \ldots \ldots \ldots \ldots \ldots \ldots \ldots \ldots$

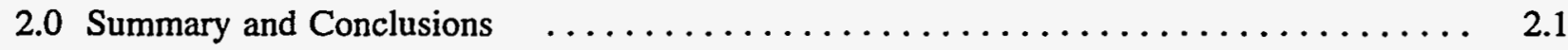



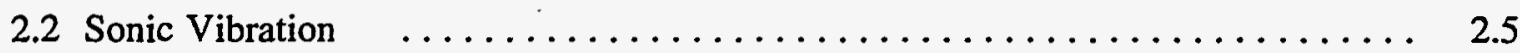

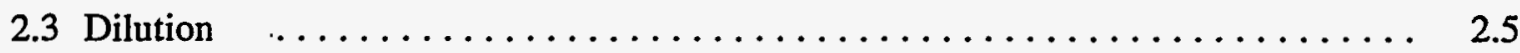

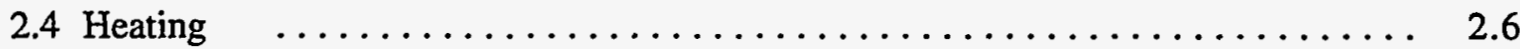

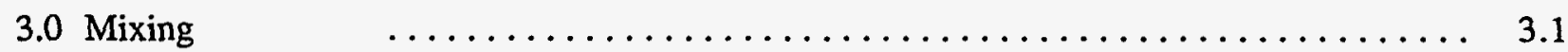

3.1 Waste Tank Characteristics and GRE Behavior $\ldots \ldots \ldots \ldots \ldots \ldots \ldots \ldots \ldots \ldots$

3.2 Effect of Mixing on GRE Behavior $\ldots \ldots \ldots \ldots \ldots \ldots \ldots \ldots \ldots \ldots \ldots \ldots \ldots \ldots \ldots$

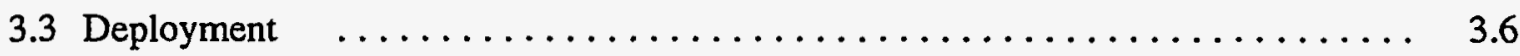

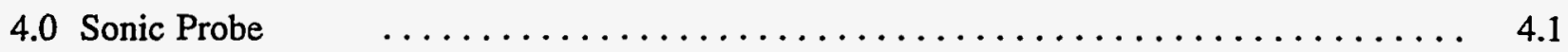

4.1 Choice of Frequency Range and Parameter Domain $\quad \ldots \ldots \ldots \ldots \ldots \ldots . \ldots$

4.2 Sonic Probe Reference System $\quad \ldots \ldots \ldots \ldots \ldots \ldots \ldots \ldots \ldots \ldots \ldots \ldots .4$

4.3 Advantages and Limitations of the Sonic Probe $\ldots \ldots \ldots \ldots \ldots \ldots \ldots . \ldots$ 
4.4 Feasibility and Safety Issues $\quad \ldots \ldots \ldots \ldots \ldots \ldots \ldots \ldots \ldots \ldots \ldots \ldots \ldots \ldots \ldots \ldots \ldots$

4.5 Experimental Evidence and Test Results $\ldots \ldots \ldots \ldots \ldots \ldots \ldots \ldots \ldots . .5$

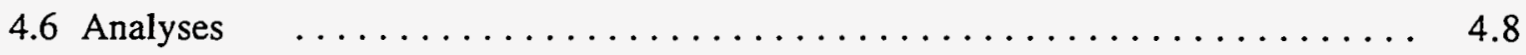

4.7 Mitigation Region Size and Gas Release Estimates $\ldots \ldots \ldots \ldots \ldots \ldots \ldots .4 .9$

4.7 .1 Assumed Conditions $\quad \ldots \ldots \ldots \ldots \ldots \ldots \ldots \ldots \ldots \ldots \ldots \ldots \ldots \ldots \ldots \ldots$

4.7.2 Assumed Gas Release Mechanisms $\ldots \ldots \ldots \ldots \ldots \ldots \ldots \ldots . \ldots \ldots$

4.7.3 Probe Effects on Nonconvective Layer Material . . . . . . . . . 4.12

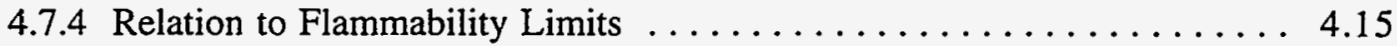

4.7.5 Conclusions from Mitigation Region and Gas Release Analyses . . . 4.17

4.8 Transient Gas Release Simulations $\quad \ldots \ldots \ldots \ldots \ldots \ldots \ldots \ldots \ldots \ldots \ldots \ldots \ldots$

4.9 Conclusions from Analysis $\ldots \ldots \ldots \ldots \ldots \ldots \ldots \ldots \ldots \ldots \ldots \ldots \ldots \ldots \ldots \ldots \ldots \ldots .19$

5.0 Dilution $\quad \ldots \ldots \ldots \ldots \ldots \ldots \ldots \ldots \ldots \ldots \ldots \ldots \ldots \ldots \ldots \ldots \ldots \ldots \ldots \ldots \ldots \ldots$

5.1 Effect of Dilution on Waste Properties $\quad \ldots \ldots \ldots \ldots \ldots \ldots \ldots \ldots \ldots \ldots .2$

5.1 .1 Chemical Composition and Solubility $\quad \ldots \ldots \ldots \ldots \ldots \ldots \ldots .2$

5.1 .1 .1 Nitrate Solubility $\ldots \ldots \ldots \ldots \ldots \ldots \ldots \ldots \ldots .5$

5.1 .1 .2 Nitrite Solubility $\ldots \ldots \ldots \ldots \ldots \ldots \ldots \ldots \ldots \ldots .5$

5.1 .1 .3 Carbonate Solubility $\ldots \ldots \ldots \ldots \ldots \ldots \ldots \ldots \ldots .6 . \ldots \ldots$

5.1 .1 .4 Aluminate Solubility $\ldots \ldots \ldots \ldots \ldots \ldots \ldots \ldots \ldots \ldots$

5.1.1.5 Solubility of Metal Salts and Hydroxides . . . . . . . . 5.9

5.1.1.6 Equilibrium Modeling $\ldots \ldots \ldots \ldots \ldots \ldots \ldots . \ldots \ldots$

5.1.2 Rheological and Physical Properties $\ldots \ldots \ldots \ldots \ldots \ldots . \ldots . . . \ldots$

5.1.2.1 Viscosity and Shear Strenth $\ldots \ldots \ldots \ldots \ldots \ldots \ldots \ldots .10$

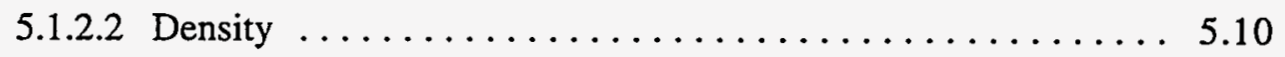

5.1.2.3 Solids Content and Dissolution $\ldots \ldots \ldots \ldots \ldots \ldots . \ldots \ldots$

5.1.3 Tank Behavior Relating to Dilution $\quad \ldots \ldots \ldots \ldots \ldots \ldots \ldots \ldots$

5.2 Mitigation By Dilution $\quad \ldots \ldots \ldots \ldots \ldots \ldots \ldots \ldots \ldots \ldots \ldots \ldots \ldots \ldots \ldots \ldots \ldots \ldots \ldots \ldots \ldots .18$

5.2.1 Dilution and Gas Retention $\quad \ldots \ldots \ldots \ldots \ldots \ldots \ldots \ldots \ldots \ldots .18$

5.2.2 Potential Effect of Dilution on Gas Release Events . . . . . . . . . . 5.19 


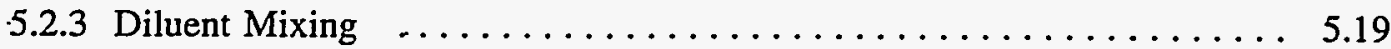

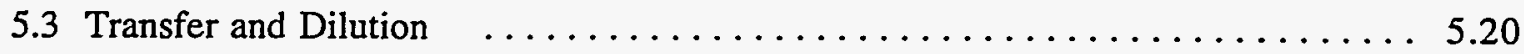

5.3.1 Dilution and Transfer System for Tank 241-SY-101 to 101-SN $\ldots \ldots \quad 5.20$

5.3.2 Dilution to Meet Transfer Line Requirements f........... 5.22

5.3.3 Effect of Transfer on GRE Behavior $\ldots \ldots \ldots \ldots \ldots \ldots \ldots \ldots . \ldots \ldots$

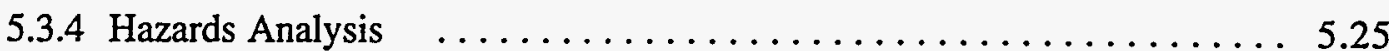

5.4 Long-Term Behavior $\ldots \ldots \ldots \ldots \ldots \ldots \ldots \ldots \ldots \ldots \ldots \ldots \ldots \ldots \ldots \ldots \ldots \ldots \ldots .28$

5.4.1 Waste Temperature Decrease $\ldots \ldots \ldots \ldots \ldots \ldots \ldots \ldots \ldots . \ldots .29$

5.4.2 Waste Properties at Lower Temperature $\ldots \ldots \ldots \ldots \ldots \ldots \ldots . \ldots .29$

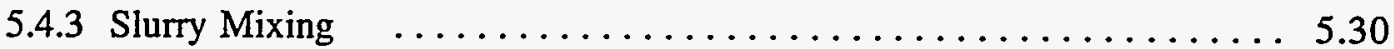

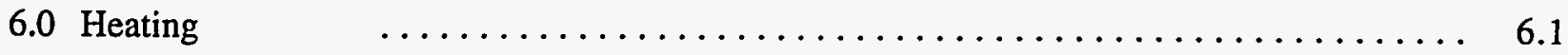

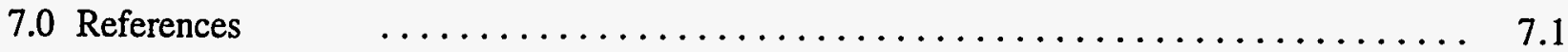

Appendix A: Oscillatory Sonic Probe Performance Model $\ldots \ldots \ldots \ldots \ldots \ldots \ldots$ A.1

Appendix B: Acoustic Wave Processes and Attenuation Mechanisms

in Bubbly Media $\ldots \ldots \ldots \ldots \ldots \ldots \ldots \ldots \ldots \ldots \ldots \ldots \ldots \ldots \ldots$, B.1

Appendix C: Inducing the Transition from Elastic Material to Liquid

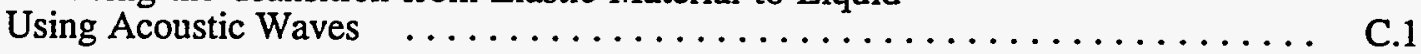

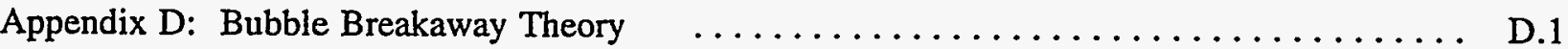

Appendix E: Modeling of Transients in Material Yielding and Gas Release in Sonic

Probe Mitigation of Gas-Producing Radioactive Waste Tanks $\ldots \ldots \ldots \ldots$ E.1

Appendix F: Effects Of Dilution. On Volume Of Potential Gas Releases $\quad \ldots \ldots \ldots \ldots \ldots$ F.1

Appendix G: Analysis Of Potential Gas Releases After Transfer Of Waste From Tank 101-Sy To 101-SN 


\section{Figures}

Figure 1.1. Schematic of a Mixer Pump $\ldots \ldots \ldots \ldots \ldots \ldots \ldots \ldots \ldots \ldots \ldots \ldots \ldots$

Figure 1.2. Schematic of a Sonic Probe $\ldots \ldots \ldots \ldots \ldots \ldots \ldots \ldots \ldots \ldots \ldots \ldots \ldots \ldots \ldots \ldots \ldots$

Figure 1.3. Schematic of a Dilution System $\ldots \ldots \ldots \ldots \ldots \ldots \ldots \ldots \ldots \ldots \ldots \ldots$

Figure 1.4. Schematic of a Heating System $\ldots \ldots \ldots \ldots \ldots \ldots \ldots \ldots \ldots \ldots \ldots \ldots \ldots \ldots$

Figure 1.5. Pumpable Liquid Content of FGWL Tanks $\ldots \ldots \ldots \ldots \ldots \ldots \ldots \ldots \ldots$

Figure 1.6. Specific Gravity of FGWL Tanks $\ldots \ldots \ldots \ldots \ldots \ldots \ldots \ldots \ldots \ldots \ldots \ldots \ldots$

Figure 1.7. Waste Volume as a Fraction of Capacity of FGWL Tanks $\ldots \ldots \ldots \ldots$

Figure 3.1. Typical Vertical Temperature Profiles $\ldots \ldots \ldots \ldots \ldots \ldots \ldots \ldots \ldots \ldots \ldots .2$

Figure 3.2. Vertical Temperature Profiles Before and After Pump Mixing $\ldots \ldots . . . .3$

Figure 3.3. Schematic of Tank Waste Configuration $\ldots \ldots \ldots \ldots \ldots \ldots \ldots \ldots \ldots$

Figure 3.4. Formation of Nonconvective Layer After GRE I $\ldots \ldots \ldots \ldots \ldots \ldots \ldots \ldots$

Figure 3.5. Vertical Temperature Profile of Settling After Pumping $\ldots \ldots \ldots \ldots \ldots$

Figure 3.6. Profile View of Tank 241-SY-101 Mixer Pump Installation $\ldots \ldots \ldots \ldots .7$

Figure 4.1a. Attenuation Length Versus Frequency for Viscosity $1,000 \mathrm{cP} \ldots \ldots \ldots .2$

Figure 4.1b. Attenuation Length Versus Frequency for Viscosity $10,000 \mathrm{cP} \ldots \ldots .2$

Figure 4.1c. Attenuation Length Versus Higher Frequency, Viscosity $1,000 \mathrm{cP} \ldots \ldots .3$

Figure 4.2. Minimum Bubble Breakaway Radius Versus Frequency $\ldots \ldots \ldots \ldots \ldots$

Figure 4.3. Minimum Bubble Breakaway Radius Versus Pressure Amplitude $\ldots \ldots \ldots \ldots .10$

Figure 4.4. Pressure versus Distance from Probe Axis for Reference Probe in Medium with 0.01 Void Fraction Comprising 0.1-mm-Radius Bubbles ............. 4.14

Figure 4.5. Yield Radius Versus Frequency with Void Fractions $0.01,0.04$, and 0.06 Comprising 0.1-mm Bubbles in Medium with Viscosity $1000 \mathrm{cP} \ldots \ldots \ldots \ldots .14$

Figure 4.6. Volume of Hydrogen Released Versus Frequency with Initial Void Fraction 0.075 , Unreleasable Void Fraction 0.01 , Bubble Radium $0.1 \mathrm{~mm}$, Viscosity $1000 \mathrm{cP} 4.15$

Figure 4.7. Prompt and Ultimate Release Volumes of Hydrogen with Initial Void Fraction 0.075 , Unreleasable Void Fraction 0.01, Bubble Radius $0.1 \mathrm{~mm}$, Viscosity $1000 \mathrm{cP} \quad 4.16$

Figure 4.8. Calculated Gas Release Transient After Initial and Repeated Sonification of Unmixed 241-SY-103 Waste 
Figure 5.1. Solubility of Sodium Aluminate in Solutions Saturated with NaNO3, NaNO2,

$\mathrm{Na} 2 \mathrm{SO} 4$ and $\mathrm{Na} 2 \mathrm{CO} 3$ [modified from Bamey (1976)] . . . . . . . . . 5.8

Figure 5.2. Solubility of Sodium Aluminate in Waste Simulant $\ldots \ldots \ldots \ldots \ldots \ldots \ldots$

Figure 5.3. Effect of Dilution on Yield Point of Mixed Slurry (Tingey et al. 1994) _. . . . 5.11

Figure 5.4. Effect of Dilution on Viscosity of Mixed Slurry (Tingey et al. 1994) $\ldots \ldots \ldots 5.11$

Figure 5.5. Supernatant Liquid Density as a Function of Dilution $\left(\right.$ at $\left.50^{\circ} \mathrm{C}\right) \ldots \ldots .13$

Figure 5.6. Settled Slurry Density as a Function of Dilution (at $50^{\circ} \mathrm{C}$ ) $\ldots \ldots \ldots \ldots . \ldots$

Figure 5.7. Effect of Dilution on Weight of Filtered Solids (at $50^{\circ} \mathrm{C}$ ) $\ldots \ldots \ldots \ldots .14$

Figure 5.8. Dissolution Fraction as Function of Dilution Ratio $\left(\right.$ at $\left.50^{\circ} \mathrm{C}\right) \ldots \ldots \ldots \ldots$

Figure 5.9. Effect of Dilution on Settled Slurry Height $\ldots \ldots \ldots \ldots \ldots \ldots \ldots \ldots$

Figure 5.10. Specific Gravities of Flammable Gas Tanks $\ldots \ldots \ldots \ldots \ldots \ldots \ldots \ldots$

Figure 5.11. Transfer System for Tank $241-S Y-101 \ldots \ldots \ldots \ldots \ldots \ldots \ldots \ldots \ldots$

Figure 5.12. Viscosity Versus Tank Dilution Ratio $\ldots \ldots \ldots \ldots \ldots \ldots \ldots \ldots \ldots \ldots$

Figure 5.13. Bulk Waste Density Versus Tank Dilution Ratio $\ldots \ldots \ldots \ldots \ldots \ldots \ldots . \ldots$

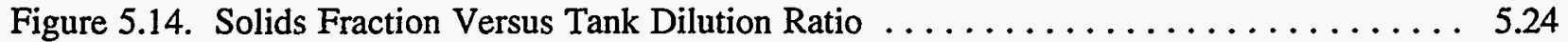

Figure 5.15. H2 Concentrations and Gas Release Ratios for Tank 241-SY-101 to 101-SN

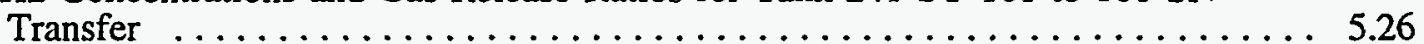

Figure 5.16. H2 Concentrations versus Waste Generation for Tank 241-SY-101 to 101-SN

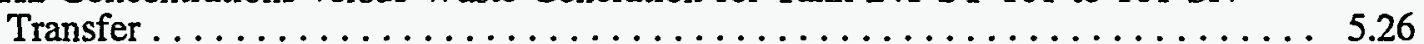

Figure A.1. Sonic probe coordinates, with $\mathrm{X}$ and $\mathrm{Y}$ coordinates of shell (mass $\mathrm{M}$ ) measured from mean position, and $x$ and $y$ of eccentric center of mass (mass $m$ ) measured

from shell center.

Figure E.1. Gas Release from 241-SY-101 for Reference Condition "Previously Mixed" . . E.9

Figure E.2. Predicted Convective Velocity at $500 \mathrm{Sec}$ with Sonification of "Aged" Tank 241-SY-101 Waste $\ldots \ldots \ldots \ldots \ldots \ldots \ldots \ldots \ldots \ldots$ E.10

Figure E.3. Predicted Gas Volume Fraction of $1 \mathrm{~mm}$ Bubbles at $500 \mathrm{Sec}$ with Sonification of "Aged" Tank 241-SY-101 Waste ............... E.11

Figure E.4. Predicted Gas Release History for "Aged" SY-101 Waste with Probe Operation at 400 Second Intervals $\ldots \ldots \ldots \ldots \ldots \ldots \ldots \ldots$ E.12

Figure E.5. Predicted Convective Velocities for Unmixed SY-103 Waste at 1 Hour with Probe Sonification at 400 Second Intervals $\ldots \ldots \ldots \ldots \ldots \ldots \ldots$ E.13

Figure E.6. Volume Fraction Distribution at 1 Hour from $1 \mathrm{~mm}$ Bubble Size Gas in SY-103 Unmixed Waste with 400 second Intermittent Probe Sonification . . E E.14 
Figure E.7. Radial Profile of Peak Pressures for Mid-Slurry Plane and Sludge Plane in SY-103 Unmixed Waste $\ldots \ldots \ldots \ldots \ldots \ldots \ldots \ldots$

Figure E.8. Yield Front Radial Extent Versus Height in SY-103 "Aged" Waste

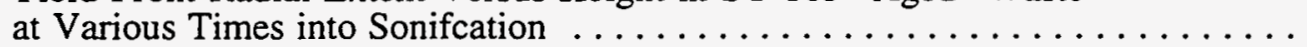

Figure E.9. Predicted Convective Velocities at $500 \mathrm{Sec}$ in SY-103 Waste with Probe Operation at 200 Second Intervals $\ldots \ldots \ldots \ldots \ldots \ldots \ldots$

Figure E.10. Predicted Bulk Density Distribution at 500 Seconds in Unmixed SY-103 Waste with Probe Sonification at 200 Second Intervals $\ldots \ldots \ldots \ldots \ldots \ldots \ldots$

Figure E.11. Gas Volume Fraction Distribution from $1 \mathrm{~mm}$ Bubbles at $500 \mathrm{Sec}$ in Unmixed SY-103 Waste with Probe Sonification at 200 Second Intervals

Figure E.12. Gas Release History from Unmixed SY-103 Waste with Probe Sonification at 200 Second Intervals

Figure E.13. Gas Release History from Unmixed SY-103 Waste with Probe Sonification at 400 Second Intervals

Figure E.14. Gas Release History fromUnmixed SY-103 Waste with Probe Sonification at 1000 Second Intervals

Figure E.15. Predicted Convective Velocities in Unmixed SY-103 Waste at 1 Hour

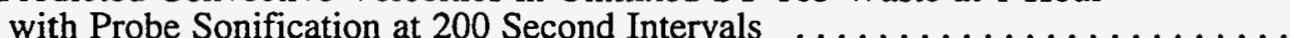

Figure E.16. Predicted Gas Volume Fraction from $1 \mathrm{~mm}$ Bubbles in Unmixed SY-103 Waste with Probe Sonification at 200 Second Intervals $\ldots \ldots \ldots \ldots \ldots \ldots$

Figure F.1. In-Tank Dilution Schematic $\ldots \ldots \ldots \ldots \ldots \ldots \ldots \ldots \ldots \ldots \ldots \ldots \ldots$ F.2

Figure F.2. Sludge and Liquid Density versus Dilution Ratio. $\ldots \ldots \ldots \ldots \ldots \ldots \ldots \ldots \ldots$ F.2

Figure F.3. Relative Magnitude of Pressure, Density, and Dissolution Effects $\ldots \ldots \ldots \ldots$ F.4

Figure F.4. Gas Release Ratio versus Dilution Ratio. $\ldots \ldots \ldots \ldots \ldots \ldots \ldots \ldots \ldots \ldots$ F.4

Figure G.1. Maximum Hydrogen Concentration (Volume Fraction) Predicted for Either Tank's Dome Space After Transfer and Dilution. .............

G.10

Figure G.2. Maximum Ratio of Gas Release Volume (After-to-Before) Predicted for Either Tank as a Result ff Transfer and Dilution.

Figure G.3. Amount of Additional Waste Volume Generated by Transfer and Dilution, Expressed as a Fraction of Original 101-SY Waste Volume 


\section{Tables}

Table 1.1. Waste Classification in FGWL Tanks $\ldots \ldots \ldots \ldots \ldots \ldots \ldots \ldots \ldots \ldots \ldots \ldots$

Table 2.1. Characteristics, Features and Problems of the Mitigation Methods $\ldots \ldots \ldots . . . .2$

Table 5.1. Calculated Average Chemical Composition of Tank 241-SY-101 Contents . . . . 5.4

Table 5.2. Solubility of Sodium Nitrate, Sodium Nitrite and Sodium Aluminate Solutions in

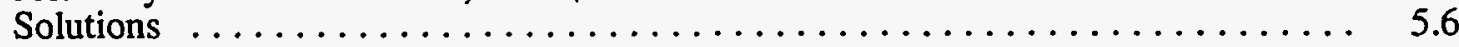

Table 5.3. Physical Properties of Window $C$ Samples $\ldots \ldots \ldots \ldots \ldots \ldots \ldots \ldots \ldots$

Table E.1. Sonic Probe Analysis Matrix $\ldots \ldots \ldots \ldots \ldots \ldots \ldots \ldots \ldots \ldots \ldots \ldots \ldots \ldots \ldots \ldots$

Table E.2. Void Fraction Distribution, Tank 241-SY-101 Mixed $\ldots \ldots \ldots \ldots \ldots \ldots$ E.7

Table E.3. Void Fraction Distribution, SY-103 Unmixed $\ldots \ldots \ldots \ldots \ldots \ldots \ldots \ldots$ E.7

Table E.4. Void Fraction Distribution, Sy-101 Aged $\ldots \ldots \ldots \ldots \ldots \ldots \ldots \ldots \ldots \ldots$

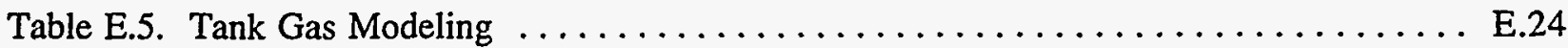




\subsection{Introduction}

Since 1943, large underground concrete storage tanks (currently numbering 177 ) have been used at Hanford to store byproducts of plutonium production. The tanks are steel-lined, up to 75 feet in diameter, and up to 32 feet high, capable of holding up to one million gallons of waste. The waste in these tanks is chemically complex and ranges from mostly liquid to thick, sticky sludge to a crystalline salt cake. The sludge has the consistency of soft mud, and the salt cake is similar to lowgrade concrete. Most of the tanks contain at least some liquid. Several of these tanks have been placed on the flammable gas watch list (FGWL), because the waste in them is either known or suspected to be generating, storing, and periodically releasing flammable gases.

The waste in the FGWL tanks will be moved to safer, more permanent storage or disposed of as part of the Hanford cleanup program. However, while awaiting retrieval operations, each tank must be maintained in a safe condition. That is, the accumulation of flammable gases in the waste must be averted, and potentially hazardous and uncontrolled episodic releases of large volumes of gas must be prevented. The actions to accomplish this constitute mitigation activity as it pertains to the flammable gas tanks.

\subsection{Unreviewed Safety Question and Tank 241-SY-101}

The potential for quantities of hydrogen and nitrous oxide gas to exist as a flammable mixture within the dome space and ventilation system of certain Hanford underground waste tanks was declared to be an unreviewed safety question in 1990. A Waste Tank Safety Task Team was established to evaluate the safety of the tanks, to characterize the waste and the released gases, and to develop an effective method of controlling or preventing gas accumulation and preventing uncontrolled releases (i.e., to develop a method of mitigation). The potentially hazardous tanks were identified, and interim operating procedures to minimize the risk of possible ignition were promptly implemented. Currently, there are 25 waste tanks on the watch list for potentially generating, storing, and periodically releasing various quantities of hydrogen.

Flammable gas mitigation efforts were first focused on Tank 241-SY-101, because that tank was releasing large quantities of hydrogen, nitrous oxide, ammonia, and other gases during and after gas release events (GREs) that had been occurring every 100 to 150 days since about 1981 (Antoniak 1993). A waste characterization program was initiated to support development of the best mitigation method. Vapor space samples, crust samples, and full-depth core samples were obtained and analyzed. Synthetic waste experiments were focused on gas generation, retention, and release behavior. The tank monitoring system was upgraded with the installation of a video camera, radar surface-level gauge, and additional gas monitoring equipment. Thermohydraulic modeling was begun to assist in identifying the best methods for mitigation.

The Tank 101-SY Flammable Gas Mitigation Test Project Plan (WHC-EP-0550) was released in May 1992. The plan addressed the selection, design, analysis, fabrication, installation, and testing of flammable gas mitigation system equipment and included activity descriptions and cost estimates for a number of mitigation approaches, including forced convection, ultrasonic disruption, heating, dilution, and sonic disruption. Pump mixing was selected as a candidate mitigation strategy in 1992, and the jet mixer pump was installed on July 3, 1993, seven days after Event I, a major GRE. 


\subsection{Tank Waste Characteristics, Gas Retention and Release (Tank 241-SY-101)}

Core samples taken in mid-1991 showed that the waste in Tank 241-SY-101 was stratified in layers that were distinct in composition and rheology. The layers nominally consisted of a 40 -inch "crust" floating on about 160 inches of liquid, with a 200 -inch layer of settled solid material, or sludge, on the bottom (Babad et al. 1992a; Stewart et al. 1994). Based on the vertical temperature profiles, the liquid has been termed the "convective" layer, because a uniform temperature profile indicated that it is free to circulate in response to natural convection, while the solid, sludge layer, which exhibited a nonuniform profile, is called the "nonconvective" layer. The large, nearly isothermal, liquid layer had a relatively low solids content, while the bottom layer contained large quantities of settled solids. The relatively thin crust layer (about one meter thick) provided thermal insulation from the dome space ventilation system.

Video recordings in Tank 241-SY-101 showed that the episodic GREs were accompanied by extensive disruption of the waste surface. This suggested that these gas releases involved large-scale movement of waste from the lower layers, or "rollovers." The thickness of the sludge layer and the amount of solids suspended in the convective layer varied depending on the size and origin of the last GRE. Gas monitor data showed that the bulk of the potentially flammable gas released during a GRE occurred during the initial minutes, but gas continued to issue at a significant rate for many hours thereafter.

One understanding of the GRE sequence is the cohesive structure or "gob" theory (Babad et al. 1992a; Allemann 1993). This appears consistent with the behavior of Tank 241-SY-101 and could be extrapolated to other similar waste tanks. Briefly, this theory suggests that the cohesiveness of the sludge enables it to retain gas. The local density decreases as gas is generated, and the sludge eventually becomes buoyant with respect to the liquid above it. When the buoyancy of the gasretaining mass exceeds the cohesive forces, a portion of the sludge (i.e., a "gob") breaks loose. The buoyant gob rises quickly through the liquid layer and breaks through the crust to the waste surface, where the bulk of the gas is released immediately. Gas remaining in the gob continues to evolve at a relatively slow rate, giving the appearance of effervescence, until the gas content is insufficient for buoyancy. The gob will then begin to sink, and any remaining gas will be recompressed as the hydrostatic head increases.

Without intervention, the cycle of gas retention and release would continue indefinitely. Vertical temperature profile data suggest that the section of the tank involved in the GRE temporarily becomes well-mixed, with most of the sludge in that section becoming resuspended in the liquid. The waste that has not retained enough gas to become buoyant remains undisturbed, possibly becoming the source region for a succeeding GRE. The basic aim of all the mitigation concepts considered here is to break the cycle by destroying the ability of the waste to retain gas. Then gas is released about as soon as it is generated, eliminating large GREs.

The sludge appears to be very different from clay, sand, or other sediments in its ability to retain gas. The density of the solid material is only about $20 \%$ greater than the liquid, and it consists of relatively small crystal particles (Herting et al. 1992b). Once suspended, the relatively light small particles tend to stay suspended, particularly if bubbles are attached.

The mixer pump has altered the 'normal' configuration of the waste. Current temperature profiles indicate the unmixed sludge layer (undisturbed by pump mixing) may be only 16 to 28 inches thick. Above the bottom sludge layer, the original sludge and liquid have apparently been mixed into a mobile slurry, up to 300 inches deep, over which about 50 inches of liquid or thinner slurry remains during pump operation. The upper mobile layer tends to grow deeper slowly during periods of gentle mixing as solids settle out, but it can be erased by a few days of aggressive pump operation. 
The magnitude and potential hazard of the GREs that were exhibited by Tank 241-SY-101 are not an accurate gauge of the situation in the other tanks on the FGWL, such as the 241-AN Tank Farm Tanks 241-AN-103, -104 and -105, and Tank AW-101. Although the basic characteristics exhibited by Tank 241-SY-101 are also present in these tanks (i.e., surface level drops, pressure increases, and temperature profiles), they are exhibited to a lesser degree (Reynolds 1994). The 241AN and AW Tank Farm tanks have had only small drops in surface level, and the pressure changes that occur are not sufficient to release an amount of gas that would cause the dome space to exceed the LFL for hydrogen.

\subsection{Mitigation and Remediation Concepts Working Group}

At the end of July 1991, three working groups were set up to consider mitigation and remediation concepts for tanks that exhibited generation, storage, and periodic release of hydrogen gas (Babad et al. 1992b). Twenty-two mitigation and remediation ideas were examined under three main .groups: ultrasonic agitation, waste mixing, and chemical treatment. Application of the decision methodology produced four basic concepts for further study:

- $\quad$ diluting the waste (applicable to the double-shell tanks only)

- $\quad$ heating waste to a temperature less than atmospheric boiling (applicable to all tanks)

- mixing using various types of pumping concepts (applicable to the double-shell tanks only)

- ultrasonic agitation using compressional waveguides (applicable to all tanks)

It was concluded that the four mitigation concepts could be used in various combinations; for example, dilution and mixing.

Engineering studies were initiated in October 1991 on the selected concepts with the objective of completing these studies by January 1992 so that laboratory testing and design for implementation could begin. Only the mixing pump concept has proceeded to full-scale, in-tank testing and demonstration to date.

\subsection{Goals and Performance Requirements of Mitigation}

The primary goal of mitigation is to reduce the intensity or severity of the safety hazard; that is, the potential for quantities of hydrogen and nitrous oxide gas to exist as a flammable mixture within the dome space and ventilation system of certain Hanford underground waste tanks. Within the context of evaluating the mitigation concepts, and bearing in mind that each concept is at a quite different stage of engineering product development, the goal can be more narrowly stated: to provide a means (active or passive) for the controlled and safe release of flammable gas and, if possible, to slow the rate of gas generation while the tank awaits waste retrieval.

The main performance requirement for mitigation systems is to maintain average hydrogen concentrations at the exhaust header and in the dome space at less than $25 \%$ of the hydrogen/nitrous oxide/air lower flammability limit (LFL).(a) In addition, dome space pressure is to be maintained below atmospheric pressure to prevent contaminant release, and installation or operation of the mitigation system must not compromise tank integrity. These three are the primary performance requirements and were developed in the context of the pressing need to mitigate Tank 241-SY-101.

(a) The LFL is defined as $3 \%$ hydrogen concentration in the Tank 241-SY-101 mixer pump safety assessment (LANL 1994). 
Specific operating criteria, such as minimum and maximum waste levels and temperature, have been developed to ensure that these requirements continue to be met (LANL 1994). These are also important in that they largely determine the instrumentation, data acquisition and storage, and operating control systems.

Current plans include the mitigation of six tanks (including Tank 241-SY-101) for periods of five years or more. This brings into focus several additional key functional requirements: service life, reliability, operability, maintainability, and transportability, as well as ease of installation, removal, decommissioning, and decontamination. Integral with all of these requirements is safety. The complete set of functional requirements drive mitigation system design criteria for each specific tank. The task of establishing these requirements within such a complex and large program is a daunting prospect, and an exhaustive treatment of that subject is well beyond the scope of this report. However, comparisons of some of the main requirement areas as they pertain to each of the four mitigation concepts are offered in Section 2.0.

\subsection{Overview of the Mitigation Concepts}

The viability of any of the four mitigation concepts that were selected for further development (pumped waste mixing, material yielding by sonification, waste dilution, and waste heating) can be finally assessed only after the concepts are tested with real waste under actual tank conditions and the following questions pertaining to tank waste behavior are answered:

- How are the gases generated, retained, and released?

- What are the rheological and chemical properties of the waste that drive the gas generation and retention mechanisms?

- How do the mitigation concepts alter these properties in the short- and long-term?

Finding answers to these questions has been the subject of extensive data analysis, theoretical modeling, and waste characterization work. Much has been learned and significant progress made in researching and developing the mitigation methods; however, each concept is at a very different stage of engineering product development. Therefore, it is difficult to compare the concepts and to draw meaningful conclusions.

However, the methods can be distinguished in at least two important aspects. First, pump mixing, sonification (sonic probe), and waste heating (and cooling) require continual overt actions (i.e., none achieves passive mitigation), whereas dilution would potentially achieve passive mitigation. Once the waste has been diluted, no further action should be required. Second, the methods operate on different principles. Mixing and sonification seek to alter the physical properties of the waste mechanically, dilution chemically, and heating thermally. A brief overview of the four selected mitigation methods and their current development status is presented below (refer also to Table 2.1).

\subsubsection{Mixing}

Pumped mixing of the waste is intended to promote sustained release of gas to the tank dome space to limit the amount of gas retained in the nonconvecting bottom layer and to reduce the concentrations of hydrogen and nitrous oxide released during GREs to less than 25\% of the LFL. Mixer pump operation is intended to keep enough gas-generating material in suspension that gas is released continually instead of periodically in large, potentially dangerous GREs.

A spare 150-hp mixing pump from the Hanford Grout Program was modified and installed in Tank 241-SY-101 on July 3,1993, and is currently operating. It pulls in liquid from the 260-inch level and injects it as a high-speed jet about two feet from the tank bottom in the sludge layer. Pump operations have homogenized the original convective and nonconvective layers to a great extent. 
Thermocouple data show a nearly isothermal layer extending through much of the waste's depth. There is also some evidence that the rheological properties of the waste have been changed significantly, possibly decreasing the ability of the waste to retain gas. Since December of 1993 very little waste surface level growth has occurred, indicating that most of the generated gas is now released by approximately constant evolution or stimulated by pump action.

A schematic of a mixer pump installed in a tank is shown in Figure 1.1. In Tank 241-SY101 , the pump is mounted just west of the tank centerline. The pump has two opposing nozzles. This configuration not only injects liquid into the waste at high velocity, but, because the injected liquid is less dense than the surrounding sludge, it also imparts a considerable vertical buoyant motion to the jet. Gas bubbles expand as they are lifted by the resulting vertical circulation and are more readily released at the surface.

In general terms, waste mixing, specifically by jet pumping, should be effective where a layer of settled solids exists that can be excavated and mobilized by the erosive action of the pump jets and there is enough liquid that circulation can be established in the mixed slurry. The pump design itself and the power required to achieve mobilization and circulation obviously depend on the waste properties, depth, and volume of each layer.

The results of operating this pump in Tank 241-SY-101 since July 1993 have been extensively documented (Allemann et al. 1994; Stewart et al. 1994). Large scale episodic gas releases have not occurred since the pump operations began, and there is no evidence that mixing has created any new hazardous condition. It has been concluded that, because hydrogen concentrations have remained below 25\% of the LFL and the waste level below 402 inches from late November 1993 to the present, the jet mixer pump has successfully mitigated Tank 241-SY-101 and is apparently capable of maintaining mitigation indefinitely.

\subsubsection{Material Yielding by Low-Frequency Sonic Vibration}

The sonic probe mitigation concept is intended to release trapped gases frequently in a controlled manner using sonic vibration, thereby avoiding potentially hazardous GREs. The sonic probe mitigation concept is based on the theory that pressure waves will yield the gel-like nonconvecting (sludge) and change it from a deformable solid to a liquid. This liquid will then release the gas by allowing buoyant convection and free bubble rise, and possibly by the detachment of bubbles from suspended solids. Trapped gases are expected to be released in a controlled manner; however, low-frequency vibration (as opposed to ultrasonic excitation) is not expected to release dissolved gases.

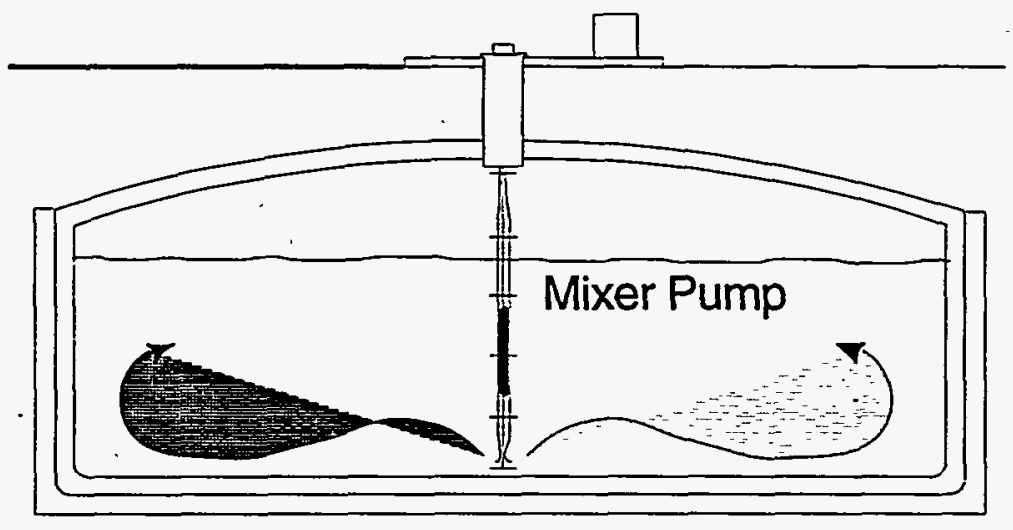

Figure 1.1. Schematic of a Mixer Pump 
Westinghouse Hanford Company filed an invention disclosure for application of a sonic probe concept on February 3, 1992. Proof-of-principle experiments were completed in April 1992 using a commercial concrete vibrator and an organic simulant. A cold test program was conducted during the first quarter of FY 1993 to evaluate two probe design concepts, piezoelectric and rotary eccentric mass, and a proposed secondary containment well ("wet" well) for the probe. Based on the test results, the decision was made to continue development of the rotary eccentric mass probe concept only and to abandon further consideration of the secondary containment well. (Alternate methods utilizing piezoelectric transducers for generating ultrasound vibrations have been considered and rejected due mainly to problems arising from the severe attenuation of pressure waves at high frequencies.)

A formal $30 \%$ design review of the sonic probe was carried out in 1993. Analytical and computational models were developed for the sonic probe, and predictions of its operational performance, including gas release estimates, were made during FY 1994. Preliminary design of the probe was completed in August 1994.

The device proposed to generate the acoustic waves is a cylindrical shell oscillator with an internal eccentric mass driven to rotate about a shaft on the cylinder (see Figure 1.2). The sonic probe would be activated periodically in a waste tank, as needed to prevent hazardous gas buildup. Based on the most recent design calculations, it is expected that a sonic probe device in Tank 241-SY101 would operate at a frequency of less than about $100 \mathrm{~Hz}(6000 \mathrm{rpm})$ for $5-10$ minutes per week.

\subsubsection{Waste Dilution}

Dilution is expected to accomplish mitigation by dissolving a portion of the gas-retaining material and reducing or eliminating its ability to retain gas. Gas retention and release is thought to be tied closely to the strength of the sludge that forms when solids settle. To provide mitigation, dilution must therefore dissolve a significant fraction of the solids while preventing precipitation of other ions that may create similar problems requiring further mitigating actions. There are indications in the core sample data and in the behavior of other flammable gas tanks that dilution may eliminate gas retention ability, but this has not been confirmed or quantified.

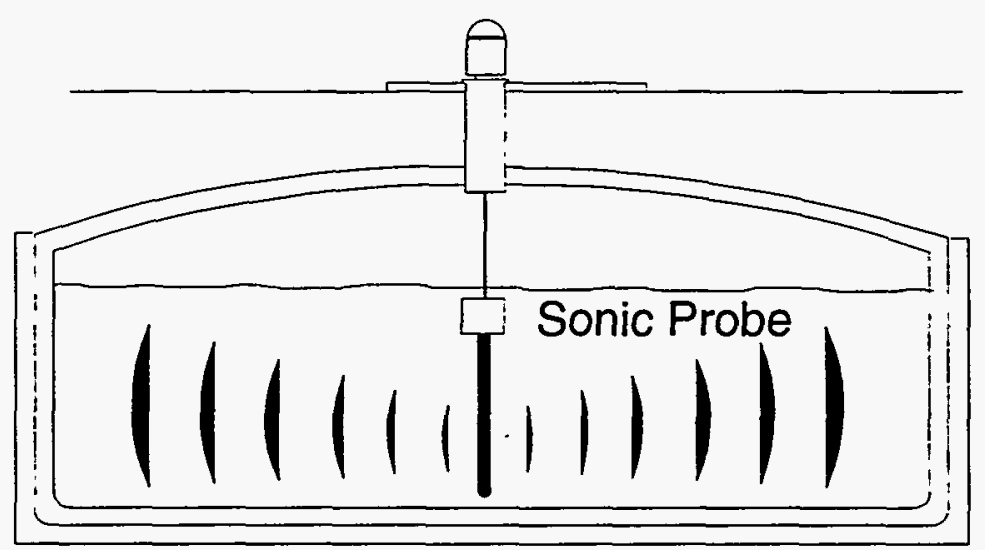

Figure 1.2. Schematic of a Sonic Probe 
Dilution does not require ongoing operations to periodically mix or yield the waste by active means (for example, by using the mixing pump or sonic probe device). This method, therefore, has distinct, long-term operating cost and safety advantages. However, if the waste volume is at or near tank capacity, dilution requires partial retrieval, transport, and storage of the diluted waste in another tank.

This is the case for Tank 241-SY-101. Plans are being made for construction of a new, million-gallon storage tank in the 200 West area for intermediate storage of the waste until a final disposition processing facility is on line. Though the current mixer pump in Tank 241-SY-101 has mitigated flammable gas releases from this tank, the tank is expected to return eventually to the earlier large episodic gas release behavior if the pump should fail and a replacement could not be installed. Thus it would be desirable to achieve passive mitigation by dilution so that the mixer pump would not be needed.

A dilution system concept for Tank 241-SY-101 has been developed that will support dilution of the waste for both retrieval/transfer operations and potential mitigation. A small transfer pump will be installed in a spare riser. The current mixer pump will be used to mix the tank prior to transfer. The transfer pump includes features to introduce diluent either at the pump suction intake or through pipes attached to the pump column (see Figure 1.3). It would take approximately five days of transfer pump operation to transfer half the contents of Tank 241-SY-101 to the new tank.

After the transfer, diluent will be added directly into Tank 241-SY-101 to bring the level up to about the 280 inches that is required to keep the inlet of the current mixer pump submerged. Conditioned water from the hot water/caustic isolation tank will be routed through the transfer pump column. These pipes discharge approximately 3-1/2 feet from the tank bottom. When the desired amount of dilution fluid has been added to the tank, the existing mitigation pump will be run to mix the waste and diluent.

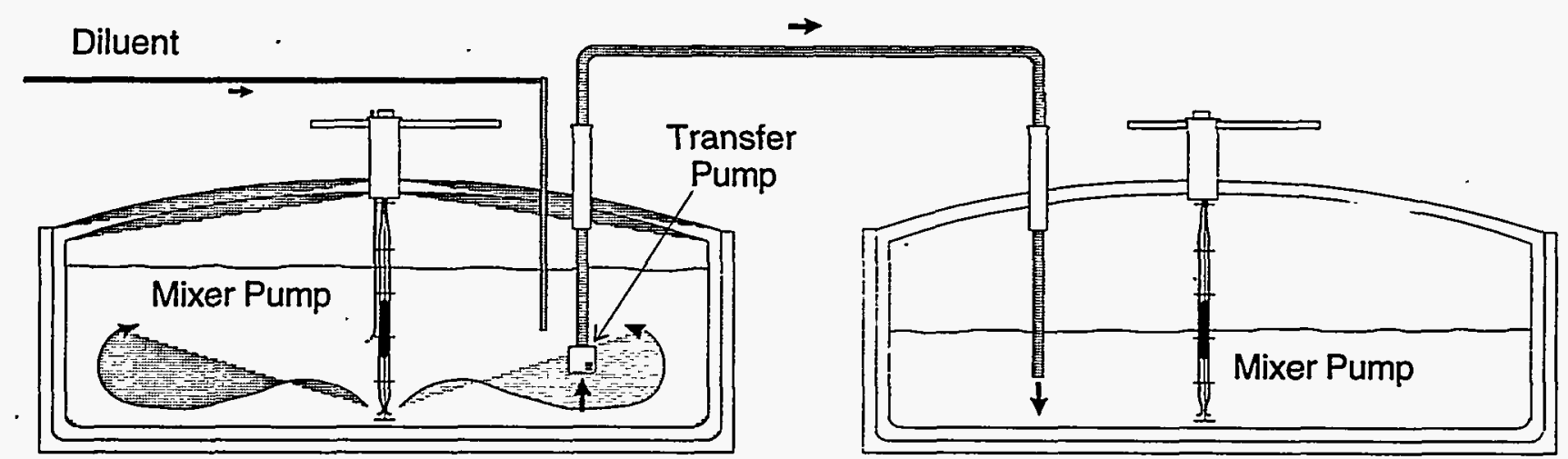

Figure 1.3. Schematic of a Dilution System 


\subsubsection{Waste Heating}

Heating the waste to below the atmospheric boiling point dissolves the sodium salts that make up the nonconvective layer and lowers the viscosity and yield strength of the sludge. It has been postulated that the combination of reducing of the amount of material that can retain gas and diminishing its ability to do so could mitigate episodic GREs in a manner similar to dilution.

Heating scored highest of the chemical treatment methods considered in the initial mitigation/remediation study (Babad et al. 1992b) and was one of the four concepts recommended for further study. However, technical challenges and safety concerns have slowed its development relative to the other concepts. No external heating system has been designed, and no hazards assessment has been performed.

An additional intrusive heating system (see Figure 1.4) will be required in most tanks. The thermal mass of the waste is so large that neither using a mixing pump nor heating the ventilation air can transfer enough heat to raise the temperature within a reasonable time period or maintain the desired temperature. However, in some tanks, the waste may generate enough heat to raise the temperature by reduced cooling.

\subsection{Potential Deployment in Other Tanks}

Because of the high priority given to mitigating Tank 241-SY-101 over the past few years, much more is known and much more experience has been gained concerning this tank than any of the others. Therefore, by necessity, this report is based on data obtained almost entirely from Tank 241-SY-101 and designs developed specifically for Tank 241-SY-101. There is simply not enough data from other tanks to make a general study possible at this time.

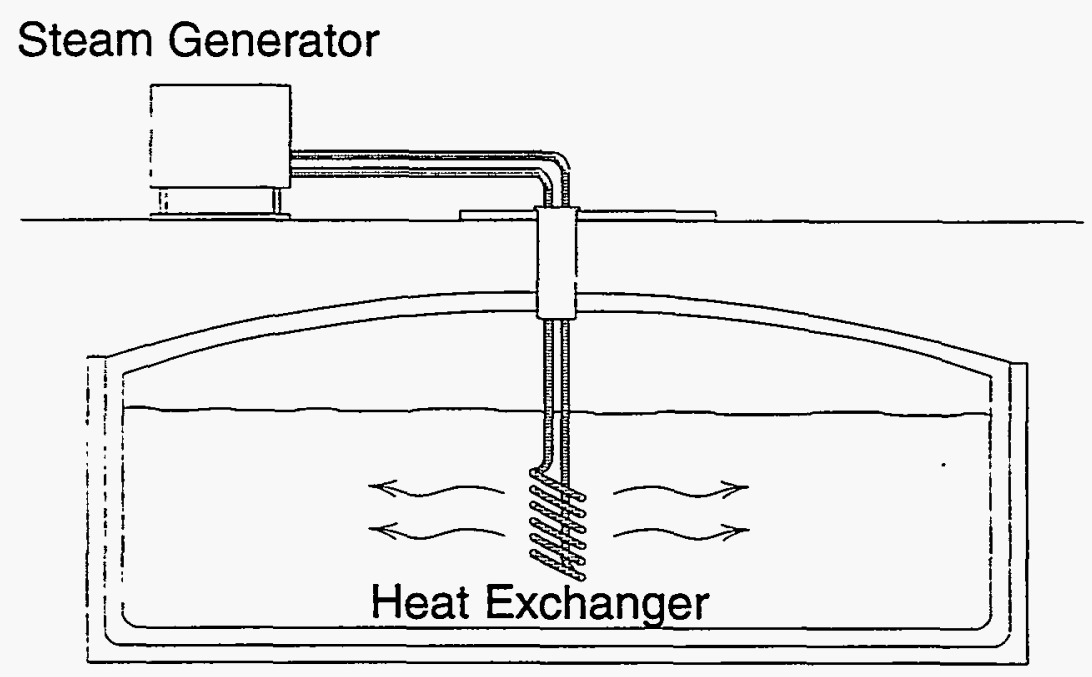

Figure 1.4. Schematic of a Heating System 
Nevertheless, we feel confident that differences among tanks, when known and quantified, will not disqualify appropriate conclusions on technical aspects of the various mitigation concepts. In fact, it is possible that they will be more similar than dissimilar. The total collection of Hanford tanks is not in view here. Relatively few of the watch list tanks will probably be designated as requiring mitigation. The current data deficit will eventually be filled. Any mitigation system will require a thorough characterization of the waste, a survey of the tank structure, detailed performance predictions, and a complete safety analysis specific to the intended tank. These will all drive the system design details.

In this section we make a cursory overview of the watch list tanks based on tank volume and waste type. The detailed chemistry and waste configuration of most tanks can only be approximated from fill histories. Actual tank data are extremely sparse.

\subsubsection{Waste Material Classification}

The Tank Farm Surveillance and Waste Status Summary Report (WHC-EP-0182-70) identifies the primary waste material in each of the 25 FGWL tanks in five broad classes: concentrated complexant, dilute complex waste, double-shell slurry, double-shell slurry feed, and non-complexed. Briefly, concentrated complexant is the product from evaporation of dilute complexed waste. Both concentrated complexant and dilute complex waste have high concentrations of organic carbon. Double-shell slurry exceeds the evaporator sodium aluminate saturation limit and, for purposes of reporting, is treated as a solid. Double-shell slurry feed is waste concentrated to the point just short of the sodium aluminate saturation limit. Noncomplexed waste is a general term applied to liquors not identified as complexed. Table 1.1 lists the flammable tanks grouped by this broad waste material process classification.

Three of the flammable gas watch list tanks are identified as holding concentrated complexant. Dilute complex waste and double-shell slurry are listed once each. Ten tanks hold double-shell slurry feed. The balance of the FGWL tanks are listed as holding noncomplexed waste liquors. Tank SY-101 is listed as a concentrated complexant tank. The other concentrated complexant tanks are AX-103 and SY-103.

However, the contents are not so distinct and well-defined as might appear from this listing. The fill history of SY-101; for example, shows that this tank actually contains about $48 \%$ double-shell slurry and 52\% concentrated complexant (Babad et al. 1992a). Further, AN-103 contains 73\% double shell slurry and $27 \%$ is heel left over from several years of staging for the 242-A evaporator system (Reynolds 1994). AN-104 and AN-105 contain a similar mixture.

\subsubsection{Tank Inventory}

The inventories of a number of the flammable gas watch list tanks are apparently similar. But given inventory variations due to differences in fill histories, the primary waste material in the tank is not the only factor to consider when evaluating mitigation options. Consideration must also be given to the form of the waste in the tank. Here it is difficult to proceed without core samples or some other definitive assay of the current tank layering configuration. However, some basic information in the surveillance report may be useful.

The ratio of pumpable liquid to total tank volume and the ratio of total waste volume to the approximate tank capacity might serve as preliminary screens when considering mitigation options. Figure 1.5 shows the ratio of pumpable liquid to total waste volume for each of the tanks computed from the information listed in the surveillance report. Extreme values of 1 and 0 were computed for AN-105 and SX-109 respectively. AN-103 is also shown to have minimal liquid. Relative to mitigation options, these extremes imply that AN-105 may be amenable to mixing whereas dilution may need to be considered for SX-109 and AN-103. 
But this information may be misleading. Tank SY-101 is listed as having only $24 \%$ pumpable liquid, but core samples and temperature profiles showed a 160 -inch convective layer that represented $40 \%$ of the tank volume prior to mixer pump installation. Mixer pump operational data clearly indicates that almost the entire tank content is pumpable when mixed. Similar behavior might be expected from SY-103, for example, and AN-103 might not need as much dilution as the plot would indicate. Figure 1.6 shows the estimated specific gravity of each tank (excluding SX-109).(a) This shows that AN-103 has an average density similar to SY-101.

The ratio of total waste volume to tank capacity provides a first level assessment of which tanks may be amenable to dilution without an initial transfer as well as which tanks have space available to receive transferred waste. Figure 1.7 shows the ratio of waste volume to approximate tank capacity for the flammable gas tanks. The three highlighted tanks, AX-103, SX-101, and SX-109 are less than 50\% full and could possibly be considered as transfer receivers or as dilution candidates.

Deployment of mixer pumps in SY-103, AW-101, AN-103, AN-104, and AN-105 is currently assumed. If the information for each tank given in Table 1.1 and Figures 1.5, 1.6 and 1.7 generally (if approximately) represents the tank contents, this would appear feasible in a broad context, given the experience with SY-101.

(a) Brager, H. R. 1994. Summary of Information on Flammable Gas Watch List Tanks (Draft). Westinghouse Hanford Company, Richland, Washington. 
Table 1.1. Waste Classification in FGWL Tanks

\begin{tabular}{|c|c|}
\hline $\begin{array}{c}\text { Tank } \\
\text { (DS }=\text { Double-Shell) }\end{array}$ & Waste Material \\
\hline SY-101 (DS) & Concentrated Complexant \\
\hline SY-103 (DS) & $"$ \\
\hline$A X-103$ & $"$ \\
\hline SX-101 & Dilute Complex Waste \\
\hline AN-103 (DS) & Double Shell Slurry \\
\hline AN-104 (DS) & Double Shell Slurry Feed \\
\hline $\mathrm{AN}-105$ (DS) & $"$ \\
\hline AW-101 (DS) & $"$ \\
\hline A-101 & $"$ \\
\hline $\mathrm{AX}-101$ & $"$ \\
\hline S-102 & $"$ \\
\hline SX-102 & $"$ \\
\hline SX-104 & $"$ \\
\hline SX-105 & $"$ \\
\hline U-107 & $\bar{~}$ \\
\hline S-111 & Noncomplexed \\
\hline$S-112$ & $\bar{n}$ \\
\hline SX-103 & " \\
\hline SX-106 & $"$ \\
\hline SX-109 & " \\
\hline $\mathrm{T}-110$ & $"$ \\
\hline $\mathrm{U}-103$ & $" \quad "$ \\
\hline U-105 & $" 1$ \\
\hline U-108 & $" \quad "$ \\
\hline U-109 & $"$ \\
\hline
\end{tabular}




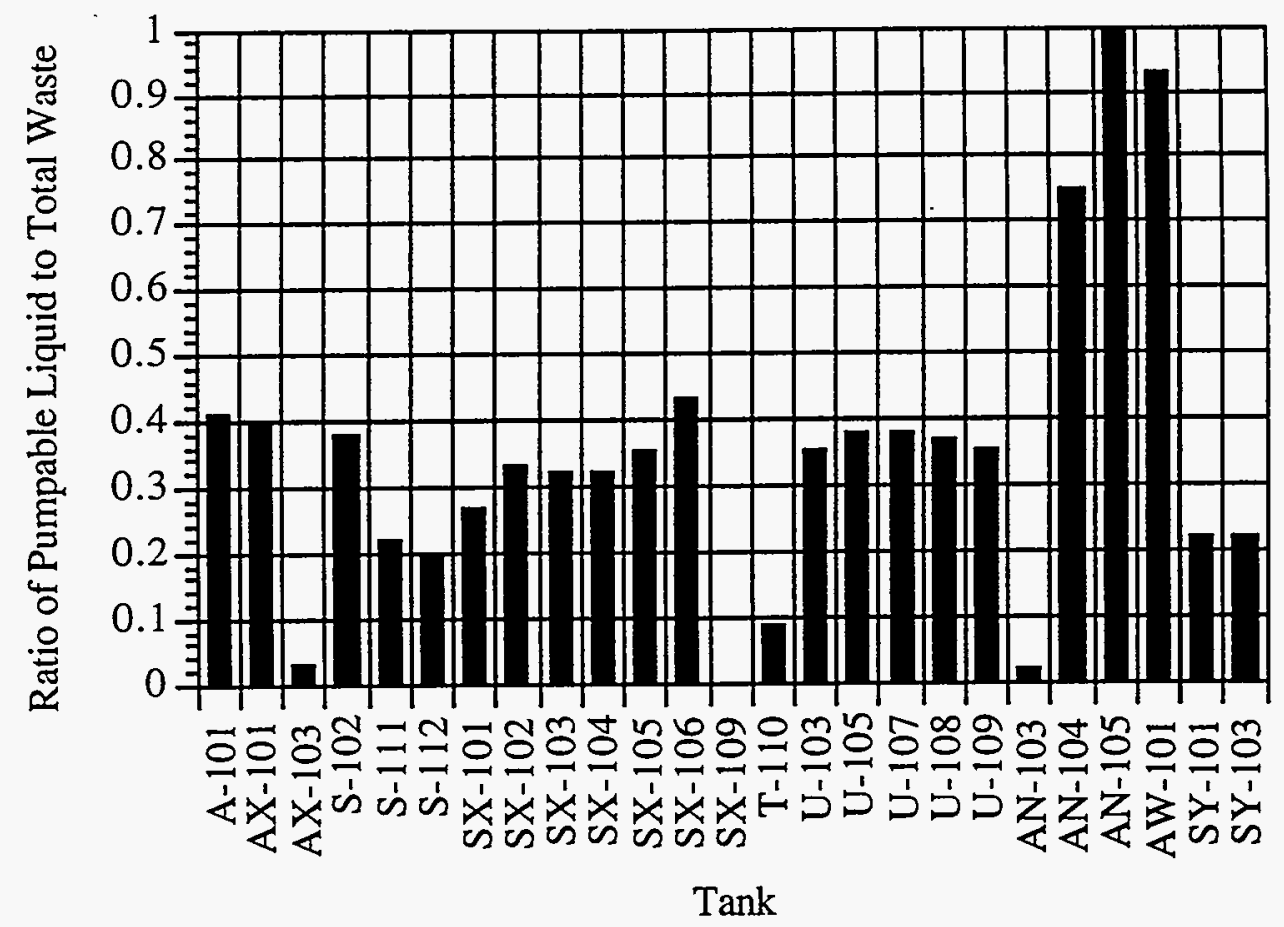

Figure 1.5. Pumpable Liquid Content of FGWL Tanks

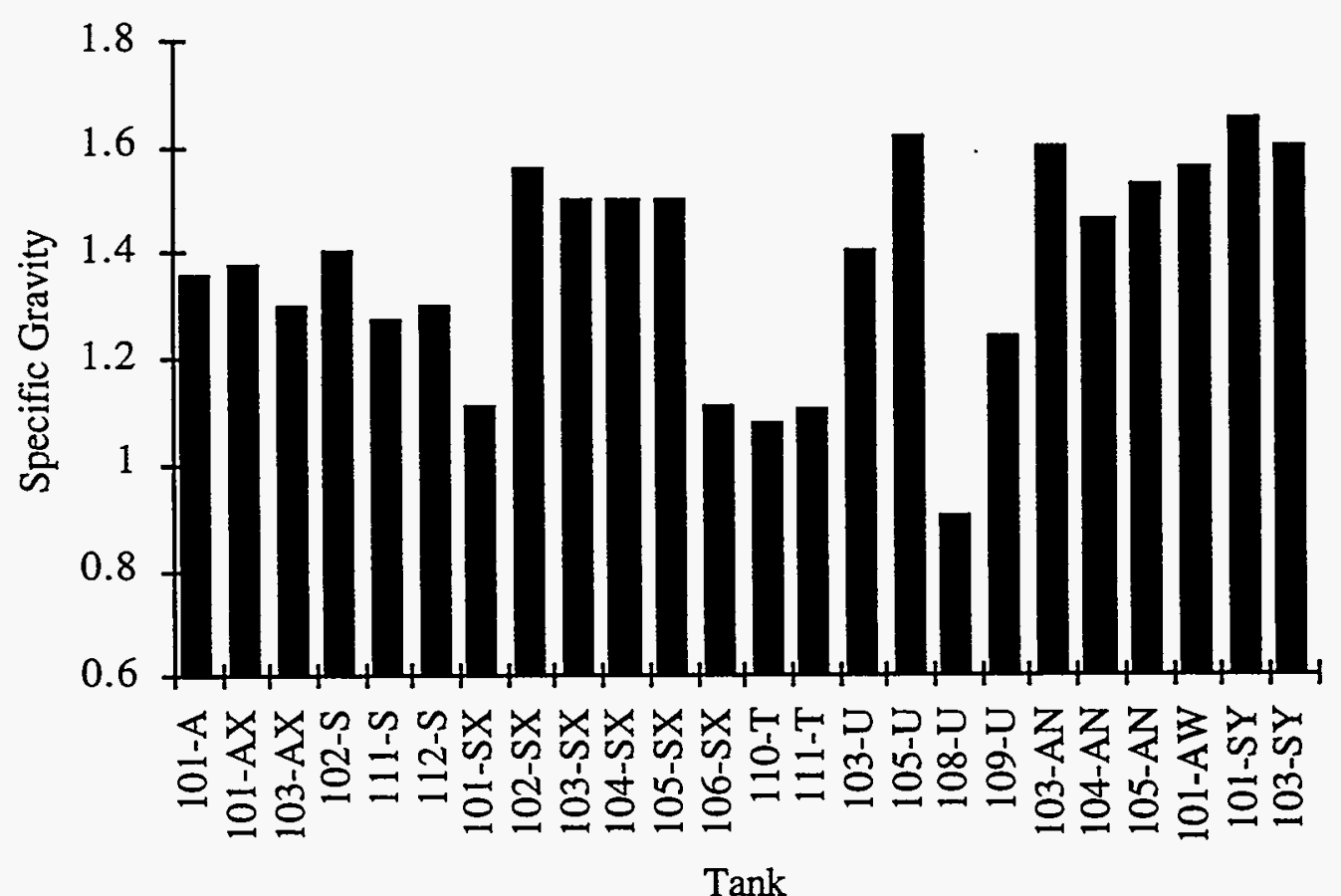

Figure 1.6. Specific Gravity of FGWL Tanks 
S-112

SX-101

SX-102

SX-103

SX-104

$\mathrm{SX}-105$

$\rightarrow$ SX-106

SX-109

$\mathrm{T}-110$

U-103

U-105

U-107

U-108

U-109

AN-103

AN-104

AN-105

AW-101

SY-101

SY-103

io

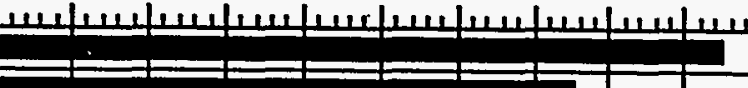

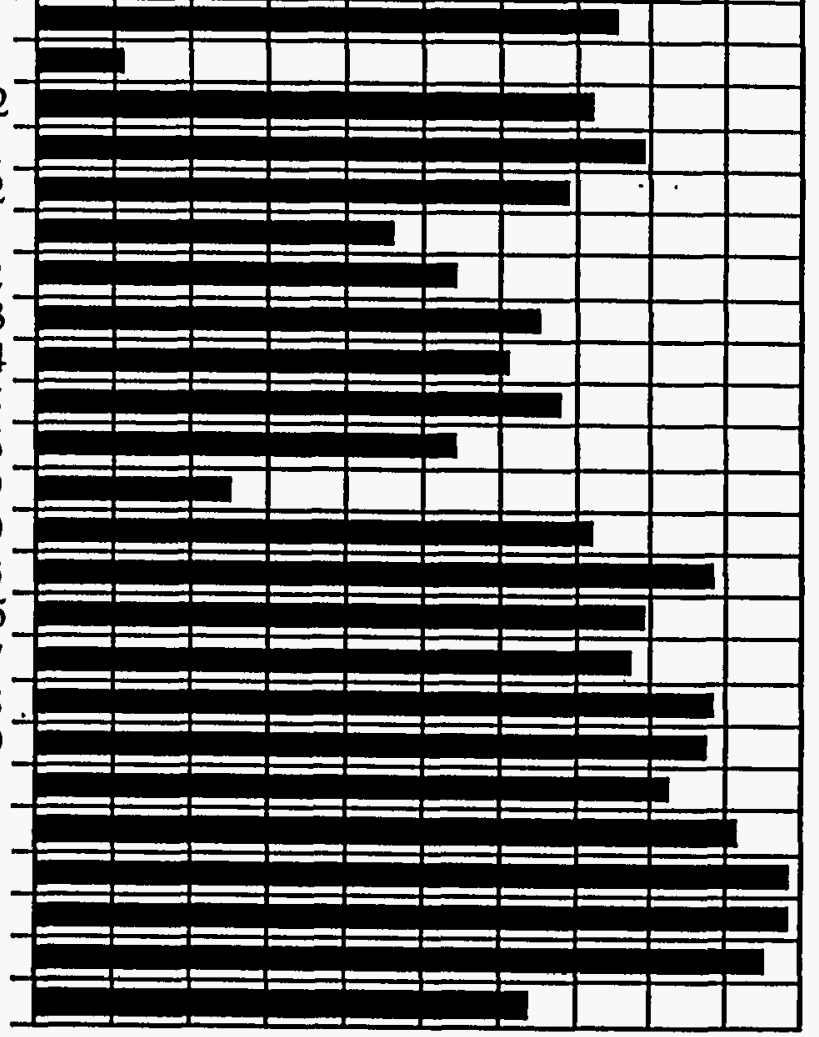




\subsection{Summary and Conclusions}

The term "mitigation," as applied to Hanford waste tanks, can be defined as elimination of the hazard of flammable gas releases. For Tank 241-SY-101, this requires keeping the tank in a state such that no gas releases occur that result in the average hydrogen concentrations in the tank dome exceeding $25 \%$ of the lower flammability limit (LFL).(a) Mitigation methods can be described as active or passive. Active mitigation requires continued operation of some installed system, like a mixer pump; passive mitigation does not, except for ancillary systems such as ventilation and monitoring, require such systems.

The four mitigation concepts selected for this study are pump mixing, low frequency sonic vibration, dilution, and heating. As stated in Section 1, it is difficult to compare and make conclusions about mitigation concepts that are at such disparate levels of development. Only the mixer pump has actually been proven to be an effective mitigation method by operating in an actual waste tank. A full-scale prototype design has been completed for the sonic probe concept, but testing is still required. A system has been conceptualized for dilution and transfer of 241-SY-101 waste, but the effectiveness of dilution relies on knowledge of waste behavior that is not now available. Heating has not been studied nearly as comprehensively as the other three.

It is also. somewhat misleading to discuss the four selected concepts independently. Mechanical mixing is required to blend diluent and waste to achieve dilution and possibly to distribute added energy to accomplish heating. Heating may be required to compensate for the increased heat losses created by mixing and the reduced heat generation of dilution to keep waste temperatures in a safe range. Intrusive devices like mixer pumps, sonic probes, and waste heaters use water for initial insertion and decontamination spray at removal. This creates at least a modest amount of dilution.

Nevertheless, the natures of the concepts allow some definite conclusions on their comparative effectiveness. Given the caveats, these are the findings of this report concerning the four concepts:

- The 150-hp mixer pump in Tank 241-SY-101 has proven to be a safe and effective mitigation method for that tank. Tank data for over one year of operation show this power level is needed to mix the waste at the outer radii, even though only a few hours of operation per week are required to maintain mitigation. Installation of similar mixer pumps in five more tanks is currently assumed for planning purposes. We are confident that mixer pumps will effectively mitigate other tanks with waste configurations and properties comparable to Tank 241-SY-101. Mixing is an active mitigation method.

- Low-frequency sonic vibration (the current sonic probe design) is predicted by analysis, laboratory testing, and past industrial experience to be safe and effective for mitigation. It is also an active mitigation method that is potentially less costly than a mixer pump and may be useable in tanks that are not amenable to direct mixing. We recommend that a full-scale cold test program, aimed toward a trial in a waste tank, be considered for the sonic probe. Ultrasonic (acoustic) mitigation devices are not considered practical due to severe attenuation by the waste at high frequencies.

- Existing data are not sufficient to prove that dilution can mitigate GRE behavior or to predict what dilution ratio is necessary. Dilution may be the most costly and complex option. It generates additional waste, waste must be moved to other (new) tanks in many cases to make space for the diluent, and mixing is required to effectively introduce the diluent. However, there are indications that practical dilutions (around 1:1) may eliminate gas retention. Also, a dilution/transfer system will be required eventually for remediation. Most importantly,

(a) LFL is defined as a 3\% hydrogen concentration in a nitrous oxide atmosphere (LANL 1994). 
dilution is the only concept of the four that potentially offers true passive mitigation. Therefore, we recommend that dilution studies related to gas retention be given high priority.

- Like dilution, heating the waste below $100^{\circ} \mathrm{C}$ cannot be proven to mitigate GRE behavior with available information, nor can the necessary temperature range be specified. Also, the huge thermal inertia of most tanks makes heating potentially difficult and costly. An additional heating system is required to achieve and maintain elevated temperatures in most tanks. Thus heating qualifies as an active mitigation concept. Because other active mitigation methods are already proven or are being actively pursued, it is recommended that research on dilution have higher priority than heating as a future mitigation method.

Two additional conclusions developed during analysis have important implications:

- Removing a relatively small fraction of waste from a tank (35\% for Tank 241-SY-101) can prevent flammable gas concentrations exceeding the LFL by reducing the volume of potential GREs while providing more dome space for mixing. Since it does not stop GRE behavior and average concentrations may exceed the 1/4 LFL criterion, transfer does not satisfy the definition of mitigation. But it greatly reduces the main hazard, does so passively, and generates a minimum of new waste. Transfer might be considered a means to mitigate the consequences of mixer pump failure in Tank 241-SY-101.

- Recent dilution tests on 241-SY-101 core samples indicate that current WHC transfer pipeline requirements can be satisfied with dilutions of under $0.4: 1$, rather than $1: 1$ as originally supposed.

The reasons behind these conclusions and recommendations are summarized in the rest of this section, and the details are given in the sections devoted to each concept. The mixer pump is described in Section 3.0 and the Sonic Probe in Section 4.0. Dilution is covered in Section 5.0, and heating is discussed in Section 6.0.

A parallel listing comparing characteristics, features, and problems of the four concepts is given in Table 2.1. This table is not intended to be totally comprehensive or provide a formal rating system for the concepts, but to summarize a collection of issues on a few pages for quick comparison. Note that successful mitigation is assumed in some cases where potential operational consequences are discussed. This is purely semantic and no conflict with the conclusions above is implied.

\subsection{Mixing}

Pump jet mixing prevents episodic GREs by mobilizing the greater part of the settled sludge layer and keeping it in suspension so it cannot trap gas. Gas generated in the waste is released more or less continuously instead of in large episodic events. Pump mixing should be effective in any tank with a sludge layer that can be mobilized hydraulically and that has sufficient liquid content to suspend the sludge. The pump design requirements for a particular tank depend on the waste properties and the depth of each of the layers.

A spare 150-hp mixer. pump from the Hanford Grout Program was modified and installed in Tank 241-SY-101 July 3, 1993, following a natural GRE. Since then, two major test periods have been conducted: Phase B, from November 25 to December 18, 1993; and Full-Scale testing, from February 4 to April 13,1994. The results of these tests are documented in detail in Allemann et al. (1994) and Stewart et al. (1994), respectively.

Experience to date has shown that only intermittent mixer pump operation (typically no more than three one-hour runs per week) is necessary to mitigate Tank 241-SY-101. Since mid-November 1993, when the waste was first fully mixed, the waste level has stayed near the minimum allowable height, and the average dome hydrogen concentration has remained well below $25 \%$ of the LFL. 
Table 2.1. Characteristics, Features and Problems of the Mitigation Methods

\begin{tabular}{|c|c|c|c|c|}
\hline \multirow[b]{2}{*}{ Parameter } & \multicolumn{4}{|c|}{ Mitigation Method } \\
\hline & Mixer Pump & Sonic Probe & Dilution & Hèating \\
\hline $\begin{array}{l}\text { Effectiveness in meeting the } \\
\text { main goal of mitigation and } \\
\text { relation to other methods. }\end{array}$ & \begin{tabular}{|l} 
Effectiveness has been \\
de monstrated by be \\
successful operation since \\
July 1993 in Tank $241-$ \\
SY-101. Heating may be \\
necessary to offset \\
increased heat loss.
\end{tabular} & $\begin{array}{l}\text { Not demonstrated. } \\
\text { Evaluated analytically for } \\
\text { Tank 241-SY-101 and } \\
\text { estimated for } 241-S Y- \\
\text { l03. Heating may be } \\
\text { necessary to offset } \\
\text { increased heat loss. }\end{array}$ & $\begin{array}{l}\text { Not demonstrated. } \\
\text { Evaluated by analysis } \\
\text { and lab testing for Tank } \\
241-S \text { Y }-101 \text { only. } \\
\text { Mixing is required for } \\
\text { initial dilution. Heating } \\
\text { may be necessary to } \\
\text { offset increased heat } \\
\text { loss. }\end{array}$ & $\begin{array}{l}\text { Not demonstrated. } \\
\text { Evaluated by analysis } \\
\text { and lab tests for Tank } \\
241-S Y-101 \text { only. }\end{array}$ \\
\hline $\begin{array}{l}\text { Safety hazards specific to } \\
\text { the concept. (Note that the } \\
\text { test plan, operating plan and } \\
\text { safety analysis for each } \\
\text { concept must be tailored to } \\
\text { each tank.) }\end{array}$ & $\begin{array}{l}\text { Safety has been } \\
\text { demonstrated in full-scale } \\
\text { tests and routine operation } \\
\text { in Tank 241-SY-101. } \\
\text { Hazards include large } \\
\text { GRE during initial mixing, } \\
\text { damage to tank during } \\
\text { installation and removal. }\end{array}$ & $\begin{array}{l}\text { No formal safety analysis. } \\
\text { Initial hazards evaluation } \\
\text { for Tank 241-SY-101 in } \\
\text { progress. Operational } \\
\text { hazards similar to mixer } \\
\text { pump. Potential effects of } \\
\text { vibration on tank structure } \\
\text { are being assessed. }\end{array}$ & $\begin{array}{l}\text { No formal safety } \\
\text { analysis. Initial hazards } \\
\text { evaluation completed for } \\
\text { Tank } 241-S Y-101 . \\
\text { Adding diluent raises } \\
\text { hydrostatic pressure and } \\
\text { reduces tank head space } \\
\text { so that potential GREs } \\
\text { tend to be larger and } \\
\text { more likely to exceed } \\
\text { LFL. Very difficult to } \\
\text { reverse dilution if } \\
\text { problems arise. }\end{array}$ & $\begin{array}{l}\text { No formal safety } \\
\text { analysis or hazards } \\
\text { evaluation. If problems } \\
\text { arise, it could take } \\
\text { months to lower the } \\
\text { temperature due to the } \\
\text { huge thermal mass. }\end{array}$ \\
\hline $\begin{array}{l}\text { Active or passive mitigation } \\
\text { method? Active implies that } \\
\text { periodic overt actions are } \\
\text { necessary to maintain } \\
\text { mitigation (such as operating } \\
\text { a mixing pump for a short } \\
\text { period). }\end{array}$ & Active. & Active. & $\begin{array}{l}\text { Passive mitigation } \\
\text { potentially achieved } \\
\text { following the initial } \\
\text { active dilution. }\end{array}$ & $\begin{array}{l}\text { Active. } \\
\text { (Continued heat } \\
\text { addition required for } \\
\text { most tanks). }\end{array}$ \\
\hline Simplicity of construction & $\begin{array}{l}\text { Relatively the most } \\
\text { complex of the three } \\
\text { a ctive mitigation } \\
\text { approaches. Much less } \\
\text { complex than dilution and } \\
\text { transfer. }\end{array}$ & $\begin{array}{l}\text { Less complicated than the } \\
\text { mixer pump system. }\end{array}$ & $\begin{array}{l}\text { In-t ank equipment } \\
\text { includes a mixer pump. } \\
\text { Transfer system is quite } \\
\text { complex. Potentially } \\
\text { includes construction of } \\
\text { new tanks. But the } \\
\text { system may be required } \\
\text { for future remediation. }\end{array}$ & $\begin{array}{l}\text { Unable to assess at this } \\
\text { time. } \\
\text { Requires an external } \\
\text { heating system for most } \\
\text { tanks. }\end{array}$ \\
\hline $\begin{array}{l}\text { Lifetime (meets operating } \\
\text { service life requirements) }\end{array}$ & $\begin{array}{l}\text { Current experience with } \\
\text { Tank 241-SY-101 mixer } \\
\text { pump suggests that the } \\
\text { duty cycle may allow } \\
\text { operation for } 2 \text { to } 10 \\
\text { years. A spare mixer } \\
\text { pump is being built as a } \\
\text { backup. }\end{array}$ & $\begin{array}{l}\text { Test article design life is } \\
50 \text { hrs. A mature sonic } \\
\text { probe system should } \\
\text { probably have a greater } \\
\text { service life than a mixing } \\
\text { pump due to simplicity } \\
\text { and isolation of moving } \\
\text { parts from the waste. }\end{array}$ & $\begin{array}{l}\text { If passive mitigation is } \\
\text { achieved, service life is } \\
\text { not an issue after the } \\
\text { initial dilution (and } \\
\text { transfer). }\end{array}$ & $\begin{array}{l}\text { Unable to assess, but } \\
\text { likely typical of } \\
\text { industrial boilers and } \\
\text { heat exchangers. Slow } \\
\text { changes in tank } \\
\text { temperature reduce } \\
\text { importance of service } \\
\text { life as an issue. }\end{array}$ \\
\hline $\begin{array}{l}\text { Ease of installation, removal, } \\
\text { and decontamination }\end{array}$ & $\begin{array}{l}\text { The mixer pump assembly } \\
\text { is relatively difficult to } \\
\text { re move and } \\
\text { decontaminate. }\end{array}$ & $\begin{array}{l}\text { Potentially more portable } \\
\text { than the mixer pump. } \\
\text { Decontamination should } \\
\text { be much easier. }\end{array}$ & $\begin{array}{l}\text { Dilution and transfer } \\
\text { system is essentially a } \\
\text { permanent installation. }\end{array}$ & $\begin{array}{l}\text { Unable to assess. } \\
\text { Portability of an } \\
\text { intrusive heat } \\
\text { exchanger should } \\
\text { compare to mixer pump } \\
\text { and sonic probe. }\end{array}$ \\
\hline $\begin{array}{l}\text { Ease of maintenance and } \\
\text { operations }\end{array}$ & $\begin{array}{l}\text { In tank components of the } \\
\text { pump assembly in Tank } \\
241-S Y-101 \text { cannot be } \\
\text { replaced or repaired } \\
\text { without extracting the } \\
\text { assembly. Operation } \\
\text { requires a large effort and } \\
\text { close monitoring. }\end{array}$ & $\begin{array}{l}\text { Somewhat easier than the } \\
\text { mixing pump, however a } \\
\text { bearing failure, for } \\
\text { example, would require } \\
\text { the removal of the probe } \\
\text { assembly for repair. } \\
\text { Simplicity may provide } \\
\text { potential for automated } \\
\text { operation. }\end{array}$ & $\begin{array}{l}\text { If passive mitigation is } \\
\text { achieved, maintenance } \\
\text { and operation effort is } \\
\text { not an issue after initial } \\
\text { dilution (and transfer). }\end{array}$ & $\begin{array}{l}\text { Potentially the easiest } \\
\text { active system to } \\
\text { operate and maintain } \\
\text { because almost all } \\
\text { components requiring } \\
\text { maintenance can be } \\
\text { installed above ground. }\end{array}$ \\
\hline
\end{tabular}


Table 2.1 continued

\begin{tabular}{|c|c|c|c|c|}
\hline \multirow[b]{2}{*}{ Parameter } & \multicolumn{4}{|c|}{ Mitigation Method } \\
\hline & Mixer Pump & Sonic Probe & Dilution & Heating \\
\hline $\begin{array}{l}\text { Probable consequences } \\
\text { (waste behavior) if } \\
\text { mitigation system were to } \\
\text { fail. (Assuming initial GRE } \\
\text { behavior). }\end{array}$ & $\begin{array}{l}\text { Waste is expected to } \\
\text { return to uncontrolled } \\
\text { periodic GREs eventually. }\end{array}$ & $\begin{array}{l}\text { Waste is expected to } \\
\text { return to uncontrolled } \\
\text { periodic GREs eventually. }\end{array}$ & $\begin{array}{l}\text { No change after initial } \\
\text { dilution (unless heating is } \\
\text { required as described } \\
\text { elsewhere). The waste } \\
\text { should remain in a } \\
\text { passively mitigated state. } \\
\text { This is the most distinct } \\
\text { advantage of dilution. }\end{array}$ & $\begin{array}{l}\text { Little change expected } \\
\text { for many months. } \\
\text { Failure of the tank } \\
\text { heating system will } \\
\text { begin a slow cooling } \\
\text { (due to the large } \\
\text { thermal mass). Waste } \\
\text { would eventually retum } \\
\text { to uncontrolled GREs. }\end{array}$ \\
\hline $\begin{array}{l}\text { Applicability to other } \\
\text { flammable gas tanks (what } \\
\text { kind of tanks can this method } \\
\text { potentially be applied to?) }\end{array}$ & $\begin{array}{l}\text { Waste must contain } \\
\text { sufficient liquid to be } \\
\text { pumpable when mixed. } \\
\text { Sludge must have } \\
\text { sufficiently low yield } \\
\text { strength to be mobilized } \\
\text { by the jet. Tank must be } \\
\text { relatively free of large } \\
\text { obstructions. }\end{array}$ & $\begin{array}{l}\text { Sludge properties must be } \\
\text { such that it can be yielded } \\
\text { by sonic vibration of } \\
\text { reasonable power. } \\
\text { Rheology of sonified } \\
\text { sludge must allow buoyant } \\
\text { convection and bubble } \\
\text { rise. }\end{array}$ & $\begin{array}{l}\text { Sludge properties and } \\
\text { chemistry must be such } \\
\text { that practical dilution } \\
\text { can eliminate gas } \\
\text { retention. Provision } \\
\text { required for other } \\
\text { tank(s) to receive part of } \\
\text { the diluted waste or the } \\
\text { tank has sufficient } \\
\text { excess capacity to hold } \\
\text { the diluted waste. }\end{array}$ & $\begin{array}{l}\text { Sludge properties and } \\
\text { chemistry must be such } \\
\text { that gas retention } \\
\text { ceases at a reasonably } \\
\text { a } \mathrm{c} \text { h } \mathrm{e} \text { v b } \mathrm{l} \text { e } \\
\text { temperature. Tank and } \\
\text { waste configuration } \\
\text { permit a heating system } \\
\text { to be installed or waste } \\
\text { generates enough heat } \\
\text { that temperature can be } \\
\text { raised by reduced } \\
\text { cooling. }\end{array}$ \\
\hline $\begin{array}{l}\text { Reversible?: Are other } \\
\text { realistic mitigation, retrieval, } \\
\text { and/or disposal options } \\
\text { foreclosed? }\end{array}$ & $\begin{array}{l}\text { All in tank components } \\
\text { can be extracted (with } \\
\text { some difficulty) and the } \\
\text { tank returns to } \\
\text { approximately its original } \\
\text { state. The mixer pump } \\
\text { can be used to aid } \\
\text { retrieval. }\end{array}$ & $\begin{array}{l}\text { All in tank components } \\
\text { can be extracted and the } \\
\text { tank returns to } \\
\text { approximately its original } \\
\text { state. Sonification may } \\
\text { aid retrieval. }\end{array}$ & $\begin{array}{l}\text { The waste composition is } \\
\text { changed and the volume } \\
\text { of the tank waste } \\
\text { increases. This might be } \\
\text { reversible (with great } \\
\text { difficulty) by by } \\
\text { evaporation. Installed } \\
\text { equipment may be } \\
\text { necessary for retrieval. }\end{array}$ & $\begin{array}{l}\text { All in tank components } \\
\text { can be extracted such } \\
\text { that the tank returns to } \\
\text { a pproximately its } \\
\text { original state (after } \\
\text { many months). }\end{array}$ \\
\hline
\end{tabular}

The mixer pump has also demonstrated the ability to mobilize sludge down to within 16 inches of the bottom of the tank to a radius of at least 28 feet (tank radius is 37 feet). With the current duty cycle, the pump lifetime could be as long as 10 years.

A complete formal safety analysis controls pump operation and is updated regularly as more experience is gained (LANL 1994). The 241-SY-101 mixer pump safety analysis is an excellent model for installing new mixer pumps in other watch-list tanks. There is no evidence to date that mixing has created any new hazardous condition.

The current 241-SY-101 mixer pump has the inlet about 18 feet above the discharge nozzles, which enhances mixing by forcing vertical circulation and avoids loading the nozzles with sludge during initial operation. It restricts the pump operation to waste levels of at least $20-24$ feet, which limits the potential of the current pump to provide mixing for future retrieval and transfer operations. However, the solids settling rate has proven to sufficiently slow that it would be feasible to mix the tank before transfer. Future mixer pumps may have a lower suction height, depending on tank conditions.

On the debit side, the mixer pump is a large, heavy, and complex machine that demands a significant effort to operate. Its physical size and complexity make installation and removal relatively costly. A large riser (42-inch for the current design) is required, and the added dome loading is significant. Because the pump is submerged in the waste, it is impossible to perform maintenance or repairs (except changing motor oil) without removing the pump. And decontamination and storage of a decommissioned mixer pump is a burden on the overall life-cycle cost. 


\subsection{Sonic Vibration}

Sonic vibration is expected to eliminate large GREs by producing acoustic waves of sufficient intensity to liquify the sludge and release trapped gas by allowing bubbles or buoyant regions of sludge to rise or by forcibly detaching smaller bubbles that might be attached to particles. Like mixing, this releases gas more steadily, instead of suddenly during infrequent large events, but it is not expected to release dissolved gases. Low-frequency vibrators have been successfully used for decades to remove air bubbles from fresh concrete by this same mechanism. Sonic vibration may be effective in tanks whose sludge layers can be yielded by vibration of sufficient intensity and whose sonified sludge is sufficiently dilute to allow buoyant convection and bubble rise.

The sonic probe device currently proposed is a cylindrical shell with an internal eccentric mass driven to rotate about a shaft inside the cylinder by a hydraulic motor. The sonic probe is expected to operate at frequencies in the vicinity of $100 \mathrm{~Hz}(6000 \mathrm{rpm})$. The duty cycle is expected to involve only 5-10 minutes of vibration per week. Detailed design is due to be completed at the end of FY 1994.

Though relatively large (18 feet long and almost 1 foot in diameter) and heavy, it has a smooth surface and can be easily decontaminated upon removal. There are no moving parts in contact with the waste. It can be installed in mid-sized risers, and the installation is expected to be a much simpler process than the mixer pump. It may be feasible to remove and reinstall a sonic probe if repairs were needed.

A full safety assessment has not been done on the sonic probe, but an initial hazard analysis has revealed no disqualifying problems to date. Transmission of acoustic waves is inherently selflimiting with respect to uncontrolled gas release in that a higher gas content attenuates the wave more strongly and limits the induced gas release by reducing the volume of sludge that can yield during any one operation.

Extensive analyses predict that the sonic probe can operate effectively and safely, but performance calculations depend heavily on waste properties (e.g., bubble size distribution and sludge yield criteria for pressure waves) that can only be estimated at this time. Therefore there is some uncertainty in the performance predictions. But the uncertainty is more of degree than of substance-there is little doubt that low-frequency sonic vibration will successfully release trapped gas in waste similar to that originally in Tank 241-SY-101. The concept is ready for full-scale testing.

Higher-frequency ultrasonic mitigation devices were not considered practical. The small bubbles in the waste severely attenuate high-frequency pressure waves. Thus mitigation of a typical waste tank would require many ultrasonic devices (and available risers to accommodate them) operating at high power for long periods. This raises concerns about cavitation and sound-induced chemical reaction.

\subsection{Dilution}

Dilution is expected to dissolve a portion of the gas-retaining material and change its properties to reduce or eliminate its ability to retain and ultimately release gas. At this point, there are insufficient data to determine how much dilution is necessary, or whether any practical amount of dilution (1-to-1 or less) can eliminate gas retention in the sludge. But adding liquid to a tank tends to increase the volume of potential GREs and reduces the head space such that flammable concentrations would be more likely. Therefore, dilution can be considered an effective mitigation method only if it can be shown conclusively to eliminate or greatly reduce the ability of settled solids to retain gas. 
On the other hand, transferring mixed slurry out of a tank greatly reduces the potential GRE volume and increases tank head space such that the flammability hazard can be essentially eliminated even if GREs continue. It can be shown that transferring about 35\% of the waste out of Tank 241SY-101 will prevent flammable gas concentrations exceeding the LFL during a GRE. This is not truly mitigation, because episodic gas releases can occur and concentrations may exceed $1 / 4$ of the LFL, but it greatly reduces the hazard and does so passively. Because this is accomplished with minimum dilution, it also creates a minimum of additional waste volume.

A dilution system concept for Tank 241-SY-101 has been developed by the Initial Tank Retrieval Systems Project W-211 that can support dilution of Tank 241-SY-101 waste for both retrieval/transfer operations and mitigation. In this concept, waste will be transferred to a new tank, diluted in-line at about a $0.4: 1$ ratio to meet current WHC pipeline requirements. Tank Tank 241SY-101 will be backfilled with diluent, at least to the level that will permit mixer pump operation. The proposed diluent is a 2-molar solution of $\mathrm{NaOH}$. A mixer pump is necessary to initially effect dilution, because the diluent is much less dense than liquid waste and would form a stratified layer on the surface. It is not appropriate to depend on the rollover motion of a 'natural' GRE to mix the diluent.

Once proven, dilution may be effective in tanks whose sludge properties and chemistry permit elimination of gas retention by a practical dilution. The tank and waste configuration should also be amenable to mixer pump operation. Provision must be made for other tank(s) to receive part of the diluted waste, or the tank must have sufficient excess capacity to hold the diluted waste.

The main advantages of dilution are that it is passive and permanent. The major demerits of dilution for mitigation may be that it creates additional waste volume that must be dealt with later, and it tends to aggravate the gas release hazard if it fails to eliminate GREs. In addition, dilution requires a complex system of tanks, pumps, and piping to be installed above the tank that must be considered permanent as well as a mixer pump in the waste. However, both a mixer pump and a dilution system of some form will eventually be required to retrieve and transfer the waste for final treatment.

There are indications from tank behavior and dilution tests on Tank 241-SY-101 core samples that dilution might prevent GRE behavior, but further studies are necessary to relate gas retention to the dilution ratio. Because dilution is the only concept that promises true passive mitigation, we feel this work should have high priority.

\subsection{Heating}

Heating the waste to below the atmospheric boiling point causes dissolution of sodium salts that make up the nonconvective layer and lowers the viscosity and yield strength of the sludge. The combination of reducing the amount of material that can retain gas and diminishing its ability to do so could suppress episodic gas releases in a manner similar to dilution. Also, there are insufficient data at this time to state what temperature is necessary to achieve mitigation by heating-if it can be achieved at all.

The mitigating effects of heating may be less than were expected initially. Past data from Tank 241-SY-101 show that large episodic gas releases continued to occur at waste temperatures of up to $65^{\circ} \mathrm{C}$. The gas generation rate increases markedly above $65^{\circ} \mathrm{C}$, tending to cancel any benefit from reducing the gas-retention ability of the waste.

Heating would require a large energy input to heat and then to maintain the desired temperature in most tanks. About $20 \mathrm{~kW}$ would be required to maintain waste temperatures at $25^{\circ} \mathrm{C}$ above the current level in Tank 241-SY-101. It would not be practical to add this much energy by continuous operation of the current mixer pump design or by heating the dome and/or annulus ventilation air. An additional waste-intrusive heating system (e.g., steam coils) would be required. 
For this reason, heating must be considered an active mitigation method.

If it is confirmed as an effective mitigation method, heating could be applicable in tanks whose sludge properties and chemistry permit elimination of gas retention at a reasonably achievable temperature. The tank and waste configuration must permit a heating system to be installed or the waste must generate enough heat that the temperature can be raised by reducing the cooling.

The major risk of heating is that, if unwanted chemical reactions or physical changes began, several months would be required to lower the temperature due to the huge thermal mass of the waste. No detailed hazards analysis has been performed for mitigation by heating. 


\subsection{Mixing}

Mixing has been tested as a near-term mitigation strategy in Hanford Tank 241-SY-101. The notoriety of this tank grew out of its large, reasonably predictable, cyclic gas release events (GREs). Along with the impressive waste motion, these events created potentially flammable concentrations of hydrogen gas in the tank dome space. Extensive investigations were undertaken to address the safety questions surrounding these GREs. Possible mechanisms of gas generation, retention, and release were investigated, and the waste form was characterized.

These studies supported a review of possible mitigation options. Heating, dilution, sonic agitation, and mixing were concluded to be the leading candidate options for mitigating Tank 241SY-101 (Babad et al. 1992b). Parallel efforts were undertaken to design and deploy 1) a test chamber to investigate the individual and combined effects of heating, dilution, mixing, and sonic agitation, and 2) a jet mixer pump using an available pump from the Hanford Grout Program. Later, the test chamber was dropped because of safety and cost concerns while development of the mixer pump option continued. Safety analyses related to the pump were completed, and the pump was installed July 3, 1993.

Subsequent mixer pump tests have demonstrated conclusively that, for a waste structure and behavior similar to that of Tank 241-SY-101, jet mixing is an effective mitigation technique. The results of mixer pump testing are described in the Phases A and B Testing report (Allemann et al. 1994) and the Full-Scale Testing report (Stewart et al. 1994).

\subsection{Waste Tank Characteristics and GRE Behavior}

Prior to pump installation, Tank 241-SY-101 exhibited the gas generation, retention, and release characteristics of increasing waste level, vertical thermal profiles indicating convective (predominantly liquid) and nonconvective regions (sludge or slurry), and large periodic GREs (rollovers). The "gob" theory described in Section 1.2 appears to characterize this behavior reasonably well as shown by measurements of transient gas composition, variations in waste surface level, and comparisons of vertical profiles before and after GREs. Historical records of these data (see Antoniak 1993) provide a baseline of tank behavior prior to active intervention.

Vertical temperature profiles through the various layers show characteristic patterns, depending on the dominant heat transfer mode, and the local waste form can be inferred from the dominant heat mode. A parabolic temperature profile (Figure 3.1) is characteristic of conductiondominated heat transfer with an internal heat source. The relatively flat uniform temperature profile indicates a convection-dominated region where fluid motion distributes the heat. Therefore, a parabolic profile would indicate a solid, nonconvective sludge. A linear temperature profile is indicative of simple conduction through a solid like the crust; it can also indicate a stratified layer between convective regions of different densities. A flat, uniform profile implies a liquid or mobile slurry.

The efficacy of jet action can therefore be deduced from changes in the temperature profile. Disrupting the sludge layer and mixing it with the liquid above will likely convert the nonconvective sludge to convective slurry, and the uniform temperature profile associated with effective mixing will replace a parabolic one in the lower levels of the tank.

Comparing premixing baseline patterns of gas composition/volume, waste surface level, and temperature profiles with post-mixing patterns can provide indirect evidence of changes in the waste. Selected examples of patterns observed in Tank 241-SY-101 before and after mixing are discussed in the following section (Section 3.2). 


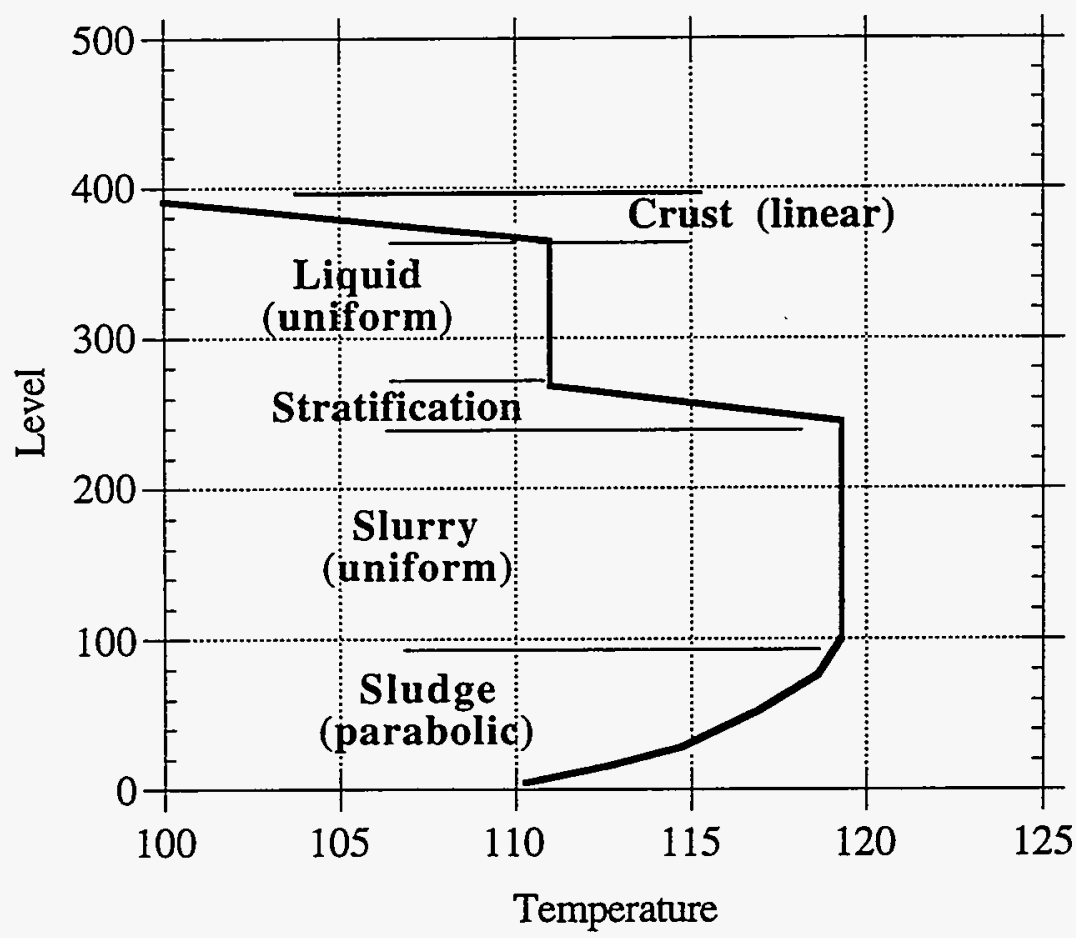

Figure 3.1. Typical Vertical Temperature Profiles

\subsection{Effect of Mixing on GRE Behavior}

Mixing, specifically by fluid jets, is intended to disrupt the gas-retaining sludge layer and keep the material in suspension. Without a cohesive sludge layer, gas is released gradually at approximately the same rate as it is generated, and large, disruptive events are prevented. Disruption of the cohesive sludge layer allows more continuous bubble/particle migration through the waste and ultimately into the dome space. Other gas retention/release mechanisms, such as adherence to solid particles and bubble migration, are probably not directly, or as strongly, affected by mixing.

Recent experience with the mixer pump in Tank 241-SY-101 illustrates changes in waste behavior that can be attributed directly to mixer pump operation. Disruption of the nonconvective sludge layer and mixing of tank contents is evidenced by the change in vertical temperature profiles before and after mixing. Figure 3.2 shows vertical temperature profiles in Tank 241 -SY-101 before GRE I (June 25, 1993-before pump installation), at the completion of Phase B testing (December 18, 1993), and after the jet penetration tests of Full-Scale testing (April 14, 1994). The temperature profiles after completion of Phase B and jet penetration tests are essentially flat, indicating effective mixing. Operation of the mixer pump has evidently changed the configuration of waste in Tank 241-SY-101, as shown schematically in Figure 3.3.

The rate of solids settling that might eventually lead to sludge reformation has evidently been reduced by mixing. Prior to mixing, a nonconvective layer would reform within weeks of a GRE, as shown by the growth of the parabolic temperature profile in Figure 3.4. Although settling after pump operation is inevitable, the settled slurry does not behave as a nonconvective layer. A settled 


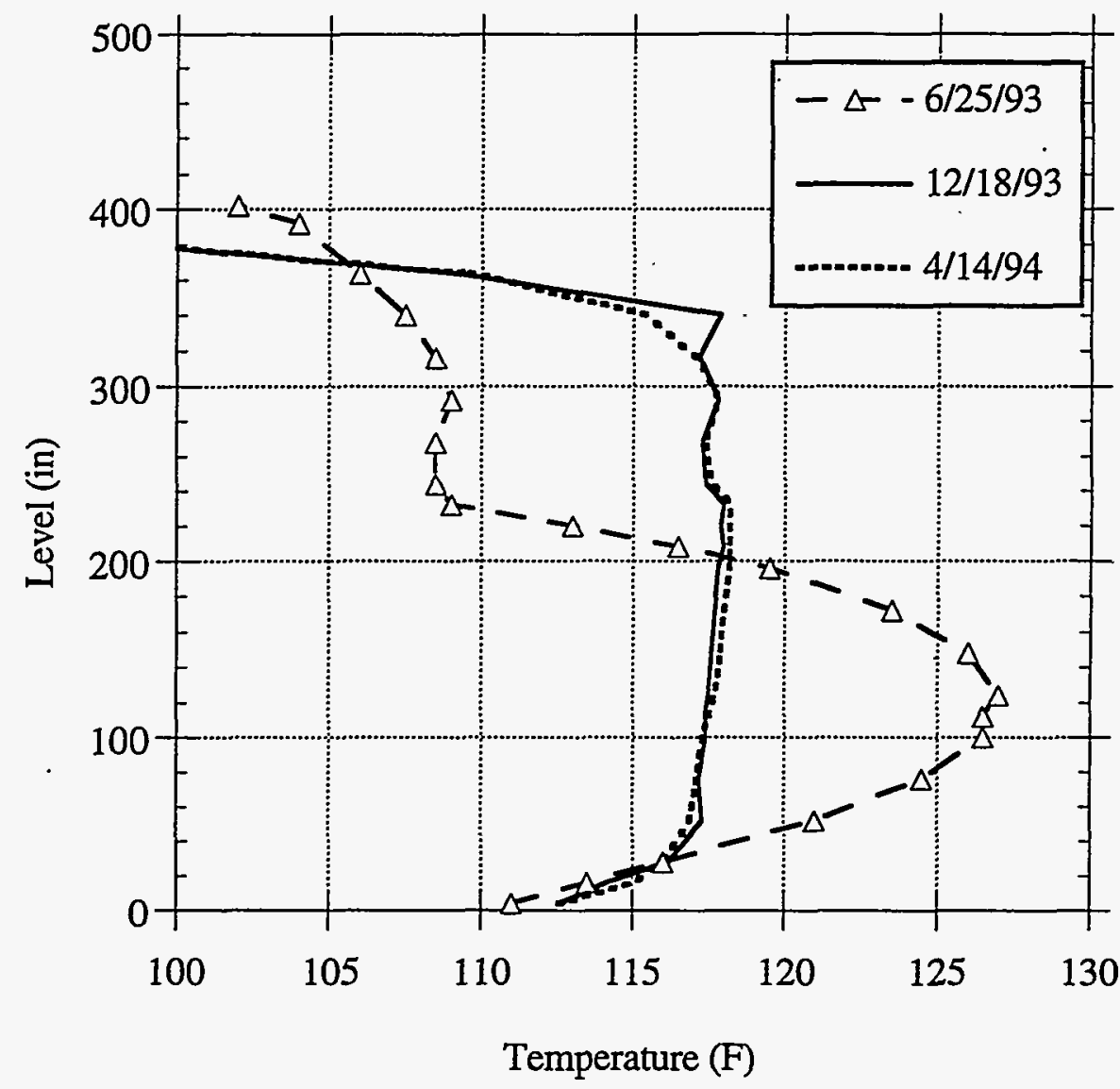

Figure 3.2. Vertical Temperature Profiles Before and After Pump Mixing

layer between about 80 and 240 inches formed during the regrowth test period of Full Scale testing in March 1994. However, once vigorously mixed, the slurry tends to remain convective, as indicated by the temperature profile in Figure 3.5. The implication is that, once a waste similar to that in Tank 241-SY-101 has been suspended, only intermittent pumping is required to keep the solids in suspension.

Mixing has reduced, but not eliminated, gas retention. The impact of mixing on the gas retention characteristics of the waste in Tank 241-SY-101 is illustrated by the difference in the basal hydrogen concentration before and after mixing. The basal hydrogen concentration is created by gas released during quiet periods with no pump-induced or natural waste motion. Before pump installation, the hydrogen concentration due to the basal release was estimated at about $15 \pm 3 \mathrm{ppm}$. It increased to $25 \pm 5 \mathrm{ppm}$ after completion of Phase B testing. A basal hydrogen concentration of about $45 \mathrm{ppm}$ at a vent flow of $550 \mathrm{cfm}$ would match the estimated generation rate of $100 \mathrm{SCF} /$ day (Stewart et al. 1994). A good measure of the total gas content in the tank is the waste level. The waste level in Tank 241-SY-101 has remained below 402 inches since the greater portion of the tank was mixed in mid-November 1993. This shows that the mixer pump kept gas from accumulating while operating only a few hours per week. As of August 1994, the mixer pump had operated a total of only about 70 hours in 13 months of service. 


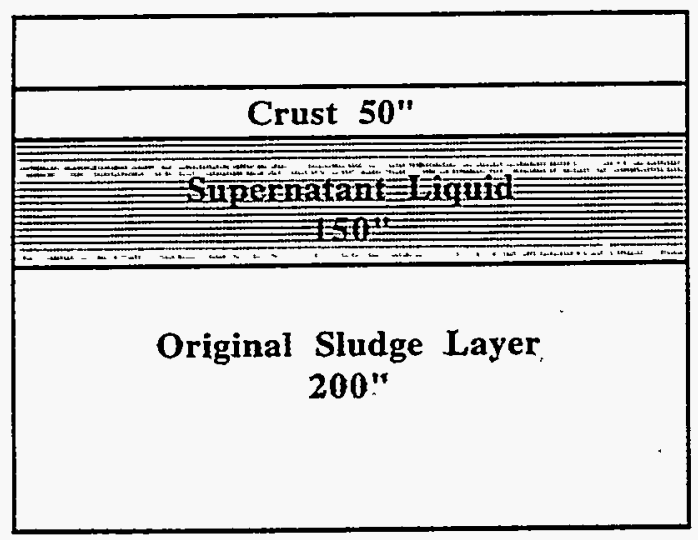

A. Before Mixing

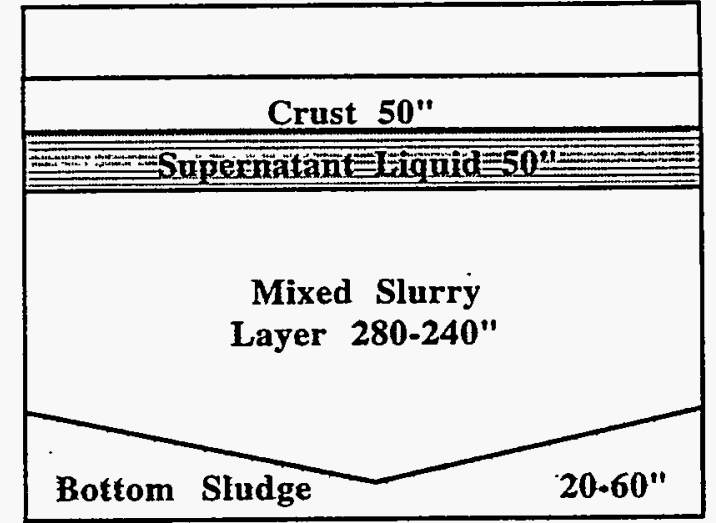

B. After Mixing

Figure 3.3. Schematic of Tank Waste Configuration

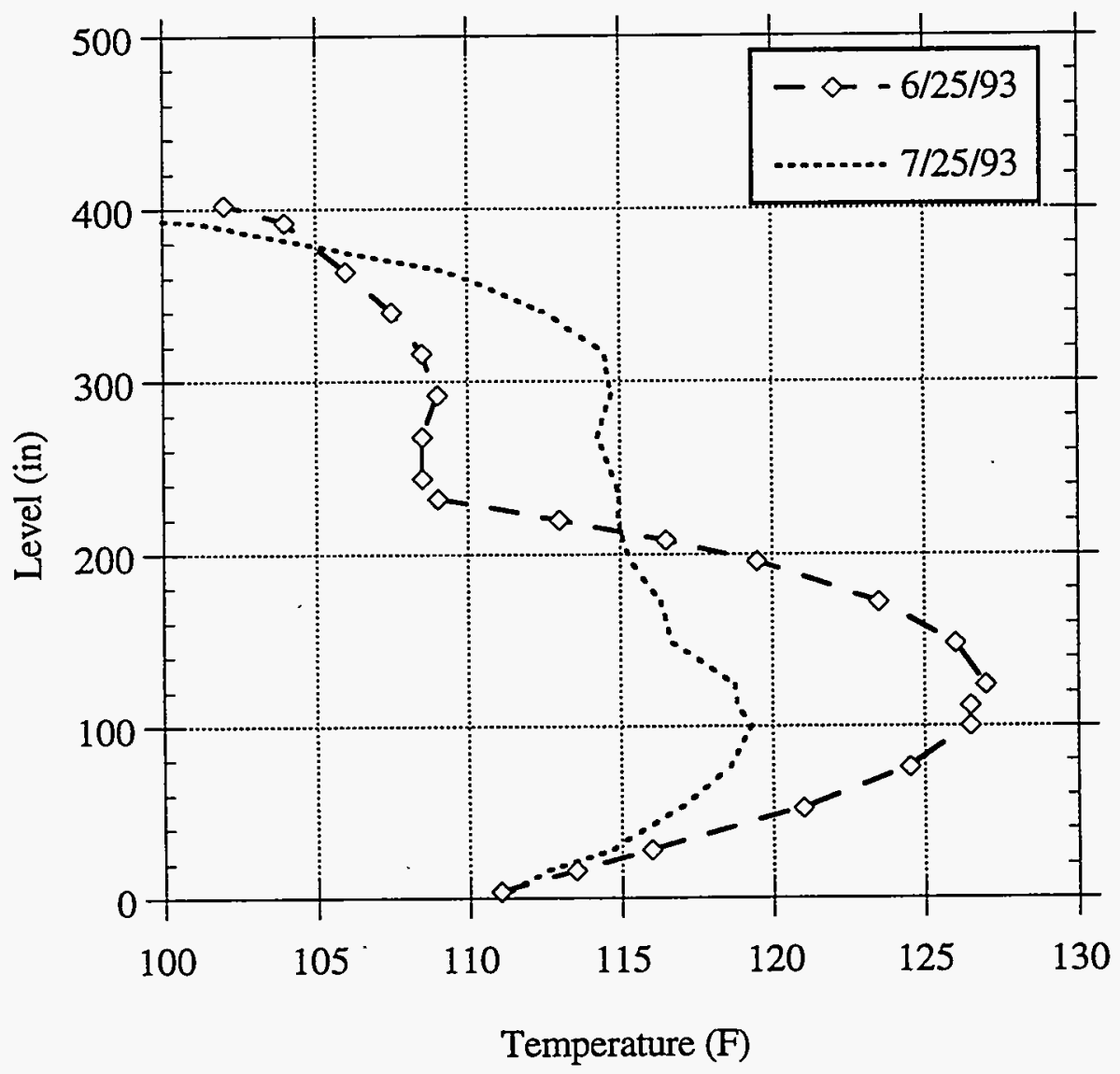

Figure 3.4. Formation of Nonconvective Layer After GRE I 


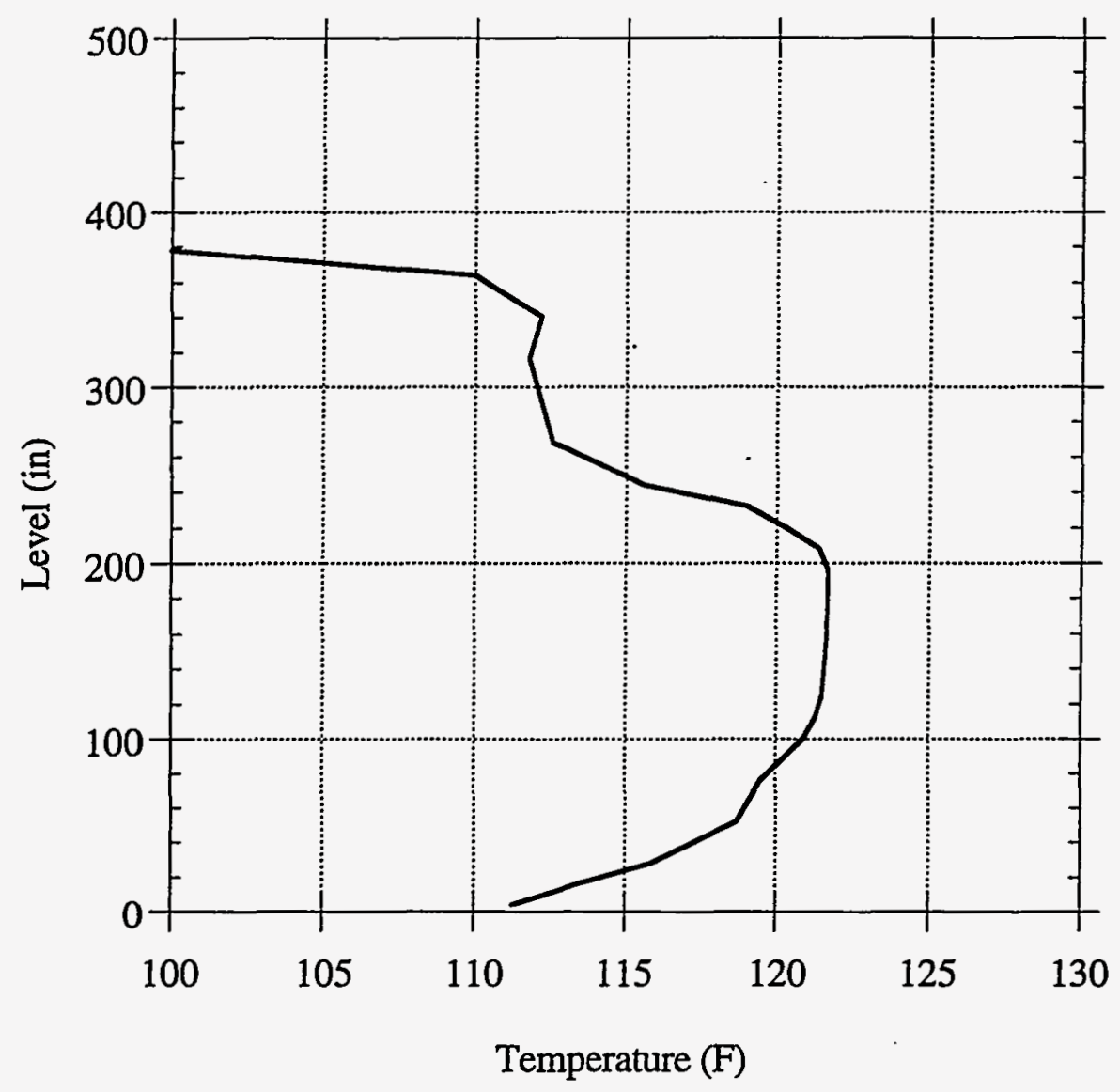

Figure 3.5. Vertical Temperature Profile of Settling After Pumping

Mixing has not altered the gas generation mechanisms in Tank 241-SY-101. The gas generation rate has not changed measurably before and after mixing. Neither have the ratios of component gases (e.g., hydrogen to nitrous oxide, hydrogen to ammonia) changed in a way that would indicate a major alteration of the underlying chemical or radiolytic processes (Allemann et al. 1994; Stewart et al. 1994). The only directly observable long-term effect has been a slight cooling trend apparently due to increased heat losses brought on by convection in the mixed slurry and thinning of the insulating sludge layer on the tank bottom. This might eventually result in a temperature reduction of $10-15^{\circ} \mathrm{F}$, but a reduction in annulus ventilation flow is predicted to maintain nominal temperatures (Stewart et al. 1994).

The primary results of mixing in Tank 241-SY-101 are 1) a semi-continuous, low-level gas release has been established and maintained and large GREs have been prevented, 2) average flammable gas concentrations in the dome space have remained below $1 / 4$ of the LFL, 3) the waste level has stabilized at a low value, 4) no evidence of adverse long-term effects has been observed. 


\subsection{Deployment}

Deployment of a mixer pump in a million-gallon radioactive waste tank requires a number of activities in addition to hardware fabrication. Extensive supporting safety analyses and operational predictions are required. Procedures and training may be necessary to accomplish the installation in a potentially short "window" between GREs. An initial test campaign must be crafted that gradually increases pump speed and duration to avoid triggering a GRE while the original sludge layer is being mixed initially. Finally, provisions must be made for pump removal, including decontamination, disposal/storage, and replacement in case of failure. Figure 3.6 depicts the scale of the mixer pump installed in Tank 241-SY-101.

The test mixer pump in Tank 241-SY-101 was a modified grout pump. Experience has led to design improvements for pumps that may eventually be deployed in other tanks. Ability to change motor oil is one example; possible use of a bottom suction configuration is another. More extensive changes were envisioned for a permanent mixer pump designed specifically for mitigation;(a) however, the success of the Tank 241-SY-101 test pump led to a decision to put this effort on indefinite hold.

Universally applicable criteria defining application of mixer pumps to waste tanks in general have not been developed. But the following incomplete set of criteria were listed based on the extrapolation of observed behavior of Tank 241-SY-101 and review of the permanent mixer pump functional design criteria (WHC 1993). The criteria assume an adequate knowledge of the specific tank structure and the waste it contains:

- A riser of adequate size (42-inch) and structural integrity must be available.

- The waste must be relatively free of obstructions that prevent free action of the fluid jet. These might include large suspended hardware (e.g., airlift circulators) or regions of hard, rock-like waste.

- Tank dome loading must allow the additional weight of the suspended pump.

- Waste must be pumpable. There must be sufficient liquid volume to disrupt the sludge and keep the mixed slurry pumpable. Properties must be such that reformation of sludge can be prevented by intermittent mixing.

- Care must be taken in design and operation to avoid the nozzle plugging experienced with the initial mixer pump operation in Tank 241-SY-101.

- Waste must remain physically well-behaved under pumping conditions (e.g., high shear). It must not foam excessively, form a cohesive gel, "set up," or otherwise cease to be pumpable.

- Pertinent gas generation and release mechanisms must not be aggravated by pumping. Potential concerns include 1) inducing additional gas generation by changing the local concentration of critical reactants and 2) refreshing the exposed liquid surface, thereby replenishing a source for evaporation and diffusion of soluble gases such as ammonia.

- The slight heating of waste by pumping must not be a concern.

Deployment of a mixer pump of a design similar to the test pump installed in Tank 241-SY101 requires that precautions and mitigation strategies be identified that are commensurate with the

(a) System Design Description for Mitigation Mixing Test of Hanford Site Hydrogen Gas Generating Waste Tank 101-SY. Draft report WHC-SD-WM-SDD-040, Westinghouse Hanford Company, Richland, Washington. 
consequence of credible postulated accident scenarious. Events related to installation, operation, and removal of the pump that have been evaluated include the following:

- maximum gas release (burp) with and without burn and/or ventilation during installation and removal

- waste spill during installation and removal

- $\quad$ pump drop during installation and removal

- $\quad$ gas release through an unfiltered riser during installation and removal

- maximum expected burp with or without burn and ventilation during operation.

Details of these accident scenarios are described in the Tank 241-SY-101 mixer pump safety analysis (LANL 1994). None of the potential safety consequences considered thus far have disqualified the mixer pump for mitigation. Limits on operating parameters have been defined that continue to permit safe operation. The conclusion is that, if the waste tank is observed to behave in a manner similar to that experienced with Tank 241-SY-101, and the waste characteristics are compatible with pumping, then mixing is an excellent candidate to mitigate large, episodic gas releases.

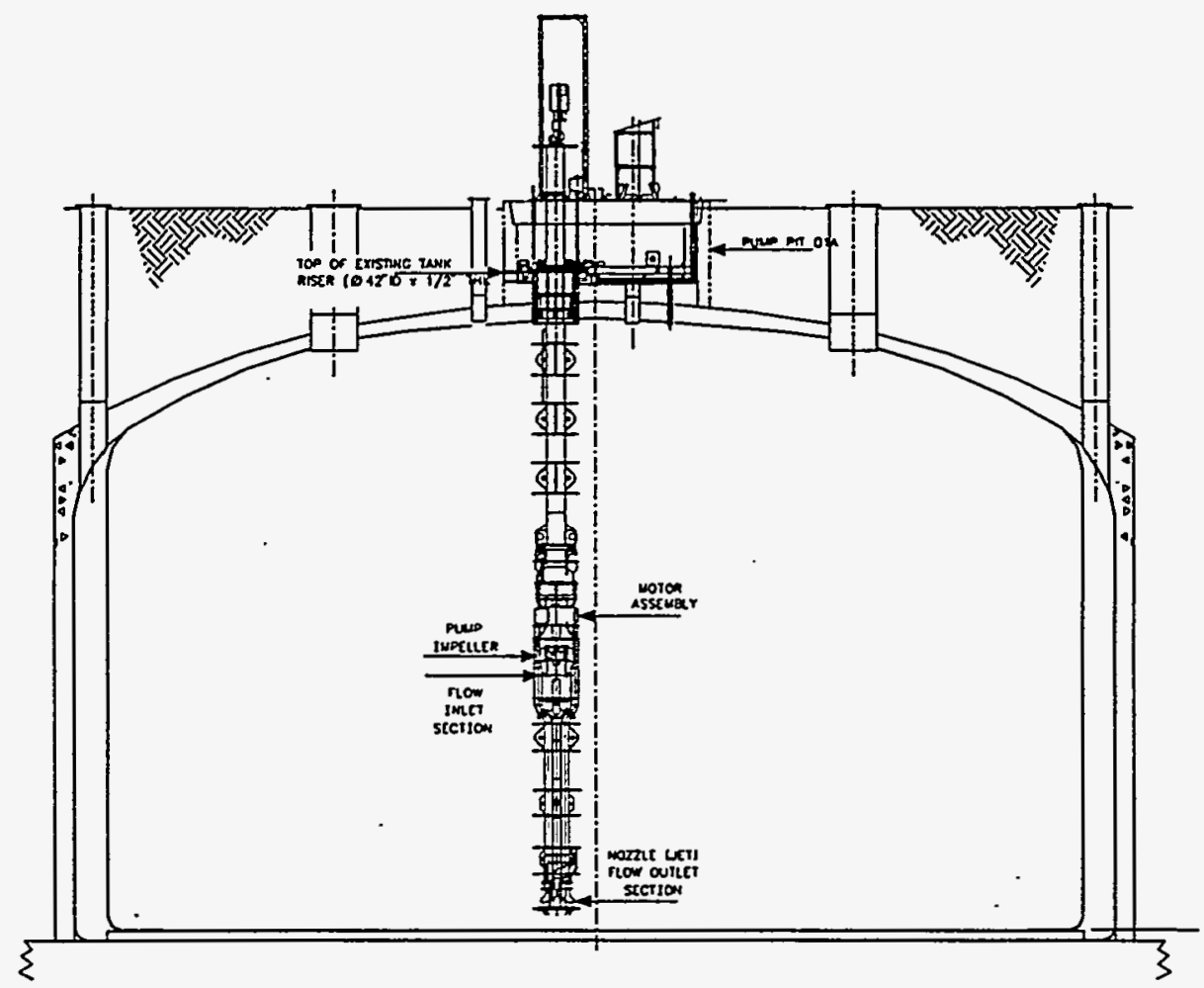

Figure 3.6. Profile View of Tank 241-SY-101 Mixer Pump Installation 


\subsection{Sonic Probe}

The sonic probe mitigation concept is intended to release trapped gas in a controlled manner using low-frequency sonic vibration, thereby avoiding large, potentially hazardous, spontaneous gas release events (GREs). The acoustic waves are expected to yield the nonconvective sludge and convert it from a deformable solid to a liquid, thereby allowing gas release by free bubble rise, buoyant convection, or the subsequent detachment of bubbles from suspended solids. The sonic probe would be activated periodically in a waste tank as needed to prevent hazardous gas buildup. Effects on gas generation rate are expected to be secondary, although there may be long-term reductions in the ability of the waste to retain gas due to altered rheological properties.

The device proposed for this purpose is a cylindrical shell oscillator with an internal eccentric mass driven to rotate about the cylinder axis. Alternative methods utilizing piezoelectric transducers for generating acoustic (or ultrasound) vibrations have been considered and rejected. The frequency dependence of acoustic attenuation has led to selection of frequencies of less than $100 \mathrm{~Hz}$ and rejection of much higher frequencies, including ultrasound.

\subsection{Choice of Frequency Range and Parameter Domain}

The choice of frequency range can be understood from Figure 4.1a-c, which show the trends of attenuation length with frequency, viscosity, and diameter of bubbles in a liquid with entrained bubbles of monodisperse size. The attenuation length is seen to decline with increasing frequency in the $40-150 \mathrm{~Hz}$ range chosen as of greatest interest in the present study (Figure $4.1 \mathrm{a}$ and $\mathrm{b}$ ), and also in the extended range of $40-25,000 \mathrm{~Hz}$ shown in Figure 4.1c. The calculated attenuation lengths in these figures are based on models for attenuation taken from the literature by Harri Kytomaa of Massachusetts Institute of Technology and are summarized in Appendix B. Mechanisms considered include viscous damping of radial bubble motion, thermal oscillations associated with bubble compression and rarefaction, relative motion of bubbles and liquid, and acoustic scattering.

In the low frequency range, attenuation length also declines with increasing bubble diameter and viscosity. Presumably, the bubbles that remain after the probe has operated and released bubbles have cleared are small. Figure 4.1a and $\mathrm{b}$ present results for bubble diameters of $0.1 \mathrm{~mm}(100 \mu \mathrm{m})$, $0.2 \mathrm{~mm}$, and $0.3 \mathrm{~mm}$. We intuitively favor a size distribution for bubbles in the thoroughly mechanically degassed tank similar to the size distribution of the solids, which tend to be on the order of $0.1 \mathrm{~mm}(100 \mu \mathrm{m})$. A gas fraction (void fraction) of 0.01 is assumed in each of the figures.

The sludge (as opposed to supernatant liquid or solid crust) tends to be a non-Newtonian fluid after yielding, so its effective viscosity is a function of shear rate. In the yielded sludge, we expect a phenomenon not of 'shear thinning' but of 'dilatational thinning' due to the pressure oscillations of the acoustic wave. This is not a commonly measured quantity, nor even a frequently discussed concept in rheology. Thus we do not know where to pick off representative viscosities from the usual curves of effective viscosity versus shear rate. The viscosity values $\mu=1,000 \mathrm{cP}$

(Fig. 4.1a) and $\mu=10,000 \mathrm{cP}$ (Figure 4.1b) are used in this report for estimates. The volumetric oscillations of bubbles are likely to produce an effective viscosity reduction locally around bubbles in a shear thinning liquid.

From the short attenuation lengths associated with frequencies higher than $150 \mathrm{~Hz}$, especially for those in the ultrasound range, we conclude that these higher frequencies would be useful only if several probes at different locations were used (in the few hundred $\mathrm{Hz}$ range) or if a system for moving multiple probes around the tank were installed (for the ultrasound range). Both these approaches were considered more complex than a single probe to yield a significant fraction of the tank volume. This single, low-frequency probe approach is the subject of this study. 


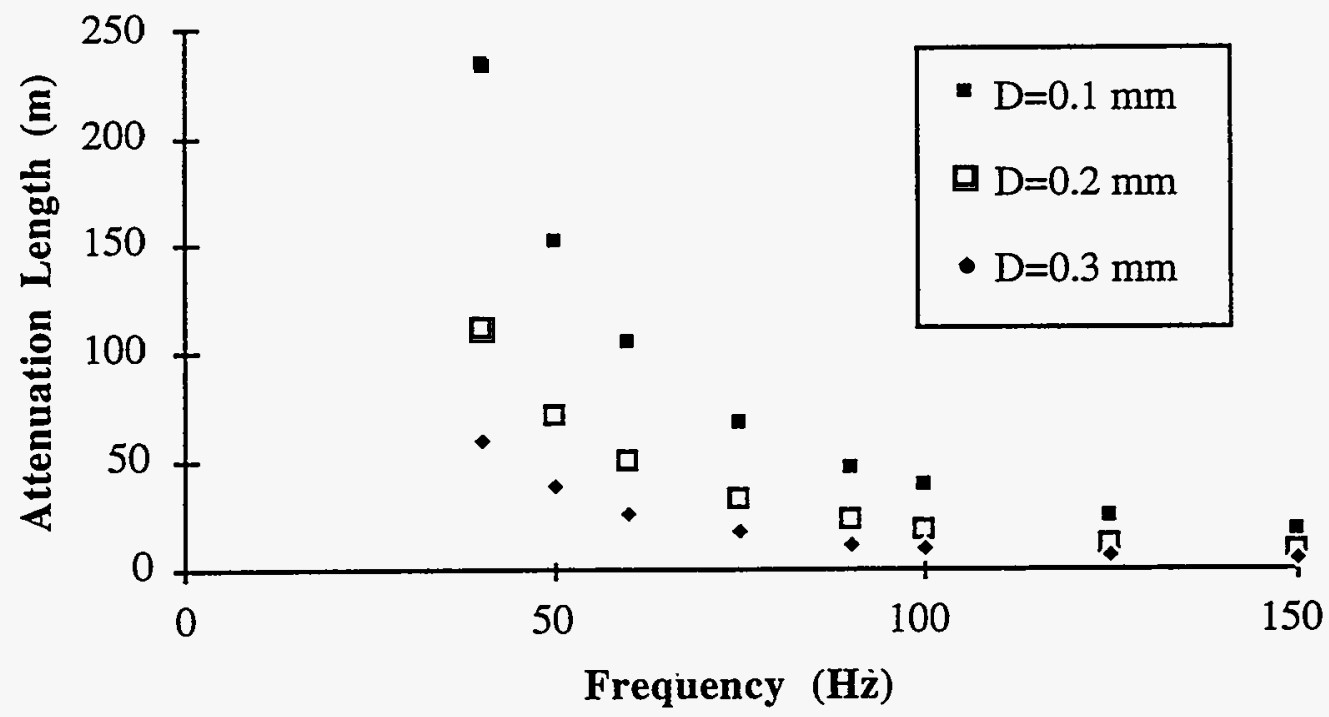

Figure 4.1a. Attenuation Length Versus Frequency for Viscosity $1,000 \mathrm{cP}$

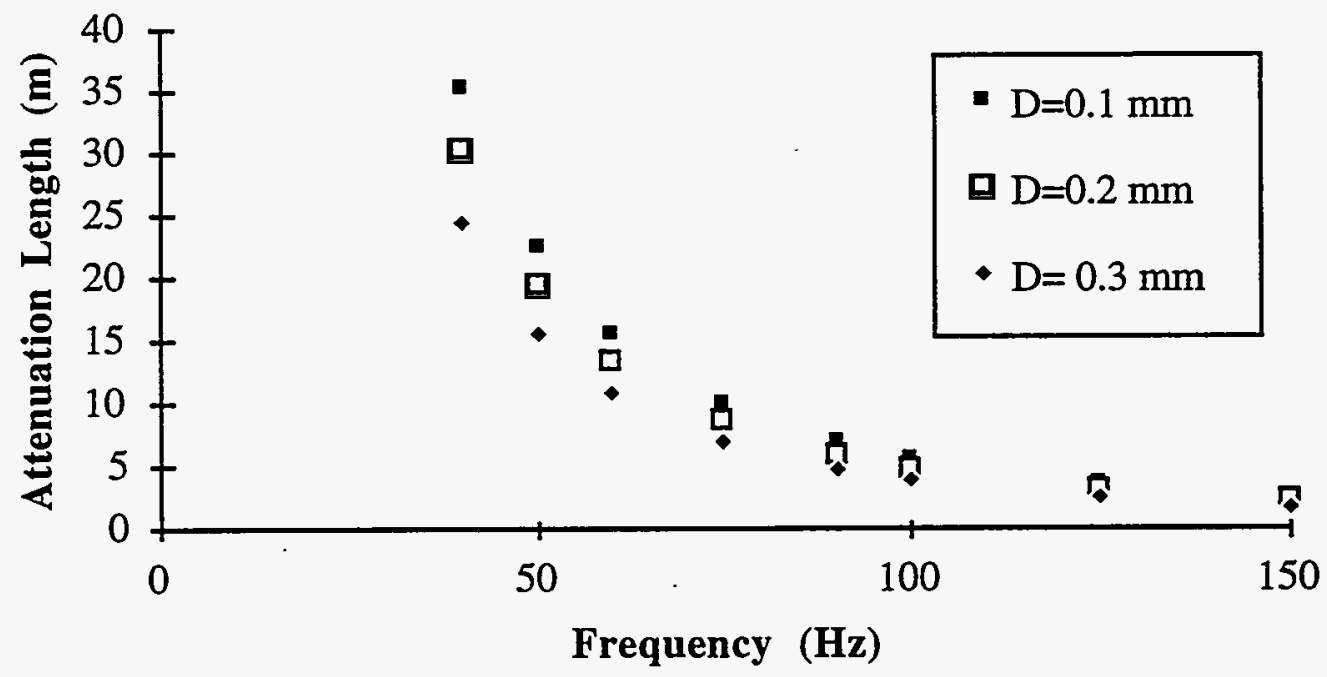

Figure 4.1b. Attenuation Length Versus Frequency for Viscosity $10,000 \mathrm{cP}$ 


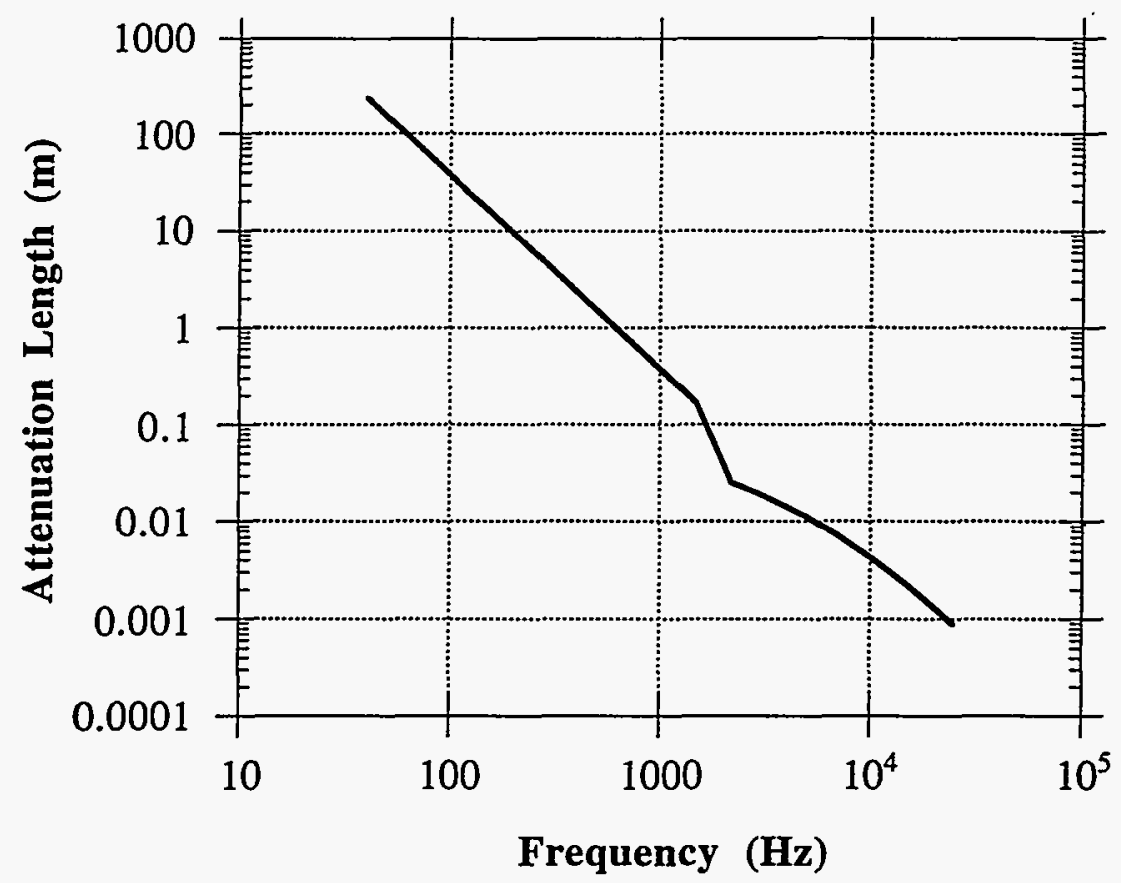

Figure 4.1c. Attenuation Length Versus Higher Frequency, Viscosity 1,000 cP

The sonic probe mitigation concept should be applicable to tanks in which the gas is held in layers that can be yielded and degassed by sonic vibrations. This requires that the probe generate pressure waves of sufficient amplitude to meet the yield criterion or gas release criterion out to at least a significant fraction of tank radius. The criteria for sonic yielding and degasification and the acoustic attenuation properties are not well known even for the best-characterized of the tanks exhibiting GREs, although estimates can be made.

The sonic probe, as specifically designed for Tank 241-SY-101 at present, has an outer cylinder diameter of 11 inches (to fit available 12-inch risers) and an active length equal to the thickness of the original nonconvective layer before the mixer pump was installed, or 18 feet. The reference design for Tank 241-SY-101 has a hydraulically driven eccentric rotor, with the hydraulic motor inside the probe shell and the hydraulic pump outside the tank.

The decision to make the shell diameter a size commensurate with available risers is based on the approximate relation for oscillatory pressure amplitudes,

$$
P(r)=P_{0}\left(r_{0} / r\right)^{1 / 2} \exp \left[-\xi\left(r-r_{0}\right)\right]
$$

where $1 / \xi$ is the attenuation length. One sets oscillatory surface pressure amplitude $P_{0}$ to avoid cavitation (a design and operation limit) or to limit the range to which material is yielded (an operation limit). The greatest range is then obtained with the greatest probe radius $r_{0}$. More details of the reference mechanical and hydraulic design developed by Southwest Research Institute appear in the following section. With Tank 241-SY-101 hazards apparently already mitigated by the current mixing pump, other tanks are candidates for sonic probe testing, although a cautious approach might conceivably involve initial testing in Tank 241-SY-101. 


\subsection{Sonic Probe Reference System}

This section provides details of the mechanical integrity, reliability, lifetime, and control of the sonic probe. The sonic probe design consists of a $5,070 \mathrm{lbm}(2300 \mathrm{~kg})$ active element 11 inches $(24.8 \mathrm{~cm})$ in diameter by $18 \mathrm{feet}(4.57 \mathrm{~m})$ long. It has a total of 5,880 inch-oz $(65.6 \mathrm{~kg}-\mathrm{cm})$ imbalance distributed among 28 segments. Each segment has two shielded roller bearings that support the eccentric mass. The segment drive shafts are connected by a heavy-walled bellows providing vibration insolation between the segments. The active element is smooth-surfaced and rounded at the bottom.

A 130-hp $(97 \mathrm{~kW})$ hydraulic motor, mounted internally in the probe at the top of the active element, drives the eccentric mass 28 -segment vibrator. Above the hydraulic motor is a reducing flange that necks down to the 8-inch $(20.3-\mathrm{cm})$ support, which extends upward to the two-joint swivel attached (in 241-SY-101) directly to the multi-port riser (MPR) assembly at the top of riser 5-A.

The probe has two joints that allow the probe to move with waste motion and "wasteberg" impact up to 22 degrees toward the horizontal, should a GRE occur with the probe installed. Each joint comprises monoballs in a U-joint configuration, the upper with two segments, the lower with four segments.

The probe is variable speed, from 0 to $6000 \mathrm{rpm}$. Hydraulic lines extend upward through the flexible joint support, out of the MPR, and then 50 feet to a hydraulic power module mounted on a self-contained trailer. A 2-1 chain gear increaser allows operation of the hydraulic motor up to a maximum of $3000 \mathrm{rpm}$. The power module will vary the speed of the probe by control of a variable displacement pump from the Data Acquisition Control System (DACS).

Leak monitoring sensors are located at the probe bottom and at the hydraulic sump. Blowout tubes allow remote clearing of any leaking hydraulic fluid during dormant periods. One accelerometer is located at the hydraulic motor elevation with six thermocouples to monitor probe surface temperature. A mechanical speed meter with a cable drive directly connected to the drive motor and with readout mounted above the tank gives positive indication of operation.

Design life is 10030 -minute cycles or other operation patterns totaling 3000 minutes of use. Installation life is 10 years. The system is, in principle, transportable to other tanks after surface decontamination.

\subsection{Advantages and Limitations of the Sonic Probe}

Advantages claimed for the sonic probe (based on Tank 241-SY-101 waste properties) include the following:

- $\quad$ Effectiveness - Early estimates suggested that the sonic probe could yield the gas-bearing sludge out to a radius of about nine meters, which would allow degasification of a major part of the tank volume.

- $\quad$ Simplicity of construction - The probe internals are somewhat simpler than those of a mixing pump, and its weight is somewhat less, which is important for limiting load on the tank dome.

- Lifetime - Simplicity and non-contact of moving parts with tank waste should allow design for long life. (Probe bearings, probe joints, and the driving system for the eccentric are the critical items, and, unfortunately, rotating eccentric masses provide high dynamic loads on them.) 
- Portability and ease of decontamination - Because the sonic probe ingests no waste, decontamination need be done only on relatively smooth external surfaces. Thus sonic probes could conceivably be removed for repairs and re-installed if necessary.

- Reliability - Nozzle plugging is not a problem; bearings and hydraulics can be designed to withstand the loads and temperatures encountered.

- Control of gas releases - Release of gases by a sonic probe can be initiated safely by cautious and systematic escalation of the oscillation frequency (intensity of waves) and the duration of runs. One constraint on frequency escalation, however, is that the natural resonant frequency of the probe must be avoided or passed through quickly. After preliminary tests provide experience, releases can almost certainly be controlled very effectively by the operation sequence, as is now possible with the mixer pump in Tank 241-SY-101.

The limitations of the sonic probe are 1) it does not forcibly mix tank contents and 2) questions of feasibility and safety have not been totally resolved. In particular, the range and extent of degasification are somewhat uncertain; and the possibility of unwanted densification and stratification cannot yet be ruled out.

\subsection{Feasibility and Safety Issues}

Various issues have been raised related to the safety or effectiveness of sonic probes for mitigation. Many have already been addressed by prior analyses and experiments, but some will only be resolved by full-scale prototype testing and eventual operation in an actual waste tank. These issues include the following:

- the mechanism of material yielding and bubble release, its dependence on material properties, and scaling

- $\quad$ power levels, frequency, and duty cycles

- volume of sludge yielded as a function of probe parameters, frequency, run duration, and applicable attenuation mechanisms

- potential for and the effects of wall or crust erosion

- the influence of probe operation on structural integrity of tank and suspended hardware

- waste consolidation by densification/stratification to form a material of higher yield strength

- foam generation

- cavitation at the probe surface

- aerosol generation at the waste surface

- rate and volume of gas release, specifically the fraction of the LFL reached in the dome space and vent header.

\subsection{Experimental Evidence and Test Results}

Some of the feasibility and safety issues have been resolved or at least downgraded on the basis of experiments performed or common practice. Mechanical concrete vibrators are known to 
achieve degasification of concrete pours; thus there is some degasification mechanism that works in some media at an achievable pressure amplitude. Concrete vibrators, like the candidate sonic probe for tank degasification, are designed to marginally avoid cavitation at the probe surface and liquid surface at top speed, so maximum surface pressure amplitudes are 1500-2000 mbar (1.5 to 2 . times 105 Pascals). Concrete probes are operated in bursts of 2-15 seconds to avoid segregation and settling of the larger size aggregate. In this mode, the effective range of a large concrete vibrator (probe diameter $\approx 3 \mathrm{in}$., or $7.62 \mathrm{~cm}$ ) is considered to be approximately $3 \mathrm{ft}(0.9 \mathrm{~m})$.

Longer times would give a larger radius for degasification. If one assumed that pressure amplitudes obeyed Equation 4.1, and that attenuation lengths $1 / \xi$ were similar for wet concrete and tank waste, the corresponding effective treatment radius for the tank probe would be $5.7 \mathrm{ft}(1.75 \mathrm{~m})$. Presumably, longer or repeated operation would extend this distance considerably, and, of course, the attenuation length $1 / \xi$ is plausibly longer and the yield strength lower in tank waste than in wet concrete. As mentioned below, cold tests of vibrators in a tube filled with wet concrete showed a change front that moved large distances (about $40 \mathrm{ft}$ ) on a time scale of a few minutes, so motion of a degasification front out to comparable distances in tank waste is plausible. The material, the boundary conditions, and the geometrical attenuation factors all differ in the two cases, of course. It is anticipated that segregation will be much less prevalent in the tank waste than in wet concrete, because the solid particles in the tank waste are much smaller $(100 \mu \mathrm{m}$ in tank waste, $2 \mathrm{~cm}$ or more for the largest in concrete).

Hall (1993) reports the measurements by J. M. Tingey (PNL) on yield stresses of Tank 241SY-101 segments 4-22 from Window C and segments 3-19 from Window E. Segment numbers increase from top to bottom, so segment 22 is very close to the tank bottom where the sludge is most dense. Yield stresses ranged from 3300 to 6200 Pascals for Window C, 1300 to 7200 Pascals for Window $E$; these yield stresses are on the order of the pressure amplitudes that can be generated out to several meters with a sonic probe. If pressure oscillations can produce shear oscillations (or if either this or some other mechanism operates, as it must in wet concrete), yielding the sludge should be possible in a waste tank. Measurements on the re-settled material from the formerly nonconvective layer after either operating the mixing pump or stirring prior to sonification tests typically give yield stresses of 300 Pascals to within a factor of $\approx 4$.

Experiments performed with laboratory bench oscillation of a column of simulant showed negligible tendency to densify or strengthen the material. Repeated oscillation experiments showed a trend toward decreased, not increased, strength over time with vibration in a simulant. However, one experiment by Cannon (1994) on a Los Alamos simulant did show the possibility of hardening as one interpretation of results.

Experimenting with 241-SY-101 waste that had been previously heated and vibrated, Cannon (1994) reported reduced yield stress following high shear rates (to $700 / \mathrm{sec}$ ), with the effect lasting for at least 300 hours; lower shear rates (to $60 / \mathrm{sec}$ ) also reduced the waste's yield stress, but recovery occurred after 18 hours. While shear rates from the sonic probe are presumed to be small, we anticipate that a 'dilatational thinning' phenomenon from pressure oscillations may play a comparable role, but with magnitudes unknown.

Negligible foam or aerosol generation was seen in these experiments, nor is it a problem in concrete degasification. Thus concerns over unwanted generation of foam or aerosol are not supported by experience so far. Cavitation problems have in principle been avoided by designing the probe to produce pressure amplitude just less than that which would produce cavitation at the design frequency $(100 \mathrm{~Hz})$.

Cannon (1994) reported sound speed measurements in both a simulant developed at LANL and actual tank waste, before and after vibration treatments. In the simulant, there was some evidence of segregation from vibration by a VTS-100 shaker table and an apparent rise in sound velocity as measured by transit time. The reduction in transit time for sound could be caused by segregation producing a higher-sound-speed layer or by degasification. In the tank waste, Cannon found a 
reduction in sound speed from vibration. This would be consistent with a breaking of bonds in the vibration process to produce a material of lower Young's modulus. Because the waste had been heated and stirred prior to the sound speed measurements, its gas content was not necessarily representative of tank waste.

Degasification was apparently not the dominant effect on sound speed in the tank waste after this processing, as degasification is expected to increase sound velocity. From the results of these measurements of yield strength and sound speed, it is unlikely that hardening of the waste by sonification is a problem, although the results with the LANL simulant leave some slight concern about this possibility. It is unfortunate that quantitative measurements of void fraction are not available to accompany the sound speed measurements, because these would help separate void fraction bulk modulus effects from unyielded elastic medium restoring force effects.

Experiments with a low-power probe in a cylinder of wet concrete were seen to produce a change (possibly degasification) front that proceeded with a finite velocity. This is consistent with a hypothesis that the front progresses because of one or both of the following effects: 1) progressive reduction with time of the attenuation in the path between vibration source and the degasification front, and 2) a finite energy absorption to break bonds in the gas release process. This alleviates somewhat concerns over an. instantaneous release of gas from an objectionably large volume. Internal reflection, tube compliance, and other complications limited the quantitative interpretation of this wet concrete tube experiment, however. As we shall see later, the time scale for migration of released gas bubbles to the tank plenum sets a useful time scale in keeping hydrogen concentrations below the LFL.

Experiments performed on a waste simulant that exhibited rollover behavior give evidence of the ability of the sonic probe to liquefy and degasify a material having both gas content and a yield strength (Hall 1993). Before sonification, a simulant composed of water, cornmeal, cornstarch, powdered sugar, and dry yeast exhibited periodic rollover accompanied by gas release in a 36-inchdiameter tank filled to a depth of about 12 inches. Two different sonic probe heads were tested; one had a diameter of 1.0625 inches and a nameplate rating claiming ability to produce $150 \mathrm{lbf}$ on the liquid at $186 \mathrm{~Hz}$; the other had a diameter of 1.75 inches and a $900 \mathrm{lbf}$ rating at $186 \mathrm{~Hz}$. Both had active regions (containing the eccentric) approximately one foot in length. Both produced a halt in rollovers and an observable degasification, although the effect was more dramatic with the larger probe. Rheology tests indicated a yield strength of the cornmeal simulant on the order of 300 Pascals and a shear thinning to an apparent viscosity of $4000 \mathrm{cP}$; thus the simulant mix exhibits qualitative but not quantitative features of Tank 241-SY-101 waste rheology.

To quantify somewhat the degasification observed in the cornmeal simulant, calculations were performed using a sonic probe model that is described in Appendix A of this report. Masses of the eccentric and the shell and the radius of gyration of the eccentric were chosen to give the approximate name-plate force ratings for the probes. The predicted pressure amplitude at a distance in an infinite medium equal to the 18-inch tank radius was predicted for the smaller probe to be 5700 Pascals. The larger probe, operating at $75 \%$ of full power, was predicted to produce a pressure amplitude of 26,000 Pascals at that same distance.

While these pressure amplitudes are large (by factors of 19 or more) compared with the 300 Pascal shear strength of the cornmeal simulant and thus probably do not give thresholds for yielding, they do show that acoustic waves can produce yielding and gas release. This simulant may differ in size spectrum of the bubbles present, however, and the frequencies (186 Hz for the smaller probe, $175 \mathrm{~Hz}$ for the larger probe when operated at $75 \%$ of full power) were somewhat higher than those proposed for the tank mitigation. At the same pressure amplitude, higher frequencies of sound are expected to be more effective in detaching bubbles from solids because of the higher pressure gradient. The differences in bubble size spectrum and in sound frequency should be kept in mind in interpreting this experiment. 
Further evidence of degasification by sonic waves was obtained by LANL with the chemical simulant of 241-SY-101 waste developed by PNL (Hall 1993). The bubble content was sampled by looking for bubble size-dependent resonances in ultrasound propagation before and after sonification at $186 \mathrm{~Hz}$ by a Vibramite Concrete Vibrator. Again, a reduced bubble population was found.

\subsection{Analyses}

General considerations and a few idealizations allow some analysis and evaluation of the concept. Issues on which at least some insights can be gained from analysis include mechanisms for material yielding and bubble release; power and pressure amplitude levels produced by a given probe design and choice of operating parameters; size of material regions that can be treated; pressure amplitudes experienced by tank internals, walls, and cake layers; bounds on gas release rates; and trends with material properties.

Many features of sonic probe performance can be predicted with a suitably idealized model that has an analytical solution. Idealizations are that the eccentric drive system transmits torque but no force transverse to the axis, that the amplitude of probe oscillation is small compared with the shell radius, that the system near the probe can be treated in infinite cylinder geometry with neglect of end effects, that the acoustic pressure waves in the medium obey a classic wave equation, and that the compressibility of the medium applicable to pressure oscillations is adequately given by the simple expression used.

These assumptions allow solution for amplitudes of probe oscillation and of acoustic waves generated with actual circular probe oscillations. Calculable quantities from this model with these idealizations are power, surface pressure, and force on the eccentric bearings as a function of geometry, masses, driving frequency, and fluid properties. The model for this is summarized in Appendix A, and its results are used in the analyses reported here.

By applying a calculated ad hoc attenuation factor (but one based on well-defined models of acoustic waves in media containing bubbles) for the acoustic waves, one can also calculate approximate pressure profiles in the fluid. These pressure profiles are useful in estimating the size of the region mitigated and the forces on tank structures. The attenuation mechanisms for bubbly media and the expressions used for their attenuation effects are summarized in Appendix B of this report. For estimating the size of the region in which the material yields, an assumption is made that the simple acoustic waves in the (already yielded) fluid region around the probe drive longitudinal waves of comparable amplitude in the elastic material medium around it. In a more precise treatment, there would necessarily be some reflection from the interface between yielded and unyielded material. It is assumed that shear stress plays a major role in the yielding of the sludge. The generation of shear stress by longitudinal waves in such a medium is discussed in Appendix C of this document.

Another mechanism by which sonic probes may promote degasification of liquid or slurries containing both solids and gases is promoting detachment of bubbles from solids. An approximate model for this process is presented in Appendix D. Larger bubbles are more readily detached from solids by the pressure gradient field of an acoustic wave. According to the arguments presented in Appendix $\mathrm{D}$, the minimum diameter $\mathrm{D}_{\mathrm{B}}$ of bubbles that will be detached from a much denser solid particle in the mix obeys

$$
D_{B}{ }^{2}=3 S \operatorname{ch} /\left(\pi P_{0} f\right)
$$

where $S$ is the surface tension of the liquid-bubble interface, $c$ is the speed of sound in the mix, $h$ is the ratio of $L_{c r} / \pi$ to bubble diameter, $L_{c r}$ is the critical release perimeter in the breakaway of the bubble from the solid, and $P_{o}$ is the pressure amplitude of the acoustic wave of frequency $f$. 
Figure 4.2 shows the minimum bubble diameter as a function of frequency for release by an acoustic wave of amplitude $P_{0}=6700$ Pascals, assuming a sound speed $c=70 \mathrm{~m} / \mathrm{s}$, surface tension $S=0.075 \mathrm{~N} / \mathrm{m}$, and $\mathrm{h}=0.5$. The value 6700 Pascals is representative of the widely varying shear strengths of untreated sludge. Figure 4.3 shows the minimum bubble diameter as a function of acoustic wave pressure amplitude for release by an acoustic wave of $100 \mathrm{~Hz}$. Figures 4.2 and 4.3 show that there is sufficient net force in the pressure gradient of the acoustic wave to play a role in dislodging the larger bubbles. A pressure amplitude of 6700 Pascals would dislodge bubbles of

2-mm diameter; a pressure amplitude of 1 atmosphere at $100 \mathrm{~Hz}$ would dislodge bubbles of $0.5-\mathrm{mm}$ diameter. The ability of a 6700 Pascal wave at $100 \mathrm{~Hz}$ to dislodge $2 \mathrm{~mm}$ bubbles adds credibility to using 6700 Pascals as a criterion for yielding because 1) $2 \mathrm{~mm}$ is a plausible upper limit to the size of bubbles found in great numbers in the sludge, and 2) bubble breakaway from solids by the larger bubbles may be part of the yielding process.

It is possible that the role of bubble breakaway in degassing the cornmeal simulant at $186 \mathrm{~Hz}$ is different from that in degassing the tank waste at $100 \mathrm{~Hz}$ or less, however, because of the differences in frequency and possibly bubble size spectrum. The cornmeal mix could have larger bubbles that are more readily detached and play a role in yielding of the material, particularly with the larger of the two probes used in the cornmeal simulant degassing tests. Despite differences from the proposed tank waste sonification, the cornmeal simulant experiments are valuable for their insights. The approximate bubble breakaway model suggests caution in interpreting the results.

In a less idealized treatment, one can solve an acoustic wave equation including dissipation terms to arrive at spatial dependence of the acoustic wave pressure amplitude in a medium with inhomogeneous bubble density. The bubble density is nonuniform because of fluid convection and bubble rise after the material yields. Such an acoustic wave solution, together with a pressure amplitude criterion for yielding, has been used repeatedly within the TEMPEST code to determine the size of the region yielded. Solution of the fluid equations for the yielded region within TEMPEST give predictions on the transient gas release to the tank dome. The TEMPEST model for the flow of the re-liquidized slurry featured a two-size bubble spectrum with correlations for bubble motion relative to the liquid. TEMPEST simulations of fluid convection, gas motion, and gas release are discussed in the next section.

\subsection{Mitigation Region Size and Gas Release Estimates}

In this section, we present methods for and results from estimating the amount of gas that would be released in initial testing of a sonic probe of plausible design with plausible testing protocols. In particular, we present plots of mitigation radius, mitigated volume, and gas release from operation of a sonic probe of plausible design as functions of frequency and unreleasable void fraction (defined later). We assume tank conditions consistent with what is known or believed for Tank 241-SY-101 at the time of this writing, and a two (or more)-day settling period after the last mixer pump operation. We relate these upper bound gas release predictions to the LFL of hydrogen. Some discussion of expected results for previously untreated burping tanks will also be presented.

The sonic probe has not yet been tested in actual tank waste, nor is its effectiveness exactly calculable with what is now known about the tank contents. Even with a sophisticated model for release of bubbles from Bingham fluids (or, more generally, materials with a yield strength that exhibit viscous.liquid properties after yielding) with suspended particles as well as bubbles, one would probably need information on the distribution of bubble sizes and the tenacity with which they are held by particles or by globs of unyielded Bingham fluid. However, in this report we bypass some of this unknown detail by using a parameter, the "unreleasable gas fraction," $\alpha_{\min }$, which is postulated to apply to the regions in which sonic yielding of the tank material has occurred. The unreleasable gas fraction is the minimum gas fraction achievable with the sonic probe, and it would strongly influence the size of the region that can be made to yield through its effect on compressibility, sound speed, and attenuation. 


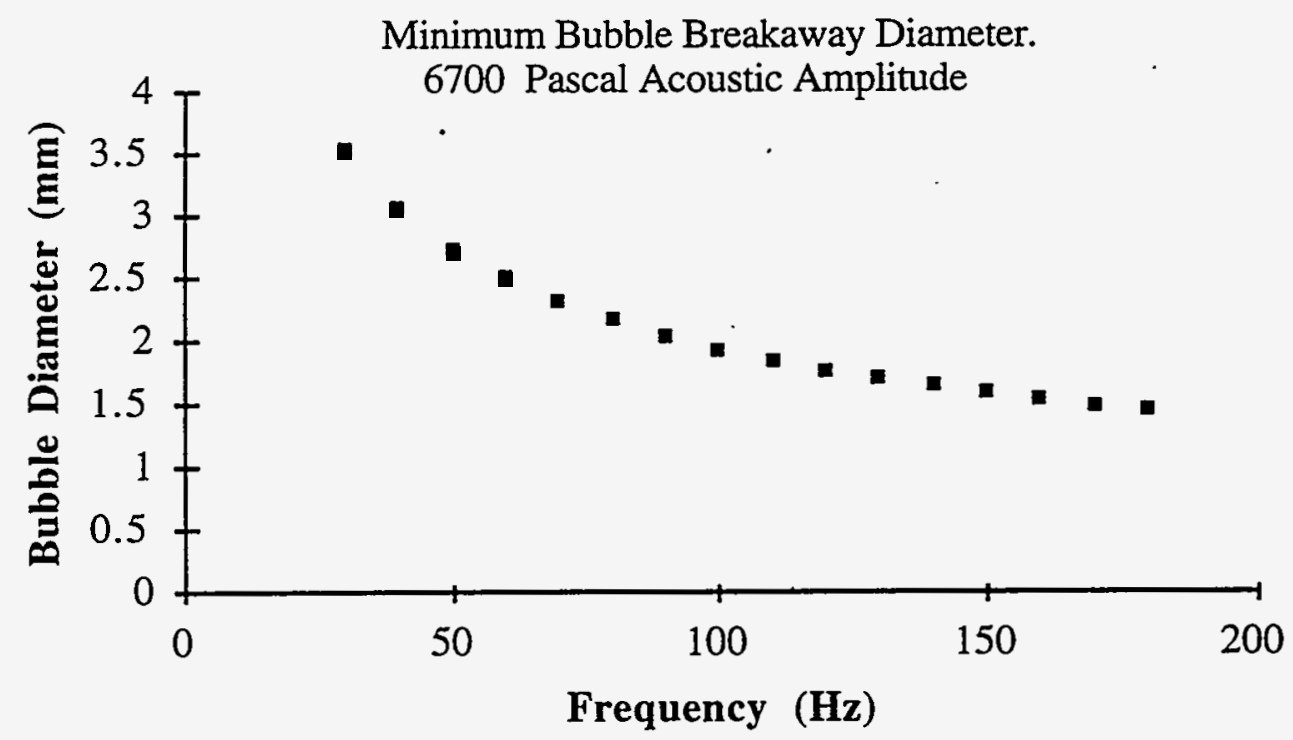

Figure 4.2. Minimum Bubble Breakaway Radius Versus Frequency for Pressure Amplitude 6700 Pascals

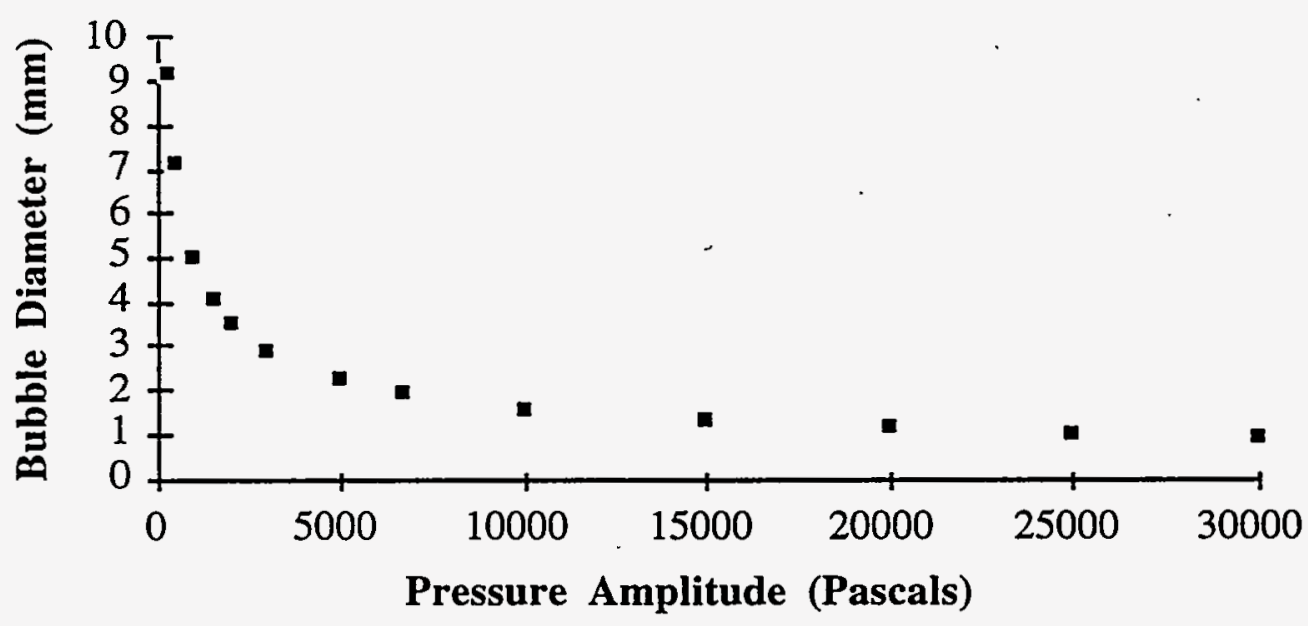

Figure 4.3. Minimum Bubble Breakaway Radius Versus Pressure Amplitude for $100 \mathrm{~Hz}$ Frequency

\subsubsection{Assumed Conditions}

We assume for this analysis that the waste is stratified, with a liquid layer above a region of material with a yield strength. If the tank has been previously subjected to mixing pump action, then it is assumed that solids and bubbles kicked up by the pump have mostly left the liquid. Crust layers do not enter this analysis, because we make the infinite cylinder approximation and, further, assume that gas is released only from the yieldable sludge. We will, for the most part, consider yield strengths consistent with virgin material, even though we take void fractions consistent with previously pump- 
mixed material. 'This is consistent with having the bounds of the newly yielded region lying in previously unmixed material.

The gas-bearing sludge has a yield strength that must be exceeded before it can release gas bubbles. Based on measurements by J. M. Tingey (PNL), Hall (1993) recommends a yield criterion of $6700 \mathrm{~Pa}$ for the nonconvective layer prior to any disruptive treatment processes. Tingey's yield strength values were from the lower part of the nonconvective layer near the tank bottom and are therefore probably high. More recent measurements by Tingey on recently disturbed and resettled sludges suggest a much lower value(a).

We postulate that minimum acoustically generated tensile-compressional stress for yielding is comparable to that measured in shear, on the assumption that inhomogeneities contribute stress enhancement and stress-type conversion. Our analysis uses 6700 Pascals for previously unyielded nonconvective layer material (which presumably has a fairly high gas fraction, about $10-15 \%$ ). A value of $600 \mathrm{~Pa}$ would be representative of previously yielded material (which presumably has gas fractions half or less of the unyielded value). A 6700 -Pascal pressure amplitude in a $100-\mathrm{Hz}$ sound wave is also approximately the value needed to detach a $2-\mathrm{mm}$-diameter bubble from a solid particle, which lends a little support to using this value as a pressure (as opposed to shear stress) criterion. Our analysis presents gas release amounts assuming that the released region mostly has gas content characteristic of previously yielded, formerly nonconvective layer material. If a value of $600 \mathrm{~Pa}$ were used as the release criterion, a sonic probe of the tentative design is capable of yielding the entire formerly nonconvective region at $100 \mathrm{~Hz}$.

\subsubsection{Assumed Gas Release Mechanisms}

The sonic probe will yield material in the nonconvective layer only out to the distance where the pressure amplitude falls below the yield criterion. This distance can be controlled by limiting the rotational frequency and thus the power to the probe. The larger bubbles of previously trapped gas within the yielded region will be free to rise to the surface and escape, although possibly through a sequence of captures and breakaway from solid particles; smaller bubbles in that region will probably remain in place or clear very slowly; and the unyielded region will retain essentially all its bubbles. We do not expect sonification to release any dissolved gases; gas release in this report refers only to bubbles that rise to the liquid surface and dissipate.

For purposes of estimating gas releases, we postulate an unreleasable gas fraction $\alpha_{\min }$ for gases from the yielded region, and we use a single value for this unreleasable gas fraction throughout the sonically yielded region. We believe that the spectrum of bubble sizes released will actually be sonic intensity-dependent and thus position-dependent, but quantitative information on bubble numbers or bubble volume versus bubble size is not known at present. Also, we can offer only an approximate model for the minimum size of bubbles released as a function of sonic intensity, wavelength, and surface tension (Appendix D). Thus taking a single number for unreleasable gas fraction $\alpha_{\min }$ is probably a necessary expedient.

The probe can also affect bubbles in the supernatant liquid, although the tentative probe designs have its length and operating location approximately coinciding with the original (pretreatment) nonconvective layer thickness and location. Hence, the fluid mix in the region occupied by the liquid prior to use of the mixer pump will be exposed to sound waves of lower intensity than those in the region formerly or currently occupied by the nonconvective layer. Also, the undissolved gas retained in the liquid will be mostly limited to that attached to particles to give near neutral buoyancy. For these two reasons, the amount of gas released from the supernate will be . fairly small, with or without mixing.

(a) Tingey, J. M., P. R. Bredt, and E. H. Shade. 1994. The Effects of Heating and Dilution on the Rheological and Physical Properties of Tank 241-SY-101 Waste. PNL draft report, Pacific Northwest Laboratory, Richland, Washington. 
In this section, we estimate that sound waves are cylindrical and that yielding of material accompanied by release of gases occurs only from the region formerly occupied by the nonconvective layer. The cylindrical wave approximation overpredicts the region yielded, particularly when it reports that the whole formerly nonconvective layer is yielded. In any region, we believe that sufficiently large bubbles attached to particles by surface tension forces can be torn free by acoustic waves of sufficient intensity and frequency (under conditions the approximate model attempts to describe), resulting in release of gas. In fact, we do not know that the bubbles really cling to the particles after yielding, but some "unreleasable gas fraction" is plausible.

Both the radius for yielding sludge and the minimum bubble size acoustically released are expected to be strongly dependent on the gas content between the sonic probe and the yield front. This dependence comes from the effect of the gas content on both the compressibility of the mix (which strongly affects sound speed) and the attenuation, which decreases with decreasing gas fraction. Hence we encounter an inherent safety mechanism in sonification of gas-trapping sludge.

Early in the sonification, bubbles will not have had time to rise very far, and the gas fraction in the yielded material will be approximately that prior to yielding. The intensity at the yield front will be characterized by that of the sonic oscillator operating in a mix having this gas fraction. As the gas clears from the yielded region, the attenuation declines, and as the compressibility there declines, the yield front will experience an intensity increase, and the yield front will move outward.

Thus it is meaningful to define a "prompt yield radius" and an "ultimate yield radius" for a given set of sonic probe parameters (shell mass, eccentric mass, shell radius, radius of gyration of the eccentric, and rotational frequency of the eccentric). The prompt yield radius is the distance to the yield front when the gas content is essentially at its pre-yielding value. The ultimate yield radius is the one applicable when the gas content gets down to the unreleasable gas fraction.

One can calculate the "prompt release" and "ultimate release" volumes of gas, assuming that the "prompt release" quantity is the amount of gas coming out of the prompt release region, with sonification assumed to stop before the gas clears from the region between probe and yield front. The "prompt release" gas actually emerges from the yielded region on a time scale of the gas transport to the surface, which may be about an hour or more for complete clearing, depending on viscosity. That prompt release gas eventually emerges assumes that the bubbles do not permanently reattach after sonification stops and that the fluid does not regain its yield strength before the released gas clears.

\subsubsection{Probe Effects on Nonconvective Layer Material}

Assuming that little gas will be released from the liquid layer, we can estimate 1) the gas release from the volume of sludge yielded by the probe and 2) the initial and unreleasable void fractions. These estimates and other parameters of interest are calculated using a spreadsheet model developed at PNL with the following features:

- A probe model predicts surface pressure amplitude, radial pressure profile, power consumption, and force on the eccentric bearings for a cylindrical sonic probe with rotating eccentric; the assembly is operated in a medium in which pressure oscillations obey a classical acoustic wave equation. Probe parameters are shell mass, eccentric mass, eccentric radius of gyration, rotational velocity, radius, and length, but axial invariance (infinitely long cylinder approximation) is assumed.

- Acoustic wave attenuation is accounted for in pressure profiles by multiplying the nodissipation pressures by $\exp \left[-\xi\left(r-r_{\text {probe }}\right)\right]$. 
- The attenuation parameter $\xi$ is calculated from models for radial oscillation of bubbles, thermal effects associated with those radial oscillations, viscous dissipation from relative motion of bubbles and liquid, and other effects, all according to a theory proposed by Harri Kytomaa of Massachusetts Institute of Technology.

- The radial pressure profiles are searched to find the radius at which the pressure amplitude falls to the criterion value for yielding of the material; this is the "yield radius."

- The volume of the released region is calculated as the volume within the tank and within the sludge layer at a distance less than the release radius.

- The volume of specific gases released is calculated as the product of the volume released times the excess of the void fraction above the "unreleasable void fraction" times the expansion factor to standard conditions times the fraction that the specific gas is of the total noncondensable gases there.

To prevent cavitation, it is necessary to limit the surface pressure through appropriate specification of the eccentric mass or radius. We used a criterion of a probe surface pressure amplitude $90 \%$ of the cavitation threshold at $1.5 \mathrm{~atm}$ and $100 \mathrm{~Hz}$ in a medium of 0.001 void fraction to choose an eccentric mass for each total probe mass. We found that higher total probe masses tended to be more effective. Approximately $2300 \mathrm{~kg}$ is an upper limit from the density of stainless steel, the fraction of the probe shell volume that can be metal, and the probe length and radius specified. A $213 \mathrm{~kg}$ eccentric with a $2-\mathrm{cm}$ radius of gyration was found to meet the cavitation criterion for a $2300-\mathrm{kg}$ probe. Results reported here assume these values.

The density of the fluid is $1660 \mathrm{~kg} / \mathrm{m}^{3}$, and the viscosity assumed for acoustic wave attenuation calculation was $1,000 \mathrm{cP}$. For acoustic attenuation calculations, residual bubbles of unreleasable gas were assumed to be of $0.2 \mathrm{~mm}$ diameter. This is an assumed "mean" or effective diameter for attenuation by the unreleased bubbles. If, for example, bubbles of diameter less than $0.5 \mathrm{~mm}$ were unreleased, the mean diameter-would be some value between 0 and $0.5 \mathrm{~mm}$.

Figure 4.4 shows acoustic pressure amplitude plotted as a function of radius for probe operation at 30,70 , and $100 \mathrm{~Hz}$. Both geometrical and dissipative effects contribute. A void fraction of $\alpha=0.01$ is assumed. Figure 4.5 shows the yield radius or maximum clearing radius, assuming residual void fractions of $\alpha=0.01,0.04$, and 0.06 . As can be seen in these plots, the range ultimately cleared depends on how well the region between probe and yield front is cleared of attenuating gas.

The range cleared tends upward with frequency up to some optimum because of the increasing amplitude of the surface pressure, despite increasing attenuation. At frequencies above the optimum, further increases in frequency result in smaller cleared radii because of further increases in attenuation, and the maximum cleared radius is reduced. The optimum frequency decreases with increasing unreleasable void fraction, because attenuation increases with both void fraction and frequency. Figure 4.5 suggests that optimum frequency is on the order of $100 \mathrm{~Hz}$, and the clearing range is on the order of 4 to 12 meters.

Figure 4.6 shows the volume [at standard temperature and pressure (STP)] of hydrogen released from Tank 241-SY-101 with assumptions of initial void fraction $\alpha=0.075$, unreleasable void fraction $\alpha_{\min }=0.01$, hydrogen content $28 \%$ of the noncondensable gases, and a probe location five meters from the center of the tank. Release volumes with yield criteria of 3000,6700, and 10000 Pascals are shown. 


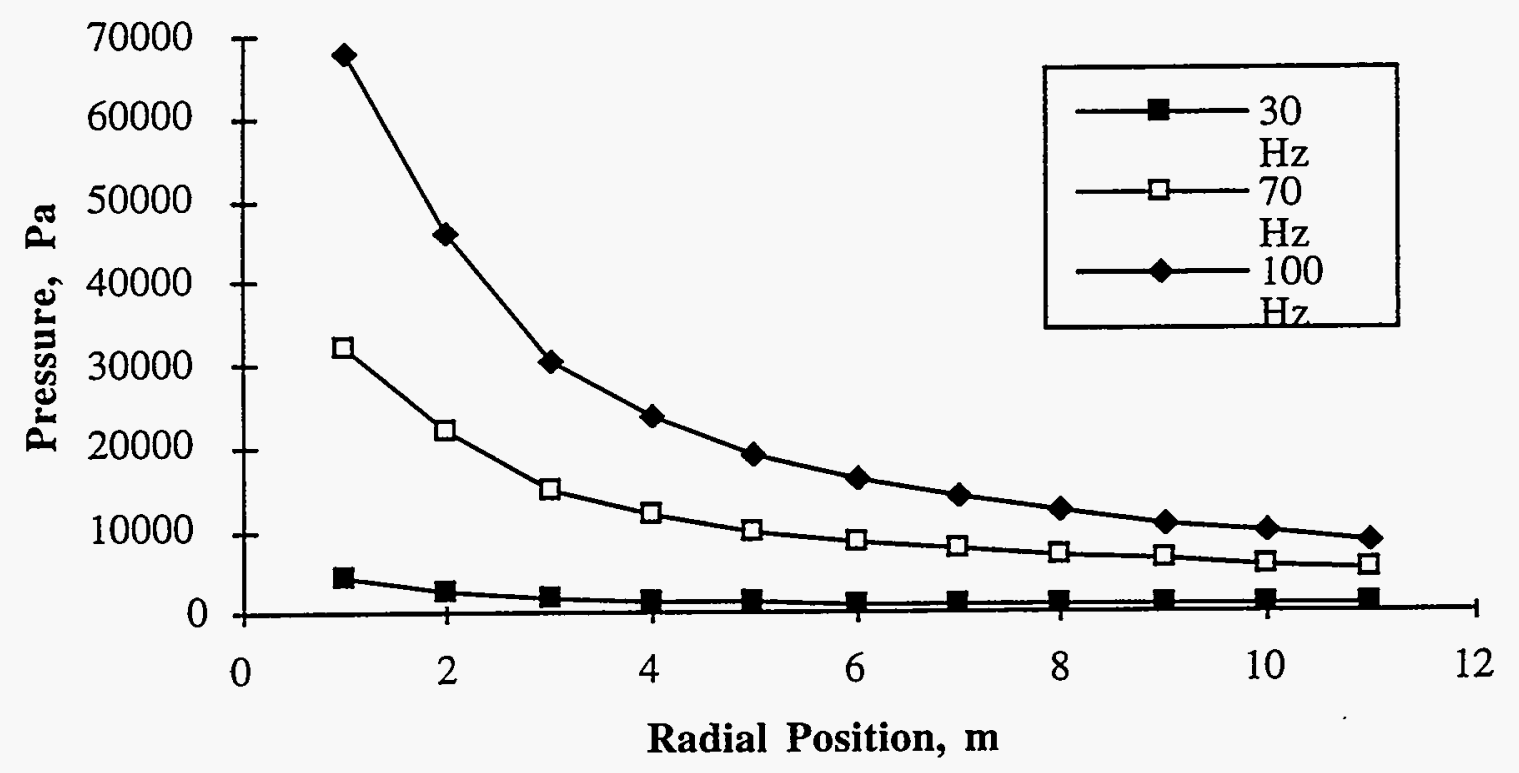

Figure 4.4. Pressure versus Distance from Probe Axis for Reference Probe in Medium with 0.01 Void Fraction Comprising 0.1-mm-Radius Bubbles

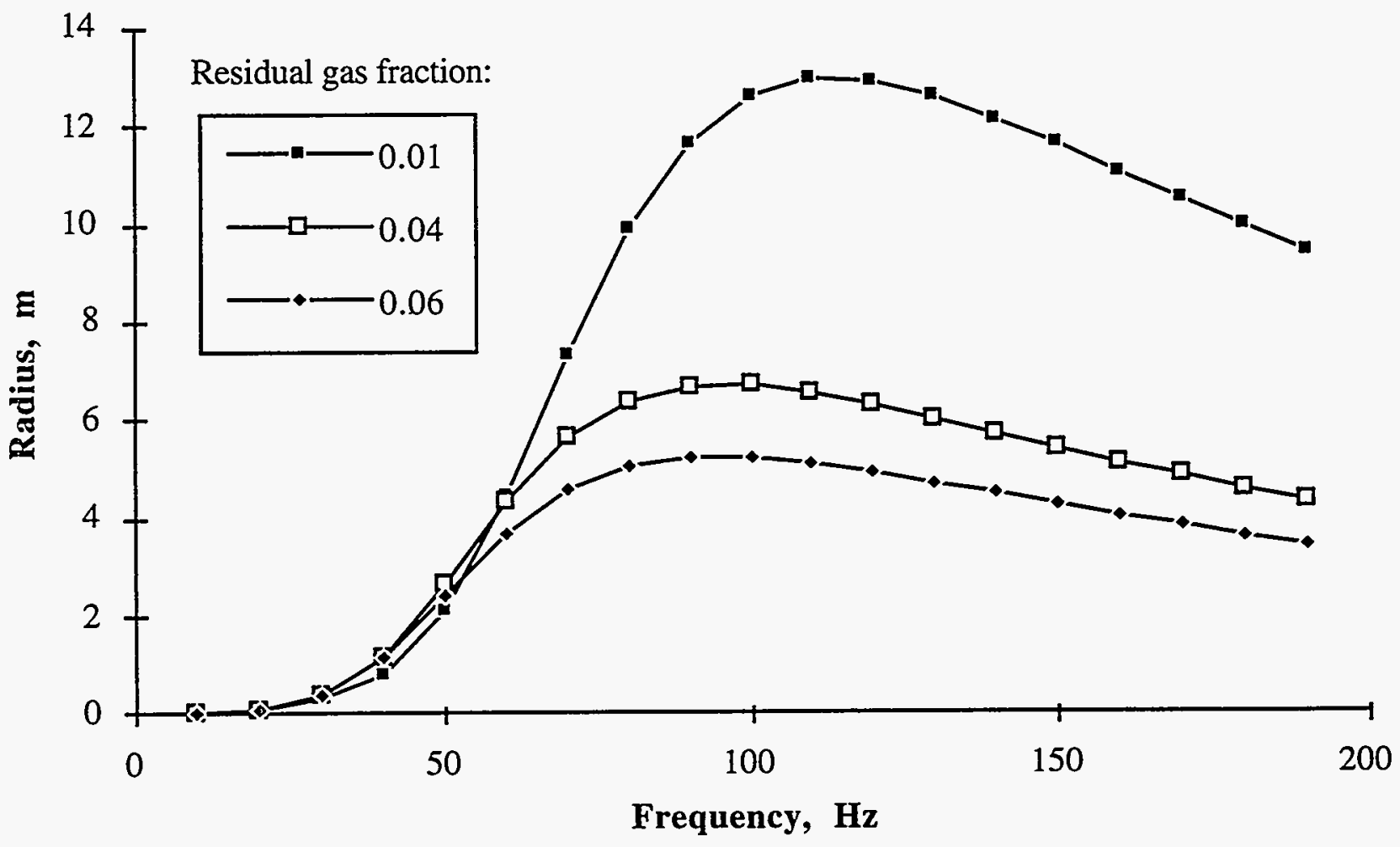

Figure 4.5. Yield Radius Versus Frequency with Void Fractions 0.01, 0.04, and 0.06 Comprising 0.1 -mm Bubbles in Medium with Viscosity $1000 \mathrm{cP}$ 


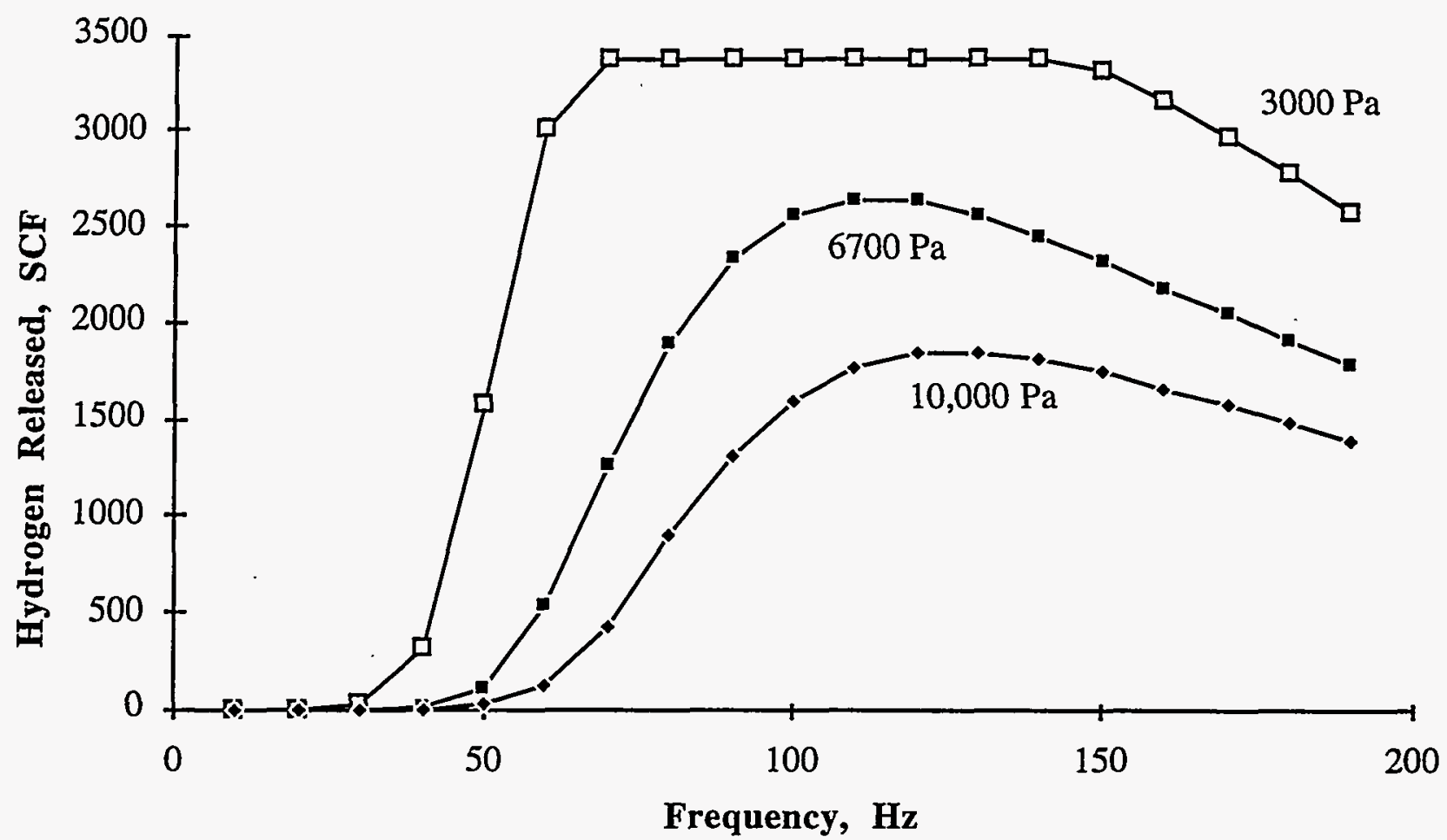

Figure 4.6. Volume of Hydrogen Released Versus Frequency with Initial Void Fraction 0.075 , Unreleasable Void Fraction 0.01 , Bubble Radium $0.1 \mathrm{~mm}$, Viscosity $1000 \mathrm{cP}$ (release volumes with 3000,6700 , and 10000 Pascal pressure amplitude criteria are shown)

The frequency range at which the release volume is invariant with the $3000 \mathrm{~Pa}$ criterion is the range in which the entire tank is predicted to be yielded. A yield criterion of $600 \mathrm{~Pa}$ (representative of all of the tank having been previously yielded by the mixing pump) would result in a prediction of re-yielding of the entire tank by the sonic probe through an even larger frequency range.

These figures demonstrate that the range of the sonic probe in degasifying the tank waste is strongly.dependent on two parameters: 1) how effectively the probe reduces the void fraction in the near-probe region and 2) the criterion for yielding of the material and the release of bubbles.

Figure 4.7 compares the prompt and ultimate release volumes of hydrogen for a range of frequencies of operation of the reference design probe. The prompt release gases are assumed to come from the region yielded by the probe, but the released gases of the initial $\alpha=0.075$ void fraction are still present and contributing to attenuation when the probe is turned off. The ultimate release quantities come from the region released when the region between probe and yield front has cleared of gas down to the unreleasable void fraction when the probe is turned off. As bubbles near the probe are cleared, attenuation is reduced, allowing material farther from the probe to be yielded. An unreleasable void fraction of 0.01 is assumed for both curves in Figure 4.7.

\subsubsection{Relation to Flammability Limits}

The volume of the head space in Tank $241-\mathrm{SY}-101$ is approximately $4 \times 10^{4} \mathrm{ft}^{3}$. Lower flammability limits for hydrogen in air are usually taken as $4 \%$. However, the safety analyses for the mixer pump in Tank 241-SY-101 conservatively assumes 3\% as the LFL for hydrogen (LANL 1994) when methane, $\mathrm{N}_{2} \mathrm{O}$, and ammonia were also present. 


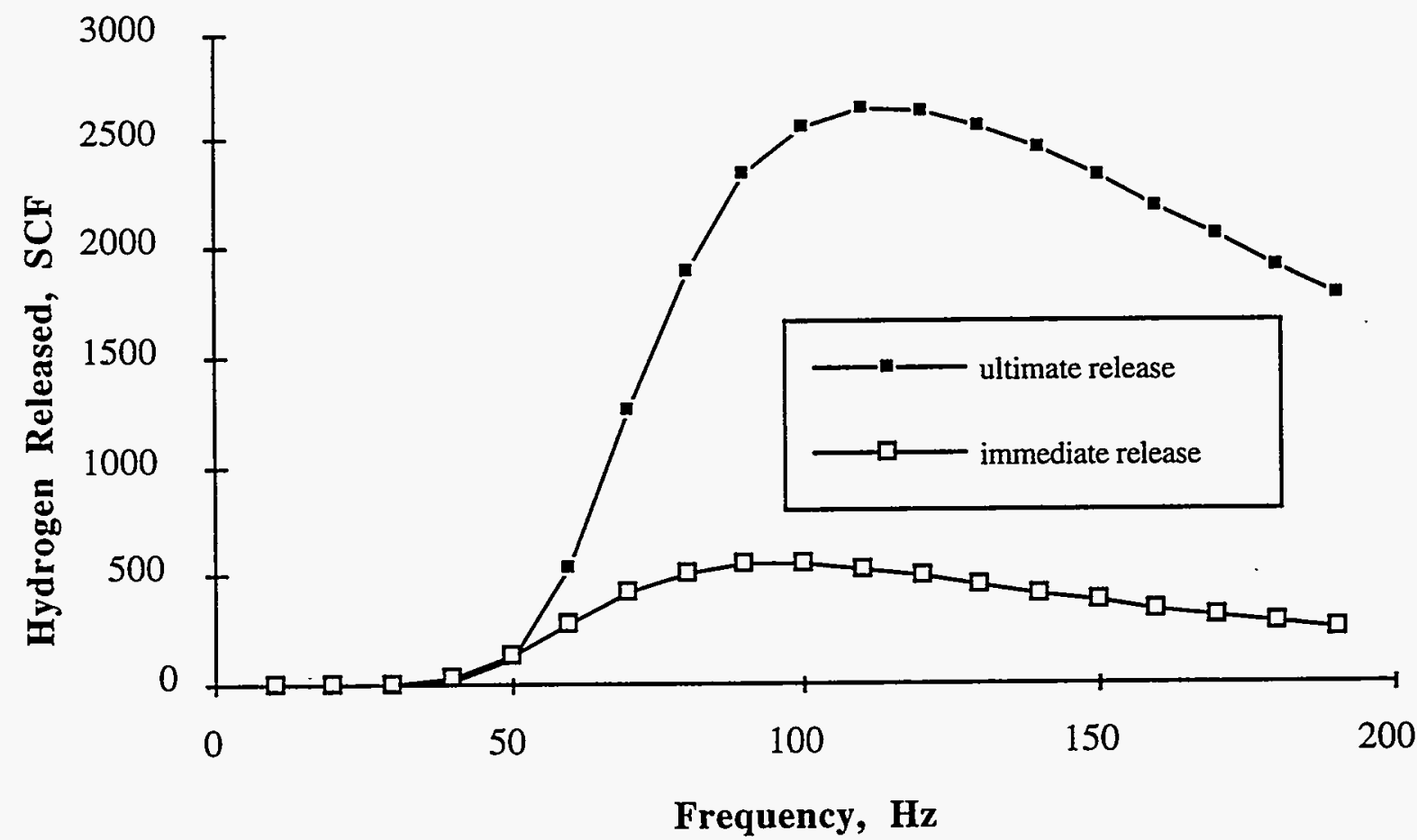

Figure 4.7. Prompt and Ultimate Release Volumes of Hydrogen with Initial Void Fraction 0.075, Unreleasable Void Fraction 0.01, Bubble Radius $0.1 \mathrm{~mm}$, Viscosity $1000 \mathrm{cP}$

The volume of hydrogen released to give $3 \%$ of the head space volume would be $1200 \mathrm{ft}^{3}$ in a static system, but Tank $241-\mathrm{SY}-101$ is normally vented at $550 \mathrm{ft} 3 / \mathrm{min}$. For the total release to significantly exceed $1200 \mathrm{ft}^{3}$ of hydrogen without exceeding this LFL, however, the duration of the release must be on the order of or greater than $V_{\text {head }} /(d V / d t)_{\text {vent }}$ or 73 minutes, where $V_{\text {head }}$ is dome space volume and $(\mathrm{dV} / \mathrm{dt})_{\text {vent }}$ is the volumetric vent rate.

The total possible hydrogen releases that we calculate from sonic probe action, either prompt or ultimate, can exceed these values, depending on initial gas volume fraction, probe frequency, and yield criterion. As can be inferred from Figures 4.6 and 4.7 , however, the quantities released can be limited by limiting the upper frequency to which the sonic probe is driven. Presumably, released quantities can be kept sufficiently small in any probe run that dome space and normal gas venting keep hydrogen concentrations to desired safety levels as long. as a massive rollover is avoided. The gas release transient modeling reported in Section 4.8 gives 500 seconds as the approximate time for release rates from the liquid into the tank gas space to peak, so this must be kept in mind in planning and monitoring probe runs to keep hydrogen concentrations below some desired fraction of the LFL.

Although information is incomplete, it seems likely that many other waste tanks that produce GREs will offer less severe problems than 241-SY-101 in one or more of the following ways: lower yield strength, smaller total waste volume, larger tank dome space, and/or lower gas generation rates. Hence sonic probe effectiveness (size of region mitigated, smallness of pressure amplitude required, length of period between needed probe operations) is expected to be greater and hazards (volume released, hydrogen concentrations produced) lower than for 241-SY-101. However, rheology (yield strength and the apparent viscosity versus shear rate curve) and the attenuation length for sonic waves can also vary in unfavorable directions in other tanks, so no general conclusions can be drawn. 


\subsubsection{Conclusions from Mitigation Region and Gas Release Analyses}

It appears that the sonic probe could potentially be quite effective at degassing the contents of Tank 241-SY-101 and other tanks of similar content and rheology. However, the performance is apparently sensitive to parameters such as the yield stress of the material(s) in the tank, the residual gas fraction, and the acoustic wave attenuation. The criterion for yielding of the material in any of the tanks by sonic waves is uncertain and unverified. Parameters that affect the acoustic wave attenuation include bubble size spectrum and viscosity of the mix. Because of the large number of attenuation mechanisms and their dependence on a variety of parameters of the sludge, a measurement of that attenuation in materials similar to tank contents would be needed to justify confidence in a prediction. Nevertheless, the somewhat broad range of possible consequences presented here suggest that the probe could be effective and that it could be safely operated, although further tests would be necessary to conclude that a particular probe design would accomplish mitigation.

\subsection{Transient Gas Release Simulations}

The purpose of the release transient simulations was to determine the time scales for gas release rates to peak, for most released gases to clear from tank liquid, and for the yield front to advance. Release transients were simulated by adding an intermittent calculation of the probegenerated acoustic waves to the fluid dynamics calculations in the TEMPEST code (Trent and Eyler 1993). Fluid motion is assumed to occur only in computational cells in which the sonic pressure amplitude has exceeded a yield criterion value. This formulation uncouples the sonic wave from the hydrodynamic motion. The tank-scale hydrodynamic motion in a probe-sonified tank occurs on a time scale that is large compared with a period of probe motion. Thus the effects of interest from the acoustic wave are the yielding of the sludge and possibly the detachment of bubbles from solids; the oscillatory motion of the fluid in the sonic wave need not be further described.

Simulations were performed for certain scenarios for Tanks 241-SY-101 and 241-SY-103, although to some extent the assumptions either span or are typical of a significant number of waste tanks to which sonic probe mitigation might be applied.

A calculated sonic probe-induced gas release transient for a previously unmixed tank (241SY-103) is shown in Figure 4.8. A total initial void fraction of $16 \%$ is assumed to have equal contributions from bubble classes of $1-\mathrm{mm}$ and $0.01-\mathrm{mm}$ diameter. The smaller bubble size class is artificially small but was used to represent bubbles whose velocity relative to the liquid is very small for various reasons. As seen in the figure, the release rate peaks approximately 500 seconds after the first sonification, and the tank is largely cleared of bubbles in one hour. Similar time scales and qualitative shapes of release history curves were found for other tanks and scenarios. features:

The release transient simulations reported in this section incorporate a number of additional

- Transient effects are incorporated in flow and bubble rise phenomena, so that release rate histories are predicted.

- Material inhomogeneities arising from relative motion of gas and liquid are taken into account in propagating the acoustic waves. 


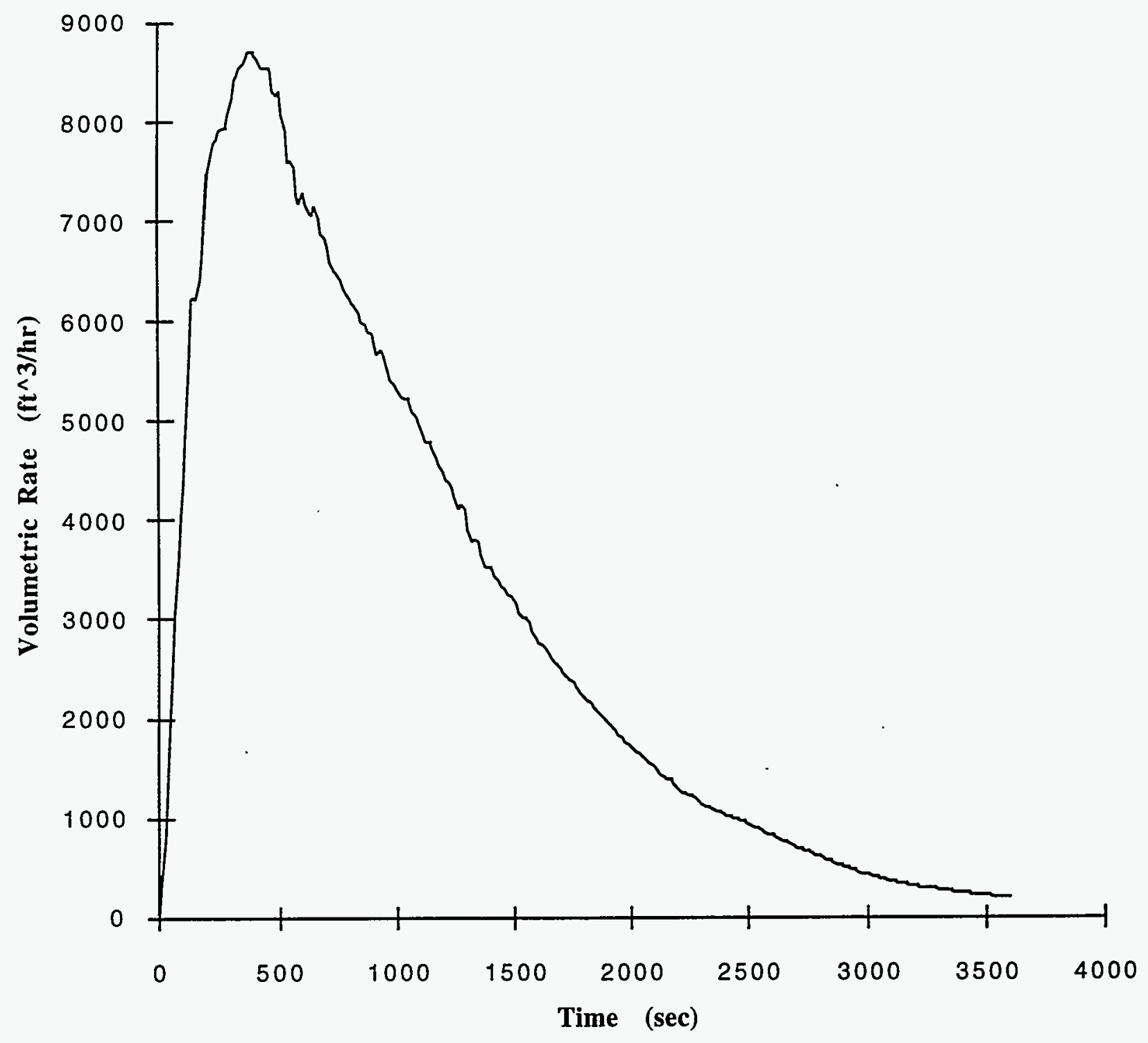

Figure 4.8. Calculated Gas Release Transient After Initial and Repeated Sonification of Unmixed 241-SY-103 Waste

- Both acoustic wave calculations and fluid dynamic calculations are performed in two dimensions $(r, z)$ rather than one ( $r$ only). (However, rotational symmetry was imposed by taking the probe location at the tank axis instead of at the five-meter offset in the 11-m-radius tank.)

- A test for whether a computational cell in the model of the system transient has been yielded is applied locally, with the computational cell treated as allowing fluid flow and gas bubble migration only after it has been yielded. 
The important new pieces of information from this transient analysis are the following:

- The time scale for releases of gas from the liquid to the tank gas space to reach a peak is on the order of 500 seconds.

- The time scale for most of the released gases to leave upward through the liquid surface is one hour. (These two time scales would be altered somewhat by bubble size distribution, tank geometry, viscosity, and void fraction.)

- Convective motion driven by buoyancy sets these time scales, which are shorter than the rise times of bubbles in stationary liquid.

- The yield front moves outward from the probe qualitatively, as anticipated, due to clearing of wave-attenuating bubbles.

A description of the computations and more detailed results appear in Appendix E.

\subsection{Conclusions from Analysis}

The analyses suggest, but do not ensure, the efficacy of the sonic probe to serve as a mitigation device for burping waste tanks. These are the leading uncertainties:

- The criteria for yielding and/or release of bubbles from the sludge are not known. Experiments set only a huge upper bound for the cornmeal simulant, and no bound is available at all for the tank waste. The criteria used in the simulations are unverified.

- The attenuation distances for the actual tank waste at the frequencies of interest are somewhat uncertain. The theoretical expressions used for the mechanisms considered were based on bubbles of known size in liquid; a significant percentage of the tank waste is suspended solids. Bubbles may interact with them in a variety of ways: attachment of a single bubble to a solid particle; surrounding of a bubble by a suspended solids "armor"; surrounding of a solid by a coating of bubbles; distortion of a bubble into a dendritic structure between solid particles. Even attempts to measure the attenuation from bubbles in a liquid (diluted syrup) were unsuccessful.

- The size spectrum of the bubbles is uncertain. Thus there would be an uncertainty in the parameters for attenuation, yielding, and bubble release, even if the mechanisms were completely understood for well-characterized mixes of solid, liquid, and gas.

It seems likely, however, that the following will occur:

- Yielding of the sludge will occur at some acoustic pressure amplitude not exceeding the values (6700 Pascals and less) assumed in our simulations by more than a factor of 20 and probably less than 2 , based on concrete degasification experience and the commeal simulant experiment. This is also suggested by the finite (but variable) measured shear yield stresses combined with the result known from analysis that inhomogeneities in a medium produce a variety of stress amplification and stress conversion effects.

- Release of most bubbles above some size limit will occur for a given acoustic pressure amplitude and frequency. This is based on concrete degasification experience, the cornmeal simulant experiment, measurements at Los Alamos National Laboratory of the bubble size dependent resonant attenuation of ultrasound before and after vibration, and the approximate bubble breakaway model presented in this report. From the approximate bubble breakaway model, a 2-mm diameter is a reasonable estimate of minimum bubble size released at the yield front at which location pressure amplitude is estimated to be 6700 Pascals. 
- For a given frequency and pressure amplitude, there is some unreleasable gas comprising bubbles below some size limit. A bubble diameter of $0.5 \mathrm{~mm}$ is a reasonable estimate for this limit from a limiting force model, although volumetric oscillations may lead to detaching of much smaller bubbles. The mean or effective size of the remaining bubbles would be smaller than this value.

- Attenuation will occur by mechanisms such that attenuation length will decrease with increasing frequency, void fraction, and bubble size.

- There are two natural rate limiters that set characteristic time scales for gas release into the tank's gas space, the circulation time for buoyancy-driven flow, and the bubble-clearing time for a combination of bubble rise and convection. These limiters set a time scale of about 500 seconds for the release rates to peak and one hour for most of the gas to clear from the liquid, although these times will vary somewhat with viscosity. The delays in gases reaching the surface provide a measure of protection against exceeding the LFL in the tank dome or vent system.

- Hazards associated with large gas releases during preliminary tests can be reduced or even eliminated by progressive ramping of frequencies and durations of test runs, starting at a time when tank conditions are not ready for a spontaneous rollover. 


\subsection{Dilution}

Dilution has been proposed to mitigate flammable gas releases by decreasing the volume of gas-retaining material and reducing or eliminating its ability to retain, and ultimately release, gas. The retention and release behavior is tied closely to the properties of the sludge that forms as the solids settle. To provide mitigation, dilution must therefore dissolve a significant fraction of the solids and change the waste properties so that gas can migrate to the surface continuously instead of being held in the sludge.

But dilution is not an effective mitigation method unless it eliminates or greatly reduces the ability of settled solids to retain gas. Merely adding liquid to a tank actually increases the volume of gas that can potentially be released in a GRE and reduces the head space so that flammable concentrations are more likely to occur. On the other hand, transfer of waste out of a tank greatly reduces the potential GRE volume and increases tank head space such that the flammability hazard can be essentially eliminated even if GREs continue. Dilution is therefore most beneficial when combined with transfer so that the waste level is held constant or reduced.

Tank 241-SY-101 will be the focus in this section simply because much more is known about it and much more attention has been devoted to its mitigation than other flammable gas tanks. However, the basic principles discussed herein should be applicable to tanks with similar waste characteristics.

Although the current mixer pump in Tank 241-SY-101 has maintained flammable gas concentrations below $1 / 4$ of the lower flammability limit (LFL) and has prevented large gas releases events to date, it is expected to return eventually to the earlier large episodic gas release behavior if the pump should fail and a replacement could not be installed. Thus it would be desirable to achieve passive mitigation by dilution or other means so that the mixer pump would not be needed.

Because Tank 241-SY-101 is nearly full, some waste must be removed before diluent can be added. Space for dilution will be provided by a new tank, 241-SN-101, scheduled to be available in 1998. The plan is to transfer mixed slurry from Tank 241-SY-101 into the new tank, diluting approximately $1: 1$ or less during the transfer to meet pipeline requirements and using the existing mixer pump to homogenize the waste prior to transfer. After transfer, if the waste level in Tank 241SY-101 is below the pump suction, diluent will be added to bring the waste level up to about 260 to 280 inches to ensure net positive suction head at full pump speed so the mixer pump can continue mitigation. Mixer pumps will also be present in 101-SN to ensure mitigation is maintained. Filling both tanks uniformly would give about a 1:1 dilution.

At this point there are not sufficient data to determine how much dilution is necessary for passive mitigation, or even whether dilution (say 1:1 or less) can even achieve passive mitigation of Tank 241-SY-101 or other flammable gas tanks. We are confident that transferring some waste out of Tank 241-SY-101 will reduce the volume of potential GREs and prevent flammable gas concentrations from reaching the (LFL) during a GRE, but we cannot prove that dilution will prevent GREs from occurring in the absence of mixing.

There are indications in the data from core sample analysis and in the behavior of other flammable gas tanks that dilution may eliminate gas retention ability. But this key aspect has not yet been confirmed or quantified. In-tank measurements with instruments like the ball viscometer and void fraction meter are necessary to correlate tank behavior with waste conditions. Additional dilution testing on core samples from Tank 241-SY-103, including chemical analysis before and after dilution, will relate changes in solid and liquid composition to the amount of dilution.

Dilution is measured in terms of diluent to waste ratios. We have attempted to consistently use the volume of diluent added to the original waste volume. Thus a ratio of $0.5: 1$ (diluent:waste), or a 0.5 dilution fraction, can be achieved by adding $5 \mathrm{~mL}$ of diluent to $10 \mathrm{~mL}$ of waste. Also, dilutions 
of core samples must eventually be related to dilutions of the entire tank for the purposes of physical property calculations. For example, Tank 241-SY-101 contained about 200 inches of nonconvective sludge before mixing out of just over 400 inches of total waste. Because a core sample of nonconvective material represents $1 / 2$ of the tank's contents, a $0.5: 1$ dilution of the sludge core sample would be roughly equivalent to twice that, a 1:1 dilution, in the entire tank. Other adjustments would be necessary in other tanks. On the other hand, dilution of a whole-core composite sample might compare closely with tank dilution. Dilution ratios are not adjusted when discussing dissolution, because added diluent will dissolve the same amount of solids (approximately) regardless of the existing liquid volume.

This section contains a discussion of the effects of dilution on the waste, an analysis of the potential for mitigation by dilution, and a description of the system envisioned to accomplish dilution in Tank 241-SY-101, including the results of an initial hazards analysis and potential long-term effects.

\subsection{Effect of Dilution on Waste Properties}

A complete fill history is available for Tank 241-SY-101 and is described in some detail by Babad et al. (1992a). Most of the waste consists of double-shell slurry from evaporator campaigns and complex concentrates that contain a considerable volume of soluble organic material. Samples of the waste were obtained in January 1986, May 1991, and December 1991. Detailed analyses are reported on the 1991 samples. Although most of the reports deal with the characterization of the individual sample segments and layers within the tank, the information generated is still valuable in characterizing the composition of the liquid and solid phases and thus may be interpolated to give an estimate of current tank conditions.

\subsubsection{Chemical Composition and Solubility}

The Window C analyses [of the May 1991 samples by Herting et al. (1992a) and Reynolds (1992)] examined the individual segments for chemical composition, radiological composition, organic composition, percent moisture, density, rheology, percent solids, and particle size. The uniform chemical composition of the liquid phase throughout the tank was a major trend observed in this study (Reynolds 1992). While Window E data [from the December 1991 samples, reported by Herting et al. (1992b) and Reynolds (1993)] suggest the dissolved solids in the liquid phase are slightly more concentrated in the lower segments (up to $10 \%$ for most components), Window $\mathrm{C}$ data do not directly contradict this observation. Analyses of the liquid phases from Windows $\mathrm{C}$ and $\mathrm{E}$ show the tank liquids are saturated with respect to nitrate, nitrite, and carbonate. The solubilities of these ions have been determined by Barney (1976) and by Reynolds and Herting (1984) for simulated waste saturated with respect to nitrate, nitrite, carbonate, and aluminate. The aluminate concentrations from Windows $\mathrm{C}$ and $\mathrm{E}$ tank liquids are thought to be half the value of a saturated solution.

Matrix interferences limit the techniques available for determination of the actual chemical composition of tank waste. Chemical analyses are generally limited to the elemental analysis of major constituents and anion analysis. Solids identification was carried out on Window $\mathrm{C}$ material using microscopic examination and X-ray diffraction. Sodium nitrate and nitrite were the only solids found by X-ray diffraction; this technique is limited to crystalline solids and cannot identify minor components. Microscopic examination detected $\mathrm{Na}_{2} \mathrm{CO}_{3} \cdot \mathrm{H}_{2} \mathrm{O}$ and $\mathrm{NaAlO}_{2}$. The presence of $\mathrm{NaAlO}_{2}$ in the solids and an aluminate concentration below saturation in the liquid phase suggests that the aluminum chemistry is more complicated than was thought earlier.

One of the objectives of the Window $\mathrm{E}$ core analyses was to examine the layers existing in Tank 241-SY-101. Segments from Window E were combined to form composites representing the layers; composites were prepared "by combining proportional amounts (by weight) of several 
homogenized segment samples" (Herting et al. 1992b). It is not clear from the report whether "proportional" means equal masses from each segment or a mass ratio equal to the ratio of material extruded from each segment. Liquid and solid phases were separated by centrifuging for two hours at $60^{\circ} \mathrm{C}$. Using centrifugation for separation leaves some interstitial liquid in the solids. No test was run to determine if solids remained in the liquid phase, and the liquids were not filtered.

Several important trends in Window E results are mentioned by Herting et al. (1992b):

- $\mathrm{Cr}, \mathrm{Fe}$ and $\mathrm{Ni}$ are predominantly in the solid phase

- $\mathrm{PO}_{4}{ }^{3-}$ concentration is slightly higher in the solid phase, but significant concentrations exist in both phases

- $\mathrm{Cl}$ - values are higher than estimates based on feed material

- $\quad \mathrm{Na}$ concentration is slightly higher in the solid phase

- Al has the same concentration in both the liquid and solid phases given experimental uncertainty

- Total organic carbon (TOC) concentration is approximately two times higher in the solids than in the liquids.

Trends observed for $\mathrm{OH}^{-}, \mathrm{TOC}$, and $\mathrm{Na}$ differed between Windows $\mathrm{C}$ and $\mathrm{E}$. Window $\mathrm{C}$ material was centrifuged for 5-10 minutes at room temperature. This method left visible solids in the liquid phase that are thought to be the cause of the inconsistency between windows.

Results from the composite analyses were used to calculate an overall tank composition. The crust was ignored in this calculation. Results are given in Table 5.1. Becasue the tank has been mixed by the mitigation pump, this table probably represents the best information available on the current tank contents.

The effects of heating and dilution on the chemical composition of Tank 241-SY-101 waste were also studied using Window E material (Herting 1992b; Reynolds 1993). Tests were run at $50^{\circ} \mathrm{C}$, $65^{\circ} \mathrm{C}$, and $80^{\circ} \mathrm{C}$ with dilutions of $0: 1,0.15: 1,0.3: 1$ using $0.01 \mathrm{M} \mathrm{NaOH}$. A whole-tank composite was used for this test. The following trends were observed:

- Weight percent of aluminum, nitrate, and phosphate in the centrifuged solids decreased with dilution.

- Percent water increased in the centrifuged solids with dilution.

- Weight percent of aluminum and phosphate decreased with increasing temperature.

- Weight percent water of the centrifuged solids increased with temperature.

An understanding of the solubilities of the waste components is critical to predicting the chemical and physical characteristics of the waste during and after the dilution processes. This section now focuses on the current understanding of the waste solubility and what effect the dilution processes will have. For this, the composition and solubility properties of Tank 241-SY-101 waste are used. The wastes in the many Hanford tanks vary somewhat in composition (even among the other double-shell tanks) from that found in Tank 241-SY-101. For example, 241-AP-102 contains a significant amount of concentrated phosphate waste and 241-AN-103, and -105 contain neutralized cladding removal waste, both of which are very different from the complexed concentrate and double-shell slurry wastes found in Tank 241-SY-101. [See Van Vleet (1993) for an overview of 
Table 5.1. Calculated Average Chemical Composition of Tank 241-SY-101 Contents

\begin{tabular}{|c|c|}
\hline Analysis & $\begin{array}{ll}\begin{array}{l}\text { Calculated } \\
\text { Average }(\text { wt } \%)^{a}\end{array} & \text { Tank } \\
\end{array}$ \\
\hline $\mathrm{Na}$ & 20.7 \\
\hline $\mathrm{Al}$ & 3.2 \\
\hline $\mathrm{Cr}$ (Total) & 0.41 \\
\hline $\mathrm{Cr}(\mathrm{VI})$ & 0.002 \\
\hline $\mathrm{Ca}$ (Acid Dig) & 0.023 \\
\hline $\mathrm{Fe}$ & 0.028 \\
\hline $\mathrm{K}$ & 0.326 \\
\hline $\mathrm{Ni}$ & 0.015 \\
\hline $\mathrm{Zn}_{\mathrm{n}}$ & 0.002 \\
\hline $\mathrm{NO}_{3}$ & 11.7 \\
\hline $\mathrm{NO}_{2}^{-}$ & 10.5 \\
\hline $\mathrm{OH}^{-}$ & 2.47 \\
\hline TOC & 1.53 \\
\hline TIC & 0.63 \\
\hline $\mathrm{PO}_{4}^{3-}$ & 0.64 \\
\hline $\mathrm{SO}_{4}{ }^{2-}$ & 0.40 \\
\hline $\mathrm{Cl}^{-}$ & 0.79 \\
\hline F- & 0.03 \\
\hline $\mathrm{NH}_{3} / \mathrm{NH}_{4}{ }^{+}$ & 0.19 \\
\hline $\mathrm{Wt} \% \mathrm{H}_{2} \mathrm{O}$ (grav) & 35.5 \\
\hline \multicolumn{2}{|c|}{$\begin{array}{l}\text { a) From Herting (1992b) using weighing factors of } \\
28.2 \% \text { for composites } 1 \text { and } 2 \text { and } 21.8 \% \text { for } \\
\text { composites } 3 \text { and } 4 \text {. }\end{array}$} \\
\hline
\end{tabular}

double-shell tank wastes.] Information similar to what is presented here will be required for each tank that may be diluted for mitigation purposes, even for tanks that contain wastes similar to that in Tank 241-SY-101.

The kinetics of the solubility reactions in approaching equilibrium have been the topic of relatively few studies, yet they may play an important role in modeling the dilution, transport, and mitigation processes. Certain simplifications may be possible if equilibrium results can be directly used. If the solution/dissolution of the constituents occurs rapidly (compared with the time scales of the process), an equilibrium model may be applied for the time diluent is added. On the other extreme, when solution or dissolution occur very slowly (possibly the case for aluminum dissolution), 
the reagents may propagate through the dilution and transport process unreacted. In this case, an equilibrium model may be applied to the propagated constituents to estimate the behavior and characteristics of the waste after long periods of time.

The discussion in the remainder of this section focuses on the solubility of individual waste constituents. Where available, information is presented that gives the component's solubility as a function of temperature, its hydroxide concentration, and the concentration of other major constituents (nitrate, nitrite, etc.). These relations are useful in calculating how the waste containing these constituents will respond to dilution, temperature, and changes in the concentrations of other chemical constituents.

Although much of the solubility work (particularly with waste simulants) has focused on ranges of sodium hydroxide concentration and temperature that are higher than those of interest to dilution processes, this work provides-many useful results, particularly in the solubilities of sodium nitrate, sodium nitrite, and sodium carbonate, that make up a significant part of the solid phase. The solubilities of these components are relatively well characterized, and their effects can be predicted by current models.

In addition to the kinetics of dissolution, there are other aspects of aluminum solubility in waste that remain unresolved. Dilution with water will clearly precipitate aluminum hydroxides, which will transform to gibbsite. To what extent this will occur with more concentrated (e.g., $2 \underline{M}$ $\mathrm{NaOH}$ ) solutions is yet undetermined. An equilibrium model is now available that may be an effective tool for determining phase and chemical equilibria. This model incorporates much of the experimental work related to aluminum chemistry in tank wastes.

Many of the metal hydroxides and salts will not dissolve during dilution without a dramatic decrease in pH (e.g., acid washing). While some of the metals are found in both liquid and solid phases, the solubility of many of the metals in the waste is not currently documented. However, these metal compounds constitute a small fraction (less than $1 \mathrm{wt} \%$ ) of the total solids fraction.

\subsubsection{Nitrate Solubility}

Reynolds and Herting report solubilities of sodium nitrate as a function of hydroxide concentration, sodium nitrite concentration, sodium aluminate concentration and temperature (Reynolds and Herting 1984). These solubilities were obtained using waste simulants. The data were correlated for the temperature range from 60 to $100^{\circ} \mathrm{C}$, for hydroxide concentrations from 2.0 to $7.5 \mathrm{M}$, for nitrite concentrations from 2.0 to $7.0 \underline{\mathrm{M}}$, and for aluminate concentrations from $0.5 \underline{\mathrm{M}}$ to $1.7 \underline{\mathrm{M}}$.

The nitrate solubility data of Reynolds and Herting indicate that hydroxide concentration and temperature have a large influence on sodium nitrate solubility. The influence of other ionic concentrations can be significant as well, with the solubility of nitrate decreasing with increasing concentrations of the other ions. The effect of temperature on sodium nitrate solubility is shown in Table 5.2. The data are for $2 \underline{\mathrm{M}}$ sodium hydroxide solutions that are saturated with respect to sodium nitrite and sodium aluminate.

While these data describe solubilities at higher temperatures than those expected for the dilution process (current tank temperatures are approximately $50^{\circ} \mathrm{C}$, with a decrease in temperature expected following dilution), the current tank waste is approximately $2 \underline{M}$ in sodium hydroxide,and the expected diluent is $2 \underline{M}$ sodium hydroxide solution. Extrapolation of this data may give a reasonable estimate for solubilities near $50^{\circ} \mathrm{C}$ at ionic concentrations similar to those before and after the dilution process.

\subsubsection{Nitrite Solubility}

Reynolds and Herting also report solubilities of sodium nitrite as a function of hydroxide concentration, sodium nitrate concentration, sodium aluminate concentration, and temperature for 
Table 5.2. Solubility of Sodium Nitrate, Sodium Nitrite and Sodium Aluminate Solutions in Solutions Saturated in the Other Two Ions and at a Sodium Hydroxide Concentration of $2 \underline{M}$ (Reynolds and Herting 1984)

\begin{tabular}{|l|l|l|l|}
\hline Temperature $\left({ }^{\circ} \mathrm{C}\right)$ & $\mathrm{NaNO}_{3}(\underline{\mathrm{M}})$ & $\mathrm{NaNO}_{2}(\underline{\mathrm{M}})$ & $\mathrm{NaAlO}_{2}(\underline{\mathrm{M}})$ \\
\hline \hline 60 & 3.9 & 5.6 & 1.9 \\
\hline 80 & 4.9 & 6.7 & 1.5 \\
\hline 100 & 6.0 & 8.1 & 1.2 \\
\hline
\end{tabular}

nearly identical temperature and ionic concentration ranges. These show that, while sodium nitrite is more soluble than sodium nitrate, the solubility curves are very similar.

The effect of temperature on nitrite solubility is also given in Table 5.2 for solutions of $2 \underline{\mathrm{M}}$ sodium hydroxide. The solution here is saturated with respect to nitrate and aluminate. Comparisons with the nitrate solubility show that sodium nitrite is more soluble on a mole basis than sodium nitrate, but on a mass percent basis, their solubilities are similar.

\subsubsection{Carbonate Solubility}

Sodium carbonate solubility has been the subject of relatively few studies. Reynolds reports efforts to model solubility of sodium carbonate in high-ionic-strength solutions. (a) As with most other ions, the solubility of sodium carbonate was found to be lower in solutions of high ionic strength. Reynolds modeled the solubility using calculated activities in a solubility product model. The model gave reasonable estimates but consistently underpredicted carbonate precipitation when compared with laboratory data.

Herting and Buratto reported an investigation of sodium carbonate crystal hydrate formation in which, at total sodium $\left(\mathrm{Na}^{+}\right)$concentrations above $10 \mathrm{M}$ (at $\left.50^{\circ} \mathrm{C}\right)$, only anhydrous precipitate formed.(b) Below $10 \mathrm{M}$ sodium, a needle-like precipitate formed that was thought to be a monohydrate. Herting and Buratto also note that the anhydrous precipitate forms in water (without the presence of other ions) only at temperatures above $110^{\circ} \mathrm{C}$. Therefore, if the dilution results in precipitation of carbonate at total sodium concentrations below $10 \underline{\mathrm{M}}$ (or temperatures less than $50^{\circ} \mathrm{C}$ ), needle-like monohydrate crystals may form. It is not clear (from the information currently available) under what conditions polyhydrate crystal formation would be expected. In any case, further information is required to determine if carbonate precipitation (in particular, crystal hydrate formation) will significantly impact any mitigation effort.

\subsubsection{Aluminate Solubility}

Aluminum chemistry and the solubility of aluminum compounds in tank waste have been the subject of numerous investigations. This is due in part to the complexity of aluminum chemistry in caustic solutions. Also, the precipitates that arise when the concentrations exceed saturation are often troublesome, because they can form crystalline or gel material that can contribute significantly to pumping problems. Because of this, much effort has been focused on understanding the solubility of aluminum in Hanford wastes.

(a) Reynolds, D. A. January 8, 1990. Sodium Carbonate Anhydrous Solubility. Internal Memo 13314-90-002, to D. L. Herting, Westinghouse Hanford Company, Richland, Washington.

(b) Herting, D. L., and S. K. Buratto. November 21, 1985. Crystal Hydrate Identification. Internal Letter 65453-85-223, Rockwell International, Richland, Washington. 
The foundational work describing aluminum solubility in solutions similar to Hanford tank wastes was performed by Barney (1976). Barney showed that aluminum solubility in solutions saturated with nitrate, nitrite, sulfate and carbonate differ greatly from that of a sodium aluminate/water system. His data are presented in the solubility diagram of Figure 5.1. The solid lines are a fit of Barney's data; the dashed line indicates the solubility of a sodium aluminate/water system [from Vol'f and Kuznetsov (1955)]. The curve sloped upward (on the left side of the figure) defines the aluminate solubility at low sodium hydroxide concentrations. At concentrations of sodium aluminate higher than this curve and at sodium hydroxide concentrations lower than this curve, aluminum hydroxides (e.g., gibbsite, bayerite) precipitate. The curve sloped downward (at higher sodium hydroxide concentrations) indicates the solubility line where sodium aluminate precipitates.

Two observations can be made from Figure 5.1. First, in the presence of the other salts, the point of maximum solubility is shifted from about $6 \mathrm{M} \mathrm{NaOH}$ to about $2 \mathrm{M} \mathrm{NaOH}$, with a significant increase at the maximum solubility point (from about $3 \underline{\mathrm{M} \mathrm{NaAlO}} 2$ to more than $4 \underline{\mathrm{M}} \mathrm{NaAlO}_{2}$ ). This suggests that sodium aluminate will be more soluble in solutions containing higher concentrations of the other salts. Secondly, the waste currently in Tank 241-SY-101 is approximately $2 \mathrm{M}$ in $\mathrm{NaAlO}_{2}$ and $2 \underline{\mathrm{M}}$ in $\mathrm{NaOH}$. Dilution with water would occur along a line from the point at $2 \underline{\mathrm{M}} \mathrm{NaAlO}_{2}, 2 \underline{\mathrm{M}}$ $\mathrm{NaOH}$ back to the origin. This path would approach or surpass the aluminate saturation line, and precipitation of aluminum hydroxides would be expected. Moreover, this tendency is exaggerated by the effect of diluting the other ionic salts. The dilution of other ions shifts the solubility curves toward higher sodium hydroxide concentrations (toward the sodium aluminate/water system shown as dashed curves in Figure 5.1), resulting in a decreased solubility of aluminate for the diluted system. Therefore, a larger amount of precipitation would occur as a result of the dilution of other ions.

Dilution with a $2 \underline{\mathrm{M}} \mathrm{NaOH}$ solution would occur along a line from the $2 \mathrm{M}, 2 \mathrm{M}$ point to the $0 \underline{\mathrm{M} \mathrm{NaAlO}}, 2 \underline{\mathrm{M} \mathrm{NaOH}}$ point (along the abscissa of Figure 5.1). At first glance, this dilution would seem only to improve the solubility of aluminate as the dilution path departs from the saturation curve. However, including the effect of diluting other ions brings the saturation curve to higher hydroxide concentrations. While this dilution path results in a higher solubility of aluminate, aluminum hydroxide (gibbsite) precipitation may still occur.

Reynolds and Herting also considered the solubility of sodium aluminate in waste simulant studies. The fit of their data is shown in Figure 5.2. The lines of this figure indicate the solubility of aluminate in solutions saturated with sodium nitrate and sodium nitrite. Like the data for sodium nitrate and sodium nitrite, the range of sodium hydroxide concentration is higher (as is the temperature range) than what is of interest for the planned dilution processes, but trends near $2 \underline{\mathrm{M}}$ $\mathrm{NaOH}$ are worth noting.

First, as with the nitrate and nitrite, the solubility of sodium aluminate decreases with increasing hydroxide concentration (gibbsite precipitation is not considered). For the solution saturated with nitrate and nitrite, increases in temperature result in a decreased aluminate solubility. This behavior is the result of the strong temperature response to the solubility of sodium nitrate and nitrite in these temperature ranges.

From these results, a number of issues remained unresolved. The most important of these from the viewpoint of dilution is the aluminum chemistry and solubility at low hydroxide concentration, particularly at low to moderate temperature. Reynolds gives an overview of typical aluminum reactions that may occur in the waste.(a) He suggests that only three aluminum hydroxides are likely to occur under tank conditions. The first is amorphous, which is transformed to a bayerite

(a) Reynolds, D. A. October 26, 1984. Current Knowledge of Gibbsite. Internal Letter 65611-84196, Rockwell International, Richland, Washington (later published as SD-WM-TI-211, Rockwell Hanford Operations, 1986). 


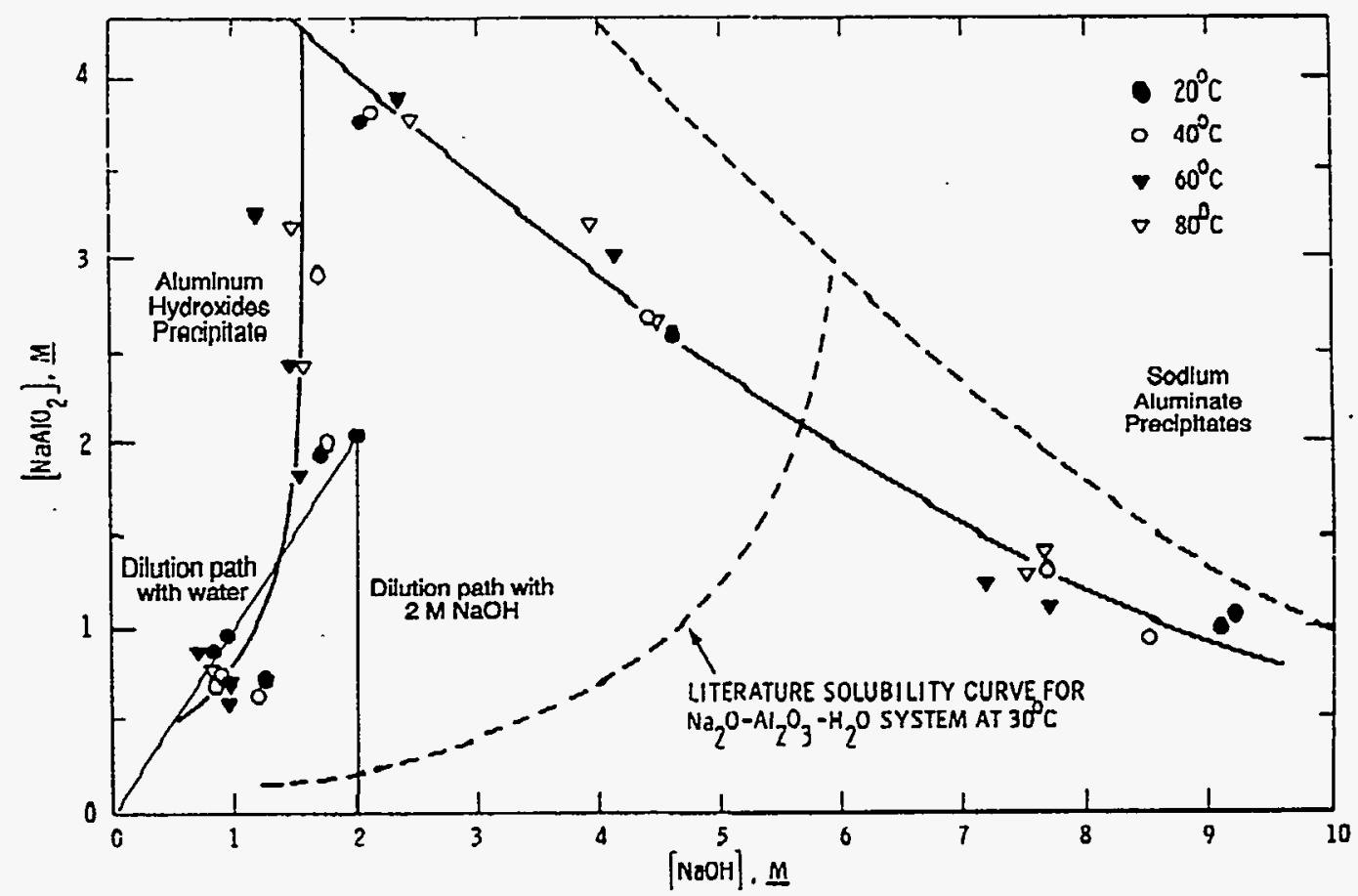

Figure 5.1. Solubility of Sodium Aluminate in Solutions Saturated with $\mathrm{NaNO}_{3}, \mathrm{NaNO}_{2}, \mathrm{Na}_{2} \mathrm{SO}_{4}$ and $\mathrm{Na}_{2} \mathrm{CO}_{3}$ [modified from Barney (1976)]

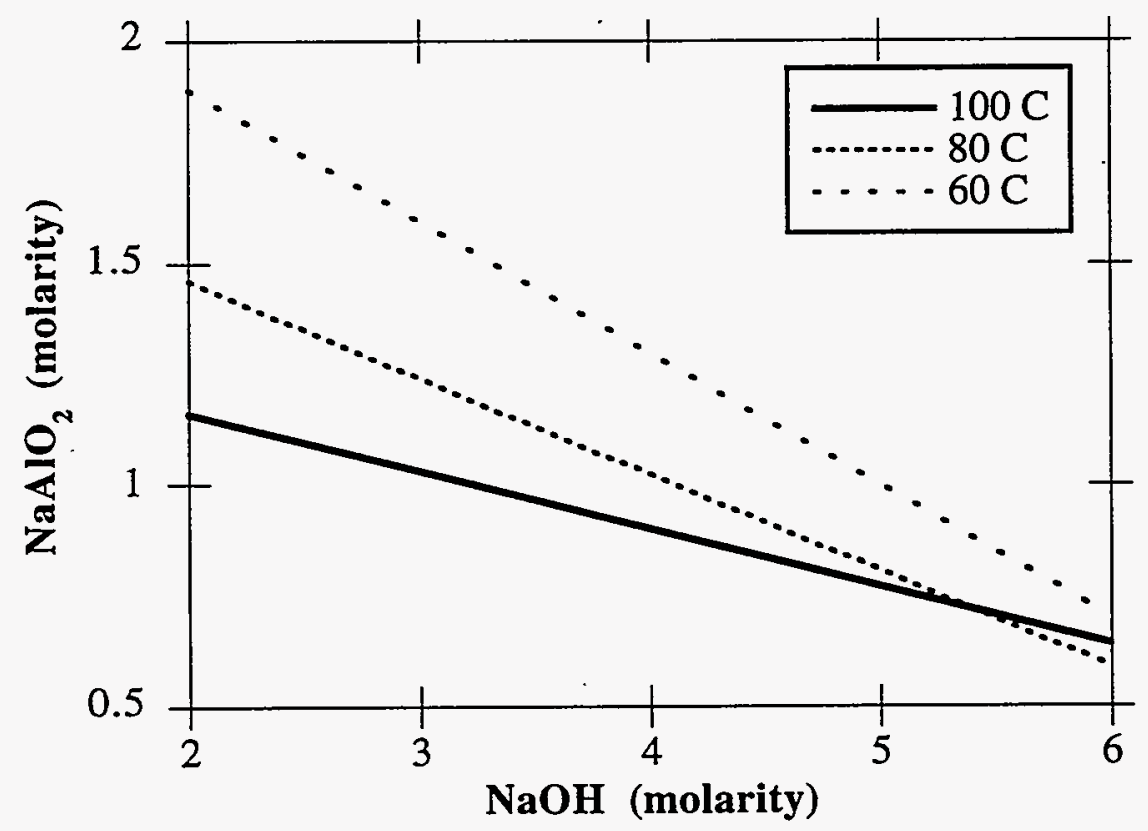

Figure 5.2. Solubility of Sodium Aluminate in Waste Simulant [modified from Reynolds and Herting (1984)] 
phase within a few days. Final transformation to gibbsite may take up to several months. In addition, Reynolds suggests that aluminum complexes could be formed with fluoride, sulfate, and other ions, but Herting and Cleavenger found that fluoride concentration had no significant effect on gibbsite solubility.

The kinetics of solution and dissolution of the aluminum hydroxides may also play an important role in determining practical solubilities. While precipitation may occur rather slowly (perhaps over weeks or months), the time required to re-dissolve the aluminum may be much longer, even at relatively high caustic concentrations.

\subsubsection{Solubility of Metal Salts and Hydroxides}

The solids of the waste in Tank 241-SY-101 contain measurable amounts of iron, chromium, potassium, and nickel in addition to the aluminum mentioned above. Some of these, such as iron and nickel, exist in metal hydroxides that are relatively insoluble within a large range of $\mathrm{pH}$. Moderate dilution, therefore, will not significantly decrease the solids content of these metals. Other metals, such at potassium and zinc, are found in both solid and liquid phases. The solubilities of several of the metals (including the radionuclides) are currently undocumented; however, work is currently in progress at Pacific Northwest Laboratory to characterize chromium solubility in these solutions.

\subsubsection{Equilibrium Modeling}

In recent work by D. A. Reynolds and D. L. Herting of WHC, much of the previous data generated in the aluminum solubility work have been integrated into a commercially available software called ESP®. This software provides an equilibrium model into which tank waste components may be entered. The software uses a large database to determine the thermodynamic equilibrium state and produces estimates for chemical and phase equilibria. Its use at the Hanford Site is currently under a site-wide license.

Reynolds has recently applied this model to dilution processes in which he considered the dilution of tank waste as reported by Herting with dilutions of $0: 1,0.25: 1,0.5: 1,0.75: 1$ and $1: 1$ (water:waste).(a) The model indicated that a large portion of the solids consisted of sodium nitrate and sodium carbonate salts, which readily dissolve in water. Certain solids (such as the iron hydroxides) did not dissolve even at higher dilution ratios. The model did indicate gibbsite precipitation, an indication consistent with the aluminate solubility discussion above.

\subsubsection{Rheological and Physical Properties}

Rheological studies were performed on the (undiluted) 1991 samples(b). These indicated that the crust had a significant shear strength $\left(\sim 50 \mathrm{kdynes} / \mathrm{cm}^{2}\right.$ at $\left.50^{\circ} \mathrm{C}\right)$ which decreases with temperature. The crust samples also demonstrated shear thinning behavior, although no viscosity measurements were reported. Samples from the predominantly liquid layer exhibited Newtonian behavior with viscosities below $30 \mathrm{cP}$ at $50^{\circ} \mathrm{C}$. Like the crust, the settled slurry layer segment samples demonstrated a temperature-dependent shear strength (up to $30 \mathrm{kdynes} / \mathrm{cm}^{2}$ at $50^{\circ} \mathrm{C}$ ). Viscosity measurements at low shear rates were as high as $10^{6} \mathrm{cP}$ at $50^{\circ} \mathrm{C}$. At high shear $\left(>500 \mathrm{sec}^{-1}\right)$, the viscosity (at $\left.50^{\circ} \mathrm{C}\right)$ was

(a) Memo, D. A. Reynolds to N. W. Kirch. April 29, 1994. Chemical Modeling for Dilution of 241SY-101. Internal Memo 7E310-94-021, Westinghouse Hanford Company, Richland, Washington.

(b) Tingey, J. M. 1992. Rheological Properties of Waste from Tank 101-SY. Letter Report, Pacific Northwest Laboratory, Richland, Washington. 
approximately $250 \mathrm{cP}$. Analytical expressions for these data have been used in thermal hydraulics modelsa.

The shear strength of all samples with significant solids content displays a strong shear history dependence, such that an irreversible decrease in the yield stress occurs once the sample experiences high shear forces(b). This behavior is thought to be the result of changing the surface characteristics of the particulate. The result is that even after samples remain undisturbed for two years, the high shear strength behavior is not regained.

\subsubsection{Viscosity and Shear Strength}

The effects of dilution on waste rheology were studiedc. They report yield stresses and apparent viscosities (at shear rates of $400 \mathrm{sec}^{-1}$ ) of the mixed slurry for dilution in the range from 0:1 to $1: 1$ for temperatures of 50,70 and $90^{\circ} \mathrm{C}$. As expected, the yield stress shown in Figure 5.3 decreases with dilution and increased temperature. At dilution rates higher than $0.2: 1$, temperature effects are not significant. One caveat is worth noting. These data are for the yield points of the mixed slurry which includes the supernatant liquid, not for the settled slurry alone. Therefore, their application to design of mixer pumps and transfer processes (where the settled slurry and the supernatant liquid are sufficiently mixed) is appropriate, whereas their application to the rheology of settled slurries (e.g., gas retention) is inappropriate.

Tingey et al. used a composite sample from the settled slurry (nonconvective) layer. Because the recent pump operations have mixed the larger layers of the waste, the settled slurry layer has effectively been diluted 1:1 with the predominantly liquid (convective) layer. Therefore, a significantly lower dilution ratio may be required to achieve a given yield point compared with that indicated by Figure 5.3.

Effects of dilution and temperature on viscosity of the mixed slurry according to Tingey are shown in Figure 5.4. A significant decrease in the viscosity was also observed with dilution, with a particularly large decrease between 11 and $25 \%$ (particularly at $50^{\circ} \mathrm{C}$ ). Once again, the temperature effects are insignificant at high dilution rates. (A caveat as above applies to the application of these data.)

\subsubsection{Density}

Measurements taken of both Window C and E samples show that the density of Tank 241-SY101 waste is fairly insensitive to temperature within the range of 50 to $90^{\circ} \mathrm{C}$. Window $\mathrm{C}$ measurements by Tingey place the predominantly liquid convective layer, the nonconvective layer, and sludge layer densities as: $1.49,1.68$, and $1.71 \mathrm{~g} / \mathrm{mL}$, respectively(d). The supernatant liquid density was reported to be $1.46 \mathrm{~g} / \mathrm{mL}$, while the centrifuged solids had a density of $1.81 \mathrm{~g} / \mathrm{mL}$. Supernatant liquid and solids densities for Window E were reported as 1.51 and $1.78 \mathrm{~g} / \mathrm{mL}$.

(a) Mahoney, L. A. and D. S. Trent. 1994. A Summary of Progress in the Compilation of Models for Physical Processes Present in Waste Tank Sludges. Draft Report, Pacific Northwest Laboratory, Richland, Washington

(b) Tingey, J. M., P. R. Bredt and E. H. Shade. 1994. The Effects of Heating and Dilution on the Rheological and Physical Properties of Tank 241-SY-101 Waste. Draft Report, Pacific Northwest Laboratory, Richland, Washington

(c) Ibid.

(d) Tingey, J. M. 1992. Physical Characterization of Tank 101-SY Core Samples from Window C. Letter Report, Pacific Northwest Laboratory, Richland, Washington 


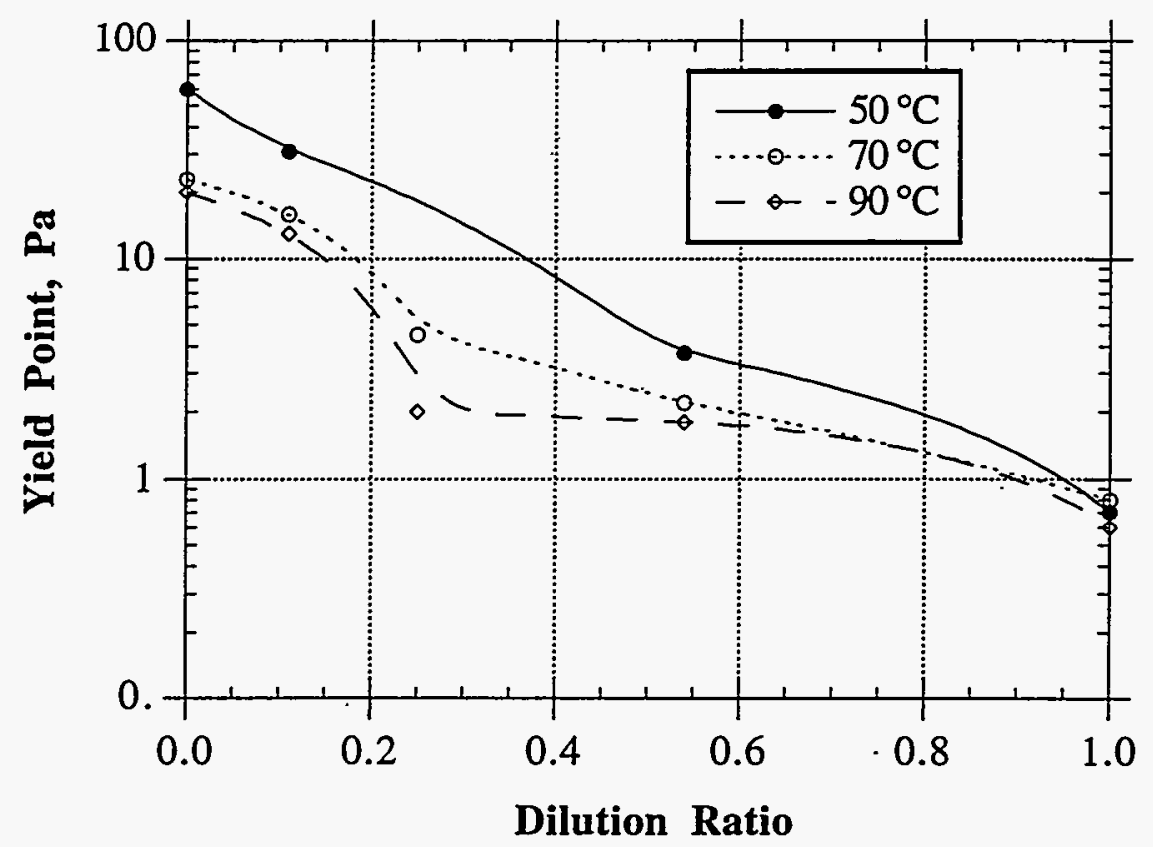

Figure 5.3. Effect of Dilution on Yield Point of Mixed Slurry

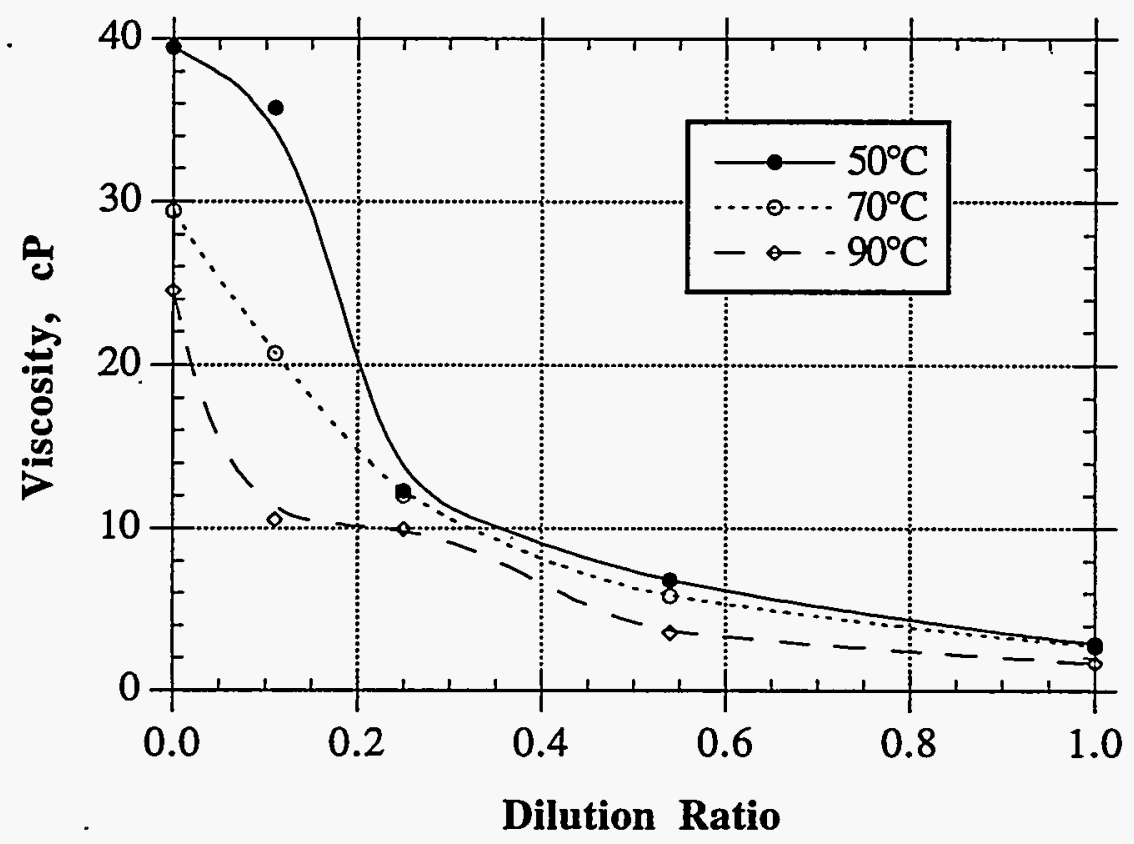

Figure 5.4. Effect of Dilution on Viscosity of Mixed Slurry 
The densities reported by Herting et al. (1992b) are comparable to those of Tingey and are included along with other physical property data in Table 5.3. Reynolds recommended densities for the stratified waste layers which were based on averages over the temperature range. A density of $1.49 \mathrm{~g} / \mathrm{mL}$ for the convective layer, $1.69 \mathrm{~g} / \mathrm{mL}$ for nonconvective layer, and $1.46 \mathrm{~g} / \mathrm{mL}$ for the supernatant (Reynolds 1993).

The effect of dilution on the density of waste samples was studied by Tingey, Herting et al. (1992a, 1992b), and Bredt(a). In these tests, samples were diluted with $2 \underline{\mathrm{M}} \mathrm{NaOH}$ solution in the range from $0: 1$ to $3: 1$. The resulting supernatant liquid densities are presented in Figure 5.5. The density of the liquid continues to decrease with further dilution, indicating that dilution does not continually remove solids from the slurry. That is, if dilution had continued to dissolve solids or had the solids been readily soluble, the density of the liquid would have remained more nearly constant over some range of dilution.

With the supernatant liquid removed, Tingey measured the density of the settled slurry. A mass balance may be used to infer this information from Bredt's data. Herting et al. report the density of the centrifuged (but not filtered) solids; these are taken to be comparable to the slurry which settles after long times. These data are presented in Figure 5.6. These indicate that the density of the settled slurry also decreases with dilution. This is likely due to less efficient packing of the solids (possibly due to dissolution of smaller particles), which results in a larger volume of interstitial fluid.

\subsubsection{Solids Content and Dissolution}

While Tingey's Window $\mathrm{C}$ measurements indicated that the solids content was not affected by temperature, his Window $\mathrm{E}$ measurements showed a clear dependence on temperature. Because neither the density of the supernatant nor that of the solids alone were temperature dependent, it was presumed that solubility effects were responsible for the observed changes.

The fraction of centrifuged solids in the Window $E$ supernatant liquid ranged from 21 to $44 \mathrm{vol} \%$ and 24 to $47 \mathrm{wt} \%$. For the settled slurry, the centrifuged solids ranged from 33 to 78 vol\% and 37 to $80 \mathrm{wt} \%$. The wide range in the percent centrifuged solids for the nonconvective slurry was a function of both depth in tank and temperature.

Table 5.3. Physical Properties of Window C Samples from Herting

\begin{tabular}{||l|l|l|l||}
\hline \hline Property $\left(50^{\circ} \mathrm{C}\right)$ & Settled Slurry & $\begin{array}{l}\text { Predominantly } \\
\text { Liquid Layer }\end{array}$ & Sludge \\
\hline \hline Density - Bulk (g/mL) & 1.74 & 1.48 & 1.70 \\
\hline Density - liquid & 1.44 & 1.43 & 1.53 \\
\hline Density - solids & 2.03 & 2.16 & 1.79 \\
\hline wt\% (solids/total) & 72 & 10 & 68 \\
\hline wt\% water & 31.4 & 38.9 & 28.5 \\
\hline
\end{tabular}

(a) Memo, P. R. Bredt to C. W. Stewart. July 25, 1994. 101-SY Dilution Studies. Pacific Northwest Laboratory, Richland, Washington. 


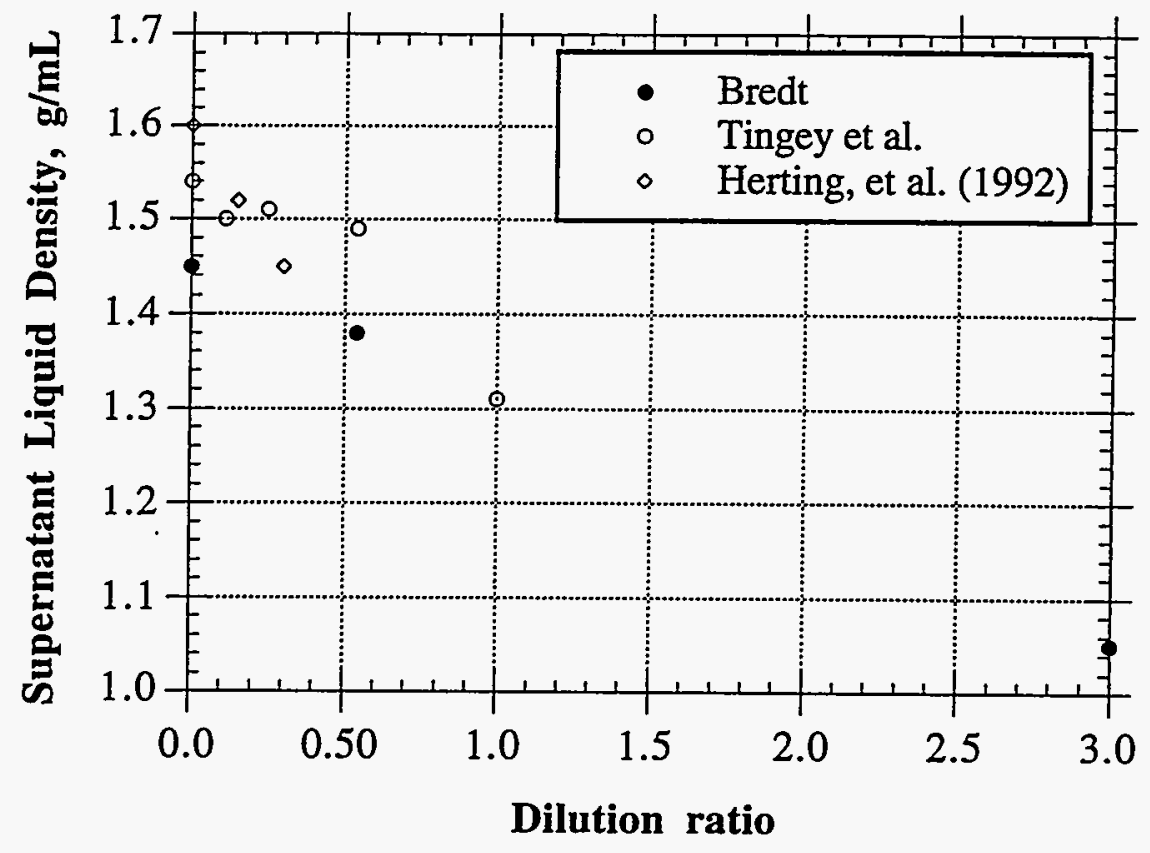

Figure 5.5. Supernatant Liquid Density as a Function of Dilution (at $50^{\circ} \mathrm{C}$ )

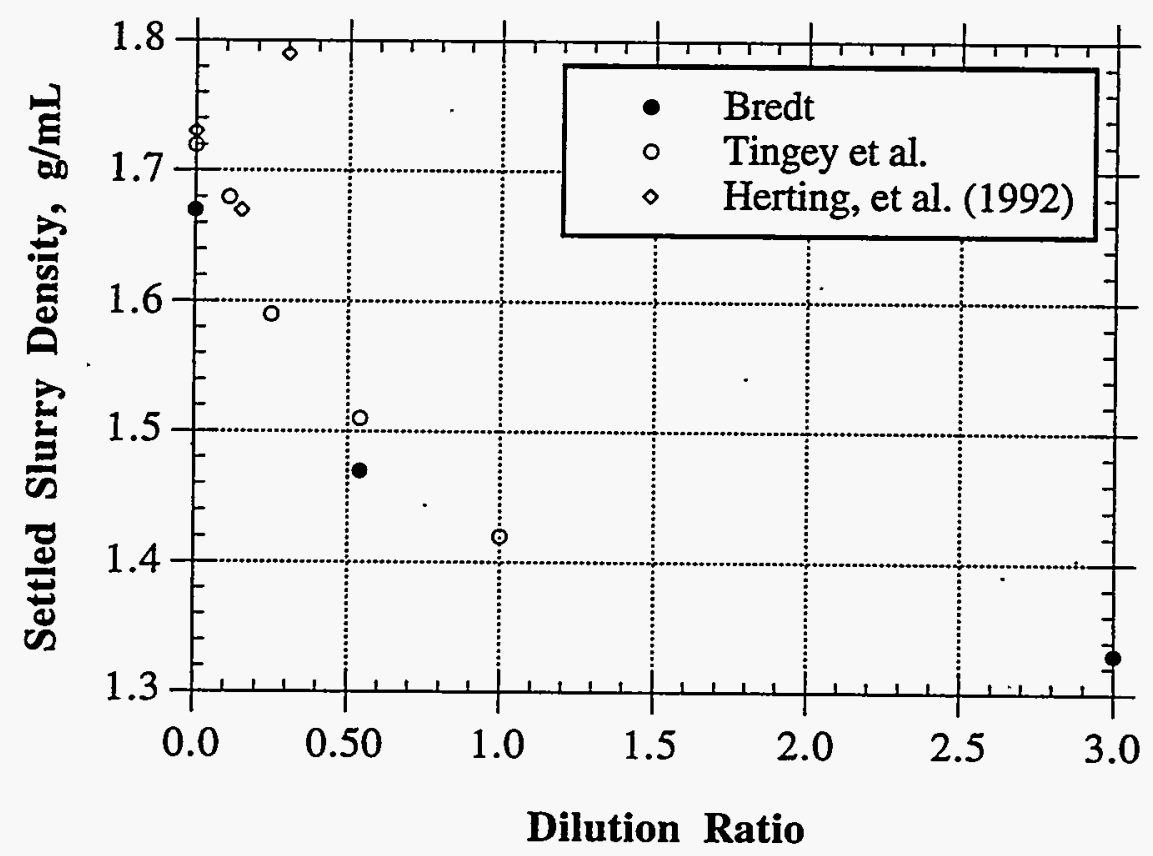

Figure 5.6. Settled Slurry Density as a Function of Dilution (at $50^{\circ} \mathrm{C}$ ) [Bredt's data were calculated from a mass balance; data of Herting et al. are from centrifuged (but not filtered) slurry] 
The effect of dilution on solids content was considered by Tingey and Bredt. These data are presented as wt\% filtered solids in Figure 5.7. Tingey's data are consistently much higher than Bredt's, probably due to the difference in the separation process. Bredt obtained filtered solids using one hour of centrifugation at $1000 \mathrm{~g}$; Tingey used only a few minutes. If we assume that the true density of the solids and liquid are given by Bredt's data (consistent with those of Herting in Table 5.1), then we can compute actual solids fraction of Tingey's solids and liquid and add the resulting true solids fractions to obtain corrected values. These are shown as the open diamond in Figure 5.7.

These data indicate that dissolution significantly reduces solids content at relatively high dilution ratios. The increase in solids fraction in the range (of dilution ratios) from $0.1: 1$ to $0.25: 1$ in the data of Tingey suggest a transition region where dissolved solids form another precipitate. In fact, the point at 0.25:1 dilution suggests a net precipitation. The data of Herting et al. (1992) at $0.15: 1$ and $0.30: 1$ dilution seem to corroborate the transition behavior. Beyond 0.5:1 dilution, solids dissolution appears monotonic.

The mass dissolution fraction, defined as the reduction in weight of solids after dilution divided by the initial weight of solids before dilution, is given by

$$
\frac{\Delta \mathrm{M}_{\mathrm{SD}}}{\mathrm{M}_{\mathrm{S} 0}}=1-\frac{\mathrm{w}_{\mathrm{D}}}{\mathrm{w}_{0}}\left(1+\frac{\rho_{\mathrm{D}} \mathrm{D}}{\rho_{\mathrm{B} 0}}\right)
$$

where $w_{D}$ and $w_{0}$ are the solids weight fractions (corrected) after dilution and before dilution, $\rho_{D}$ is the density of the diluent, $\rho_{\mathrm{B} O}$ is the initial bulk density, and $\mathrm{D}$ is the volume dilution ratio (equal to the volume of diluent divided by the initial waste volume). The dissolution is shown versus dilution ratio in Figure 5.8. Note that dissolution is not complete, even at 3:1 dilution. The curve fit given on the figure is to Bredt's data, ignoring the details of possible precipitation in the $0: 1$ to $0.25: 1$ dilution range.

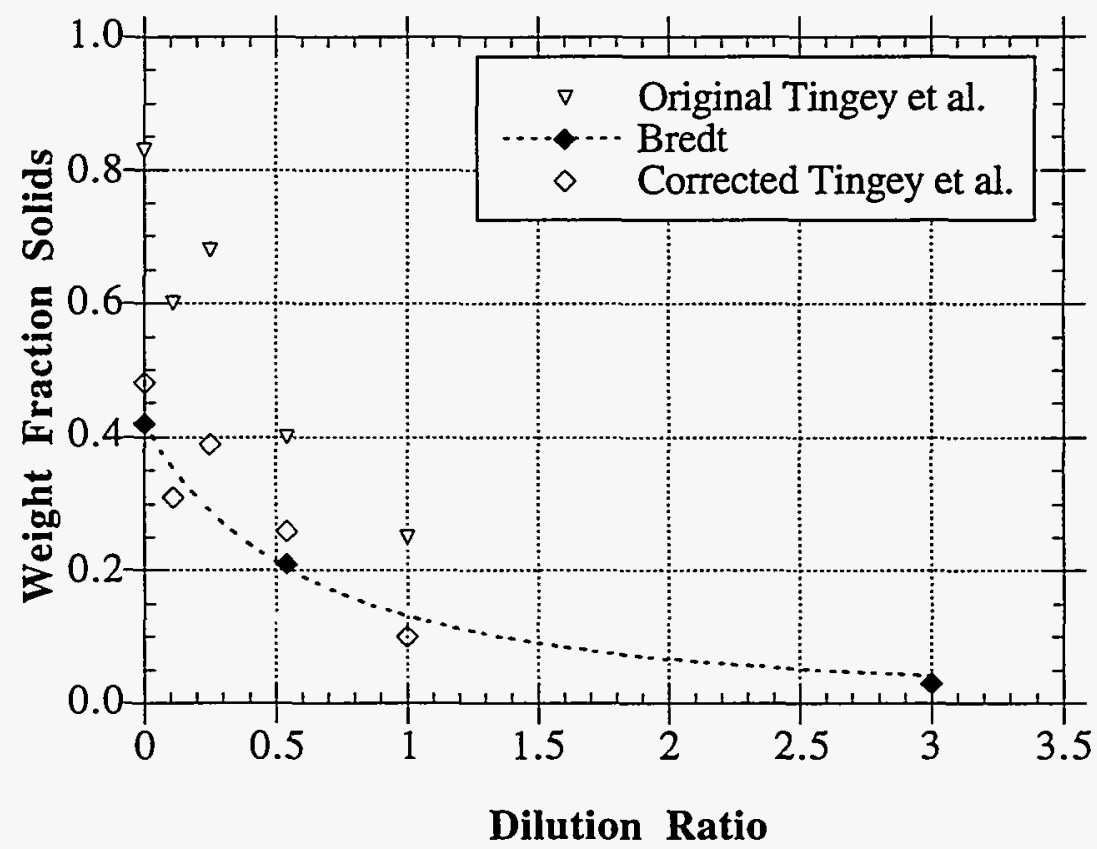

Figure 5.7. Effect of Dilution on Weight of Filtered Solids (at $50^{\circ} \mathrm{C}$ ) 


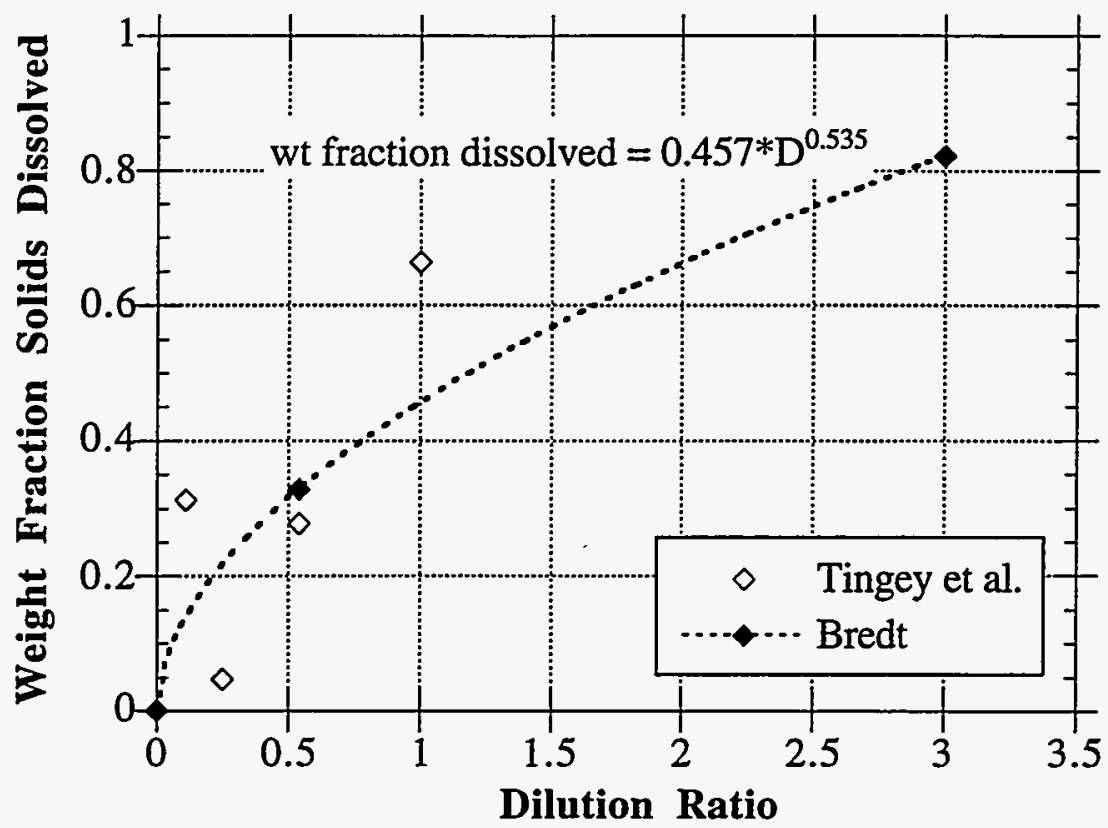

Figure 5.8. Dissolution Fraction as Function of Dilution Ratio (at $50^{\circ} \mathrm{C}$ )

Tingey and Bredt also give the volume fraction of the settled slurry which results when the diluted waste remains undisturbed for several days (Tingey allowed three days settling, while Bredt allowed 18 days). This is determined by the height of the interface between supernatant liquid and settled solids. When normalized by the total height (of the settled slurry and the supernatant liquid), this gives a normalized settled slurry height that relates the height of the settled slurry (after dilution) to the original slurry height. These data are presented in Figure 5.9. As diluent is added, the packing fraction of the solids apparently decreases, and the settled solids height actually increases. This continues until between $0.5: 1$ and $1: 1$ dilution, where the settled slurry height decreases dramatically. At 1:1 dilution, the height is only $60 \%$ of the original height and less than half the height at $0.5: 1$ dilution. At higher dilution the settle slurry heights tends to decrease (due to solids dissolution) to a minimum slurry containing insoluble solids.

Again, Tingey (and Bredt) used composite samples from the settled slurry layer, not whole tank composite samples (as did Herting). The current waste condition is therefore diluted (approximately 1:1) from the samples these studies used. Thus, the data will overpredict the dilution required to achieve these physical properties.

\subsubsection{Tank Behavior Relating to Dilution}

The behavior of certain tanks provides some evidence that dilution may destroy or greatly reduce the ability of settled solids to retain gas. None of the flammable gas tanks with an average waste specific gravity under 1.35, show waste level growth indicative of GRE behavior.(a) This result

(a) Brager, H. R. 1994. Summary of Information on Flammable Gas Watch List Tanks (Draft). Westinghouse Hanford Company, Richland, Washington. 


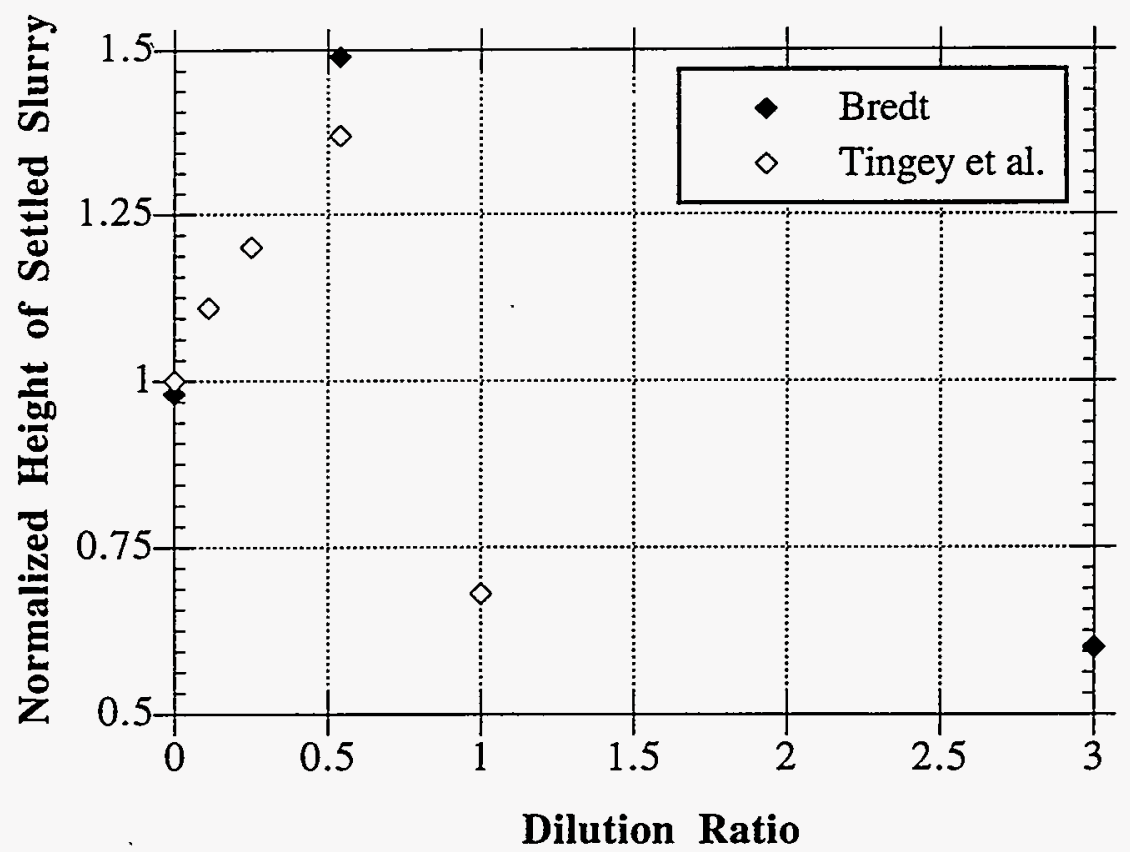

Figure 5.9. Effect of Dilution on Settled Slurry Height

is shown in Figure 5.10. The tanks exhibiting level growth are marked with ' $\mathrm{X}$.' In the case of Tank 241-SY-101, which has a specific gravity of 1.65 , about $0.5: 1$ dilution would be required for mitigation if this observation holds true. Approximately 0.35:1 dilution would mitigate 103-SY.

But there are essentially no data available on the actual contents of tanks to explain or confirm this observation. Even the specific gravity itself is estimated from the fill history no recent core samples are available to give depth, density, rheology, or chemical composition of various layers that might exist there. This information is necessary to determine why the low specific gravity tanks apparently do not experience episodic GREs and whether reducing a tank's specific gravity by dilution would eliminate GRE behavior. Furthermore, not all tanks with specific gravities above 1.35 show level growth.

The reason for the apparent 1.35 specific gravity threshold may be a change in particle shape such that the settled solids cease to be cohesive. The sudden and large decrease in settled solids volume observed in dilution tests on Tank 241-SY-101 core samples may be evidence of this (see Figure 5.9). It is interesting that the decrease in Tank 241-SY-101 settled solids volume occurs at about $0.5: 1$ dilution. This is exactly the amount required to bring the bulk specific gravity down to 1.35. It may be that larger particles are being held apart by much smaller ones or by an amorphous gel. When either dissolves, the large particles are allowed to fall together much more closely. Alternatively, beyond a certain dilution ratio a highly dendritic crystal structure may be dissolving allowing the undissolved fraction to fall together. Either of these changes might also break interparticle bonds and destroy gas retention ability. 


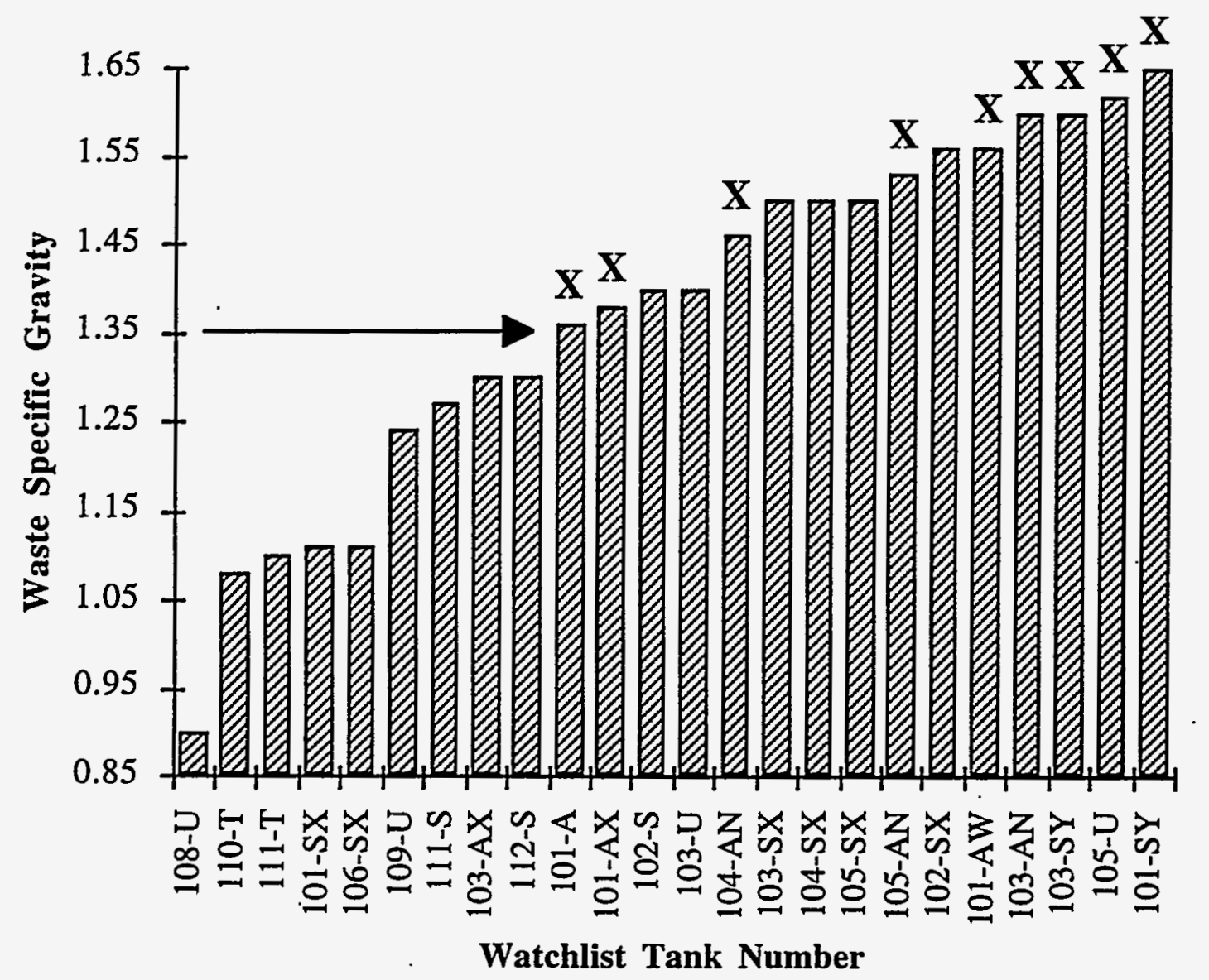

Figure 5.10. Specific Gravities of Flammable Gas Tanks

Recent studies of bubble growth and morphology in a stagnant sludge may also relate to the sensitivity of tank behavior to average density.(a) A gas bubble trapped in a liquid-solid matrix takes a spheroidal shape if it can push solid particles aside as it grows. If the weight of the particle column exceeds the outward force of surface tension, the bubble can only grow by extending through the spaces between particles and it assumes a dendritic form. The relative magnitude of gravitational forces to surface tension varies with depth and can be scaled with the dimensionless Bond number

$$
\text { Bo }=\frac{\left(\rho_{s}-\rho_{L}\right) \operatorname{Rhg}}{2 \sigma}
$$

where the $\rho_{\mathrm{s}}$ is the solids density, $\rho_{\mathrm{L}}$ is the liquid density, $\mathrm{h}$ is the depth into the sludge, $\mathrm{g}$ is the gravitational acceleration, $\sigma$ is the surface tension, and $R$ is the maximum curvature radius of the bubble, which is approximately the particle diameter. For $B o<1$, surface tension dominates and bubbles can displace solid particles. For Bo $>1$, gravity dominates and dendritic bubbles form.

(a) Gauglitz, P. A., and L. A. Mahoney. April 1994. An Improved Bubble Release Theory. Letter report, Pacific Northwest Laboratory, Richland, Washington. 
It is clear that spheroidal bubbles will tend to exist near the top of the sludge and dendritic bubbles will begin at some depth, depending on waste properties. More interestingly, experiments with bubbles growing in sugar water in a sand bed showed that a large horizontal fracture formed at the boundary between spheroidal and dendritic bubble regimes. These extended across the entire vessel for all containers tested from 2.5 to $16 \mathrm{~cm}$ diameter. Bond number scaling via equation $(5.1)$ matched the experimental conditions to a height of about 15 feet of Tank 241-SY-101 sludge, which was typically 16 feet thick prior to mixer pump operation.

It is possible that episodic gas release behavior is triggered by this kind of fracture zone in the tank. In this case, a lower average tank specific gravity would indicate a sludge layer too shallow to form dendritic bubbles and the characteristic fracture zone. With sufficient depth and solid-to-liquid density difference to make $B O=1$, a fracture could form and create GRE behavior. Tank 241-SY101 certainly satisfies the Bond number criterion and has a dramatic GRE history.

However, it is impossible to check this theory on other tanks at this time because nothing is known about the depth of the sludge layers, particle sizes, or even the material densities. Continuing core sampling or the in-tank assays planned with the newly developed ball viscometer(a) and void fraction measurement device(b) should help provide this important information.

\subsection{Mitigation By Dilution}

It is difficult to discuss dilution separate from transfer. Many of the tanks that potentially require mitigation are relatively full, and some waste must be moved to another tank to make room for dilution. At the same time, transfer for any reason will probably require some dilution to meet the pipeline requirements. However, we begin by discussing dilution as an independent mitigation method, saving transfer aspects for Section 5.3.

Although the available data and current state of knowledge summarized in Section 5.1 above are not complete, they are probably sufficient to describe the basic effects of dilution on Tank 241SY-101 waste. We can estimate the changes in yield strength, viscosity, liquid and solid densities, undissolved solids fraction, and possibly composition with increasing dilution. But this information is not sufficient by itself to determine how much dilution is necessary for mitigation or whether mitigation can be achieved by dilution at all.

\subsubsection{Dilution and Gas Retention}

The data clearly show that a substantial fraction of the solids do not dissolve, even at very high dilution ratios (refer back to Figures 5.9 and 5.10). Unless the undissolved solid material is kept in suspension by mechanical mixing, it will eventually settle out of the diluted slurry to form a nonconvective sludge layer. If this layer is able to retain gas, periodic release events are still possible. Dilution does not mitigate unless it eliminates the ability of the sludge to retain gas or reduces its volume to the point that potential gas releases cease to be a flammability hazard. This cannot be proved from existing data.

The sludge will retain gas if the solid-liquid matrix has at least sufficient strength to prevent bubbles from rising through it. The strength required to hold a single spherical bubble can be

(a) Shepard, C. L., J. B. Colson, K. O. Pasamehmetoglu, C. Unal, J. H. Edwards, and J. Abbott. January 1993. Theory of Operation for the Ball Rheometer. Letter report MIT-012694, Pacific Northwest Laboratory, Richland, Washington.

(b) Alzheimer, J. M., C. Unal, P. A. Meyer, W. Kubic, K. O. Pasamehmetoglu, and T. I. Stokes. June 1994. Void Fraction Measurement Device Theory of Operation. Letter report MIT-061794, Pacific Northwest Laboratory, Richland, Washington. 
estimated by balancing buoyancy against shear and normal forces. The required yield strength, $S$, is proportional to the bubble radius and sludge density and is given by

$$
S=\operatorname{Crg} \rho_{\mathrm{SL}}
$$

where $\mathrm{C}$ is a constant of order unity.

There have been no measurements of the evolving bubble size distribution in typical tank waste. But because bubbles are formed at individual nucleation sites in the waste, they are initially very small, and diameters of 100 microns to $1 \mathrm{~mm}$ would not be unreasonable. With a sludge density of $1,700 \mathrm{~kg} / \mathrm{m}^{3}$, a 100 -micron-diameter bubble can be held with approximately $1 \mathrm{~Pa}$ yield strength, and a $1 \mathrm{~mm}$ bubble by $10 \mathrm{~Pa}$. The yield point data in Figure 5.5, imply that over $0.8: 1$ dilution would be required to prevent retention of bubbles larger than 100 microns and $0.4: 1$ dilution would allow 1-mm bubbles to rise.

But these strength measurements do not represent a settled sludge layer. They were made on a fully mixed dilution sample, not the settled solids. This represents the properties of a diluted tank agitated by a mixer pump. There have been no rheological studies to date on the solids that settle out of a dilution, but the yield strength would almost certainly be higher than the initial slurry. It may be that quite large dilutions are necessary reduce the sludge yield strength sufficiently to free the smallest bubbles. Further studies focusing on the effects of dilution on gas retention in tank waste samples are necessary to quantify this.

\subsubsection{Potential Effect of Dilution on Gas Release Events}

It is very important that the effects of dilution be well understood beforehand because there are some potential adverse consequences. First, dilution increases the volume of radioactive waste that must be dealt with eventually. This is simply a fact that must be weighed in any decision to dilute. But, unless dilution eliminates or greatly reduces gas retention, addition of liquid to a tank actually tends to increase the potential volume of episodic gas releases and decrease the tank head space, making flammable concentrations a more likely result.

Adding diluent to a tank tends to increase the mass of gas stored at neutral buoyancy. The increased waste depth after dilution raises the average hydrostatic pressure in the sludge. This compresses the gas and increases the stored mass. When the lighter diluent is mixed with the waste, it decreases the density of the supernatant liquid that forms above the settled sludge (but also decreases the sludge density slightly). This increases the in-situ gas volume fraction required for neutral buoyancy. A simple model for these effects is derived in Appendix $F$.

The results indicate that a $0.3: 1$ ( $3 \mathrm{~mL}$ of diluent added to $10 \mathrm{~mL}$ of waste) might increase the volume of a GRE by $20-25 \%$. Reynolds (1993) obtained similar results in calculating the effects of a $0.10: 1$ dilution in Tank 241-SY-101. Also, a rollover requires a significant amount of liquid to allow a large volume of buoyant sludge to rise and release its trapped gas in a single event. Thus adding liquid to a relatively dry tank may actually launch GRE behavior.

\subsubsection{Diluent Mixing}

Mixing is necessary to effect dilution. The diluent is much less dense than liquid waste and will tend to rise to form a stratified layer on the surface, even when injected at the tank bottom. This prevents the diluent from dissolving the sludge as necessary for mitigation. It is difficult to conceive that diluent could be brought into intimate contact with solids in the lower layers of sludge without reasonably aggressive mixing. Mixing similar to that being provided by the pump in Tank 241-SY101 would seem necessary for the effective injection of diluent. 
An initial analysis of diluent mixing into Tank 103-SY was performed with the TEMPEST computer code (Trent and Eyler 1993). Only hydrodynamic mixing was modeled; dissolution/precipitation were ignored. The results showed that simply injecting diluent, even near the bottom of a tank, will almost certainly create a stratified layer on the surface with almost no mixing with the sludge at the lower levels. (One advantage of this behavior, however, is that the diluent will be in direct contact with the crust and may be able to dissolve most of it before mixing.) The current mixer pump with mid-level suction was able to mix the stratified diluent with the rest of the tank. Results of the Full Scale test program (Stewart et al. 1994) confirmed that the Tank 241-SY-101 mixer pump is capable of lifting solids to the top of the convective layer when operating at nearly full power. Recirculating waste through a small transfer pump with in-line diluent injection would mix the solids and diluent very effectively. However, this requires that the settled sludge first be mobilized, and some kind of large-scale mixing is necessary to do this.

The rollover motion of a 'natural' gas release event should not be considered as a means to reverse diluent stratification. From the results above, the first rollover following dilution could be much larger than prior events. This would improve mixing but would also increase the potential hazard. Tank 241-SY-101 has had by far the most violent rollovers, but early mixer pump test results showed that even intermittent mixer pump operation mixed the waste more effectively than the preceding large GRE (Allemann et al. 1993): Finally, it would simply not be prudent to depend on large GREs to initiate a program intended to prevent them.

\subsection{Transfer and Dilution}

In Section 5.2, addition of liquid was shown to have some potential adverse effects on GRE behavior. On the other hand, removing material by transferring waste to another tank has some very positive results independent of dilution. Transfer decreases potential GRE volume by removing solids that can form gas-retaining sludge while reducing the average hydrostatic pressure in the sludge. At the same time, it increases the head space in the tank making flammable gas concentrations less likely. Removing only $10 \%$ of the waste from Tank 241-SY-101 could reduce the potential GRE volume by $20 \%$ and cut the resulting dome hydrogen concentration in half. Any potentially adverse effects of the dilution necessary for transfer are easily balanced by the beneficial effects of drawdown.

Combined, these three factors make transfer an effective method to alleviate, if not to truly mitigate, flammable gas tanks like Tank 241-SY-101. By removing about $30 \%$ of the waste from Tank 241-SY-101, it is possible to reduce potential dome hydrogen concentration during GREs to below the LFL. This may not meet all the requirements for mitigation because episodic gas releases still occur, and hydrogen concentrations can exceed the accepted limit of $25 \%$ of the LFL, but the hazard is certainly reduced, and the reduction is achieved passively.

\subsubsection{Dilution and Transfer System for Tank 241-SY-101 to 101-SN}

This section describes a system designed specifically to transfer waste from Tank 241-SY-101 to a new tank, 241-SN-101, perhaps a mile away. A dilution system concept was developed during conceptual design of Initial Tank Retrieval Systems Project W-211.(a) This system will support dilution of Tank 241-SY-101 waste for both retrieval/transfer operations and mitigation. Figure 5.11 shows the dilution and transfer processes schematically. Results of analyzing the effect of transfer on potential GREs and a summary of an initial hazards analysis are presented along with the dilution needed to satisfy transfer requirements. While this section focuses specifically on Tank 241-SY-101, many of the issues involved also apply to other flammable gas tanks with similar properties.

(a) Westinghouse Hanford Company. September 14, 1993. Conceptual Design Report, Initial Tank Retrieval Systems, Project W-211. WHC-SD-W211-CDR-001 Rev. 0, WHC, Richland, Washington. 


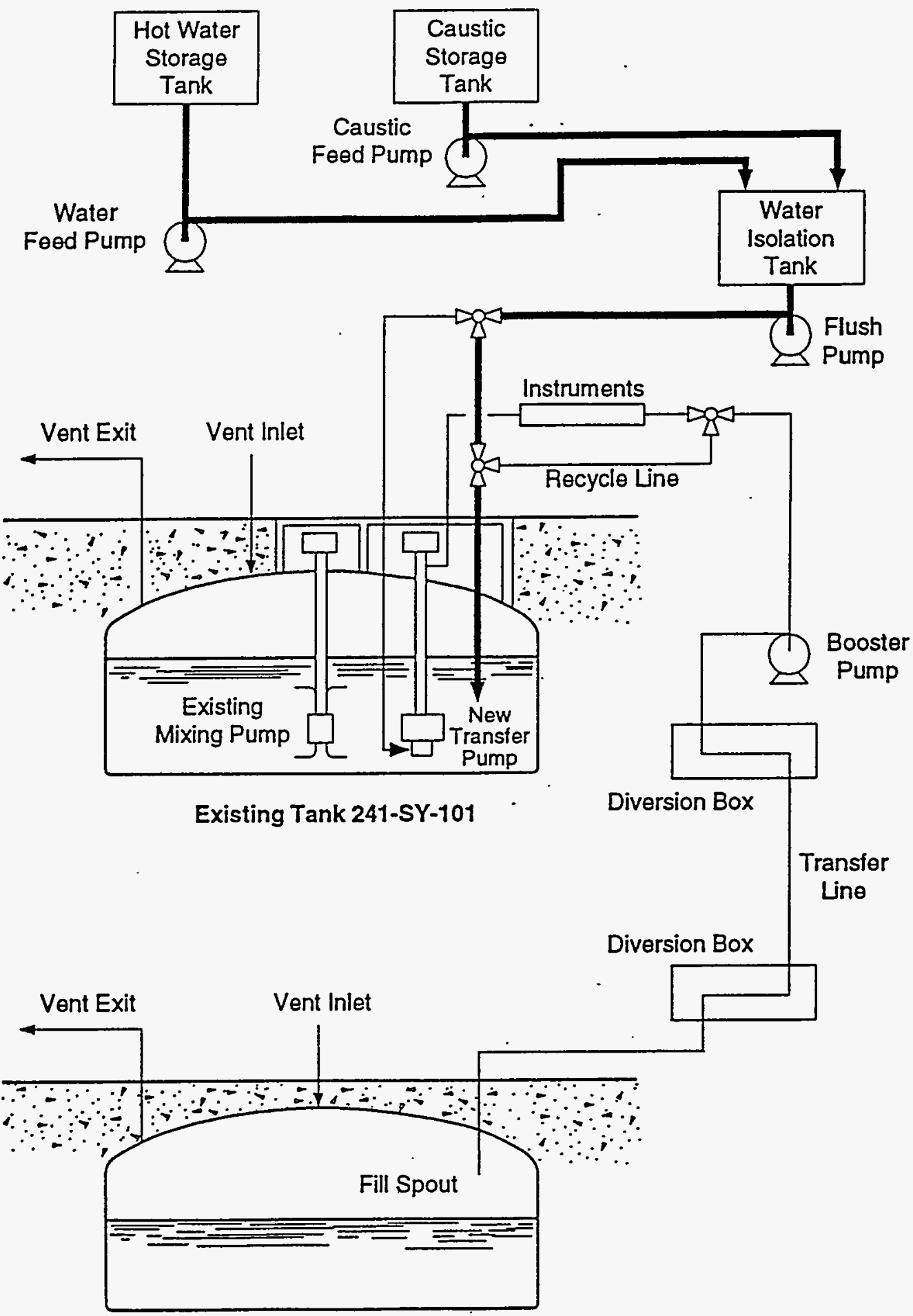

New Tank SN-101

Figure 5.11. Transfer System for Tank 101-SY 
The basic components of the Tank 241-SY-101 dilution system concept include hot water and caustic solution supply tanks, an isolation tank for mixing the water and caustic solution, and a transfer pump. The transfer pump includes features to introduce diluent at either the pump suction intake or directly into the tank through pipes attached to the pump column. On-line instrumentation will be provided at the transfer pump outlet to determine the waste properties of $\mathrm{pH}$, density, viscosity, flow, temperature, and pressure. The four modes of operation for the dilution system (dilution, transfer, bypass, and flush) are described as follows:

- $\quad$ Recirculation: The transfer pump circulates waste back into the tank while diluent is added at the pump suction until the correct properties are achieved for waste transfer, as determined by the on-line instruments in the recirculation piping loop. Then valves are opened to send the diluted waste to the transfer line.

- Transfer: The diluted waste is routed into the cross-site transfer line system and to the new tank. The transfer system includes the transfer pump to remove the waste from the tank and a booster pump to move the waste to the first pumping station of the cross-site transfer lines.

- Bypass: When the on-line instruments detect that the waste is out of specification, the flow is diverted from the transfer lines to the recirculation loop and back into the tank. Bypass continues until the dilution ratio is adjusted to bring the fluid back into specification.

- Flush: The transfer lines are preconditioned with pure diluent prior to a transfer, and to continue a transfer after a bypass. The transfer lines are also flushed after completing a transfer cycle prior to shutdown.

In-line dilution will be used for the initial batch transfer from Tank 241-SY-101. When the existing tank waste has been adequately mixed with the existing pump, the transfer pump will be started in a recirculation mode and dilution fluid from the hot water/caustic isolation tank will be added at the transfer pump suction. Assuming a 1:1 dilution ratio, a maximum of one-half the contents of Tank 241-SY-101 will be transferred to 101-SN in a 1-million-gallon batch $(500,000$ gallons of Tank 241-SY-101 waste and 500,000 gallons of diluent added in-line at the transfer pump suction). It will take approximately five days of transfer pump operation to transfer this batch. However, it is more likely that less than one-fourth of waste (250,000 gallons) will be removed from Tank 241-SY-101, or that the dilution ratio will be much lower than $1: 1$, filling 101-SN about half full.

After the transfer, diluent will be added directly into Tank 241-SY-101 to bring the level up to about 280 inches that is required to keep the inlet of the current mixer pump submerged. Conditioned water from the hot water/caustic isolation tank will be routed through the transfer pump column. These pipes discharge approximately $31 / 2$ feet from the tank bottom. When the desired amount of dilution fluid has been added to the tank, the existing mitigation pump will be operated to mix the waste and diluent.

\subsubsection{Dilution to Meet Transfer Line Requirements}

Some dilution is required for transfer, because there are restrictions on the viscosity, density, and solids loading of the material to be sent through the cross-site transfer lines. (a) Waste must have a specific gravity less than 1.5 , viscosity under $30 \mathrm{cP}$, and solids volume fraction less than $30 \%$.

(a) Westinghouse Hanford Company. June 1, 1993. Functional Design Criteria for Project W-058, Replacement of Cross-Site Transfer System. WHC-SD-W058-FDC-001 Rev. 1, WHC, Richland, Washington. These requirements are still being developed and we have not attempted to justify or challenge their bases. 
Data have already been presented above to determine the dilution needed to meet these criteria for Tank 241-SY-101. However, the measurements were made on core samples of sludge and the dilution ratios are referenced to the volume of the core sample, not to the entire tank. Because Tank 241-SY-101 contained about 200 inches of sludge out of about 400 inches of total waste when the core samples were taken, the dilution ratios reported in the data would be achieved with approximately half that ratio computed for the entire tank. For example, a 0.54:1 dilution of a core sample would require only about $0.27: 1$ in the tank.

The data for viscosity, bulk density, and solids volume fraction are plotted against the equivalent tank dilution ratio in Figures 5.12 through 5.14, respectively. The transfer criteria are indicated on the respective figures. It is clear that the bulk density is the most restrictive of the three, requiring a minimum of $0.4: 1$ dilution. Viscosity is satisfied at $0.1: 1$ dilution, and the solids loading of $30 \mathrm{vol} \%$ is met at about $0.2: 1$.

\subsubsection{Effect of Transfer on GRE Behavior}

The effects of the proposed transfer of Tank 241-SY-101 waste to a new tank, 101-SN, have been analyzed with a model similar to the one applied to in-tank dilution in Section 5.2. The details are described in Appendix G. The basic assumptions and a summary of the results are given below.

Before transfer, the waste in Tank 241-SY-101 is assumed thoroughly mixed with the existing pump. A slurry is formed from the mixture of solids and liquid excluding the crust and an undisturbed bottom sludge layer of about 40 inches depth (Stewart et al. 1994). Only the mixed slurry is removed from Tank 241-SY-101. After the transfer, diluent is added as needed to maintain a non-crust waste level of 280 inches, ensuring a net positive suction head for the mixer pump. If we assume dilution in Tank 241-SY-101 is only for this purpose, dilution is entirely determined by the amount of waste transferred.

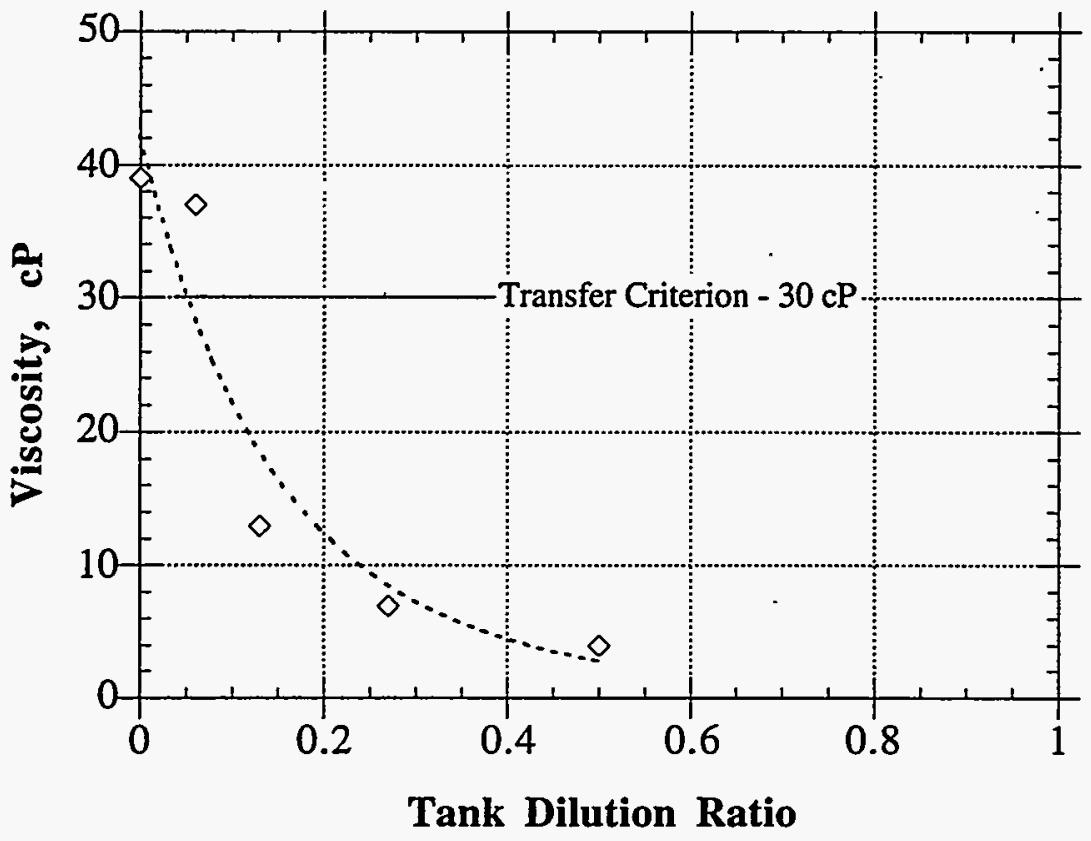

Figure 5.12. Viscosity Versus Tank Dilution Ratio 


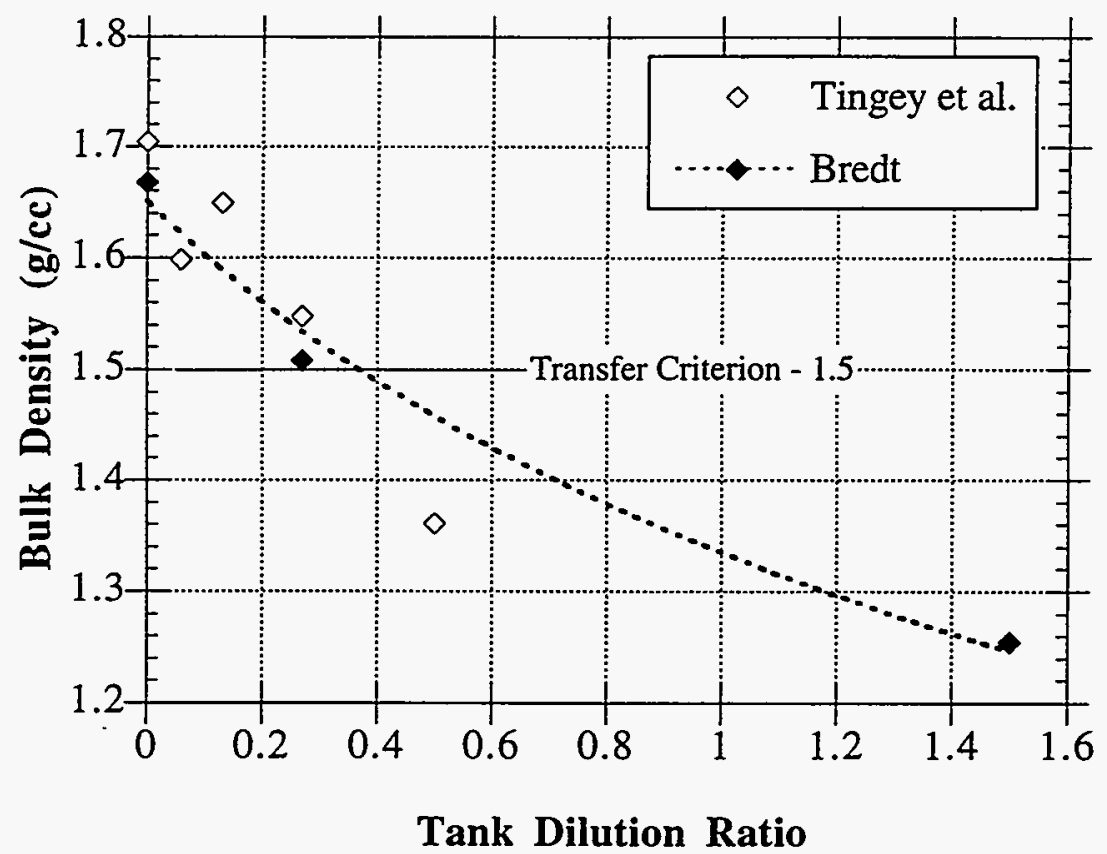

Figure 5.13. Bulk Waste Density Versus Tank Dilution Ratio

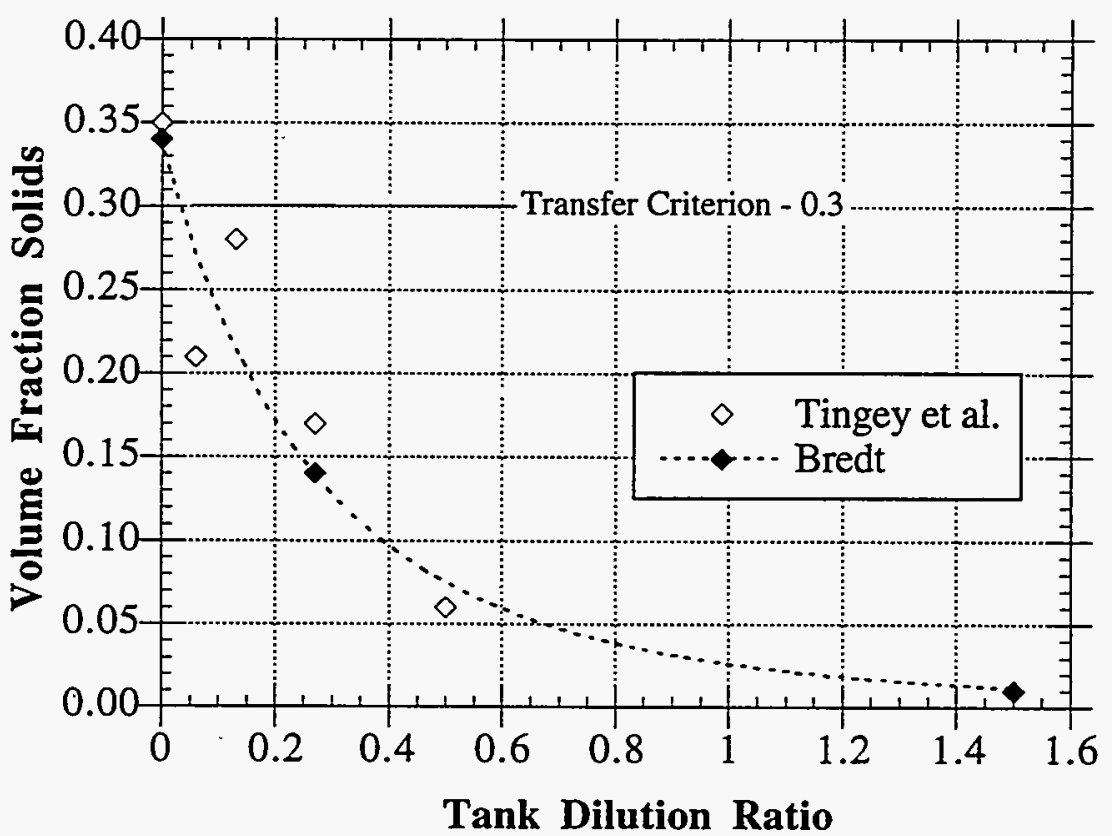

Figure 5.14. Solids Fraction Versus Tank Dilution Ratio 
During transfer to $101-\mathrm{SN}$, a variable amount diluent is added to the slurry. After the transfer process is complete, we assume that mixing ceases and all undissolved solids settle out into a sludge layer that is capable of retaining gas. Dissolution of solids is included at this stage. Eventually, the entire volume of sludge in both tanks is assumed to experience a GRE, but the GREs in the two tanks do not occur at the same time.

The effects of the amount of waste transferred and the in-line dilution ratio on the potential volume of gas released and the resulting hydrogen concentration in the dome space are computed with a simple mass balance accounting for the solids fraction in the Tank 241-SY-101 slurry and dissolution in both tanks. Figure 5.15 plots the gas release ratio (maximum potential gas volume released in either tank after transfer divided by the maximum gas release from 101-SY before transfer) and the resulting hydrogen concentration in the dome versus the amount of waste removed from 101-SY. A dilution ratio of 0.4:1 is used during transfer into 101-SN. Both the gas release ratio and hydrogen concentration decrease rapidly to the point where dilution begins in 101-SY at 84 inches transferred. After 210 inches have been transferred, the gas release ratio and the hydrogen concentration in 101-SN become the maximum values and control the behavior of the system.

The maximum hydrogen concentration falls below the LFL of 3\% (LANL 1994) when 150 inches of waste have been transferred. The lowest dome hydrogen concentration is about $2 \%$ at 210 inches transferred. Figure 5.16 provides a measure of the cost of reducing the hydrogen concentration in terms of new waste volume generated. It is clear that most of the reduction (to about $3.5 \%$ ) is achieved at a cost of only 50 inches of new waste. At this point, dilution into Tank 241-SY101 begins to extract a heavy penalty. Another 50 inches of new waste is required to reach the $3 \%$ LFL, and the final $1 \%$ reduction costs 100 inches. However, if the mixer pump suction were placed just six feet lower, such that dilution was not required in Tank 241-SY-101, the hydrogen concentration could be reduced all the way to $1 / 4$ of the LFL by transferring 150 inches into 101-SN at a cost of only 60 inches of new waste.

The above analysis takes no credit for dilution except for the reduction in solids volume by dissolution. If it is confirmed that dilution really is an effective mitigation method by eliminating the ability of the solids to retain gas, larger transfers may be desirable for that reason.

\subsubsection{Hazards Analysis}

This hazard evaluation identifies data requirements for a detailed safety assessment of mitigation by dilution in Tank 241-SY-101 (including the new tank, 241-SN-101) and to identify hazards at an early stage of the design so that preventative and mitigating measures can be incorporated into the design. We evaluated the hazards associated with long-term storage of the waste after dilution that arise from uncertainty and an incomplete understanding of the waste's behavior. This determines if dilution could create a more hazardous condition than currently exits and identifies data requirements for future safety assessments. The second part of the study identifies operational hazards that must be considered in designing the dilution process.

To investigate the hazards associated with long-term storage of the waste that arise from uncertainty and incomplete knowledge, a method similar to HazOps (AIChE 1992) was used. In this method, a simple model of the waste after dilution was used to represent the expected behavior of the system. Deviations from this model were examined systematically to determine if uncertainties or errors in the assumption could result in hazardous conditions. The Preliminary Hazard Analysis method was used to identify operating hazards. This evaluation considers operational hazards, human error, and external events that could result in the release of radioactive material, fires or explosions, the release of toxic gases, or an accidental nuclear criticality.

This summary first considers long-term storage hazards that could arise from uncertainty and lack of knowledge; next, the operational hazards are considered; finally, recommendations are made for additional study. 


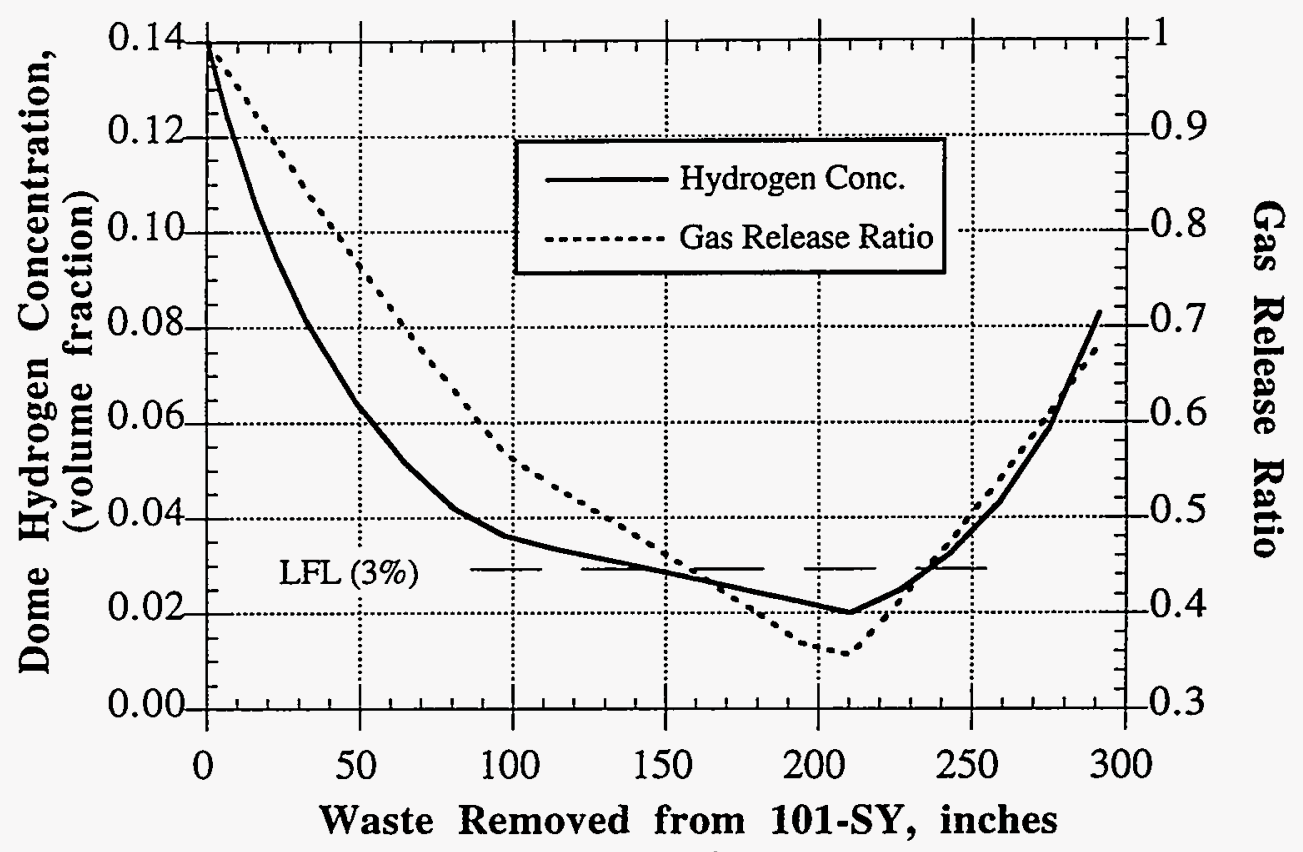

Figure 5.15. $\mathrm{H}_{2}$ Concentrations and Gas Release Ratios for 101-SY to 101-SN Transfer

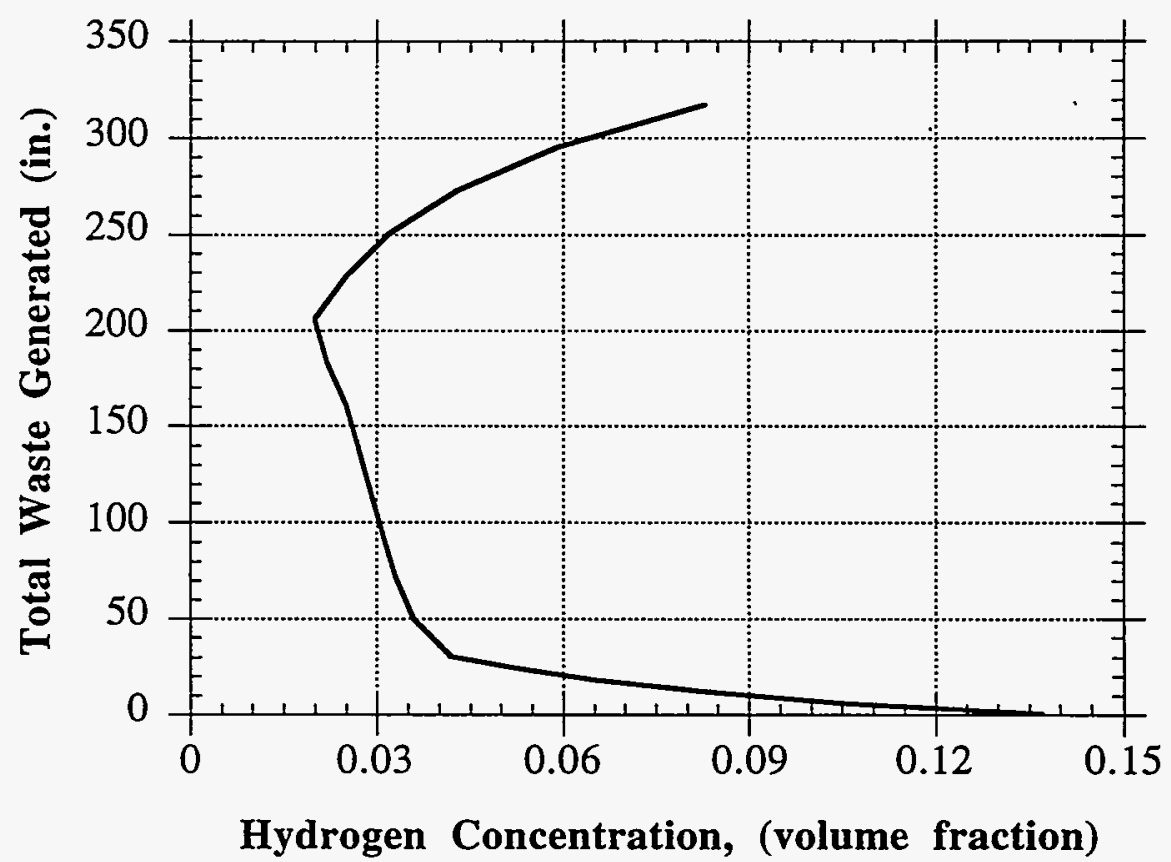

Figure 5.16. $\mathrm{H}_{2}$ Concentrations Versus Waste Generation for 101-SY to 101-SN Transfer 
The review of hazards that arise from uncertainty can be used for three purposes: to evaluate the likelihood that dilution results in passive mitigation, to identify data required to demonstrate that dilution does not make the flammable gas hazard worse, and to identify data required to support a safety analysis for dilution. The review of long-term issues produced the following findings concerning the likelihood that dilution results in passive mitigation:

- The simple, nominal model predicts that dilution and transfer decreases the solids inventory and reduces the size of GREs.

- The nominal model predicts that hydrogen concentrations will still exceed $25 \%$ of the LFL.

- The solids remaining in the waste after dilution are assumed to settle and form a layer that behaves as the nonconvective layer in Tank 241-SY-101. This is likely to be incorrect, and demonstrating that this assumption is incorrect would demonstrate passive mitigation.

The review of long-term storage hazards reveals only three deviations from expected behavior that could increase the flammable gas hazard:

- If dilution and the cooling caused by dilution significantly increase the fraction of hydrogen or other flammable gas in the retained gas, a smaller total gas release could result in a larger flammable gas release.

- If dilution causes stable alumina gels to form, gas retention and release could be increased significantly.

- If dilution creates an impermeable crust, a new mechanism for retaining large amounts of flammable gas could arise.

Several areas were identified in the review of long-term issues that may be important in preparing a safety assessment for dilution. These items may be important because they affect gas release estimates. The areas that may impact a safety assessment are

- Data used to determine the inventory in Tank 241-SY-101 before dilution, including solubilities and densities

- Data used to determine the solids inventory in the waste after dilution, including solubility, steady-state temperature after dilution, formation of sodium carbonate by carbon dioxide generation, and absorption

- Data used to determine the impact of changes in concentration and temperature on the generation and release of flammable and toxic gases.

Many of the operational hazards identified in the Preliminary Hazard Analysis have been discussed and analyzed in the mixer pump safety analysis and safety analyses of transfer operations. The additional hazards identified in this review are

- $\quad$ Release of flammable gas in Tank 241-SY-101 as a result of adding diluent

- A GRE in Tank 241-SY-101 as a result of lowering the waste level

- Damage caused by falling fragments of crust as the contents of Tank 241-SY-101 are removed

- Damage to Tank 241-SY-101 if the transfer pump is bent as a result of a rollover

- Venting flammable gas to the new tank during the transfer operation 
- Releasing large quantities of ammonia in the new tank during the transfer operations

- Leaks in the transfer line that release flammable gas

- Overfilling the tanks or improper routing of the diluent or waste.

All of these hazards can be controlled by installing proper instrumentation and implementing appropriate operational controls. Based on the findings of this hazard review, several addition studies are recommended. The following studies are recommended to help demonstrate that dilution is a feasible method of achieving passive mitigation:

- The effect of solids composition on settling and gas retention should be investigated.

- The effect of dilution and cooling on gas composition should be determined.

- Conditions under which a stable alumina gel forms should be identified.

If mitigation by dilution is feasible and is selected as preferred method of mitigation, the following studies are recommended to support a safety assessment for dilution.

- The solubility of the major salts should be determined as a function of temperature and liquid composition.

- Thermal modeling sțudies should be performed to evaluate the extent of cooling.

- Sodium carbonate formation as a result of carbon dioxide generation and absorption should be investigated.

- Mechanisms of crust formation should be investigated.

- An additional core sample is recommended if results are found to be sensitive to current initial inventory in Tank 241-SY-101.

\subsection{Long-Term Behavior}

Long-term waste behavior is critical to the evaluation of the efficacy of dilution as a mitigation strategy. Indeed, excluding the possibility of operation or safety concerns that would prohibit application of the dilution processes, the success of dilution will rely almost entirely on it providing a favorable change in long-term waste behavior.

Any prediction of long-term behavior relies on the accuracy and completeness of understanding current waste behavior, how various waste properties affect this behavior, and what will happen to these properties after dilution. Much of the effort so far has focused on exactly these areas. This section describes the current understanding of what changes in waste behavior may be expected after dilution.

Because our current understanding is less than complete in several important areas, this inevitably results in some conjecture. The discussion, therefore, is limited to a few areas that have a relatively firm technical basis and which provide insight to the long-term behavior. Other issues that may be important, but for which no technical basis is currently available, are also summarized below. 


\subsubsection{Waste Temperature Decrease}

Dilution with water or caustic will reduce the volumetric radiolytic heat generation. When dilution is accompanied by transfer of waste material from a tank, a decrease in the heat generation for the tank and a corresponding decrease in waste temperature will result. Changes in temperature could significantly and negatively impact the gas-retention characteristics of the waste.

A scoping calculation was performed using the TEMPEST code for the case where half the tank waste was removed and the remaining half diluted with an equal volume of caustic solution. The resulting radiolytic heat generation was half the current value for Tank 241-SY-101 (estimated at $46,800 \mathrm{Btu} / \mathrm{hr}$, or $13.7 \mathrm{~kW}$ ). The waste viscosity was set to $24 \mathrm{cP}$. It was also assumed that only a minimal crust (approximately four inches) remained after dilution. The ventilation flow rates were taken as $550 \mathrm{cfm}$ for the dome space and $275 \mathrm{cfm}$ for the annulus.

The maximum steady-state waste temperature from this calculation was approximately $95^{\circ} \mathrm{F}$ $\left(35^{\circ} \mathrm{C}\right)$. This should be compared to a maximum steady-state temperature of approximately $110^{\circ} \mathrm{F}$ $\left(43^{\circ} \mathrm{C}\right)$ predicted earlier with TEMPEST (Stewart et al. 1994) using the current heat load, a 42-inch crust and a 30-inch sludge layer. Thus, a 1:1 dilution may result in a decrease in waste temperature of about $15^{\circ} \mathrm{F}\left(8^{\circ} \mathrm{C}\right)$ [the current temperature in Tank $241-S Y-101$ is $115-118^{\circ} \mathrm{F}$ (46 to $\left.48^{\circ} \mathrm{C}\right)$ ]. The variance between the predicted temperatures and the observed data may be attributed partially to a higher dome ventilation rate in the model. Also, the waste in Tank 241-SY-101 has not yet reached a steady-state due to the major perturbations over the past months since the mixer pump was installed.)

\subsubsection{Waste Properties at Lower Temperature}

Accurate predictions for component solubilities are currently not possible at these lower temperatures because very little solubility data are available for the concentrated salt solutions below $50^{\circ} \mathrm{C}$. The data of Reynolds and Herting (1984) can be extrapolated near $50^{\circ} \mathrm{C}$, but this becomes precarious as the temperature decreases further. Reynolds has suggested that equilibrium constants may be calculated from heat of formation data that are available for these salts over a wide temperature range. A significant change of these constants within the range of interest could indicate a sudden change in solubility behavior. These data indicate no such problem for sodium nitrate; data for the other salts have not been reviewed.

Herting and Cleavenger report data for sodium aluminate solubility in saturated salt solutions to as low as $40^{\circ} \mathrm{C}$.(a) From these data, a major decrease in the aluminate solubility occurs from 80 to $60^{\circ} \mathrm{C}$, while a much smaller change occurs from 60 to $40^{\circ} \mathrm{C}$. (For example, at $1.5 \mathrm{M} \mathrm{NaOH}$, the aluminum solubility at $80^{\circ} \mathrm{C}$ is about $1.5 \mathrm{M}$, at $60^{\circ} \mathrm{C}$ it is about $0.5 \mathrm{M}$, and at $40^{\circ} \mathrm{C}$ it is about $0.3 \mathrm{M}$.) However, the combined effects of dilution and temperature decrease will certainly decrease further the solubility of aluminate in the diluted waste.

Very few data are available for dissolution below $50^{\circ} \mathrm{C}$, but during recent laboratory work, supernatant liquid from dilution of Tank 241-SY-101 waste was allowed to cool to approximately $30^{\circ} \mathrm{C}$ during preparation for chemical analyses. A significant amount of solids had precipitated such that the solution was described as a "slush." Upon heating to $50^{\circ} \mathrm{C}$, the precipitate dissolved. This would seem to indicate that further dissolution would occur from the supernatant liquid, although the changes may be reversible by increasing the waste temperature.

There are also few data on waste rheology below $50^{\circ} \mathrm{C}$. While the data of Tingey et al. suggest that the effective viscosity of the undiluted waste increases significantly with lower

(a) Herting, D. L. and R. M. Cleavenger. 1985. Gibbsite Solubility. WHC internal memo 6545385-098, to D. A. Reynolds, Westinghouse Hanford Company, Richland, Washington. 
temperatures, the rheology of waste with a sufficient dilution (approximately 0.2 ) displays no significant temperature dependence in the range from 50 to $90^{\circ} \mathrm{C}$.(a)

In summary, it is likely that temperature decreases resulting from lower volumetric radiolytic heat generation will reduce the solubility of the ionic salts. Waste rheology may also be affected by the lower temperatures. However, the significance of these potential problems has not been determined due to the lack of data below $50^{\circ} \mathrm{C}$.

\subsubsection{Slurry Mixing}

The changes in waste rheology that result from dilution will also impact pump mixing. The main effect will be a significant decrease in the apparent viscosity (See also section on Rheology). At $50^{\circ} \mathrm{C}$, the apparent viscosity (at a shear rate of $150 \mathrm{sec}^{-1}$ ) of a composite waste sample from Tank 241-SY-101 decreased by a factor of ten when diluted 1:1 with $2 \underline{\mathrm{M} \mathrm{NaOH}}$ solution.(b) Once diluted, the sample showed no significant effect of temperature on rheology. Therefore, for a 1:1 dilution the apparent viscosity of the waste may decrease by a factor of ten.

This change will result in an enhanced resuspension of solids and, therefore, less intense pumping will be required to mobilize the sludge. On the other hand, settling will also be enhanced, requiring more frequent pumping to achieve a mixed state. The enhanced settling which occurs as a result of dilution has been observed experimentally by Tingey et al., who noted that samples diluted by more than 0.5 "exhibited significant settling at all temperatures."(c) Settling may be described by the following equation for the terminal settling velocity, $u_{t}$, of a spherical particle in the Stokes regime:

$$
u_{\mathrm{i}}=\frac{\mathrm{gD}_{\mathrm{p}}^{2}\left(\rho_{\mathrm{s}}-\rho_{\mathrm{L}}\right)}{18 \mu}
$$

where $g$ is the gravitational acceleration, $D_{p}$ is the particle diameter, $p_{s}$ and $p_{L}$ are the sludge and liquid densities and $m$ the effective or apparent viscosity. While the idealizations in the equation are probably not realized in the waste tank, the insight the equation provides is still clear. A decrease in viscosity will proportionally increase settling velocities. (There may also be changes in particle diameter and the particle and fluid densities, but the effects of these should be smaller than the change in viscosity.) Similar arguments could be presented for resuspension.

In summary, the lower effective viscosities of the diluted material should enhance both solids resuspension and settling. This may require more frequent, but less intense, pump operations to maintain a fully mixed condition.

(a) Tingey, J. M., P. R. Bredt and E. H. Shade. 1994. The Effects of Heating and Dilution on the Rheological and Physical Properties of Tank 241-SY-101 Waste. Draft Report, Pacific Northwest Laboratory, Richland, Washington

(b) Ibid.

(c) Ibid. 


\subsection{Heating}

Heating scored highest of the chemical treatment methods considered in the initial mitigation/remediation study (Babad et al. 1992b) and was one of the four concepts recommended for further study. Heating the waste to below the atmospheric boiling point is intended to dissolve most of the sodium salts that make up the nonconvective layer and lower the viscosity and yield strength of the sludge. The combination of reducing of the amount of material that can retain gas and diminishing its ability to do so could prevent large episodic GREs. Heating the waste could potentially be easy to achieve if the existing annulus heating system could be used. Unlike dilution, heating need not increase the total waste volume. It is not clear at this time whether mixing the waste would be required to distribute the heat.

The mitigating effects of heating may be less than initially expected. The concept was proposed based on results from synthetic waste studies that showed that the material simulating nonconvective sludge from Tank 241-SY-101 did not retain gas at temperatures above $60^{\circ} \mathrm{C}$ (Delegard 1980). WHC scientist J. C. Person has presented information on actual waste studies showing that the gas generation rate increases markedly above $65^{\circ} \mathrm{C}$. This increase in gas supply tends to challenge any reduction in the gas retention ability. Similar to the case of dilution, it is not clear from the currently available data what temperature would be necessary to eliminate the ability of undissolved solids to retain gas or whether gas retention can be eliminated at all.

Past data from Tank 241-SY-101 show that large episodic gas releases continued to occur at waste temperatures of up to $65^{\circ} \mathrm{C}$ (Antoniak 1993). Sudden level decreases of 3-6 inches were typical from mid-1981 through mid-1985, while the temperatures in the nonconvective layer stayed at $60-65^{\circ} \mathrm{C}$. After 1986, larger gas releases with level drops on the order of 10 inches were typical. This behavior persisted whether the waste temperature was 45 or $60^{\circ} \mathrm{C}$. After 1991 , the waste cooled considerably to $45-50^{\circ} \mathrm{C}$, and gas releases became somewhat larger, with waste level drops up to 16 inches. While this may be evidence of some increase in gas release volume with lower temperatures, there is certainly no evidence from tank history that increasing waste temperatures up to $65^{\circ} \mathrm{C}$ would mitigate GRE behavior.

The results of Herting et al. (1992b) and Tingey et al.(a) (see Figures 5.3 and 5.4) show that the yield point and viscosity of Tank 241-SY-101 core sample material from the nonconvective layer decreases predictably with increasing temperature. But viscosity can only affect the rate of release, not retention, and the change in gas retention as shear strength decreases is not known quantitatively. As discussed in Section 5.2, a yield point of only $1 \mathrm{~Pa}$ is sufficient to trap bubbles of $0.1 \mathrm{~mm}$ in diameter. Finally, although the solubility of certain sodium salts increases with temperature (Reynolds and Herting 1984), Barney's (1976) data show that aluminate solubility is not sensitive to temperature in this range. In fact, Reynolds and Herting have shown that, for relatively low sodium hydroxide concentrations (such as found in Tank 241-SY-101), aluminate solubility decreases with increasing temperature due to increased concentrations of other ions.

There are also some difficult technical problems involved in dealing with the huge thermal inertia of a tank full of waste. A large amount of energy must be added to heat the waste initially and then maintain the desired temperature. A scoping calculation was performed using the TEMPEST code to find the heat input rate required to maintain the steady state waste temperature in Tank 241SY -101 at $15^{\circ} \mathrm{C}$ above that produced by internal generation. This study indicated that, at steady state, an additional $14 \mathrm{~kW}(47,000 \mathrm{Btu} / \mathrm{hr})$ were required, double the current radiolytic heat-generation value. From this and other available results from thermal analysis of this tank (Stewart et al. 1994), an estimated $20 \mathrm{~kW}$ would be required to maintain waste temperatures at $25^{\circ} \mathrm{C}$ above the current level.

(a) Tingey, J. M., P. R. Bredt and E. H. Shade. 1994. The Effects of Heating and Dilution on the Rheological and Physical Properties of Tank 241-SY-101 Waste. Draft Report, Pacific Northwest Laboratory, Richland, Washington 
Existing heat-addition systems are not capable of achieving this in Tank 241-SY-101, and an additional intrusive heating system (e.g., steam coils) would be required to raise the waste temperature by the desired 20 to $30^{\circ} \mathrm{C}$ in a practical amount of time. T. R. Beaver (1994) has performed transient heat transfer analyses that indicate that Tank $241-\mathrm{SY}-101$ waste could be heated by more than $40^{\circ} \mathrm{C}$ in one year by continuous operation of the mixer pump at high power settings. However, because the current mixer pump is vital to keep the tank mitigated for several more years, such huge expenditure of pump lifetime would not appear to be prudent. Heating by hydraulic dissipation, therefore, is currently not considered feasible. Beaver-also estimates that it would take a year to increase the waste temperature by $13^{\circ} \mathrm{C}$ by heating the dome and annulus ventilation air due to limitations on ventilation system temperatures. Although some tanks may generate sufficient internal heat to achieve high temperatures passively, continued operation of a heat addition system is probably required in most of them. Therefore, heating must be classed as an active mitigation method.

There also are risks in heating the large volume of waste. The huge thermal mass of the waste would require several months, even with rather aggressive heat addition, to warm up 20 to $30^{\circ} \mathrm{C}$. Temperature reduction would require similar amounts of time. The major risk is that, if unwanted chemical reactions or physical changes began, it would also take several months to reverse the process. Therefore, the consequences must be well established before heating is initiated. No detailed hazards analysis has been performed for mitigation by heating. It may be possible to satisfy safety concerns by increasing the temperature in small increments separated by long waiting times. Also, the Tank 241-SY-101 mixer pump Safety Analysis states that no dangerous runaway chemical reactions are likely below $125^{\circ} \mathrm{C}$ (LANL 1994). Therefore, it appears the hazards are not disqualifying.

It may be beneficial or even necessary to do some heating to maintain the waste temperature sufficiently high to avoid precipitation of solids in cases where other mitigation methods have reduced the temperature. Dilution lowers the volumetric heat generation rate, and both mixing and dilution increase the heat loss to the surrounding soil and ventilation flow by increasing internal circulation. In recent dilution testing with Tank 241-SY-101 core samples, supernatant liquid was observed to become solid when allowed to room temperature (about $30^{\circ} \mathrm{C}$ ). But in this case, heating is used only to control temperature, not as a separate mitigation campaign.

A strong technical basis has not been established for heating an effective mitigation strategy, and more work is needed. We need to know the temperature above which gas retention in settled solids subsides. This work must also verify that problems (e.g., increased gas generation, changes in waste properties) will not create an irreversible hazardous condition. Some supporting information on the relation of solids properties and composition to gas retention may be supplied by continuing dilution studies. Because of the technical difficulties of heating, and because at least one other active mitigation method has already been proven, we recommend that the dilution studies be given a higher priority than heating. 


\subsection{References}

Allemann, R.T., T. M. Burke, D.A. Reynolds, and D.E. Simpson. 1993. Assessment of Gas Accumulation and Retention - Tank 241-SY-101. WHC-EP-0576, Westinghouse Hanford Company, Richland, Washington.

Allemann, R. T., Z. I. Antoniak, W. D. Chavala, L. E. Efferding, J. G. Fadeff, J. R. Friley, W. B. Gregory, J. D. Hudson, J. J. Irwin, N. W. Kirch, T. E. Michener, F. E. Panisko, C. W. Stewart and B. M. Wise. 1994. Mitigation of Tank 241-SY-101 by Pump Mixing: Results of Testing Phases A and B. PNL-9423-UC-510, Pacific Northwest Laboratory, Richland, Washington.

American Institute of Chemical Engineers. 1992. Guidelines for Hazard Evaluation Procedures. 2nd Ed. AIChE, New York.

Antoniak, Z. I. 1993. Historical Trends in Tank 241-SY-101 Waste Temperatures and Levels. PNL8880, Pacific Northwest Laboratory, Richland, Washington.

Babad, H., G. D. Johnson, and D. A. Reynolds. 1992a. Understanding the Cyclic Venting

Phenomena in Hanford Site High-Level Waste Tanks: The Evaluation of Tank 241-SY-101. WHCSA-1364-FP, Westinghouse Hanford Company, Richland, Washington.

Babad, H., J. L. Deichman, B. M. Johnson, D. K. Lemon, and D. M. Strachan. 1992b.

Mitigation/Remediation Concepts for Hanford Site Flammable Gas Generating Waste Tanks. WHCEP-0516, Westinghouse Hanford Company, Richland, Washington.

Barney, G. S. 1976. Vapor-Liquid-Solid Phase Equilibria of Radioactive Sodium Salt Waste at Hanford. ARH-ST-133, Atlantic Richfield Hanford Company, Richland, Washington.

Beaver, T. R. 1994. Thermal Analysis for Tank 241-SY-101. WHC-SD-WM-ER-296 Rev. 0. Westinghouse Hanford Company, Richland, Washington.

Bryan, S. A., L. R. Pederson, R. D. Scheele, and S. R. Adami. 1993. Simulated Hanford Waste: A Study of Physical Properties, Gas Retention, and Gas Generation. In Proceedings of the Fourth Annual International Waste Management Conference. Las Vegas, Nevada.

Cannon, N. S. 1994. I0I-SY Waste Sample Speed of Sound/Rheology Testing for Sonic Probe Program. WHC-SD-WM-DTR-034, Westinghouse Hanford Company, Richland, Washington.

Delegard, C. 1980. Laboratory Studies of Complexed Waste Slurry Volume Growth in Tank 241-SY101. RHO-LD-124, Rockwell International, Richland, Washington.

Hall, M. M. 1993. Tank 101-SY Hydrogen Mitigation by Low Frequency Vibration: Rheological Analysis and Feasibility Assessment. WHC-SD-WM-ER-164, Westinghouse Hanford Company, Richland, Washington.

Herting, D. L., D. B. Bechtold, B. A. Crawford, T. L. Welsh, and L. Jensen. 1992a. Laboratory Characterization of Samples Taken in May 1991 from Hanford Waste Tank 241-SY-101. WHC-SDWM-DTR-024 Rev. 0, Westinghouse Hanford Company, Richland, Washington.

Herting, D. L., D. B. Bechtold, B. E. Hey, B. D. Keele, T. L. Welsh, and L. Jensen. 1992b. Laboratory Characterization of Samples Taken in December 1991 (Window E) from Hanford Waste Tank 241-SY-101. WHC-SD-WM-DRT-026 Rev. 0, Westinghouse Hanford Company, Richland, Washington. 
LANL. 1994. A Safety Assessment for Proposed Pump Mixing Operations to Mitigate Episodic Gas Releases in Tank 241-SY-101: Hanford Site, Richland, Washington. LA-UR-92-3196 Rev 10, Los Alamos National Laboratory, Los Alamos, New Mexico.

Reynolds, D. A. and D. L. Herting. 1984. Solubilities of Sodium Nitrate, Sodium Nitrite and Sodium Aluminate in Simulated Nuclear Waste. RHO-RE-ST-14P, Rockwell Hanford Operations, Richland, Washington

Reynolds, D. A. 1992. Tank 101-SY Window C Core Sample Results and Interpretation. WHC-EP0589, Westinghouse Hanford Company, Richland, Washington.

Reynolds, D. A. 1993. Tank 101-SY Window E Core Sample: Interpretation of Results. WHC-EP0628, Westinghouse Hanford Company, Richland, Washington.

Reynolds, D. A. 1994. Evaluation of 241 AN Tank Farm Flammable Gas Behavior. WHC-EP-0717, Westinghouse Hanford Company, Richland, Washington.

Stewart, C. W., J. D. Hudson, J. R. Friley, F. E. Panisko, Z. I. Antoniak, J. G. Fadeff, L. F. Efferding, T. E. Michener, N. W. Kirch, and D. A. Reynolds. 1994. Mitigation of Tank 241-SY-101 by Pump Mixing: Results of Full-Scale Testing. PNL-9959, Pacific Northwest Laboratory, Richland, Washington.

Trent, D. S., and L. L. Eyler. 1993. TEMPEST: A Computer Program for Three-Dimensional Time Dependent Computational Fluid Dynamics, Volume 1: Theory Manual. PNL-8857, Vol. 1, Rev. 0. Pacific Northwest Laboratory, Richland, Washington.

Van Fleet, R. J. 1993. Radionuclide and Chemical Inventories for the Double Shell Tanks. WHCSD-WM-TO-543, Westinghouse Hanford Company, Richland, Washington

Vol'f, F. V., and S. I. Kuznetsov. 1955. Zh. Prinkl. Khim., 28:597.

WHC. 1993. Tank 101-SY Mixer Pump Functional Design Criteria. WHC-SD-WM-FDC-026 Rev 1, Westinghouse Hanford Company, Richland, Washington. 


\section{Appendix A \\ Oscillatory Sonic Probe Performance Model}




\section{Appendix A \\ Oscillatory Sonic Probe Performance Model}

This appendix presents a two-dimensional (axially invariant) model for the performance of a mechanical sonic probe oscillator comprising an eccentric mass driven to rotate about the axis of a cylindrically symmetric housing. Predicted quantities are surface pressures, radial pressure profiles, power requirements, and forces on the eccentric bearings. A more extensive treatment, including pictorial representations of forces and phases and discussion of design constraints, appears in an internal letter report by J. M. Alzheimer, J. B. Colson, M. A. Friesel, and J. R. Friley, entitled Rotary Sonic Probe Derivation of Design Equations (PNLMIT \#082494). This appendix provides a purely mathematical treatment requiring no previous knowledge of acoustics (though some familiarity with complex number and Fourier techniques is assumed). This appendix makes use of principles from the above document and from Reschevkin (1963). Those desiring a more pictorial treatment and more discussion of theoretical design considerations are encouraged to see the Alzheimer et al report.

\section{Body Motion}

Consider the motion of a cylindrical shell with a rotating eccentric inside. The shaft driving the eccentric is assumed to supply torque but no transverse forces. The external medium is presumed to respond with a combination of damping, inertial, and elastic forces acting on the probe shell. Let

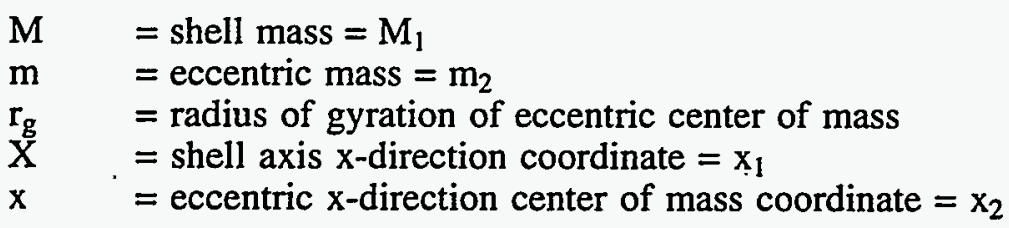

In Figure A.1, we can conveniently measure position of the eccentric center of mass from the same reference point as that for the shell:

$$
\begin{aligned}
x_{2} & =X+r_{g} \cos \omega t \\
y_{2} & =Y+r_{g} \sin \omega t \\
& =Y+r_{g} \cos (\omega t-\pi / 2)
\end{aligned}
$$

Because the drive shaft for the eccentric supplies no $\mathrm{x}$ - or $\mathrm{y}$-direction forces, the equations of motion for the eccentric are

$$
\begin{aligned}
& m \ddot{x}=f_{12, x} \\
& m \ddot{y}=f_{12, y}
\end{aligned}
$$

Here $f_{12, x}$ is the $x$-component force from probe shell (body 1 ) on the eccentric (body 2 ). In an obvious notation, $f_{12, x}=-f_{21, x}$, and similarly for $y$-components.

The $\mathrm{x}$-direction equation of motion for the shell is

$$
M X=F_{x}+f_{21, x}
$$




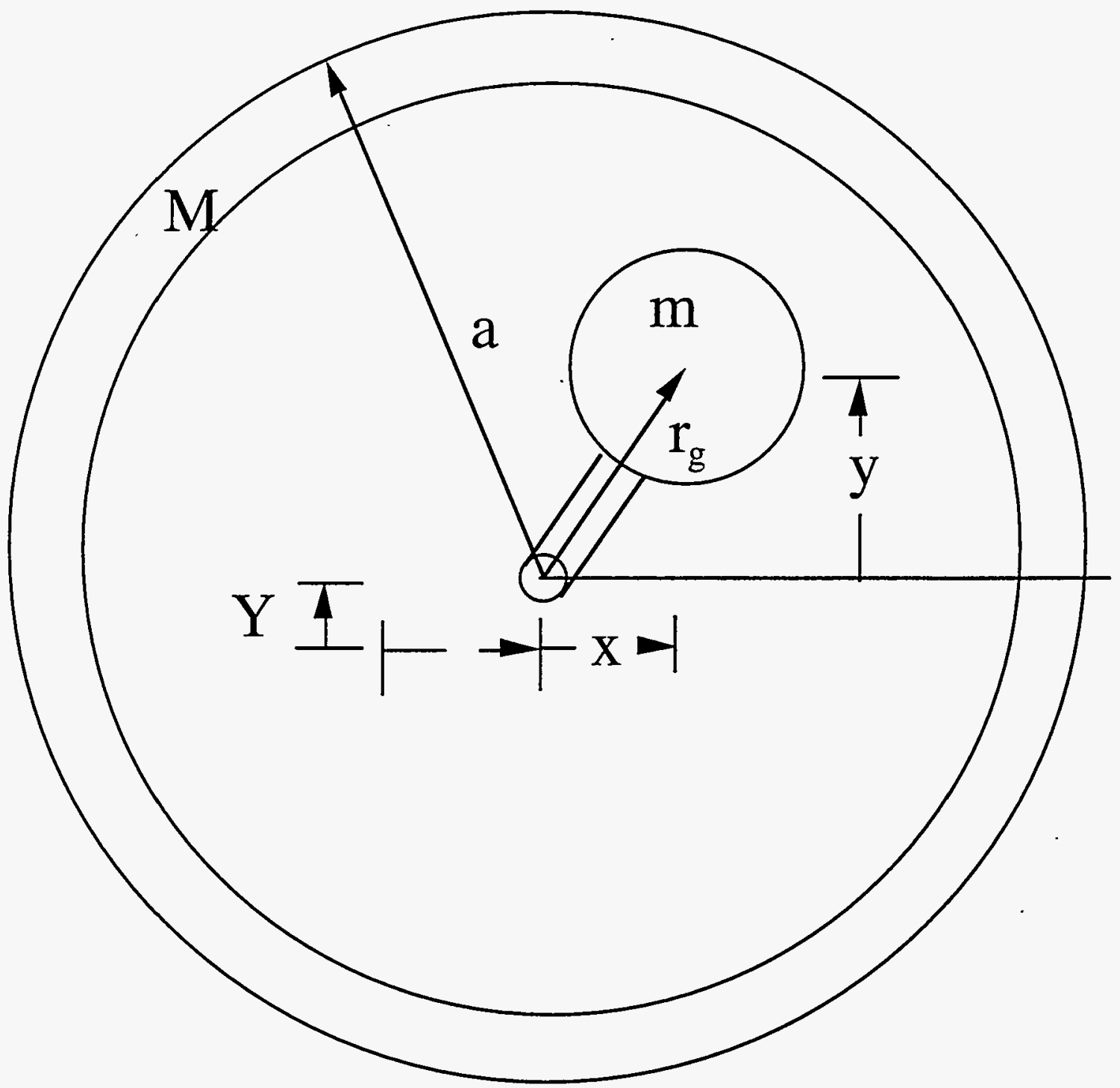

Figure A.1. Sonic Probe Coordinates, with X and Y Coordinates of Shell (mass M) Measured from Mean Position, and $x$ and $y$ of Eccentric Center of Mass (mass $m$ ) Measured from Shell Center

The x-component force on the probe shell from the fluid can be modeled as

$$
F_{x}=-m_{f} \ddot{X}-b \dot{X}-q X
$$

where $m_{f}$ is the effective inertial mass of the liquid, $b$ is a drag coefficient, and $q$ is a restoring force coefficient. Equations similar to Eq. 4 and Eq. 5 describe the y-component motion. From the form of the restoring force term, we are assuming that $\mathrm{X}$ is measured from some type of mean position. From Eq. 1-3, the force $f_{21, x}$ and $f_{21, y}$ are given by 


$$
f_{21, x}=-f_{12, x}=-m \ddot{x}
$$

or, from Eq. 1,

$$
\begin{aligned}
& f_{21, x}=-m\left(\ddot{X}-r_{g} \omega^{2} \cos \omega t\right) \\
& f_{21, y}=-m\left[\ddot{Y}-r_{g} \omega^{2} \cos (\omega t-\pi / 2)\right]
\end{aligned}
$$

Eq. 4 and the corresponding y-component equation can be solved by writing

$$
\begin{aligned}
& \cos \omega t=\operatorname{Re}\left(\mathrm{e}^{\mathrm{i} \omega t}\right) \\
& \cos (\omega t-\pi / 2)=\operatorname{Re}\left(\mathrm{e}^{\mathrm{i}(\omega t-\pi / 2)}\right)
\end{aligned}
$$

and proposing

$$
\begin{aligned}
& X=\operatorname{Re}\left(X_{0} e^{i \omega t}\right) \\
& Y=\operatorname{Re}\left(Y_{0} e^{i \omega t}\right)
\end{aligned}
$$

In Eqs. 9-12, Re indicates the real part. Substituting Eq. 5-12 into Eq. 4 and the corresponding $y$-component equation gives:

$$
\begin{aligned}
& X_{0}=\frac{m_{g} \omega^{2}}{-\left(M+m+m_{f}\right) \omega^{2}+q+i \omega b} \\
& Y_{0}=X_{0} \exp (-i \pi / 2)
\end{aligned}
$$

It should be noted that the drag-like effects of the fluid on the probe shell motion in Eq. 13 and 14 comes from the $i \omega b$ term in the denominator. The fluid can contribute an inertia-like effect or a restoring force-like effect, depending on the algebraic sign of $\left(-m_{f} \omega^{2}+q\right)$, inertia-like if negative, restoring force-like if positive. In modeling the interaction of the fluid with the probe shell, it is convenient to lump the inertial and restoring force terms together and to let the model determine which is dominant:

$$
m_{f} \omega^{2}-q=m_{e} \omega^{2}
$$

Here $m_{e}$ is the net effective inertial mass of the fluid.

From Eq. 11-14, it can be shown that the distance $r$ of the probe axis from the center of its motion is a constant satisfying

$$
r^{2}=\left|X_{0}\right|^{2}
$$

where 


$$
X_{o}=\frac{m}{-\left(M+m+m_{e}\right)+i(b / \omega)} r_{g}
$$

so that

$$
r^{2}=X_{o} X_{o}^{*}=\frac{m^{2}}{\left(M+m+m_{e}\right)^{2}+(b / \omega)^{2}} r_{g}^{2}
$$

The rate at which the probe body does work on the surrounding medium is

$$
\langle\mathrm{dW} / \mathrm{dt}\rangle=\left\langle-\mathrm{F}_{\mathrm{x}} \dot{\mathrm{X}}-\mathrm{F}_{\mathrm{y}} \dot{\mathrm{Y}}\right\rangle
$$

One can find $<\mathrm{dW} / \mathrm{d}\rangle$ by noting that

$$
\begin{aligned}
& F_{x}=\left[\left(m_{e} \omega^{2}-i \omega b\right) X_{0} \exp (i \omega t)+\left(m_{e} \omega^{2}+i \omega b\right) X_{0}^{*} \exp (-i \omega t)\right] / 2 \\
& \dot{X}=\left[i \omega X_{o} \exp (i \omega t)-i \omega X_{o}^{*} \exp (-i \omega t)\right] / 2
\end{aligned}
$$

and similar expressions for the y-components, to obtain

or

$$
<\mathrm{dW} / \mathrm{dt}>=\omega^{2} \mathrm{bX}_{\mathrm{o}} \mathrm{X}_{\mathrm{o}}^{*} / 2+\omega^{2} \mathrm{bY}_{\mathrm{o}} \mathrm{Y}_{\mathrm{o}}^{*} / 2
$$

$$
<\mathrm{dW} / \mathrm{dt}>=\omega^{2} \mathrm{bX} \mathrm{X}_{\mathrm{o}}^{*}
$$

The next task is to deduce $m_{e}$ and $b$ from a model for the generation of acoustic waves from the circular oscillatory motion of the probe axis. This is done in the next section, following the method of Rschevkin (1963).

\section{Sonic Wave Generation}

Making the classical acoustic wave approximations, we obtain the equation for the acoustic pressure $\mathrm{P}$ in a loss-free medium:

$$
\partial^{2} \mathrm{P} / \partial \mathrm{t}^{2}=\mathrm{c}^{2} \nabla^{2} \mathrm{P}
$$

If we propose solutions of the form

$$
P=P_{0}(\mathbf{r}) e^{i \omega t}
$$

we obtain the equation for the spatial dependence

$$
\nabla^{2} \mathrm{P}_{\mathrm{o}}+\mathrm{k}^{2} \mathrm{P}_{\mathrm{o}}=0
$$

where $\mathrm{k}=\omega / \mathrm{c}$. Assuming solutions that are independent of $\mathrm{z}$, and separating variables in $\mathrm{r}$ and $\phi$ gives 


$$
P_{o}(r, \phi)=\sum_{m=0}^{\infty}\left[A_{m} H_{m}^{(2)}(k r) \cos \left(m \phi-\phi_{m 2}\right)+B_{m} H_{m}^{(1)}(k r) \cos \left(m \phi-\phi_{m l}\right)\right]
$$

Here $\mathrm{H}_{\mathrm{m}}{ }^{(1)}$ and $\mathrm{H}_{\mathrm{m}}{ }^{(2)}$ are the Hankel functions of the first and second kind, respectively. With the assumed $\exp (\mathrm{i} \omega \mathrm{t})$ time dependence, the asymptotic forms show that the solution with $\mathrm{H}_{\mathrm{m}}{ }^{(2)}(\mathrm{kr})$ corresponds to outgoing waves, and those with $\mathrm{H}_{\mathrm{m}}{ }^{(1)}(\mathrm{kr})$ to incoming waves. From the approximate (low amplitude, low fluid velocity) relation

$$
\rho \partial \mathbf{v} / \partial \mathrm{t}=-\nabla \mathrm{P}
$$

we obtain, by assuming

$$
\mathbf{v}(\mathbf{r}, \mathbf{t})=\mathbf{v}_{\mathbf{0}}(\mathbf{r}) e^{\mathrm{i} \omega \mathrm{t}}
$$

and

$$
P(\mathbf{r}, t)=P_{0}(r) e^{i \omega t}
$$

that

$$
\mathbf{v}_{\mathrm{o}}(\mathbf{r})=-\frac{1}{\mathrm{i} \omega \mathrm{p}} \nabla \mathrm{P}_{\mathrm{o}}(\mathbf{r})
$$

or, in our cylindrical coordinate form (Eq. 27), for the radial component

$$
v_{o, r}(r, \phi)=-\frac{1}{i \omega \rho} \partial P_{0} / \partial r
$$

Using Eq. 32 in Eq. 27, and assuming only outgoing waves (so $B_{m}=0$ ), we obtain

$$
v_{o, r}(r, \phi) e^{i \omega t}=\sum_{m=0}^{\infty} \frac{i}{\omega \rho} A_{m} k H_{m}^{(2) 1}(k r) \cos \left(m \phi-\phi_{m 2}\right) e^{i \omega t}
$$

Here $\phi_{\mathrm{m} 2}$ is the angle of the symmetry plane for the part of the solution of index $\mathrm{m}$. We can use a known velocity distribution at a radius a to determine the coefficients $A_{m}$.

\section{Linear Oscillation of Probe}

We can simplify the determination of the coefficients by first considering a probe constrained to oscillate in a slot (x-component motion only), then using superposition to determine the form of the solution when there is motion in both $\mathrm{x}$ and $\mathrm{y}$ directions with the known phase relation of the cylindrical probe with driven eccentric rotation.

For a cylinder of radius a oscillating with angular frequency $\omega=2 \pi f$ along the $x$-axis, we can write for the fluid velocity at the surface in the small amplitude approximation 


$$
v_{o, r}(a, \phi) e^{i \omega t}=U_{o} \cos \phi e^{i \omega t}
$$

where $U_{o}$ is the amplitude of the probe oscillatory velocity in complex form:

$$
U_{0} e^{i \omega t}=i \omega X_{0} e^{i \omega t}
$$

Inserting Eq. 34 into Eq. 33, we see that

$$
\begin{aligned}
& A_{m}=0 \text { for } m \neq 1 \\
& A_{1} \frac{i}{\omega \rho} k_{1}^{(2)}(k a)=U_{0} \\
& \phi_{12}=0 \text {, i.e., the } x \text { - axis is the symmetry plane }
\end{aligned}
$$

Hence we have at arbitrary $\mathrm{r}$ and $\phi$ :

$$
v_{o, r}(r, \phi) e^{i \omega t}=U_{o} e^{i \omega t} \frac{H_{1}^{(2) t}(k r)}{H_{1}^{(2) t}(k a)} \cos \phi
$$

and

$$
P_{o}(r, \phi) e^{i \omega t}=U_{o} e^{i \omega t} \frac{\omega \rho}{i k H_{1}^{(2) t}(k a)} H_{1}^{(2)}(k r) \cos \phi
$$

Recalling that $F_{x}$ was the $x$-component of the force by the fluid on the body, we write for the complex form oscillatory force by the body on the fluid

$$
-F_{x, \omega} e^{i \omega t}=\int_{\phi=0}^{2 \pi} P_{0}(a, \phi) e^{i \omega t} \cos \phi L a d \phi
$$

or

$$
-F_{x, \omega} e^{i \omega t}=U_{0} e^{i \omega t} \frac{\omega \rho}{i k H_{1}^{(2)}(k a)} H_{1}^{(2)}(k a) L a \pi
$$

Thus the ratio of force by the probe on the fluid to its velocity in the Fourier representation (which preserves phase relationships) is

$$
\frac{-F_{x, \omega} e^{i \omega t}}{U_{0} e^{i \omega t}}=\frac{\omega p \pi a L}{i k H_{1}^{(2)_{1}}(k a)} H_{1}^{(2)}(k a)
$$

while from the probe body motion model, the corresponding ratio of force on the body to its velocity in the Fourier representation is 


$$
\frac{-F_{x, \omega} e^{i \omega t}}{U_{0} e^{i \omega t}}=\frac{-m_{e} \omega^{2} X_{0} e^{i \omega t}+i \omega b X_{0} e^{i \omega t}}{i \omega X_{0} e^{i \omega t}}=b+m_{e} \omega
$$

Equating the right sides of Eq. 43 and 44 gives us expressions for $b$ and $m_{e}$ for the cylindrical probe generating acoustic waves in the medium:

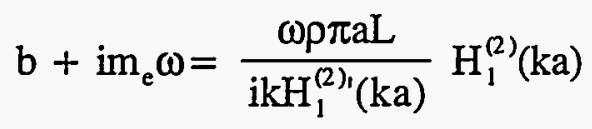

The real and imaginary parts of the right side of Eq. 45 can be separated by using relations satisfied by the Hankel $(\mathrm{H})$, Bessel $(\mathrm{J})$, and Neumann. $(\mathrm{N})$ functions:

$$
\begin{aligned}
& \mathrm{H}_{1}^{(2)}(\mathrm{z})=\frac{1}{2}\left[\mathrm{H}_{0}^{(2)}(\mathrm{z})-\mathrm{H}_{2}^{(2)}(\mathrm{z})\right] \\
& \mathrm{H}_{2}^{(2)}(\mathrm{z})=\frac{2}{\mathrm{z}} \mathrm{H}_{1}^{(2)}(\mathrm{z})-\mathrm{H}_{0}^{(2)}(\mathrm{z}) \\
& \mathrm{H}_{1}^{(2)}(\mathrm{z})=\mathrm{H}_{0}^{(2)}(\mathrm{z})-\frac{1}{\mathrm{z}} \mathrm{H}_{1}^{(2)}(\mathrm{z}) \\
& \mathrm{H}_{\mathrm{m}}^{(2)}(\mathrm{z})=\mathrm{J}_{\mathrm{m}}(\mathrm{z})-\mathrm{i} \mathrm{N} \mathrm{N}_{\mathrm{m}}(\mathrm{z})
\end{aligned}
$$

Using Eq. 46 in Eq. 45 and also using $\omega / \mathrm{k}=c$, we obtain

$$
\mathrm{b}+\operatorname{im}_{\mathrm{e}} \omega=\rho \mathrm{c} \pi \mathrm{aL} \frac{\left(\mathrm{J}_{1} \mathrm{~N}_{0}-\mathrm{N}_{1} \mathrm{~J}_{0}\right)-\mathrm{i}\left[\mathrm{J}_{1}\left(\mathrm{~J}_{0}-\frac{1}{\mathrm{ka}} \mathrm{J}_{1}\right)+\mathrm{N}_{1}\left(\mathrm{~N}_{0}-\frac{1}{\mathrm{ka}} \mathrm{N}_{1}\right)\right]}{\left(\mathrm{J}_{0}-\frac{1}{\mathrm{ka}} \mathrm{J}_{1}\right)^{2}+\left(\mathrm{N}_{0}-\frac{1}{\mathrm{ka}} \mathrm{N}_{1}\right)^{2}}
$$

All of the arguments of $\mathrm{J}$ and $\mathrm{N}$ functions in Eq. 47 are ka. The real and imaginary parts of Eq. 47 can be identified by inspection. The values of $b$ and of $m_{e}$ apply to the $y$-component oscillation as well, even though we deduced them by temporarily considering an oscillation in the $x$ direction alone. They can be substituted into Eq. 17, 18, and 22 to give total power. We will next superpose the oscillations with proper phase relations to obtain the pressure profiles.

\section{Pressure Profiles from Superposed $X$ and $Y$ Direction Oscillations With Relative Phase of Circular Motion}

Assuming linearity and superposibility of the pressure waves from the $\mathrm{X}$ and $\mathrm{Y}$ oscillations, Eq. 40 can be extended by inspection for the case of an $X$-velocity i $\omega X_{0} \exp (i \omega t)$ (whose effects are symmetric about $\phi=0$ ) and a $Y$-velocity $i \omega Y_{0} \exp (i \omega t)=i \omega\left[X_{0} \exp (-i \pi / 2)\right] \exp (i \omega t)$ (whose effects are symmetric about $\phi=\pi / 2$ ) to give 


$$
P_{o}(r, \phi) e^{i \omega t}=\left[i \omega X_{0} e^{i \omega t} \cos \phi+i \omega Y_{0} e^{i \omega t} \cos (\phi-\pi / 2)\right] \frac{\omega \rho}{i k H_{1}^{(2)}(k a)} H_{1}^{(2)}(k r)
$$

Using $Y_{o}=X_{o} \exp (-i \pi / 2), \cos (\phi-\pi / 2)=\sin \phi$, and Euler's relation, Eq. 48 simplifies to

$$
P_{o}(r, \phi) e^{i \omega t}=i \omega X_{0} e^{-i \phi} e^{i \omega t} \frac{\omega \rho}{i k H_{1}^{(2)}(k a)} H_{1}^{(2)}(k r)
$$

Eq. 49 can be expressed in terms of Bessel and Neumann functions instead of Hankel functions. Doing so and using the relations (Eq. 46) allows us to deduce the real pressure amplitude $\mathrm{P}_{\mathrm{amp}}$ from the form

$$
\begin{aligned}
& \mathrm{P}_{\mathrm{amp}}^{2}=\mathrm{P}_{\mathrm{o}}(\mathrm{r}, \phi) \mathrm{P}_{0}^{*}(\mathrm{r}, \phi) \\
& \mathrm{P}_{\mathrm{o}}(\mathrm{r}, \phi) * \mathrm{P}_{0}^{*}(\mathrm{r}, \phi)=\omega^{2} \rho^{2} \mathrm{c}^{2} \mathrm{X}_{0} \mathrm{X}_{0}^{*} \frac{\mathrm{J}_{1}^{2}(\mathrm{kr})+\mathrm{N}_{1}^{2}(\mathrm{kr})}{\left[\mathrm{J}_{\mathrm{o}}(\mathrm{ka})-\frac{1}{\mathrm{ka}} \mathrm{J}_{1}(\mathrm{ka})\right]^{2}+\left[\mathrm{N}_{0}(\mathrm{ka})-\frac{1}{\mathrm{ka}} \mathrm{N}_{1}(\mathrm{ka})\right]^{2}}
\end{aligned}
$$

Eq. 17, 47, 50, and 51 thus determine the pressure amplitude profiles in a medium that is assumed to be non-dissipative for sound waves.

\section{Force on Eccentric Bearings}

The force on the eccentric bearings, needed for design purposes, can be deduced using the preceding theory. As seen previously, the force on the eccentric transmitted through its shaft and bearings is

$$
f_{12}=f_{12, x} \hat{i}+f_{12, y} \hat{j}
$$

where

$$
f_{12, x}=m \ddot{x}_{2}=m \frac{d^{2}}{d t^{2}}\left[X+r_{g} \cos \omega t\right]
$$

or

$$
\begin{aligned}
& f_{12, x}=m \operatorname{Re} \frac{d^{2}}{d t^{2}}\left(X_{o} e^{i \omega t}+r_{g} e^{i \omega t}\right) \\
& f_{12, x}=-m \omega^{2} \operatorname{Re}\left[\left(X_{o}+r_{g}\right) e^{i \omega t}\right]
\end{aligned}
$$

Similarly, for the y-component 


$$
\begin{aligned}
& f_{12, y}=m \frac{d^{2}}{d t^{2}}\left(Y+r_{g} \sin \omega t\right) \\
& f_{12, y}=m \operatorname{Re}\left\{\frac{d^{2}}{d t^{2}}\left[Y_{o} e^{i \omega t}+r_{g} e^{i(\omega t-\pi / 2)}\right]\right\} \\
& f_{12, y}=m \operatorname{Re}\left\{\frac{d^{2}}{d t^{2}}\left[X_{o} e^{-i \pi / 2} e^{i \omega t}+r_{g} e^{i(\omega t-\pi / 2)}\right]\right\} \\
& f_{12, y}=m \omega^{2} \operatorname{Re}\left[i\left(X_{o}+r_{g}\right) e^{i \omega t}\right] \\
& f_{12, y}=-m \omega^{2} \operatorname{Im}\left[\left(X_{o}+r_{g}\right) e^{i \omega t}\right]
\end{aligned}
$$

From Eq. 55 and 61 , we see that $\mathbf{f}_{12}$ satisfies

$$
f_{12}^{2}=f_{12, x}^{2}+f_{12, y}^{2}=\left|m \omega^{2}\left(X_{o}+r_{g}\right)\right|^{2}
$$

or

$$
\mathbf{f}_{12}^{2}=\left(m \omega^{2} r_{g}\right)^{2} \frac{\left(M+m_{e}\right)^{2}+(b / \omega)^{2}}{\left(M+m+m_{e}\right)^{2}+(b / \omega)^{2}}
$$

where $b$ and $m_{e}$ are determined from Eq. 47.

\section{Force by Probe on Fluid}

Some manufacturers of mechanical vibrators such as concrete degasifiers rate their units for total force on the fluid. For matching the performance of such probes in simulations, it is useful to calculate this total force. In our previous notation, force by the probe on the fluid has components $-F_{x}$ and $-F_{y}$, which, for our complex oscillatory solution, will have the form

$$
\begin{aligned}
& -F_{x}=m_{f} \ddot{X}+b \dot{X}+q X \\
& -F_{x}=\operatorname{Re}\left\{-m_{e} \omega^{2} X_{0} e^{i \omega t}+i \omega b X_{0} e^{i \omega t}\right\}
\end{aligned}
$$

Similarly for the $y$-component of this force

$$
\begin{aligned}
& -F_{y}=\operatorname{Re}\left(-m_{e} \omega^{2} Y_{o} e^{i \omega t}+i \omega b Y_{o} e^{i \omega t}\right) \\
& -F_{y}=\operatorname{Im}\left[-m_{e} \omega^{2} X_{o} e^{i \omega t}+i \omega b X_{o} e^{i \omega t}\right]
\end{aligned}
$$

Combining Eq. 65 and 67 , we obtain for the square of the total force by the probe on the fluid

$$
\mathbf{F}^{2}=\left[\left(m_{e} \omega^{2}\right)^{2}+(\omega b)^{2}\right] X_{o} X_{o}^{*}
$$


Here $b$ and $m_{e}$ can be deduced from the real and imaginary parts of Eq. 47 , and $\left|X_{o}\right| 2$ is given by Eq. 18. Eq. 68 thus allows us to calculate the magnitude of the total force by the probe on the liquid.

\section{Dissipation and Attenuation Effects}

In the use of solutions of a non-dissipative sonic wave equation, the preceding derivation assumed that the medium in which the probe was placed produced no dissipation or attenuation effects. The effects of dissipation on the pressure amplitude profiles can be incorporated in an approximate but intuitively appealing way by simply multiplying the pressure amplidudes calculated assuming no dissipation by a factor exponential reduction giving exponential reduction with distance:

$$
\mathrm{P}_{\mathrm{amp}}(\mathrm{r})=\mathrm{P}_{\mathrm{amp}, \text { no dis }}(\mathrm{r}) \exp [-\xi(\mathrm{r}-\mathrm{rprobe})]
$$

Values of the dissipation coefficient $\xi$ can be taken form plane wave models which incorporate effects like viscous and thermal dissipation from bubble volume oscillations, viscous

dissipation from relative motion of bubbles and fluid, and acoustic wave scattering. Models for $\xi$ appear in Appendix B of this report.

\section{Summary}

The formulation presented here allows calculation of the following quantities:

Calculated quantity

Power expended on the probe

Pressure amplitude profile, including surface pressure

Force by probe on liquid
Equations Used

$22,18,47$

$50,51,18,47,69$

$68,18,47$

\section{References}

Rzhevkin, S. N. 1963. A Course of Lectures on the Theory of Sound. Macmillan Publishing Co., new York. 


\section{Appendix B}

Acoustic Wave Processes and Attenuation Mechanisms in Bubbly Media 


\section{Appendix B}

\section{Acoustic Wave Processes and Attenuation Mechanisms in Bubbly Media}

In this appendix we summarize the acoustic wave phenomena and models used in the sonic probe modeling studies. In particular, we present the model for sound speed, and the expressions used for the attenuation per unit length $\xi$. In the complex single frequency Fourier representation of an attenuating plane wave, $\xi$ is also $k_{\mathbf{i}}$, the imaginary part of the propagation vector. Mechanisms for the attenuation of the acoustic waves include thermal effects associated with expansion and contraction of bubbles in the pressure wave, viscous damping effects associated with this same expansion and contraction, bulk viscous attenuation effects, and viscous dissipation from the relative motion of bubbles and liquid. For our purposes, we assume that adequate accuracy is obtained by taking contributions to $\xi$ from various dissipation mechanisms as additive. The expressions presented here were extracted from the literature by Harri Kytomaa of Massachusetts Institute of Technology on contract with Pacific Northwest Laboratory.

\section{Sound Speed}

With the classical approximations for acoustic waves, sound speed $\mathrm{c}$ is related to the properties of medium by

$$
c^{2}=(\kappa \rho)^{-1}
$$

where $\kappa$ is the compressibility of the medium, and $\rho$ is its density. Making the approximation that all pressure-induced volume changes come from the bubbles present (which are assumed to obey a polytropic pressure-density relation), that all of the density is contributed by the liquid, but that liquid and bubbles move together to a first approximation, one obtains a sound speed $C_{m}$ of a liquid-bubble mix obeying

$$
\mathrm{C}_{\mathrm{m}}^{2}=\mathrm{kp}_{\mathrm{o}} /\left[\rho_{1} \alpha(1-\alpha)\right]
$$

where $\mathrm{k}$ is the polytropic constant for bubble compression or expansion (i.e., $\mathrm{p} p-\mathrm{k}=$ constant in the compression/expansion), $p_{o}$ is pressure inside the bubble, $\rho_{1}$ is liquid density, and $\alpha$ is the gas volume fraction. This expression is a good approximation down to void fractions $\alpha$ at which the compressive volume changes of the liquid are no longer negligible compared with those of the gas present.

\section{Dissipation Effects}

A number of the acoustic wave attenuation mechanisms are most easily presented by expressions involving the natural frequency of bubble oscillations. For bubbles sufficiently large that a surface tension correction to the pressure can be neglected (approximately $D>10 \mu$ ), the natural frequency of the bubble is given by

$$
\omega_{n}^{2}=\left[\frac{2 k p_{0}}{\rho_{1} R_{0}^{2}}\right]
$$


where frequency $\omega_{\mathrm{n}}$ is in radian/time, $R$ is the bubble radius, and the other quantities have been previously defined. At low frequencies and small bubble sizes, there is sufficient time for heat transfer that the bubble remains essentially in thermal equilibrium with the liquid, and $k$ is approximately 1, i.e., the bubble oscillations are isothermal. At higher frequencies and/or for larger bubbles, the time for heat transfer in an oscillation is insufficient, so that the process is more nearly adiabatic and $k=\gamma=C_{p} / C_{v}$, the ratio of specific heat at constant pressure to that at constant volume. A relative bubble thermal penetration depth for oscillatory temperature changes is

$$
\mathrm{d}_{\mathrm{th}}=\sqrt{\left(\frac{1}{\omega} \mathrm{D}_{\mathrm{th}}\right)}
$$

where the thermal diffusivity $D_{t h}$ is based on gas properties:

$$
D_{\text {th }}=\frac{k_{\text {gas }}}{\rho_{\text {gas }} C_{p, g a s}}
$$

with $\mathrm{k}_{\text {gas }}$ the thermal conductivity of the gas and $\mathrm{C}_{\mathrm{p} \text {,gas }}$ its heat capacity per unit mass at constant pressure. The value of polytropic constant $k$ and the mode of thermal dissipation can be expected to depend on $d_{t h} / R_{o}$.

The bubble radial oscillation viscous damping, the acoustic scattering attenuation, and the bubble oscillation thermal effects contribute to $\xi$ according to

$$
\xi=\frac{1}{\sqrt{2} C_{m o}} \delta \frac{\omega^{2}}{\omega_{n}^{2}}
$$

where $\omega$ is $2 \pi$ times the frequency, and

$$
\delta=\delta_{\mathrm{vis}}+\delta_{\mathrm{as}}+\delta_{\mathrm{th}}
$$

The viscous damping arising from radial bubble oscillations has the parameter

$$
\delta_{\text {vis }}=4 v / R_{0}{ }^{2}
$$

the kinematic viscosity $v$ being that of the liquid, and the acoustic scattering attenuation is characterized by

$$
\delta_{\mathrm{as}}=\omega^{2} \mathrm{R}_{\mathrm{o}} / \mathrm{C}_{\mathrm{l}}
$$

where $C_{l}$ is the sound speed in the liquid. 
For the thermal effects associated with oscillatory bubble compressions and rarifactions, there is a branching according to the value of $R_{o} / d_{t h}$. For $R_{o} / d_{t h}<<1$, the thermal dissipation constant is:

$$
\delta_{\mathrm{th}}=\frac{\gamma-1}{5 \gamma} \frac{\mathrm{p}_{\mathrm{o}}}{\rho_{1} \mathrm{D}_{\mathrm{th}}}
$$

For $R_{0} / d_{t h} \gg 1$, the thermal dissipation constant is

$$
\delta_{\mathrm{th}}=\frac{9 \gamma(\gamma-1) \mathrm{p}_{\mathrm{o}}}{4 \rho_{1} \mathrm{R}_{\mathrm{o}}^{3}} \sqrt{\frac{2 \mathrm{D}_{\mathrm{th}}}{\omega^{3}}}
$$

For this study, a branching or interpolation between the two forms for $\delta_{\mathrm{th}}$ was typically used.

\section{Relative Motion Effects}

The attenuation coefficient $\xi$ for relative translational motion of bubbles and liquid due to the oscillatory pressure gradient of the acoustic wave is taken as

$$
\xi_{m}=\frac{1}{9 C_{m o}}\left(\frac{\mathrm{R}_{o}^{2} \omega^{2}}{v}\right) \alpha(1-\alpha)
$$

where $v=\mu / \rho$ is the kinematic viscosity of the liquid and $C_{m o}$ is the sound speed in the mixture.

\section{Bulk Attenuation}

For pure fluid the attenuation coefficient contribution from bulk viscosity is

$$
\xi_{b}=\frac{v \omega^{2}}{C_{1}^{3}}
$$

and for multi-field fluids

$$
\xi_{b}=\frac{v \omega^{2}}{C_{m} C_{1}^{2}}
$$

where $C_{1}$ is the speed of sound in the liquid, and $C_{m}$ is the sound speed in the mix. For the case of no void in a particular cell (no bubbles), the wave equation collapses to liquid bulk dissipation alone. 


\section{Bubble Size Spectrum Averaging of Attenuation Effects}

For multiple bubble sizes in a cell, the general volumetric averaging method used for $\xi_{\text {ave }}$ was

$$
\xi_{\mathrm{ave}}=\frac{1}{\Sigma \alpha(1-\alpha)} \sum_{\mathrm{c}}\left[\xi_{\mathrm{c}} \alpha_{\mathrm{c}}\left(1-\alpha_{\mathrm{c}}\right)\right]
$$

where "c" is the constituent (bubble) type in the cell.

\section{Pressure Wave Equation Dissipation Coefficient}

The dissipation term, $\mathrm{B}$, in a dissipative acoustic pressure equation in which the dissipative term is taken as $B \partial p / \partial t$, is taken as

$$
\mathrm{B}=2 \frac{\xi_{\mathrm{t}, \mathrm{ave}}+\xi_{\mathrm{mave}}+\xi_{\mathrm{b}, \text { ave }}}{\mathrm{C}_{\mathrm{m}}}
$$

where the acoustical velocity is simply that of the mixture. 


\section{Appendix C}

\section{Inducing the Transition from Elastic Material to Liquid Using Acoustic Waves}




\section{Appendix C}

\section{Inducing the Transition from Elastic Material to Liquid Using Acoustic Waves}

The purposes of this document are 1) to present some relations among acoustically induced stress components for Hanford tank waste; 2) to show the critical role played by Poisson's ratio in these relations; 3 ) to present a method for deducing Poisson's ratio from measured values of longitudinal wave speed, compressibility, and density; 4) to show some possibly useful bounding relations on physical properties; and 5) to justify, or at least set down, a somewhat arbitrary prescription to used in simulations of the sonic probe mitigation process.

The pattern of stresses generated by an acoustic wave is influenced by the stress relief in directions perpendicular to the direction of propagation. It is informative to consider stresses in a local coordinate system in which the stress tensor is diagonal. We let the direction of the acoustic wave propagation determine the no. 1 coordinate direction, which we take to correspond to the local radial direction. Stress relief in a vertical direction would occur at the free surface of the medium driven by the probe, with some also at horizontally layered clusters of bubbles. Stress relief in the azimuthal direction would occur to some extent at radial plane clusters of bubbles. Complete stress relief in directions perpendicular to the propagation direction corresponds to propagation in a tube whose lateral surfaces are free to move. In a true continuum approximation, the medium is not free to move in directions perpendicular to the propagation direction, and the principal components of the stress tensor in the directions perpendicular to the propagation are strongly dependent on the Poisson's ratio of the composite medium, as shown below. If the medium in which the acoustic waves are propagating is effectively an infinite continuum, the generation of shear requires that Poisson's ratio be less than $1 / 2$, as shown below. In the following paragraphs, we discuss acoustically induced shear and present a method for deducing Poisson's ratio from experiments.

In a continuous elastic medium, the stress tensor $\underline{\mathbf{P}}$ and the strain tensor $\underline{\mathbf{e}}$ are related (in dyadic form) by

$$
\begin{aligned}
& \underline{\mathbf{e}}=[(1+v) / E]\{\underline{\mathbf{P}}-[v /(1+v)][\text { Trace } \mathbf{P}] \underline{\mathbf{1}}\} \\
& \underline{\mathbf{P}}=[\mathrm{E} /(1+v)]\{\underline{\mathbf{e}}+[v /(1-2 v)][\text { Trace }] \underline{\mathbf{1}}\}
\end{aligned}
$$

where $\mathrm{E}$ is Young's modulus, $v$ is Poisson's ratio, and $1\left(=\mathbf{a}_{1} \mathbf{a}_{1}+\mathbf{a}_{2} \mathbf{a}_{2}+\mathbf{a}_{3} \mathbf{a}_{3}\right)$ is the unit dyad. Zero strain satisfies Equations 1 and 2 with an isotropic stress tensor only if Poisson's ratio satisfies $v=1 / 2$, which can be shown to be the incompressible medium limit. As shown below, $v=1 / 2$ is also the fluid limit in elastic media for longitudinal wave propagation. If we consider the above relations in the frame of the principal axes of stress and let the no. 1 axis correspond to the axis of an applied static tensional or compressional stress that produces zero strain along both of the other principal axes, the corresponding tension stresses along those other two principal axes are

$$
\mathrm{P}_{2}=\mathrm{P}_{3}=[v /(1-v)] \mathrm{P}_{1}
$$

Hence the stresses in the other two principal axes directions will be zero only if $v=0$, and they will be equal to that in the no. 1 direction if $v=1 / 2$. If $\mathbf{a}_{1}, \mathbf{a}_{2}$, and $\mathbf{a}_{3}$ are unit vectors in the directions of the principal axes of the stress tensor, and orthogonal unit vectors $\mathbf{b}_{1}$ and $\mathbf{b}_{2}$ are

$$
\begin{aligned}
& \mathbf{b}_{1}=\mathbf{a}_{1} \cos \phi+\mathbf{a}_{2} \sin \phi \\
& \mathbf{b}_{2}=\mathbf{a}_{1} \sin \phi-\mathbf{a}_{2} \cos \phi
\end{aligned}
$$


then the static shear stress in direction $\mathbf{b}_{2}$ for a surface with normal $\mathbf{b}_{1}$ will be

$$
\begin{aligned}
\mathbf{b}_{1} \bullet \underline{P} \cdot \mathbf{b}_{2} & =\left(P_{1}-P_{2}\right) \sin \phi \cos \phi \\
& =P_{1}[(1-2 v) /(1-v)] \sin \phi \cos \phi .
\end{aligned}
$$

The ability of a tensional stress to generate shear under conditions of zero strain in orthogonal directions depends directly on the value of $v$, as seen in Equations 3 and 5. The $v=1 / 2$ case gives isotropic stress and hence no shear generated. As shown below, the same considerations apply to the generation of shear by a longitudinal acoustic wave. The development below also shows how to obtain $v$ for the tank waste from measured values of longitudinal wave speed and compressibility.

For a dynamic rather than static situation, we can relate the strain to the nonrotational parts of the local displacement vector $\mathbf{s}(\mathbf{r})$ of the medium (see, for example, Joos 1950):

$$
\mathrm{e}_{\mathrm{ij}}=\left(\partial \mathrm{s}_{\mathrm{j}} / \partial \mathrm{x}_{\mathrm{i}}+\partial \mathrm{s}_{\mathrm{i}} / \partial \mathrm{x}_{\mathrm{j}}\right) / 2
$$

The equation of motion for an elastic continuum becomes (see Joos 1950):

$$
\rho\left(\partial^{2} \mathbf{s} / \partial \mathrm{t}^{2}\right)=\mathbf{g}+[\mathrm{E} /(2(1+v))]\{[2(1-v) /(1-2 v)] \nabla(\nabla \cdot \mathbf{s})-\nabla \times(\nabla \times \mathbf{s})\}
$$

Here $\rho$ is density and $\mathbf{g}$ is the body force per unit volume. The second term on the right side is $\nabla \cdot \underline{\mathbf{P}}$, with $\underline{\mathbf{P}}$ related to $\underline{\mathbf{e}}$ and $\underline{\mathbf{e}}$ related to $\mathbf{s}$ as shown above. Equation 7 has irrotational or longitudinal wave solutions satisfying

$$
\nabla \times \mathbf{s}=0
$$

and shear wave solutions satisfying

$$
\nabla \cdot s=0
$$

For the sonic probe, the shear waves generated probably yield the adjacent material almost immediately, in which case shear waves no longer propagate, because there is a dissipative but no restoring force. That is, the transverse waves do not propagate from the probe surface through the fluid to the unyielded material. By contrast, we believe that longitudinal waves propagate through the fluid (yielded) medium as ordinary sound waves and drive elastic waves in the unyielded material, though we will not treat details of that coupling. Longitudinal wave solutions to Equation 7 having zero displacement in directions perpendicular to the direction of propagation will give the oscillatory part of the strain according to Equation 6. Proposing

$$
\mathbf{s}=\operatorname{Real}\left\{\mathbf{s}_{\mathrm{o}} \exp \left[\mathbf{i}\left(\mathbf{k} \cdot \mathbf{r}-|\mathbf{k}| c_{\mathrm{l}} \mathrm{t}\right)\right]\right\}
$$

gives from Equation 7, assuming zero body force

$$
\rho c_{1}^{2}=E(1-v) /[(1+v)(1-2 v)]
$$

For the longitudinal wave, Equations 8 and 10 require $\mathbf{s}$ and $\mathbf{k}$ to be parallel.

Taking the trace of both sides in Equation 1 and noting for an isotropic stress change

$$
\begin{aligned}
& \delta\{\text { Trace } \mathbf{e}\}=\delta \mathrm{V} / \mathrm{V} \\
& \delta\{\text { Trace } \mathbf{P}\}=-3 \delta \mathrm{P}_{\mathrm{o}}
\end{aligned}
$$


where $\delta \mathrm{P}_{\mathrm{o}}$ is a pressure change, gives

$$
\kappa=3(1-2 v) / E \text {. }
$$

where $\kappa$ is the compressibility of the medium defined by

$$
\kappa=-V-1(\partial V / \partial P)
$$

where appropriate and consistent conditions are held constant in Equations 13-16. Equations 13-16 assume that one can measure compressibility by applying and isotropic pressure change without yielding the material. Equations 11 and 15 provide an experimental basis for determining $v$ and $E$ from longitudinal acoustic wave speed $c_{l}$, compressibility $\kappa$, and density pof the tank waste. Solving Equations 11 and 15 for Poisson's ratio $v$ gives

$$
v=\left(1-\kappa \rho c_{1}^{2 / 3}\right) /\left(1+\kappa \rho c_{1}^{2 / 3}\right)
$$

If the longitudinal waves of speed $c_{l}$ are simply sound waves of speed $c$ in a fluid, satisfying

$$
\mathrm{c}^{2}=(\kappa \rho)^{-1}
$$

then from Equation 17, we have $v=1 / 2$, and from Equation $15, \mathrm{kE}=0$, so that $\mathrm{E}$ is zero. With $v=$ $1 / 2$ and $E=0$, Equation 11 is indeterminate, so $c_{1}=c$ (sound speed in a fluid) is an allowed and described case, and $v=1 / 2$ is the fluid limit of an elastic medium. Acoustic waves in a homogeneous (and, by definition, isotropic) nonviscous fluid do not generate shear, however, because the stress tensor will be isotropic, i.e., $P_{1}=P_{2}=P_{3}$. We can show that the generation of shear by longitudinal waves in a homogeneous elastic medium requires $v<1 / 2$ to give the needed anisotropy in the stress tensor.

From Equations 6 and 10, give for the strain dyadic in a longitudinal plane wave

$$
\underline{\mathbf{e}}=\operatorname{Real}\left\{(\mathrm{i} / 2)\left(k s_{\mathrm{o}}+\mathrm{s}_{\mathrm{o}} \mathrm{k}\right) \exp \left[\mathrm{i}\left(\mathrm{k} \cdot \mathbf{r}-\mathrm{kc} \mathrm{c}_{\mathrm{l}} \mathrm{t}\right)\right]\right\}
$$

We will take the propagating longitudinal acoustic wave as determining departures from isotropy, so that we can take the direction of one principal axis of stress as that of $\mathbf{k}=\mathbf{a}_{1} \mathrm{k}$. We will also look only at the traveling wave part of the stress, with

$$
\underline{\mathbf{P}}=\operatorname{Real}\{\underline{\mathbf{P}} \mathbf{e} \exp [\mathbf{i}(k \cdot \mathbf{r}-\omega \mathrm{t})]\}
$$

The relation

$$
\rho\left(\partial^{2} \mathbf{s} / \partial t^{2}\right)=\nabla \cdot \underline{\mathbf{P}}
$$

gives

$$
\mathrm{P}_{1} \mathrm{o}=\mathrm{i} \rho \omega \mathrm{c}_{1} \mathrm{~s}_{\mathrm{o}}
$$

We have assumed that Equation 2 relates stress and strain for the dynamic case, even though non-zero $\nabla \cdot \underline{\mathbf{P}}$ causes acceleration. We use it to relate the tensional stresses in the no. 2 and no. 3 directions (perpendicular to $k$ ), in which there is no acceleration, to the longitudinal wave oscillatory stress. Inserting Equation 19 into Equation 2 gives

$$
\mathrm{P}_{2} \mathrm{o}=[\mathrm{E} /(1+v)]\left[\mathrm{v} /(1-2 v) \mathrm{iks}_{\mathrm{o}}\right]
$$


Inserting $P_{1} \circ$ from Equation 22 and using Equation 11 gives

$$
P_{2}{ }^{o}=[v /(1-v)] P_{1}{ }^{\circ}
$$

for the traveling wave stress, as might have been suspected from the static case.

\section{Shear Forces in Viscous Fluids}

We described the shear forces generated by a longitudinal (compressional) wave in a medium with a restoring force, and we showed that those shear forces go to zero as the medium approaches the pure fluid limit. There are also shear forces of a different nature, i.e., proportional to fluid velocity, in a viscous medium traversed by a longitudinal compressional wave. A quick estimate indicates that these are probably insufficient to contribute to breakup of remaining globs of unyielded material in the viscous fluid.

The stress tensor $\underline{\mathbf{P}}$ for a viscous fluid with velocity field $\mathbf{v}$ (with the sign convention that the force per unit volume on the fluid is $+\nabla \cdot \underline{\mathbf{P}}$ ) is

$$
\mathrm{P}_{\mathrm{ij}}=\mu\left[\left(\partial \mathrm{v}_{\mathrm{j}} / \partial \mathrm{x}_{\mathrm{i}}+\partial \mathrm{v}_{\mathrm{i}} / \partial \mathrm{x}_{\mathrm{j}}\right)-(2 / 3)(\nabla \cdot \mathrm{v}) \delta_{\mathrm{ij}}\right]
$$

where $\mu$ is viscosity and $\delta_{i j}$ is the Kronecker delta ( 1 for $\mathrm{i}=\mathrm{j}$, zero otherwise). Consider the stress associated with a longitudinal wave traveling in the $\mathbf{a}_{1}$ or $+x$ direction with associated fluid velocity

$$
v=a_{1} v_{x 0} \cos (k x-\omega t)
$$

with sound speed $c=\omega / k$ and the fluid velocity related to the acoustic wave pressure amplitude $P_{0}$ and density $\rho$ by

$$
v_{x o}=P_{o} /(p c)
$$

Assuming diagonality of the stress tensor with the $\mathbf{a}_{1}$ axis in the propagation direction, we can compute stress tensor components $\mathrm{P}_{1}=\mathrm{P}_{11}$ and $\mathrm{P}_{2}=\mathrm{P}_{22}$ along two principal axes by applying the operations of Equation 25 to Equation 26:

$$
\begin{aligned}
& P_{1}=-(4 / 3) \mu v_{x o} k \sin (k x-\omega t) \\
& P_{2}=-(1 / 2) P_{1}
\end{aligned}
$$

Defining orthogonal unit vectors $b_{1}$ and $b_{2}$ as in Equation 4 , we can compute the shear stress in the $x-y$ plane

$$
\begin{aligned}
\mathbf{b}_{1} \cdot \underline{\mathbf{P}} \cdot \mathbf{b}_{2}=\left(\mathrm{P}_{1}-\mathrm{P}_{2}\right) \sin \phi \cos \phi \\
=-2 \mu \mathrm{v}_{\mathrm{x} o} \mathrm{k} \sin (\mathrm{kx}-\omega \mathrm{t}) \sin \phi \cos \phi
\end{aligned}
$$

which has a maximum value (using Equation $27, k=\omega / c$, and $\omega=2 \pi f$ ):

$$
\left(\mathbf{b}_{1} \cdot \underline{\mathbf{P}} \cdot \mathbf{b}_{2}\right)_{\max }=2 \pi f \mu \mathrm{P}_{\mathrm{o}} /\left(\rho c^{2}\right)
$$

For estimating the magnitude of this shear in an acoustic wave in the mixture, we can use as an approximate sound speed relation (see Appendix B):

$$
c^{2}=k_{\text {poly }} P_{\text {bub }} /\left[\rho_{1} \alpha(1-\alpha)\right]
$$


and density

$$
\rho=\rho_{1}(1-\alpha)
$$

where $\mathrm{k}_{\text {poly }}$ is the polytropic constant for bubble compression/expansion, $\mathrm{P}_{\text {bub }}$ is the pressure inside bubbles, $\rho_{1}$ is liquid density, and $\alpha$ is gas volume fraction. Inserting Equations 32 and 33 into Equation 31 gives

$$
\left(\mathbf{b}_{1} \cdot \underline{\mathbf{P}} \cdot \mathrm{b}_{2}\right)_{\max }=2 \pi f \mu \alpha \mathrm{P}_{\mathrm{o}} /\left(\mathrm{P}_{\text {bub }} \mathrm{k}_{\text {poly }}\right)
$$

Taking as representative values of early post-yield sonification conditions

$$
\begin{array}{ll}
\mu . & =10 \mathrm{~kg} /(\mathrm{m} \mathrm{sec})=10,000 \mathrm{cP} \\
\alpha & =0.08 \\
\text { Pbub } & =1.5 \text { atmospheres }=1.5 * 1.013 \times 105 \text { Pascals } \\
\mathrm{f} & =100 \mathrm{~Hz} \\
\mathrm{k}_{\text {poly }} & =1
\end{array}
$$

we obtain

$$
\left(\mathbf{b}_{1} \cdot \underline{P} \cdot \mathbf{b}_{2}\right)_{\max }=3.3 \times 10^{-3} \mathrm{P}_{\mathrm{o}}
$$

A pressure amplitude of 90,000 Pascals or 0.9 atmospheres would be necessary to produce a shear stress of 300 Pascals in the viscous liquid. There may be some effective shear stress amplification to globs of unyielded material in the viscous liquid, but we conclude that the shear stresses in the viscous liquid following yielding of the elastic material would be comparatively ineffective in breaking up remaining globs of material with a yield strength.

\section{Implications for Tank Waste Yielding}

If one believes measured shear strengths and this "smeared homogenous medium" approximation, and also believes that the medium yields in shear, one can calculate the longitudinal wave amplitude needed to achieve shear yielding, provided one knows the value of Poisson's ratio $v$ for the medium. The most favorable (for yielding the material) ratio of acoustic pressure amplitude to shear stress is 2, i.e., the pressure amplitude is twice as large, and this occurs for Poisson's ratio $v=0$. The $v=0$ condition occurs if there is complete "stress relief" in the direction perpendicular to the acoustic wave transmission. Because of local "stress relievers" in the directions perpendicular to the acoustic wave propagation due to local planes of gas concentration, and because of amplification of stress due to inhomogeneities like solid particles or bubbles, it is likely that some yielding does occur from acoustic waves whose amplitude is equal to the shear strength of the medium (as measured by shear vanes or other methods) to within a factor of about 2 .

The development presented here allows a prediction of Poisson's ratio for the tank waste from measurements of longitudinal wave speed, compressibility, and density. One can then calculate the ratio of shear stress to acoustic wave amplitude in the "smeared homogenous medium" approximation.

The expression for Poisson's ratio (Equation 17) also provides some useful bounds on physical properties. From the accepted bounds on Poisson's ratio

$$
0<v<1 / 2
$$


we deduce

$$
1 / 3<\kappa^{2} c_{1}^{2} / 3<1
$$

This could be used to set bounds, for example, on longitudinal wave speed in the unyielded material if its compressibility and density are known. For fluids, of course, $\kappa \rho$ determines sound speeds exactly.

The yielding of the tank waste is probably not a simple static failure in shear. The inhomogeneities introduced by bubbles and also solids can produce local stress amplifications and local shear from macroscopic tension and the reverse. Also, dynamic failure modes coming from oscillations of various kinds (radial oscillations of bubbles, thermal oscillations, and relative motion of bubbles and liquid due to oscillating pressure gradients) have been proposed. For these reasons, and also because of the large uncertainties in the shear strength, we think that requiring the acoustic pressure amplitude for yielding to be twice the measured shear strength is reasonable as a yielding criterion for predictive simulations.

It should be noted that we have not attempted to simulate the acoustic wave propagation in the elastic medium, only in the liquid. We have not addressed the problem of reflection and transmission of the acoustic wave at the interface between yielded and unyielded material. We have made the assumption that the acoustic wave in the yielded liquid couples to one of comparable amplitude in the unyielded medium.

\section{References}

Joos, G. 1950. Theoretical Physics, Third Edition. Hafner Publishing Company, Riverside, New Jersey. 


\section{Appendix D}

Bubble Breakaway Theory 


\section{Appendix D}

\section{Bubble Breakaway Theory}

We shall in this appendix deduce some features of the motion and forces experienced by objects, particularly bubbles and particles, in fluids subjected to acoustic waves. We shall make the assumption that the acoustic waves are of a single frequency and of wavelength long compared to dimensions of the objects.

In a pressure wave in the $\mathrm{x}$-direction:

$$
\begin{aligned}
& \mathrm{P}(\mathrm{x}, \mathrm{t})=\mathrm{P}_{\mathrm{O}} \cos [\omega(\mathrm{t}-\mathrm{x} / \mathrm{c})] \\
& \mathrm{v}_{\mathrm{f}}(\mathrm{x}, \mathrm{t})=\left[\mathrm{P}_{\mathrm{O}} /(\rho \mathrm{c})\right] \cos [\omega(\mathrm{t}-\mathrm{x} / \mathrm{c})] \\
& \mathrm{x}_{\mathrm{f}}(\mathrm{x}, \mathrm{t})=\left[\mathrm{P}_{\mathrm{O}} /(\omega \rho \mathrm{c})\right] \sin [\omega(\mathrm{t}-\mathrm{x} / \mathrm{c})]
\end{aligned}
$$

Here $x_{f}$ and $v_{f}$ are position and velocity, respectively, of an element of fluid measured relative to mean position and mean velocity of the fluid near position $x$. It is assumed that the amplitude of $x_{f}$, namely $\mathrm{P}_{\mathrm{O}} /(\omega \rho c)$, is small compared with the wavelength $\lambda(=2 \pi \mathrm{c} / \omega)$. In the above equations, $\mathrm{P}$ is the acoustic pressure change relative to ambient, $P_{O}$ is the amplitude of the acoustic pressure oscillation, $\omega$ is $2 \pi f, f$ is frequency, $c$ is sound speed, and $\rho$ is the mean fluid density.

The force from the acoustic pressure field on an object whose dimensions are small compared with the acoustic wavelength is given by

$$
\mathbf{F}=-\int_{S} P d S
$$

where the domain of the integration is the surface of the object, and the vector surface element dS is taken as having direction of the outward normal to the object surface. For purposes of the simplified arguments given here, we will neglect inertial and viscous flow effects in the pressure distribution in an immersed object in the acoustic pressure field. Using a linear approximation for the $x$ dependence of the pressure $\mathrm{P}$ along each volume element penetrating through the interior of the object in the $\mathrm{x}$-direction, we can approximate the $\mathrm{x}$ component $\mathrm{F}_{\mathrm{x}}$ of this force by

$$
F_{x}=-(\partial P / \partial x) V
$$

where $\mathrm{V}$ is the volume of the object, and the partial derivative is evaluated at some representative point near the object.

An object subject only to the acoustic pressure field described by Equation 1 would experience an acceleration according to Newton's second law:

$$
m \mathrm{~d}^{2} \mathrm{x}_{\mathrm{p}} / \mathrm{dt}^{2}=-(\partial \mathrm{P} / \partial \mathrm{x}) \mathrm{V}
$$

Here $m$ is the mass of the object (particle), $x_{p}$ is its position, and $d^{2} x_{p} / d^{2}$ is its acceleration. We can use this relation as both a consistency check and to confirm a relation which we might have suspected. Suppose that we examine the conditions under which an object moves with the fluid medium under the acoustic oscillation. For this to be true, it would be necessary that 


$$
\mathrm{d}^{2} \mathrm{x}_{\mathrm{p}} / \mathrm{dt} 2=\partial \mathrm{v}_{\mathrm{f}} / \partial \mathrm{t}
$$

If one substitutes into Equation 6, the value of $\partial \mathrm{v}_{\mathrm{f}} / \partial \mathrm{t}$ from Equation 2 for $\mathrm{d}^{2} \mathrm{x}_{\mathrm{p}} / \mathrm{dt}^{2}$ and the value of $\partial \mathrm{P} / \partial \mathrm{x}$ from Equation 1, one finds for the condition for the object to follow the acoustic motion of the fluid

$$
-\mathrm{P}_{\mathrm{O}} \omega /(\mathrm{pc})=-\mathrm{VP}_{\mathrm{O}} \omega / \mathrm{c}
$$

or

$$
\mathrm{m}=\rho \mathrm{V}
$$

That is, the object moves with the acoustic motion of the fluid if its mass is the same as that of the fluid it displaces. A composite body, like a bubble attached to a particle in a liquid, will move with the acoustic motion of the liquid if the average density is that of the liquid.

Now let us consider the forces necessary to keep a composite body joined while in a medium exposed to an acoustic wave. Suppose that the composite body comprises two parts: body 1, which could be a bubble, and body 2 , which could be a particle in the suspension. The equations of motion of the two parts of the composite are

$$
\begin{aligned}
& \mathrm{m}_{1} \mathrm{~d}^{2} \mathrm{x}_{1} / \mathrm{dt}^{2}=\mathrm{F}_{1, \mathrm{x}} \\
& \mathrm{m}_{2} \mathrm{~d}^{2} \mathrm{x}_{2} / \mathrm{dt}^{2}=\mathrm{F}_{2, \mathrm{x}}
\end{aligned}
$$

The forces on each of the two bodies is a sum of the acoustic pressure force and the force from the other body:

$$
\begin{aligned}
& F_{1, x}=-i \cdot \int_{S 1}, P d S+F_{21, x} \\
& F_{2, x}=-i \cdot \int_{S 2}, P d S+F_{12, x}
\end{aligned}
$$

Here S1' and S2' are the interface surfaces between body 1 and the liquid and between body 2 and the liquid, respectively. The unit vector $\mathbf{i}$ is in the $x$-direction. It is convenient to artificially extend the surfaces of integration to the entire surface of each body by defining a fictitious fluid pressure on the interface between them as that which would exist there if the bodies were absent. We can then approximate

$$
\begin{aligned}
& F_{1, x}=-(\partial P / \partial x) V_{1}+F_{21, x} \\
& F_{2, x}=-(\partial P / \partial x) V_{2}+F_{12, x},
\end{aligned}
$$

where the forces $F_{21, x}$, and $F_{12, x}$ represent the interaction forces between the two bodies in excess of that given by the pressure interaction:

$$
\begin{aligned}
& F_{21, x}{ }^{\prime}=F_{21, x}+i \cdot \int_{S 12} P d S \\
& F_{12, x}{ }^{\prime}=F_{12, x}+i \cdot \int_{S 21} P d S
\end{aligned}
$$

The surface S12 is the surface of body 1 that is the interface with body 2 , and $S 21$ is the surface of body 2 that is the interface with body 1 . It is the interaction forces $F_{21, x}$, and $F_{12, x}$, which 
we believe to be essentially those coming from surface tension effects in the case of a bubble attached to a solid. This interpretation is supported by the qualitative observation that the force to hold a gasfilled plastic bag at the bottom of a liquid-filled vessel is similar whether the bag is tied and suspended with a string or has its open end glued to the vessel bottom with the solid bottom then completing the enclosure.

Note that if the two bodies are aligned with their interface surface normal perpendicular to the $x$-direction, then

$$
F_{21, x}{ }^{\prime}=F_{21, x}
$$

and

$$
F_{12, x^{\prime}}=F_{12, x}
$$

For this case, the force trying to separate the two bodies is a shear force, which, in the case of the bubble attached to a solid, would be resisted primarily by surface tension. The bubble shape near the interface would probably be arranged so that surface tension does resist the shearing.

Most bubble breakaway in long-wavelength somic waves probably occurs in tension rather than shear, however. From Equations 10 through 16, the acceleration of the $x$-component of the relative position of the two bodies will be

$$
\mathrm{d}^{2}\left(\mathrm{x}_{1}-\mathrm{x}_{2}\right) / \mathrm{dt}^{2}=-(\partial \mathrm{P} / \partial \mathrm{x})\left(\mathrm{V}_{1} / \mathrm{m}_{1}-\mathrm{V}_{2} / \mathrm{m}_{2}\right)+\left(1 / \mathrm{m}_{1}+1 / \mathrm{m}_{2}\right) \mathrm{F}_{21, \mathrm{x}^{\prime}}
$$

We have used $F_{21, x}$ ' $=-F_{12, x}$.

Consider conditions for the left hand side of Equation 21 to be zero, i.e., for the relative positions of the two bodies to undergo zero acceleration. If $\left(V_{1} / m_{1}-V_{2} / m_{2}\right)$ is zero, i.e., if the densities of body 1 and body 2 are equal, then the force $F_{21, x}$ ' from body 2 on body 1 to hold them together is zero. That is, if both bodies have equal density, the acoustic pressure gradient (or other static pressure gradient) does not try to separate them. If, on the other hand, the density of body 1 (bubble) is negligible compared with that of body 2 (suspended solid), then the terms in $1 / \mathrm{m}_{1}$ and $\mathrm{V} / \mathrm{m}_{1}$ are huge unless their multiplier is small, and we obtain by setting the coefficient of $1 / \mathrm{m}_{1}$ on the right hand side of Equation 21 the requirement for non-separation:

$$
\mathrm{F}_{21, \mathrm{x}}=(\partial \mathrm{P} / \partial \mathrm{x}) \mathrm{V}_{1}
$$

For bubbles attached to solids, this adhesion force should be proportional to the product of some critical adhesion perimeter length $\mathrm{L}_{\mathrm{ca}}$, the liquid surface tension, and an effective cosine of angle between the surface tension force direction and the direction of separation. Observation of the shapes of droplets adhering to walls leads us to believe that just prior to breakaway, the surface tension along the critical adhesion perimeter is directly resisting breakaway. This is the case, for example, if the final stage of the breakaway process is a necking down of a gas tube connecting the main part of the bubble to the solid. Hence we write for the breakaway condition

$$
\mathrm{L}_{\mathrm{ca}} \mathrm{S}=(\partial \mathrm{P} / \partial \mathrm{x}) \mathrm{V}
$$

where $\mathrm{S}$ is surface tension, $\partial \mathrm{P} / \partial \mathrm{x}$ is the pressure gradient, $\mathrm{V}$ is bubble volume, and $\mathrm{L}_{\mathrm{ca}}$ is the critical adhesion parameter length. We expect the critical adhesion perimeter $\mathrm{L}_{\mathrm{ca}}$ to be on the order of the smaller of the solid object perimeter and the attached bubble perimeter.

It should be noted that the assumptions in the argument leading to Equation 23 are equally 
valid for static pressure gradients and for long wavelength acoustic pressure gradients. For a vertical gravitational pressure gradient, $\partial \mathrm{P} / \partial \mathrm{x}=\rho \mathrm{g}$, Equation 23 can be used to predict the breakaway diameters of bubbles leaving truncated cylindrical projections protruding from the bottom of a vessel of water at ambient conditions with $\mathrm{S}=75$ dynes $/ \mathrm{cm}$ :
Diameter of projection
Diameter of breakaway bubbles
$0.01 \mathrm{~cm}$
$0.1 \mathrm{~cm}$
$0.166 \mathrm{~cm}$
$0.358 \mathrm{~cm}$

These are plausible numbers in keeping with qualitative observations, though we have not made quantitative measurements.

In an acoustic wave (Equation 1), we expect

$$
(\partial \mathrm{P} / \partial \mathrm{x})_{\max }=\mathrm{P}_{\mathrm{O}} \omega / \mathrm{c}=\mathrm{P}_{\mathrm{O}} 2 \pi \mathrm{f} / \mathrm{c}=\mathrm{P}_{\mathrm{O}} 2 \pi / \lambda
$$

and, from Equation 23,

or

$$
\mathrm{D}_{\mathrm{B}}{ }^{3}=3 \mathrm{D}_{\mathrm{ca}} \mathrm{Sc} /(\pi \mathrm{fP})=3 \mathrm{D}_{\mathrm{ca}} \mathrm{S} \lambda /\left(\pi \mathrm{P}_{\mathrm{O}}\right)
$$

$$
\mathrm{D}_{\mathrm{B}}{ }^{2}=3 \mathrm{Sch} /(\pi \mathrm{fPO})
$$

where $P_{O}$ is the acoustic pressure amplitude, $D_{c a}$ is the critical adhesion diameter $\left(=L_{c a} / \pi\right), D_{B}$ is the minimum bubble diameter for breakaway, and $h\left(=D_{c a} / D_{B}\right)$ is the ratio of critical adhesion diameter to bubble diameter.

Equations 25 and 26 show plausible trends with all the parameters which appear there. The minimum diameter of bubbles released should increase with increasing critical adhesion diameter, surface tension, and wavelength of sound, and should decrease with frequency of sound and sound pressure amplitude.

It should be emphasized that Equations 23, 25, and 26 attempt to describe the breaking away of existing bubbles from structures to which they are adhering. They do not describe acoustic cavitation nor the "rectified diffusion" process of removal of dissolved gas from liquid into bubbles. 


\section{Appendix E}

Modeling of Transients in Material Yielding and Gas Release in Sonic Probe Mitigation of Gas-Producing Radioactive Waste Tanks 


\section{Appendix E}

\section{Modeling of Transients in Material Yielding and Gas Release in Sonic Probe Mitigation of Gas-Producing Radioactive Waste Tanks}

\section{E.1 Coupled Sonification and Fluid Dynamics Modeling}

This modeling effort seeks to predict time scales and sequences of events in the yielding and degasification of sludge with trapped bubbles by low frequency sonic vibration. A model for acoustical pressure waves that are attenuated due to geometric shape and bubble rheology of the media is coupled to a fluid dynamics calculation to investigate the spatial yielding and subsequent motion of Bingham-type fluid media (Chhabra 1993). There is circulation and gas release primarily because the material in some regions is sufficiently buoyant to rise with respect to the surrounding material. Gas release calculations require fluid dynamic simulation to describe this transport. The present method couples the sonification with the convective fluid mechanics in the TEMPEST code to predict the density driven convective flow in transporting bubbles.

Operation of the probe depends on propagating a pressure wave through the waste at an amplitude that exceeds its yield strength. However, the bubbles in the waste strongly attenuate the pressure wave. This is in addition to the geometric attenuation from the cylindrical nature of the source. Attenuation and wave velocity vary spatially, since the distribution of gas and solids varies spatially (especially as yielded material gives up its trapped bubbles, which then move). The transient nature of the sonic probe operation is apparent.

The present work includes the development of specialized models which together form an integrated computational method for predicting the probe action on waste tanks:

1. Acoustical wave propagation with spatially varying wave speed and attenuation

2. Bubble/particle attenuation of sound waves

3. Probe harmonic pressure wave generation

4. Sludge shear stress yield criteria

5. TEMPEST fluid dynamics transient calculations

Application of the computational modeling is directed at two Hanford waste tanks; 241-SY$101 \& 241-S Y-103$, though it is hoped that some results are generic to mitigation of other tanks with similar properties. The aim of the analyses is to provide trends in the coupled sludge yielding and convective transport based on available initial conditions and rheology models.

\section{E.2 Wave Equation Technique}

The sound propagation physics for bubbly media with attenuation/dissipatory mechanics is variously reported in the form (Nakoryakov, et al. 1993)

$$
\frac{\partial^{2} \mathrm{p}}{\partial \mathrm{t}^{2}}-\mathrm{c}^{2} \nabla^{2} \mathrm{p}+\left\{4^{\mathrm{th}} \text { order terms }\right\}=2\left(v \frac{\partial}{\partial \mathrm{t}}\left[\nabla^{2} \mathrm{p}\right]\right)
$$


and, in simplified form, according to Kytomaa (PNL)

$$
\frac{\partial^{2} \mathrm{p}}{\partial \mathrm{t}^{2}}-\mathrm{c}^{2} \nabla^{2} \mathrm{p}=\text { Constant } \mathrm{x}\left(v \frac{\partial}{\partial \mathrm{t}}\left[\nabla^{2} \mathrm{p}\right]\right)
$$

about $\frac{p}{t}$. The general dissipatory wave equation becomes

$$
\frac{1}{c^{2}} \frac{\partial^{2} p}{\partial t^{2}}+B \frac{\partial p}{\partial t}-\nabla^{2} p=0
$$

which has the matrix form

$$
\left\{\frac{1}{c^{2}}\right\}^{T}\{\ddot{p}\}+\{B\}^{T}\{\dot{p}\}+[K]\{p\}=0
$$

where the wave velocity (c), dissipation (B), and Laplacian [K] vary spatially. The numerical procedure for reducing the wave equation to algebraic form is the Newmark Composition (Levy and Wilkinson 1976):

$$
\begin{gathered}
\left(\left\{\frac{1}{c^{2}}\right\}^{T} a_{0}+a_{1}\{B\}^{T}+[K]\right)\left\{p^{n+1}\right\}=\{\hat{F}\}+ \\
\left\{\frac{1}{c^{2}}\right\}^{T}\left(a_{0}\left\{p^{n}\right\}+a_{2}\left\{\dot{p}^{n}\right\}+a_{3}\left\{\ddot{p}^{n}\right\}\right)+\{B\}^{T}\left(a_{1}\left\{p^{n}\right\}+a_{4}\left\{\dot{p}^{n}\right\}+a_{5}\left\{\ddot{p}^{n}\right\}\right)
\end{gathered}
$$

where

$$
\begin{aligned}
& a_{0}=\frac{1}{\alpha \Delta t^{2}} \quad a_{4}=\frac{\delta}{\alpha}-1 \\
& a_{1}=\frac{\delta}{\alpha \Delta t} \quad a_{5}=\frac{\Delta t}{\alpha}\left(\frac{\delta}{\alpha}-2\right) \\
& a_{2}=\frac{1}{\alpha \Delta t} \quad a_{6}=\Delta t(1-\delta) \\
& a_{3}=\frac{1}{2 \alpha}-1 \quad a_{7}=\delta \Delta t
\end{aligned}
$$

The Newmark parameters are selected for unconditional stability:

$$
\alpha=\frac{1}{4}(1+\gamma)^{2} ; \delta=\frac{1}{2}+\gamma
$$

where $\gamma$ is an amplitude decay factor usually taken to be a small value, typically about 0.005 . The procedure is completed by defining

$$
\left\{\ddot{p}^{n+1}\right\}=a_{0}\left(\left\{p^{n+1}\right\}-\left\{p^{n}\right\}\right)-a_{2}\left\{\dot{p}^{n}\right\}-a_{3}\left\{\ddot{p}^{n}\right\}
$$


and

$$
\left\{\dot{\mathrm{p}}^{\mathrm{n}+1}\right\}=\left\{\dot{\mathrm{p}}^{\mathrm{n}}\right\}+\mathrm{a}_{6}\left\{\ddot{\mathrm{p}}^{\mathrm{n}}\right\}+\mathrm{a}_{7}\left\{\ddot{\mathrm{p}}^{\mathrm{n}+1}\right\}
$$

\section{E.2.1 TEMPEST/PROBE Formulation}

The major assumption in the acoustical pressure field model is that the resulting traveling wave does not induce macro motion in the fluid, such as to effect the normal transport prediction being performed in TEMPEST. The corollary to this is that the pressure field predicted by the propagating wave solution is a perturbation to the nominal fluid hydrodynamic pressure and may be treated separately. The instantaneous fluid pressure is the sum of the low-frequency hydrodynamic pressure and high-frequency acoustical pressure, as

$$
P(\vec{x}, t)=p(\vec{x}, t)+P(\vec{x}, t)
$$

where $P(x, t)$ is contained in the TEMPEST formulation (Trent and Eyler 1993) of the Navier-Stokes equations:

$$
\frac{D \rho \vec{U}}{D t}=-\nabla P+\nabla \times[\mu(\nabla \times \vec{U})]+\vec{F}_{b}
$$

and $P(x, t)$ is treated with the acoustical wave formulation. In the TEMPEST/PROBE formulation, the effect of the propagating pressure wave is to determine whether the non-Newtonian fluid has yielded.

The finite difference, control volume mechanics employed by TEMPEST for fluid field equations are carried over to the wave equation procedure. Discrete wave propagation pressure nodal space is identified as the fluid cells in a model. Because TEMPEST presently forms a Laplacian for fluid pressure field solution, the mechanics are utilized in forming the [K] matrix in the wave equation. An implicit formulation of the global matrix system is constructed as

$$
(\{\mathrm{A}\}+[\mathrm{K}])\left\{\mathrm{p}^{\mathrm{n}+1}\right\}=\left\{\mathrm{b}^{\mathrm{n}}\right\}
$$

where

$$
\{A\}=\left\{\frac{1}{c^{2}}\right\}^{T} a_{0}+a_{1}\{B\}^{T}
$$

and a transient multiple time step solution is performed via skyline banded matrix solution. The boundary conditions enter by modeling "solid" cells (Type 60 in TEMPEST nomenclature) with some specified cyclic frequency and time-dependent amplitude. These cells with specified pressure may have unique delay times for the driver period, as might be expected for modeling circumferential cyclic motion.

\section{E.2.2 Fluid Transient Computation}

The fluid-wave solution methodology is to decouple the transient wave propagation excursion from the fluid transient. Resolution of the wave propagation requires much smaller time steps than the fluid TEMPEST simulation. In addition, evolution of the non-Newtonian yield-influenced coefficients is considered to occur far slower than the period for wave propagation resolution. Therefore, at particular TEMPEST time snapshots, the constitution of the pressure wave equation is 
formed and a linear transient performed to find a time-domain solution from which a "steady" peak spatial pressure amplitude field is obtained. The period of the march is assumed to be some duration much less than the TEMPEST convection history time. Several of these pressure wave computation periods occur during the convection history. The sequence is as follows:

TEMPEST: Advance fluid state in time with appropriately chosen period $\Delta t$

Wave Eq.: If it is time to update yielded cells list, divide time interval $\Delta t$ into sub-intervals $\Delta \tau$ with $N \Delta \tau=\Delta t$, solve acoustic wave equation, and update yielded cell list.

At several reoccurring "initiation" points during the TEMPEST transient, a general linear system is formed:

$$
[M]\left\{p^{n+1}\right\}=\left\{b^{n}\right\}
$$

where $[M]=\{\mathrm{A}\}+[\mathrm{K}]$ and $[\mathrm{bn}]$ is the right hand side vector. The $[\mathrm{M}]$ is constant over the period of this march $(\mathrm{N} \Delta \tau)$ if the cell acoustic velocity, $\mathrm{c}(\mathrm{x}, \mathrm{y}, \mathrm{z})$, and $\{\mathrm{B}\}$, the dissipatory coefficient, are constant. [K], by definition, is spatial only.

For the first step of $N,(N=\Delta$ period $/ \Delta \tau)$, the inverse of $[M]$ is performed such that

$$
\left\{p^{1}\right\}=[M]^{-1}\left\{b^{0}\right\}
$$

$[\mathrm{M}]^{-1}$ is stored and successive steps ( 2 through $\mathrm{N}$ ) are performed with simple linear multiplication updating $\{b\}$ at every step. The process is repeated as many times as deemed necessary during the total convection transient.

The fluid transient is then continued, with cell yield conditions updated according to the highest pressure amplitude reached, and the new constituent spatial void distribution is allowed to evolve. Successive iterations between the fluid evolution and pressure propagation fields during a transient develops the gas release prediction history.

\section{E.3 Sonic Velocity and Acoustic Dissipation Physics}

A bubbly mixture model was used in TEMPEST in a solution for acoustic waves in time domain. A condensed outline of its implementation in the TEMPEST code is presented in Appendix $\mathrm{B}$ of this report, including, in particular, the contributions to the attenuation per unit length $\xi$, where also $\xi=\mathrm{k}_{\mathrm{i}}$, the imaginary part of the propagation vector, is in the complex Fourier form.

For these computations, sonic velocity of the mixture is taken as $\mathrm{C}_{\mathrm{mo}}$, given by

$$
C_{\mathrm{mo}}^{2}=\frac{k p_{0}}{\rho_{1}} \frac{1}{\alpha(1-\alpha)}
$$

where $\mathrm{k}$ is the polytropic gas constant, and $\alpha$ is the gas volume fraction. This expression assumes that the volume fraction, $\alpha$, of the gas is sufficiently high that volume changes of the mix with pressure come predominantly from the gas. On the assumption that the bubbles are sufficiently small that they remain at the same temperature as the liquid, the polytropic constant is taken as unity. 


\section{E.3.1 Velocity-Related Parameter c}

The parameter $c$, which has dimensions of velocity, and the dissipation parameter $B$, in the linearized dissipative wave equation, are obtained by forcing agreement with the complex plane wave Fourier solution form:

$$
P=P_{0} e^{i(k x-\omega t)}
$$

Inserting this plane wave form into the linearized dissipative wave equation (with $B \partial p / \partial t$ as the dissipative term) presented earlier gives

$$
-\frac{\omega^{2}}{c^{2}}-i \omega B+k^{2}=0
$$

where

$$
\begin{aligned}
\mathrm{k}^{2} & \left.=\left(\mathrm{k}_{\mathrm{r}}+\mathrm{i} \mathrm{k}_{\mathrm{i}}\right)^{2} \quad \text { real \& imaginary }\right\} \\
& =\frac{\omega^{2}}{\mathrm{c}^{2}}+\mathrm{i} \omega \mathrm{B}
\end{aligned}
$$

$\mathrm{B}$, then, for agreement with the (assumed known) attenuation per unit length $\xi=\mathrm{k}_{\mathrm{i}}$, becomes

$$
B=\frac{2}{C_{m}} \xi=\frac{2}{\omega}\left[\frac{\omega^{2}}{c^{2}}+\xi^{2}\right]^{1 / 2} \xi
$$

Requiring that $\mathrm{k}_{\mathrm{r}} / \omega$ be the sound speed, $\mathrm{C}_{\mathrm{m}}$, of the mixture gives the parameter $\mathrm{c}$ in the linearized dissipative acoustic wave equation as

$$
c=\frac{1}{\left(\frac{1}{C_{m}^{2}}-\frac{\xi^{2}}{\omega^{2}}\right)^{1 / 2}}
$$

which is assumed correct for

$$
\frac{1}{C_{m}^{2}}>\frac{\xi^{2}}{\omega^{2}}
$$

\section{E.3.2 Pressure Wave Equation Dissipation Coefficient B}

The dissipation term, $\mathrm{B}$, in the pressure equation is set in these transient simulations as

$$
\mathrm{B}=2 \frac{\xi_{\mathrm{t} \text { ave }}+\xi_{\mathrm{mave}}+\xi_{\mathrm{b} \text {,ave }}}{C_{\mathrm{m}}}
$$


where $\xi_{\mathrm{t} \text {,ave }}, \xi_{\mathrm{m} \text {,ave, and }} \xi_{\mathrm{b} \text {,ave }}$ are the thermal, relative motion, and bulk viscosity contributions to the attenuation coefficient (see Appendix $B$ for explicit forms), and $\mathrm{C}_{\mathrm{m}}$ is the sound speed of the mixture. When multiple bubble sizes were used, the dissipation constants $\xi$ were averaged according to this prescription:

$$
\xi_{\mathrm{ave}}=\frac{1}{\Sigma \alpha(1-\alpha)} \sum_{\mathrm{c}}\left[\xi_{c} \alpha_{c}\left(1-\alpha_{c}\right)\right]
$$

where the summation index $c$ runs over the bubble size classes present.

\section{E.4 Test Validation of Code Mechanics of TEMPEST/PROBE}

The formulation presented above and its coding were tested for

- ability to replicate sinusoidal plane wave behavior

- ability to produce the approximate $\left(r / r_{0}\right)^{-1 / 2}$ dependence of pressure on radius in a cylindrical wave without attenuation

- number of nodes per wavelength required to limit dispersion to satisfactory levels.

It was found that numerical dispersion increased rapidly if the number of cells was reduced below ten per wavelength. Taking as the measure of dispersion, the peak amplitude of an initial unit amplitude plane wave after 30 cells propagation without attenuation, it was found that 11 cells per wavelength give $90 \%$ of the initial amplitude, and 20 cells per wavelength give $\approx 99 \%$ of the initial amplitude. Twenty cells per wavelength at a sound speed of $100 \mathrm{~m} / \mathrm{s}$ and a frequency of $100 \mathrm{~Hz}$ would require cell widths not exceeding $0.05 \mathrm{~m}$ or about 2 inches. In subsequent simulations, cell widths were limited to 2.5 inches. With adequate nodalization, satisfactory sinusoidal plane wave and cylindrical wave behavior were found.

\section{E.5 Yielding Criterion}

To succeed, the modeling effort must predict effects of acoustical pressure transmittal on non-Newtonian fluid mechanics of bubbly sludge media. It is assumed that the bubbly media behaves as a thixotropic Bingham material, yielding when its shear strength is exceeded. In the present modeling, the bubbles are constrained (no motion) until the yielding shear stress is locally induced. The sonic probe develops a spatial pressure wave field which is assumed to produce a local maximum shear stress half the magnitude of the pressure amplitude (Appendix C). Since attenuation and sonic velocity are functions of local void fraction, the sonic probe spatial pressure field, and thereby the induced shearing stress, change with time as the bubbles are released and convected. There is a sort of yielding transient in which material to some radius is first yielded (resulting in gas release and bubble convection), then decaying of local void fraction occurs, attenuation is consequently reduced, and further broadening of the pressure field penetration occurs. New material is yielded and the process continues until the yield radius reaches an asymptote or the probe is turned off.

\section{E.6 Tank Modeling}

Three tanks and scenarios were considered:

- Tank 241-SY-101 in mixed condition (low gas retention and infinitesimal yield strength) 
- Tank 241-SY-101 in some aged state, i.e., (allowed to settle, accumulate gas, and regain low yield strengths in the slurry)

- SY-103 in unmixed state, i.e., virgin (high gas retention and high yield strength).

The models are similar in that there are three regions (lower sludge, slurry, and upper convecting liquid). The Initial conditions of the tanks are shown in Tables E.1-E.4.

Table E.1. Sonic Probe Analysis Matrix

\begin{tabular}{||c|c|c|c||}
\hline & $\begin{array}{c}\text { 101-SY (as is) } \\
\text { "mixed" }\end{array}$ & $101-\mathrm{SY}$ (aged) & $\begin{array}{c}\text { 103-SY (as is) } \\
\text { "unmixed" }\end{array}$ \\
\hline \hline Bubble Types (2 modeled) & $0.1 \mathrm{~mm}$ and 0.01 mm & $1 \mathrm{~mm}$ and 0.01 mm & $1 \mathrm{~mm}$ and 0.01 $\mathrm{mm}$ \\
\hline Sonic Probe P(0) & $2160 \mathrm{psf}$ & $2160 \mathrm{psf}$ & $2160 \mathrm{psf}$ \\
\hline Slurry Yield stress & $1 \mathrm{psf}$ & $1 \mathrm{psf}$ & $43.2 \mathrm{psf}$ \\
\hline Sludge Yield stress & $140 \mathrm{psf}$ & $140 \mathrm{psf}$ & $140 \mathrm{psf}$ \\
\hline Temperature Dist. & isothermal & isothermal & isothermal \\
\hline
\end{tabular}

Table E.2. Void Fraction Distribution, Tank 241-SY-101 Mixed

\begin{tabular}{||l|l|l|l||}
\hline $\begin{array}{l}\text { Void Fraction Tank 241-SY- } \\
101\end{array}$ & $\begin{array}{l}\text { Top Convecting } \\
\text { Liquid }\end{array}$ & Mobile Slurry & Bottom Sludge \\
\hline \hline Bubble Size \#1 & $2 \%$ & $4 \%$ & $4 \%$ \\
\hline Bubble Size \#2 & $2 \%$ & $4 \%$ & $4 \%$ \\
\hline
\end{tabular}

Table E.3. Void Fraction Distribution, SY-103 Unmixed

\begin{tabular}{||l|l|l|l||}
\hline $\begin{array}{l}\text { Void Fraction } \\
\text { SY-103 }\end{array}$ & $\begin{array}{l}\text { Top Convecting } \\
\text { Liquid }\end{array}$ & $\begin{array}{l}\text { Nonconvecting } \\
\text { Slurry }\end{array}$ & Bottom Sludge \\
\hline \hline Bubble Size \#1 & $4 \%$ & $8 \%$ & $5 \%$ \\
\hline Bubble Size \#2 & $4 \%$ & $8 \%$ & $5 \%$ \\
\hline
\end{tabular}

Table E.4. Void Fraction Distribution, Sy-101 Aged

\begin{tabular}{||l|l|l|l||}
\hline $\begin{array}{l}\text { Void Fraction } \\
\text { Tank 241-SY-101 (Aged) }\end{array}$ & $\begin{array}{l}\text { Top Convecting } \\
\text { Liquid }\end{array}$ & $\begin{array}{l}\text { Nonconvecting } \\
\text { Slurry }\end{array}$ & Bottom Sludge \\
\hline \hline Bubble Size \#1 & $2 \%$ & $8 \%$ & $5 \%$ \\
\hline Bubble Size \#2 & $2 \%$ & $8 \%$ & $5 \%$ \\
\hline
\end{tabular}




\section{E.6.1 Generic Features}

The waste tanks were modeled as quiescent, i.e., as retaining gas but hydrostatically stable. Without perturbation, the ideal case simply would exhibit small bubble rise but virtually no hydrodynamic motion. All the waste tank models contained similar features: 1) a three-tier distribution of gas volume fraction and solid particle density, 2) a sludge and a nonconvective slurry possessing a yield strength threshold for minimum induced shear stress "unlocking," and 3) symmetry about the tank axis. Without probe sonification, the locking of the sludge and nonconvective layer restricts fluid motion to the convective liquid.

The probe is modeled as located in the center of a cylindrical field to retain azimuthal symmetry. This symmetrization is expected to alter the convective patterns but to preserve the approximate time scale of the release of gases from the surface. The probe extends from the top of the model (convecting liquid top surface) to a point about $2 \mathrm{ft}$ above the bottom of the tank. The probe diameter is $11 \mathrm{in}$. The active length of the probe is modeled as $24 \mathrm{ft}$ (that portion above the slurry does not actually impact the calculation) and extends to the probe bottom. In addition, even though the eccentric mass motion of the probe produces an azimuthal component to the propagating wave, some symmetry conditions are employed to reduce the problem to axial-symmetric 2-D. The probe is modeled as producing a harmonic. pressure wave at a frequency of $100 \mathrm{~Hz}$. The peak amplitude at the surface of the probe is 2160 psf.

Because of the resolution required to capture the wave amplitudes, the model radii were limited to about $32 \mathrm{ft}$. This required 150 radial cells with a discretization of $2.5 \mathrm{in}$. Sonic velocities vary in the analyses from $80 \mathrm{ft} / \mathrm{sec}$ to about $200 \mathrm{ft} / \mathrm{sec}$. At $200 \mathrm{ft} / \mathrm{sec}$, the wave resolution is 9.6 cells/wave length, and only about 3 at $80 \mathrm{ft} / \mathrm{sec}$.

No gas generation is accounted for over the time scale of the analyses because it is small compared with the convective effects (Allemann 1993; Fox 1993). In the probe models, bubble and solid particle motion are activated by yielding the cell material. The sludge and nonconvective layers become hydrodynamically active with bubble and particle motion. Therefore, the nonconvective layer converts to a mobile slurry.

The initial conditions are somewhat arbitrary, because bubble volume fraction and particle density are assumed uniform in each of the tiers. The temperature distribution is modeled as isothermal because most of the buoyancy is driven by solid particle mass/gas bubble volume fraction redistribution. The convective liquid, which is Newtonian and therefore has no yield stress, actually also contains gas in some non-zero bubble volume fraction. This gas is retained in a near-neutrally buoyant condition by solid particle interaction. In the computational model, it is not possible to emulate this condition; a gas volumetric fraction in Newtonian fluid will simply initiate bubble rise. To replicate the "locked" gas-buoyant convective liquid, therefore, zero gas volume fraction is specified for that region. Gas is introduced only in the non-Newtonian slurry and sludge.

Because of the computational logic in the TEMPEST/PROBE program, the probe is actually modeled as operating in an intermittent fashion. The probe is activated at intervals in the transient whereby the sonified spatial yield field is developed. While this was simply a basic, noniterative approach to solving the sonification-convection mechanics of the fluid, the modeling approximates an intermittent sonification by allowing large (and variable) transient convective times between probe operation. It does not, however, enter into any sophisticated calculation for determining the operation period to yield the slurry; it is assumed that simply exceeding the yield criterion by the local pressure amplitude yields the sludge.

Bubble rise velocity prediction is a basic driver of gas release response time. This can be simply the period of time it takes the gas to transverse the distance of initial gas retention depth or, in a more complex manner, it may be the period to induce density stratification, which, in turn, sets up a convective motion to carry the lighter regions to the surface. In TEMPEST, the bubble rise velocity is set in the viscous regime as (Trent and Eyler 1993): 


$$
V_{\text {bubble }}=\frac{1}{18} \frac{D_{b}^{2} \Delta \rho}{\mu} g_{c}
$$

For $1 \mathrm{~mm}$ bubbles and a density difference about $100 \mathrm{lb} / \mathrm{ft}^{3}$, gas bubble rise velocities of about $5 \times 10^{-3} \mathrm{ft} / \mathrm{sec}$ are predicted. This gives about 200 seconds per foot for bubble rise. For negligible convective motion, Tank 241-SY-101 would require about 1,500 seconds for initial gas release based on the transient time through the convective layer; SY-103 would require about 1,100 seconds.

\section{E.6.2 Tank 241-SY-101 "Mixed" and "Aged" Analyses}

Tank 241-SY-101 is modeled with approximately $15 \mathrm{ft}$ of convective liquid riding on $15 \mathrm{ft}$ of sludge. In Tank 241-SY-101, a simulation of the "mixed" waste condition, i.e., previously subjected to a mixer pump, without sonification exhibits a slow bubble rise/volume fraction redistribution throughout the convective liquid. Volume fraction is split equally between the bubble sizes; $2 \%$ volume fraction from $0.1 \mathrm{~mm}$ bubbles and $2 \%$ from $0.01 \mathrm{~mm}$ bubbles in the nonconvecting layer and $4 \%$ volume fraction of each in the sludge. In this "reference" model, yield strength in the nonconvective layer is considered infinitesimal and is immediately overcome by any shear mechanism. Although the Tank 241-SY-101 model is hydrodynamically stable (no buoyant density stratification), gas percolates through the convecting layer and produces a moderate gas release rate $(\sim 20 \mathrm{ft} 3 / \mathrm{hr}$ at one hour transient time). Figure E.1 exhibits the Tank 241-SY-101 reference condition gas release rate history.

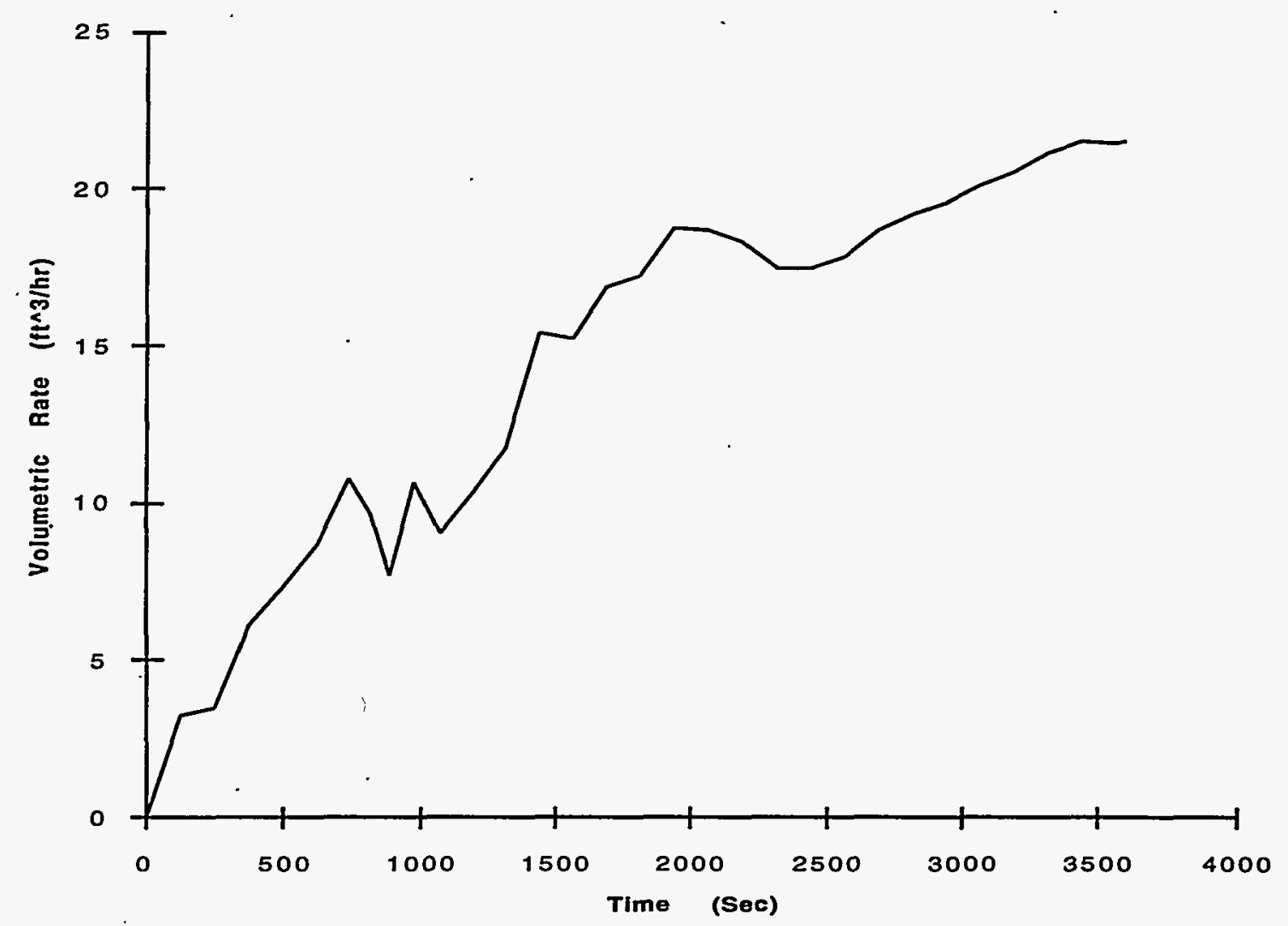

Figure E.1. Gas Release from Tank 241-SY-101 for Reference Condition "Previously Mixed" 
An "aged" alternate Tank 241-SY-101 model is emulated in which the composition of the bubble volume fraction in the nonconvective slurry is $4 \%$ from $1 \mathrm{~mm}$ bubbles and $4 \%$ from $0.01 \mathrm{~mm}$ bubbles. The model is also hydrodynamically stable. The total gas contained in the model is 3,750 $\mathrm{ft}^{3}\left(\sim 7,500 \mathrm{ft}^{3}\right.$ at standard atmosphere) in the nonconvective slurry (8\% total gas volume fraction) and $1,000 \mathrm{ft}^{3}$ in the sludge ( $16 \%$ total gas volume fraction). Initiating sonification immediately yields all of the material in the slurry (the mobile slurry yield strength of $.1 \mathrm{psf}$ is exceeded throughout the tank). The time dependent analysis following this point results in a convective hydrodynamic flow pattern, with bubble rise/particle settling inducing relative density changes causing fluid motion. The convective layer and nonconvective layer experience recirculation motion which sweeps gas to the surface. Figure E.2 shows the convective motion at 500 seconds into the transient (the point of predicted maximum gas release rate). The volume fraction distribution for $1 \mathrm{~mm}$ bubbles at this time is shown in Figure E.3.

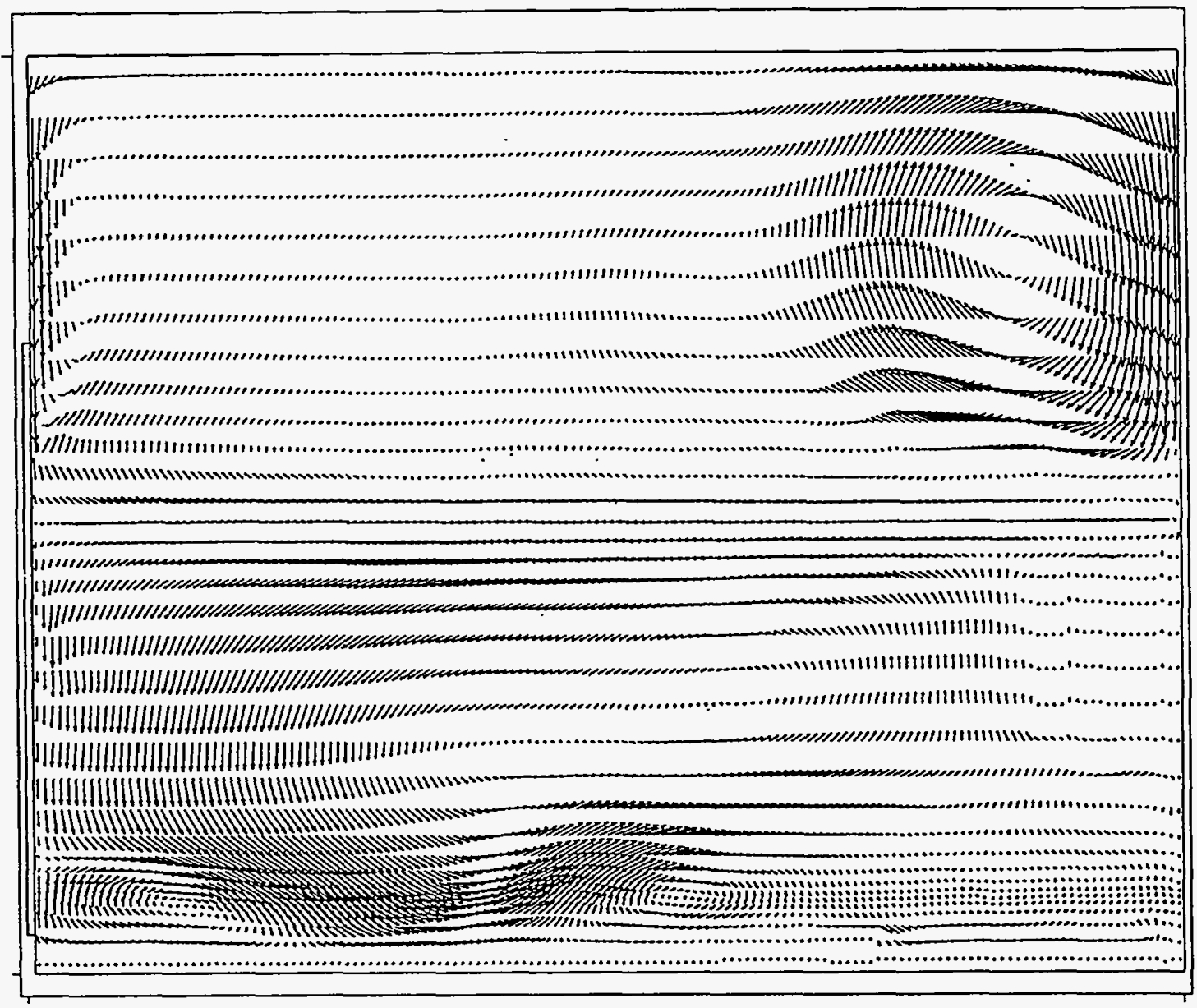

Figure E.2. Predicted Convective Velocity at 500 Second with Sonification of "Aged" Tank 241-SY-101 Waste 


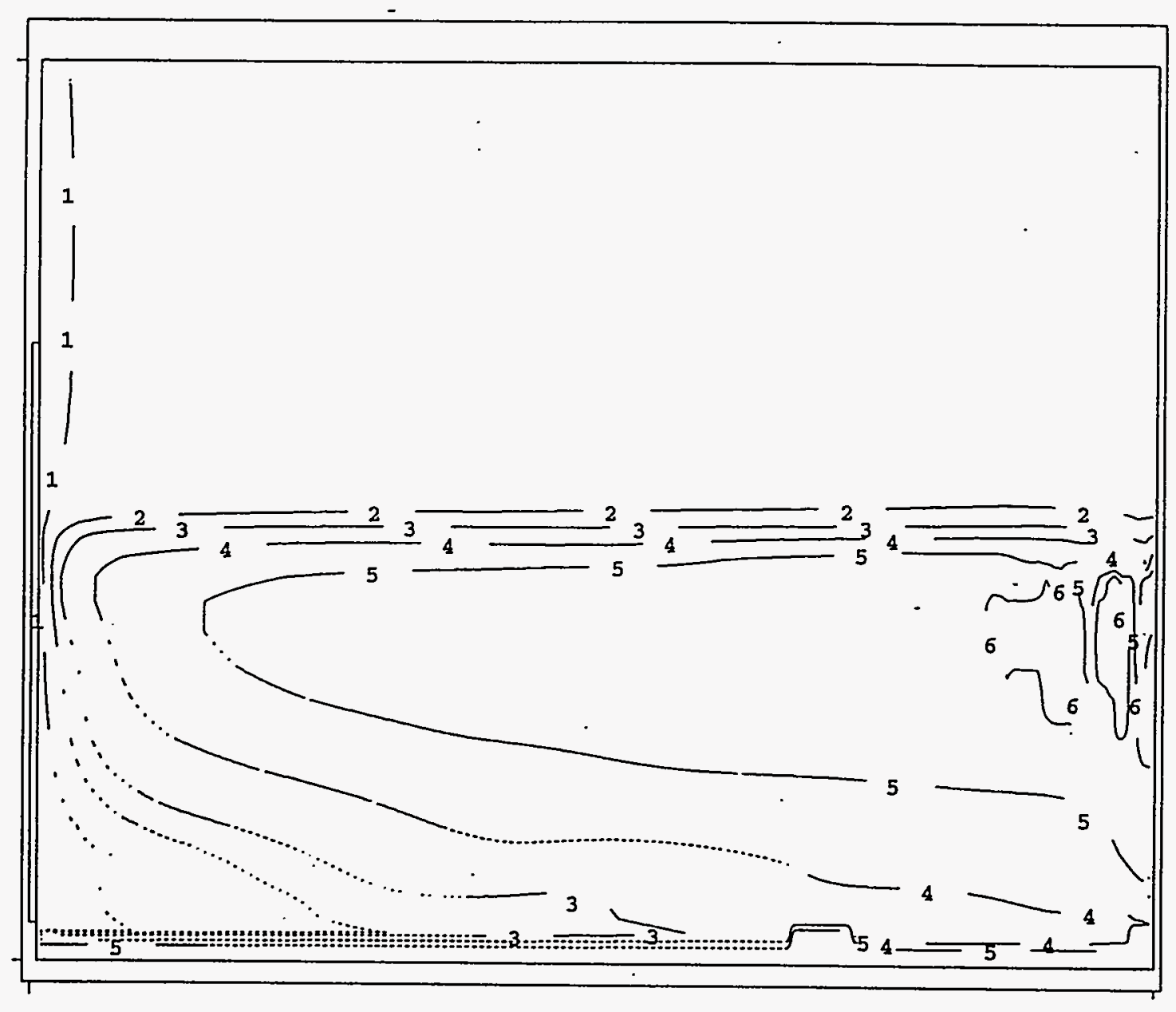

Figure E.3. Predicted Gas Volume Fraction of $1 \mathrm{~mm}$ Bubbles at 500 Second with Sonification of "Aged" Tank 241-SY-101 Waste

Note that in Figure E.2 there is a separate recirculation pattern for the nonconvective layer and for the convective liquid. This occurs because of the basic zonal density stratification; the mean density in the nonconvective layer is sufficiently greater than the convective liquid mean density that flow will not penetrate the interface. Gas passes through this quiescent interface from lower convective zone to upper convective zone. Average convective vertical ascent velocities are an order of magnitude greater than the bubble rise velocities, so that the dominating mechanism of gas release is via convective motion of the fluid in the tank rather than bubble percolation.

The gas release rate has an effective time constant much shorter than the 1500 seconds defined by simple gas percolation. Figure E.4 shows the predicted gas release history for the "aged" Tank 241-SY-101 analysis. The larger "big" bubble diameter (1 mm compared to 0.10 in the reference model) and greater volume fraction ( $8 \%$ compared to $4 \%$ ) results in a rapid increase in gas release rate up to about 500 seconds transient time. A slow decay occurs thereafter until after one hour the release rate is one order magnitude less than the maximum rate. 


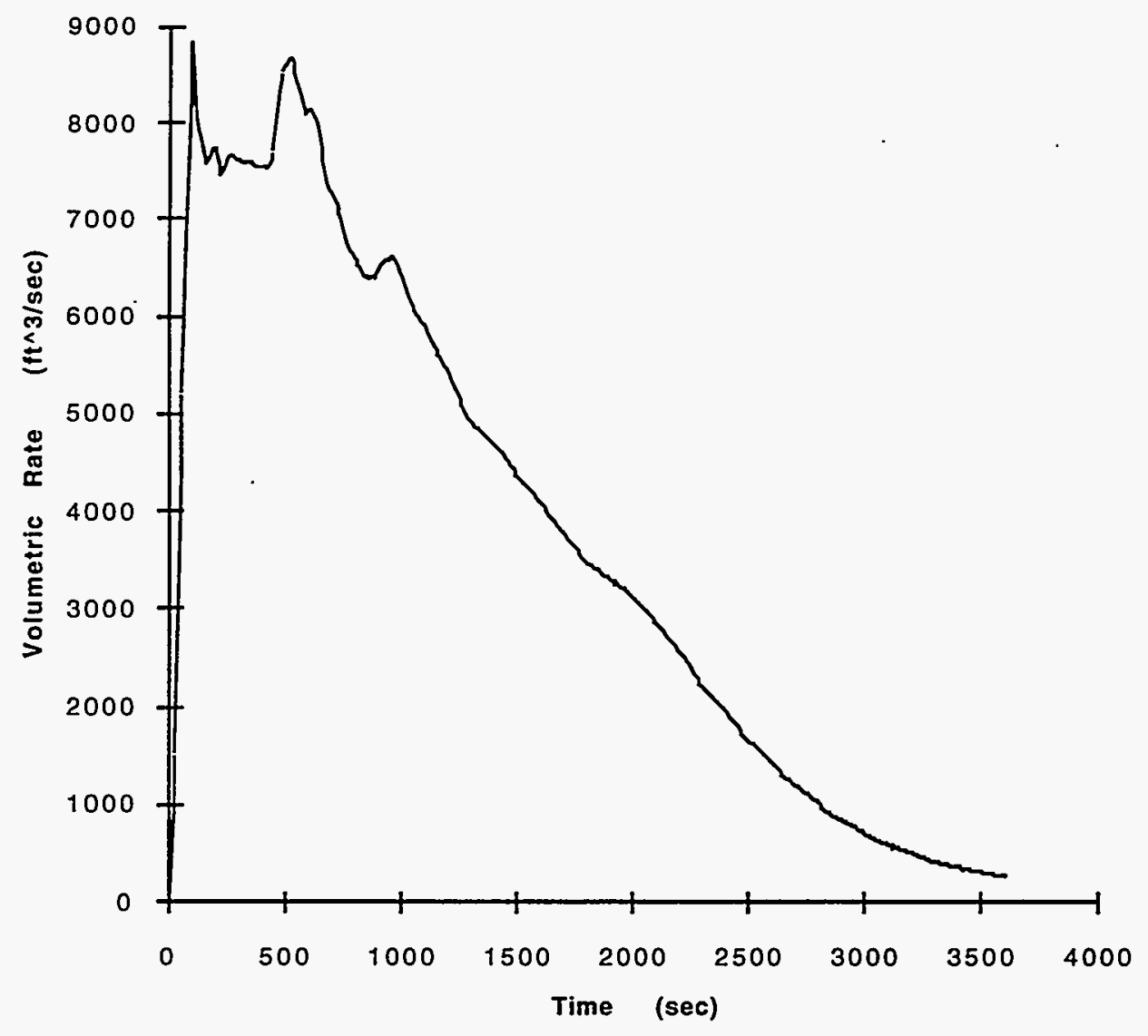

Figure E.4. Predicted Gas Release History for "Aged" 241-SY-101 Waste with Probe Operation at 400 Second Intervals

At the end of one hour, the convective motion has abated in the nonconvective layer (Figure E.5). Some convective recirculation is computed in the convective liquid, which is associated with a local radial gas volume fraction variation in the region (Figure E.6). The actual location of convective recirculation should be considered qualitative, because the developing density stratification and resulting local convective patterns are tied to evolving particle settling and relative bubble motion. It arguably does not significantly impact the gas release time scale in that the convective motion is induced by the density stratification from Stokes's specie velocities, which result in fluid motion of the predicted geometric scale and velocity in a tank of the modeled volume (Allemann, et al. 1991).

As previously indicated, sonification length of time requirements are not actually addressed by this analysis. In the present math model, the yielding of the material occurs immediately when appropriate shear stresses are reached, where in practice some accumulated shear rate time is probably required (Appendix C). Additionally, although no "reconstruction" of the shear strength is explicitly considered, the present pressure wave/stress modeling can re-introduce "rigidity" in a cell where gas bubble volume/particle mass fraction conditions alter sonification intensities and change the prior yielded state.

In general, the hydrodynamically stable mixed model of Tank 241-SY-101 produces no convective motion with small assumed bubble sizes $(0.10 \& 0.01 \mathrm{~mm})$ and gas volume fraction $(4 \%$ in the nonconvecting layer and sludge). Gas release occurs only due to percolation of the bubbles through the liquid. The "aged" model, which has a small yield strength in the nonconvective layer, 


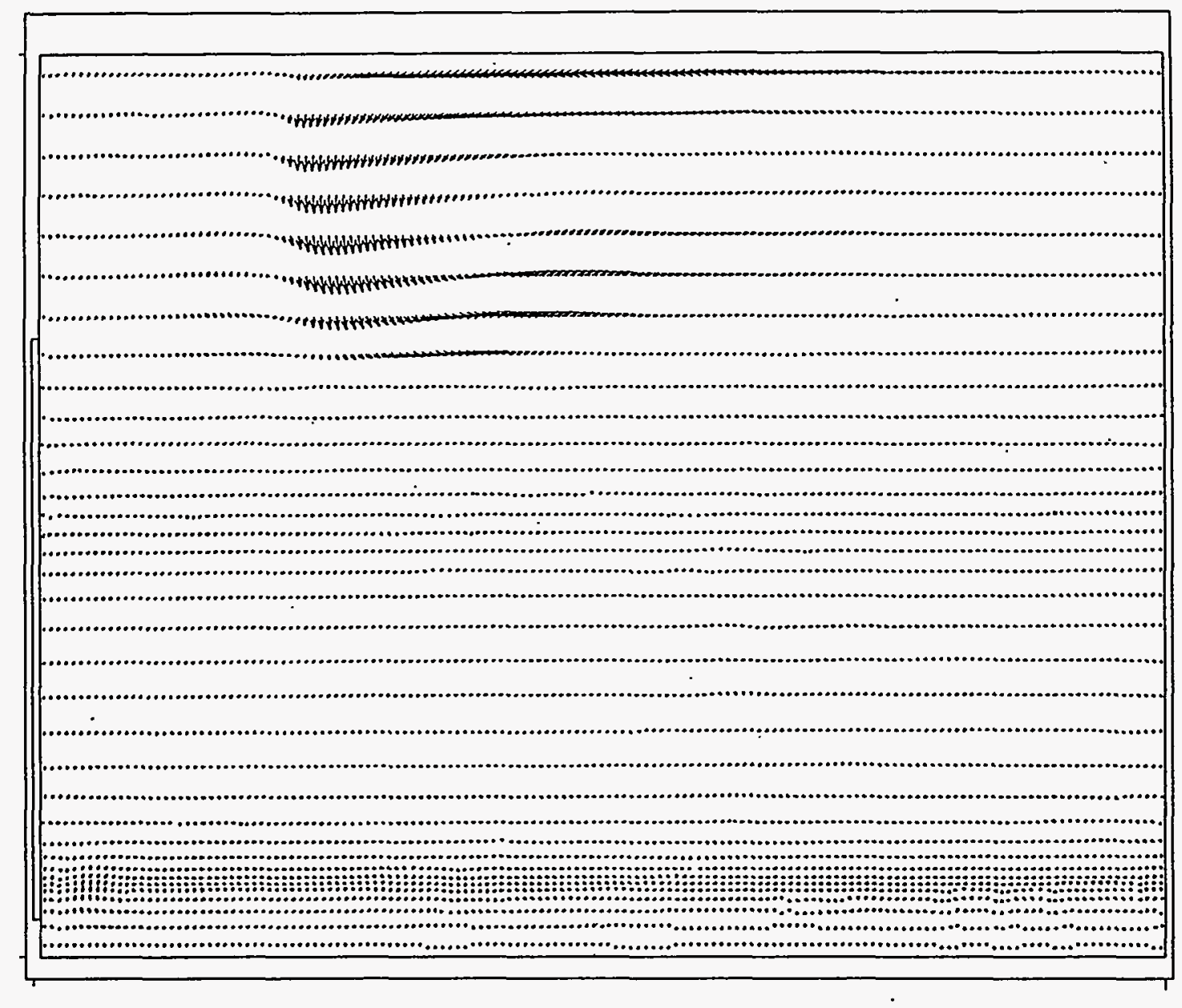

Figure E.5. Predicted Convective Velocities for Unmixed SY-103 Waste at 1 Hour with Probe Sonification at 400 Second Intervals

experiences relative large macro fluid convective motion which transports gas convectively to the surface quickly when sonified.

\section{E.6.3 SY-103 “Unmixed”. Analyses}

SY-103 differs from the Tank-241-SY-101 model primarily in 1) larger gas retention in the three layers (volume fraction), 2) larger bubble sizes compared to the "mixed" model (1 mm now becomes the largest) and 3) higher yield strength in the nonconvective layer and sludge. Tables E.1.a-d denote these differences. In addition, the nonconvective slurry is about 10 inches high with an 11-inch convective liquid level above. The sludge depth is modeled as 2 feet. For the nonsonified reference case, the convective liquid is assumed neutrally buoyant, and the nonconvective slurry and sludge layers have yield stresses that lock the bubble volume fractions motionless. 


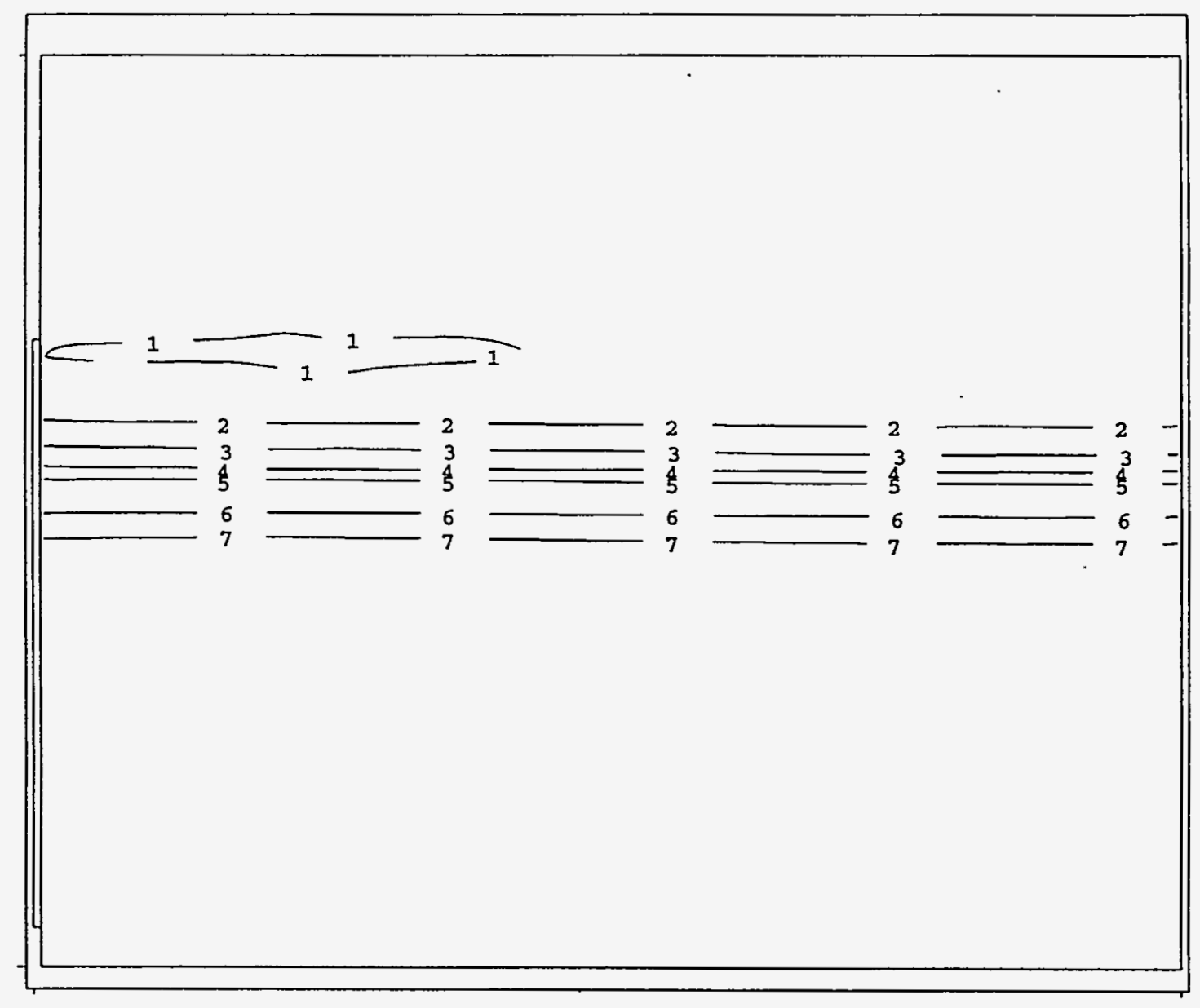

Figure E.6. Volume Fraction Distribution at 1 Hour from $1 \mathrm{~mm}$ Bubble Size Gas in SY-103 Unmixed Waste with 400 second Intermittent Probe Sonification

The total gas contained in the model is $2,800 \mathrm{ft}^{3}\left(\sim 5,600 \mathrm{ft}^{3}\right.$ at standard atmosphere) in the nonconvective slurry ( $10 \%$ total gas volume fraction) and $750 \mathrm{ft}^{3}$ in the sludge ( $16 \%$ total gas volume fraction). Sonification with the probe has a radial and an axial character in yielding the lower layers. The probe excitation does not uniformly extend over the complete height of the tank. Combined with the fact that the density and volume fraction also varies axially, the transmitted wave is contoured with its axial peak in the plane of the center of its activated length. A characteristic peak pressure radial profile for mid slurry plane and sludge plane is presented in Figure E.7.

The radial penetration of the probe yielding marches outward with time. Local material in the slurry (and bottom sludge) yields with the result that bubble rise and particle settling begins. Volume fraction and bulk density redistribution reduces attenuation and causes the yield level pressure field to extend further radially (Figure E.8). The penetration is constrained in the lower slurry and widens in the mid plane region. The overall penetration moves outward with time until the sonified radius exceeds the computational radius of the model (which is about $31 \mathrm{ft}$ ). A mild constricted penetration can be observed at the upper surface of the nonconvective slurry. This scenario occurs because bubble migration upward causes a volume fraction redistribution, which increases attenuation. 


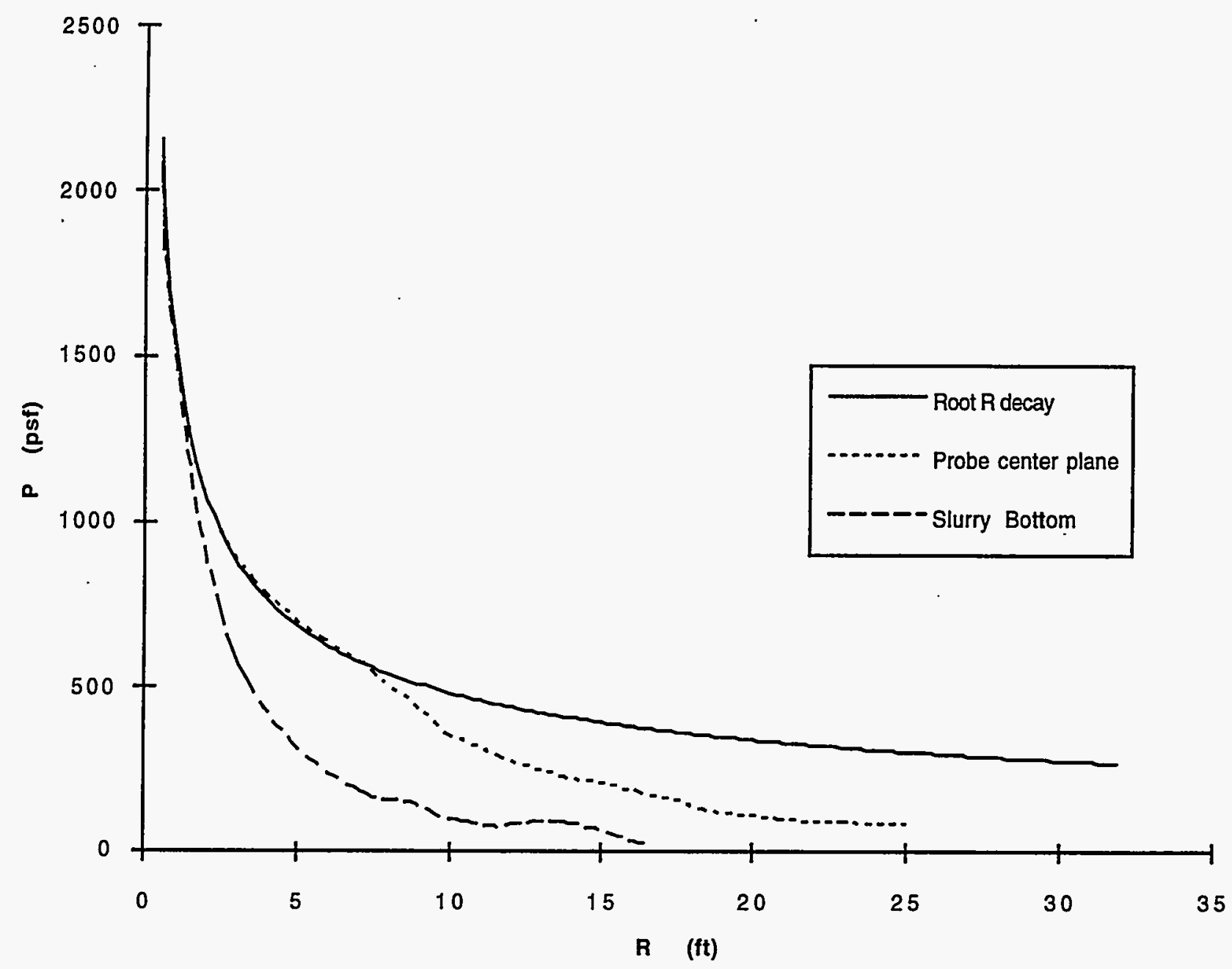

Figure E.7. Radial Profile of Peak Pressures for Mid-Slurry Plane and Sludge Plane in SY-103 Unmixed Waste

Because the rate at which the nonconvective material yields and clears of bubbles varies spatially, there are different scenarios of convective motion and gas transport depending upon the period of intermittent operation of the sonic probe. Three versions are analyzed: 1) a 200 -second intermittent probe, 2) a 400-second intermittent probe, and 3) a 1000-second intermittent probe.

As with Tank 241-SY-101 "aged" predictions, convective motion occurs in the lower slurry of the tank. For the 200-second intermittent probe at 500 seconds into the transient, the sonification has yielded the slurry nearly out to the radial extremities of model (Figure E.9). Note that the bottom sludge is yielded outward only a fraction of the tank radius. That most recent "liberated" material (locally larger volume fraction) experiences a local convective pattern transporting gas upward. Further inward, there is a generalized recirculation which carries the trend of descending motion where sonification earliest occurred and released trapped gas bubbles. 


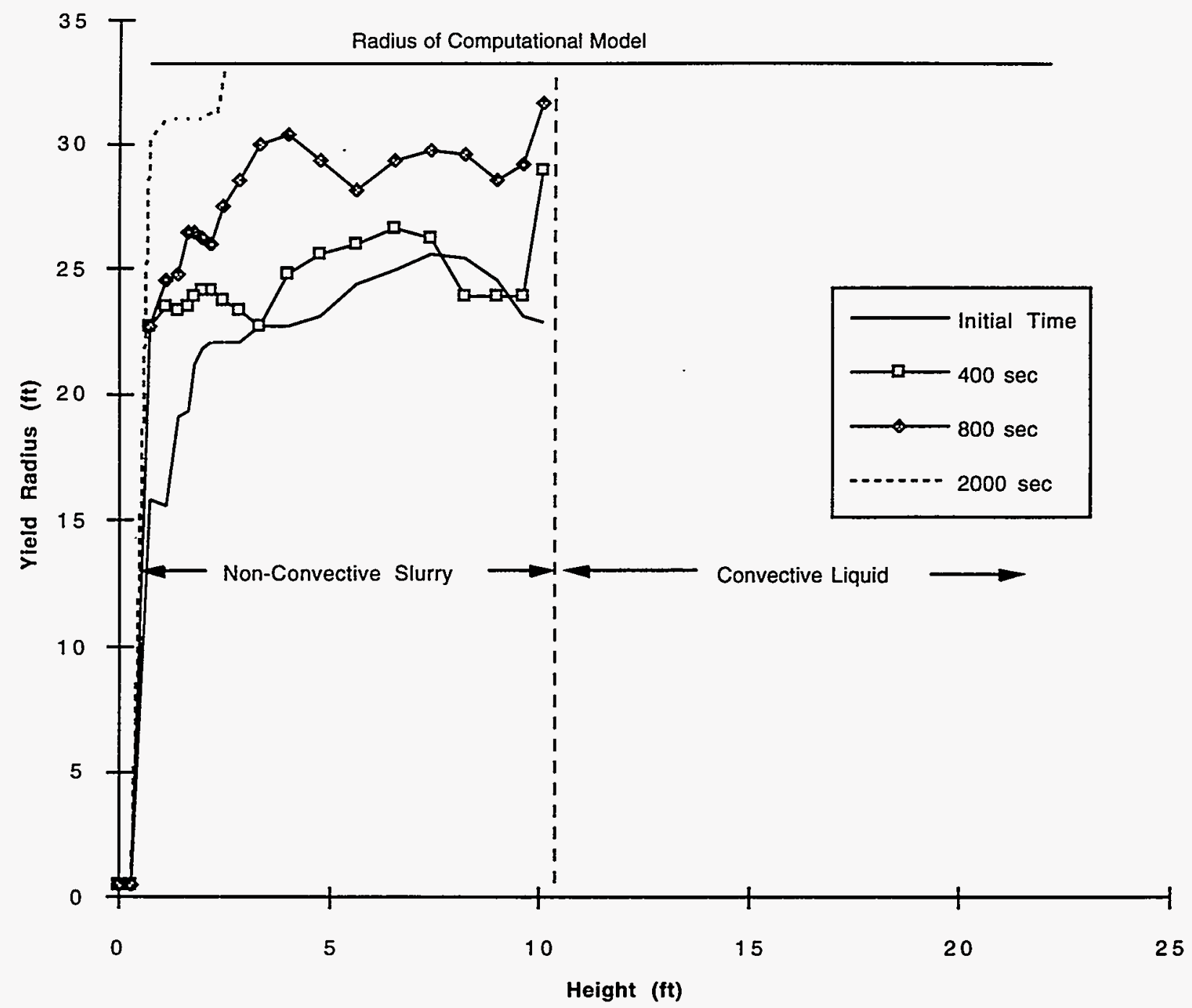

Figure E.8. Yield Front Radial Extent Versus Height in SY-103 “Aged" Waste at Various Times into Sonifcation

The overall convective pattern is quite complex. It is notable that the this pattern shows some contrast to the Tank 241-SY-101 aged scenario. For example, the circulation pattern adjacent to the bottom inner radius is of opposite direction, and results from the bulk density distribution (Figure E.10) in which the combined solid particle settling and gas bubble rise results in a buoyant region at the inner radii. Figure E.11 presents the $1-\mathrm{mm}$ gas volume fraction and exhibits its depletion in the lower slurry and inner radius region via convective transport.

Again, the locations of local density stratification predicted in TEMPEST are produced by somewhat arbitrary effective bubble size distributions. The convective patterns should be considered "generic" in nature, and simply characterize the density stratified buoyancy driven flows which would occur and transport the gas to the surface to the tank. The resulting transport times are probably reasonable estimates for the estimated bulk densities, effective viscosities, rheology, and mean particle and bubble diameters.

The sludge has been partly sonified as indicated from Figure E.11. The yield strength of the sludge is 140 psf (6700 Pascals), and there is a large axial attenuation of the sonic wave through it. 


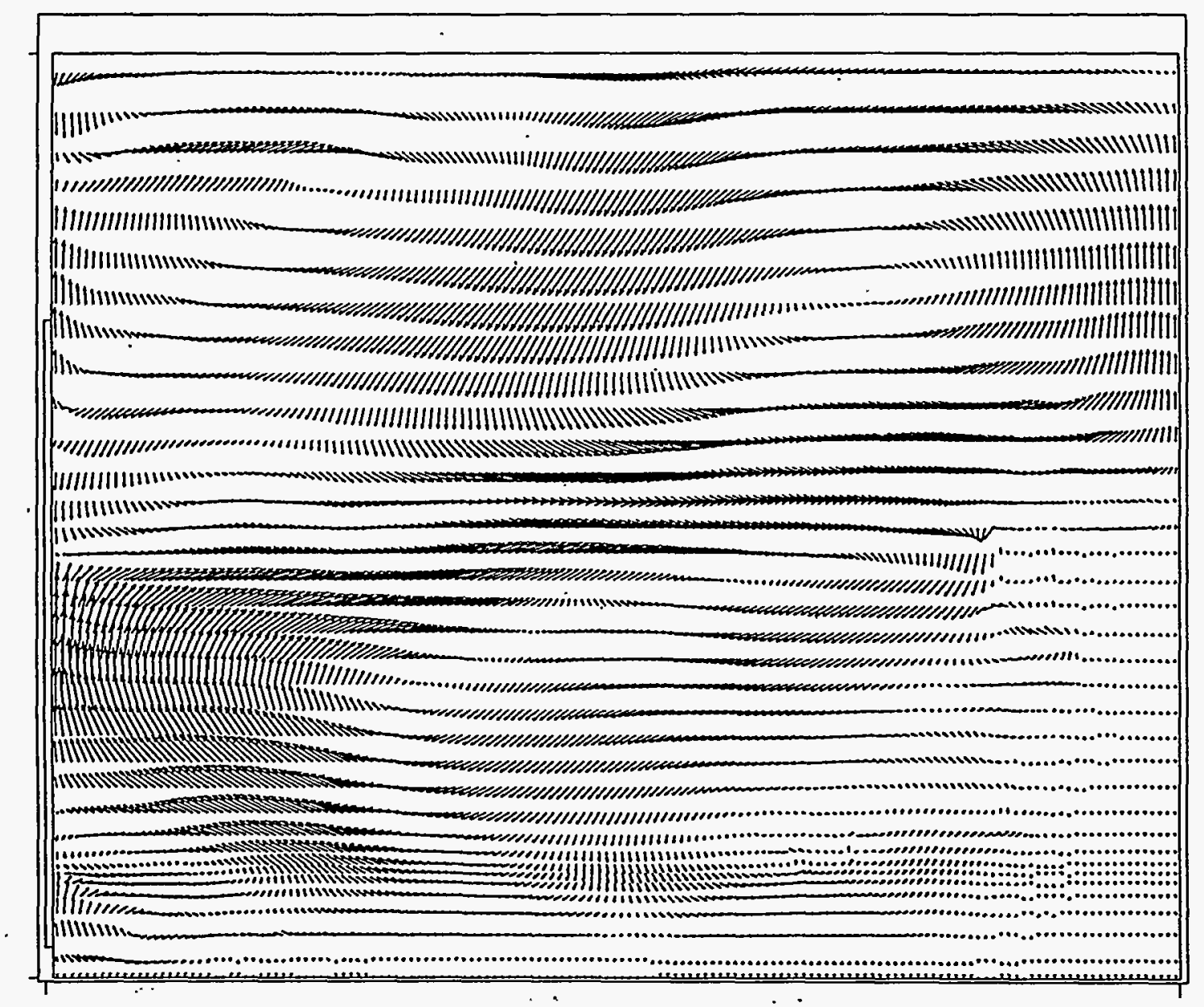

Figure E.9. Predicted Convective Velocities at 500 Seconds in SY-103 Waste with Probe Operation at 200 Second Intervals 


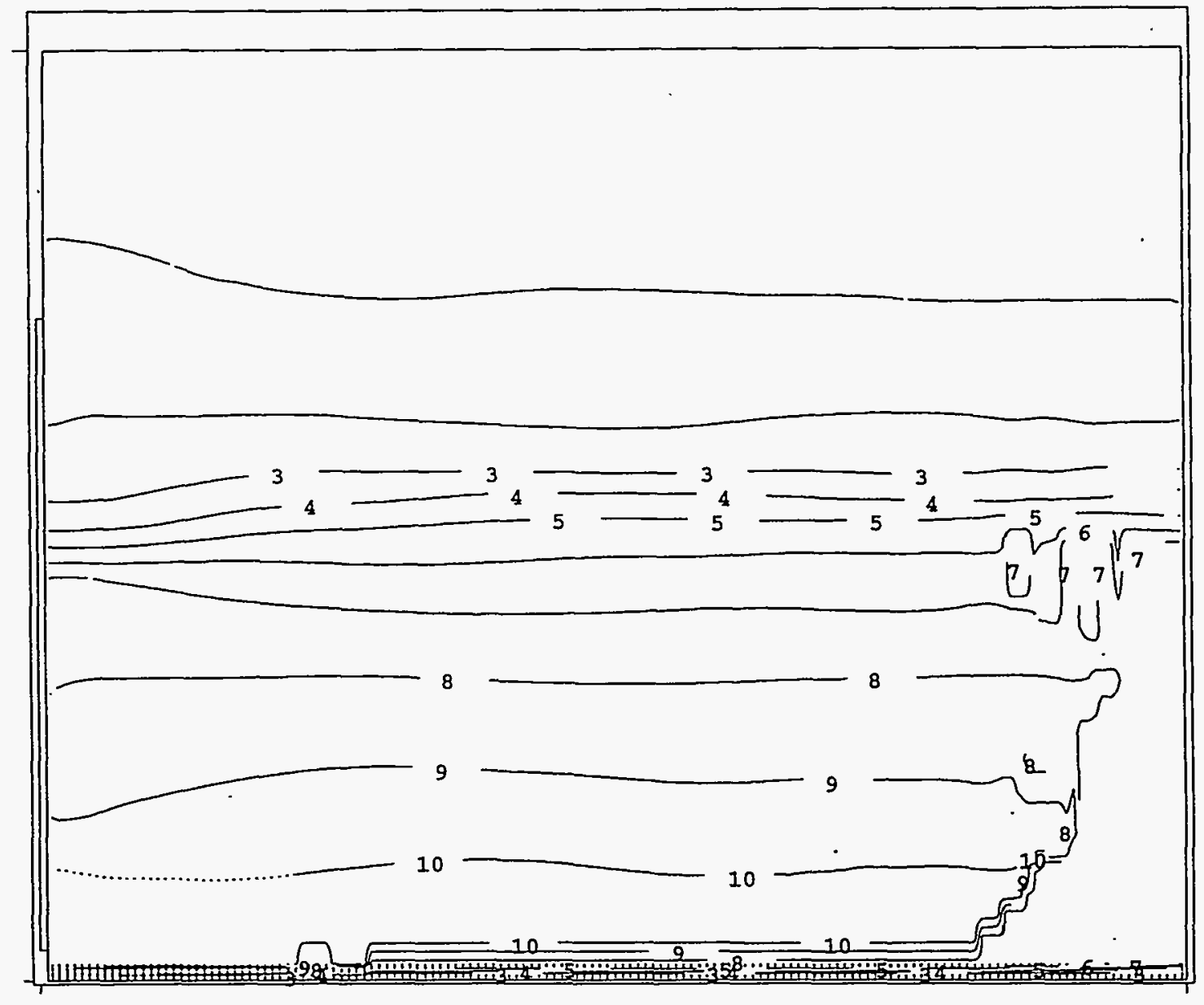

Figure E.10. Predicted Bulk Density Distribution at 500 Seconds in Unmixed SY-103 Waste with Probe Sonification at 200 Second Intervals 


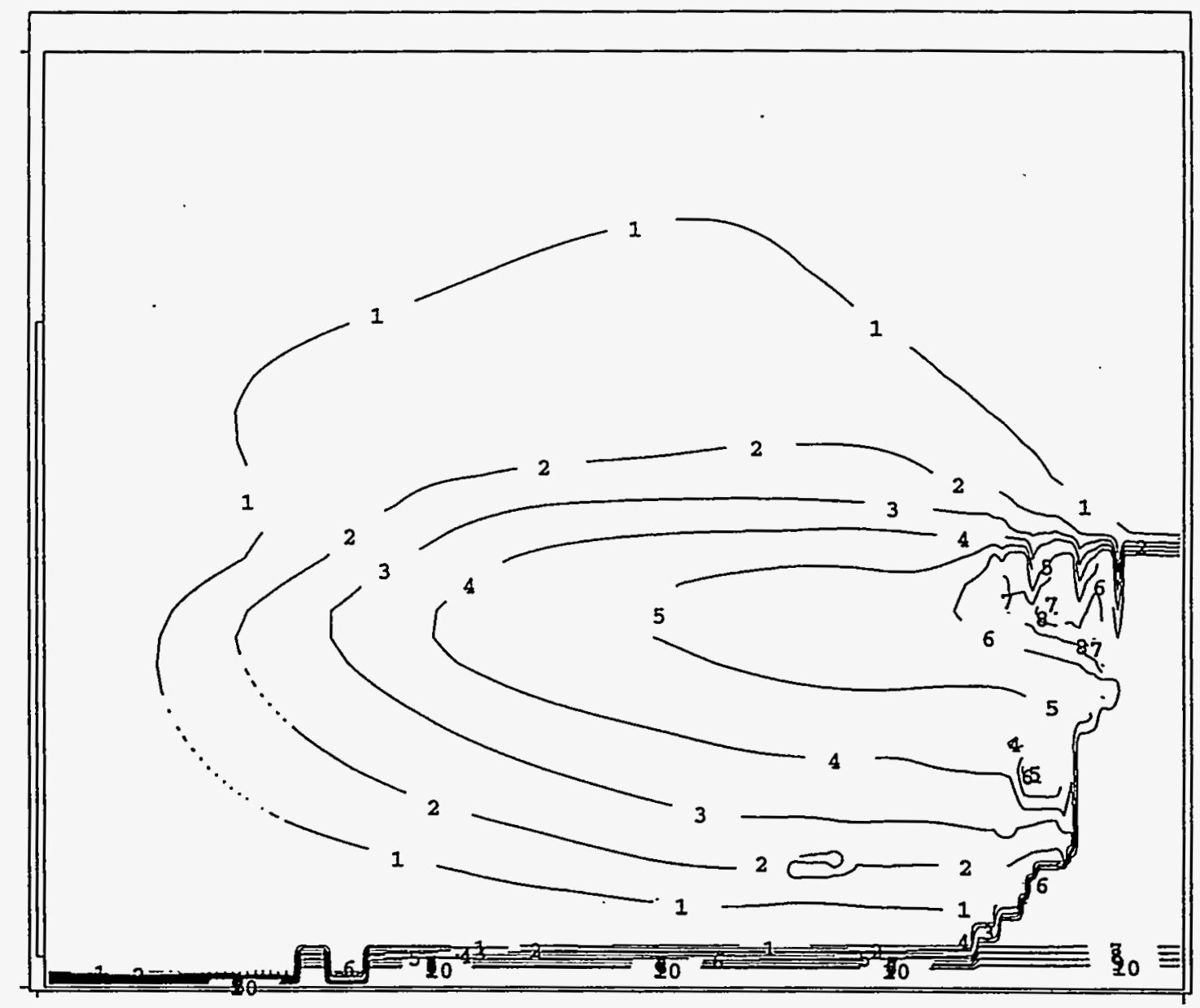

Figure E.11. Gas Volume Fraction Distribution from $1 \mathrm{~mm}$ Bubbles at 500 Seconds in Unmixed SY-103 Waste with Probe Sonification at 200 Second Intervals

In the vicinity of the probe, gas is shown released so the volume fraction has been reduced below the initial $8 \%$. Note that there are two bubble species modeled, each with $8 \%$ initial volume fraction, thereby totaling $16 \%$.

The gas release histories for three scenarios of intermittent probe operation scenarios are shown in Figure E.12 (200-second intervals), Figure E.13 (400-second intervals) and Figure E.14 (1000-second intervals). A smooth volumetric gas release rate rise is shown in Figure E.12, where the 200 -second periodic sonification is barely noted. Longer periods between sonification results in notable decay and-re-amplification of gas release rate coinciding with sonification. In Figure E.13, the peak gas release rate is slightly less than the more frequent sonification results in Figure E.12 and produces periodic "pulses" about every 400 seconds. The 1000-second intermittent sonification results in a larger spread of peak and valleys for gas release rate at about every 1000 seconds, as would be expected. These comparative results for the three probe intermittent operation scenarios are probably reasonable qualitative patterns for the trend in increasing delay times of the intermittent operation. 


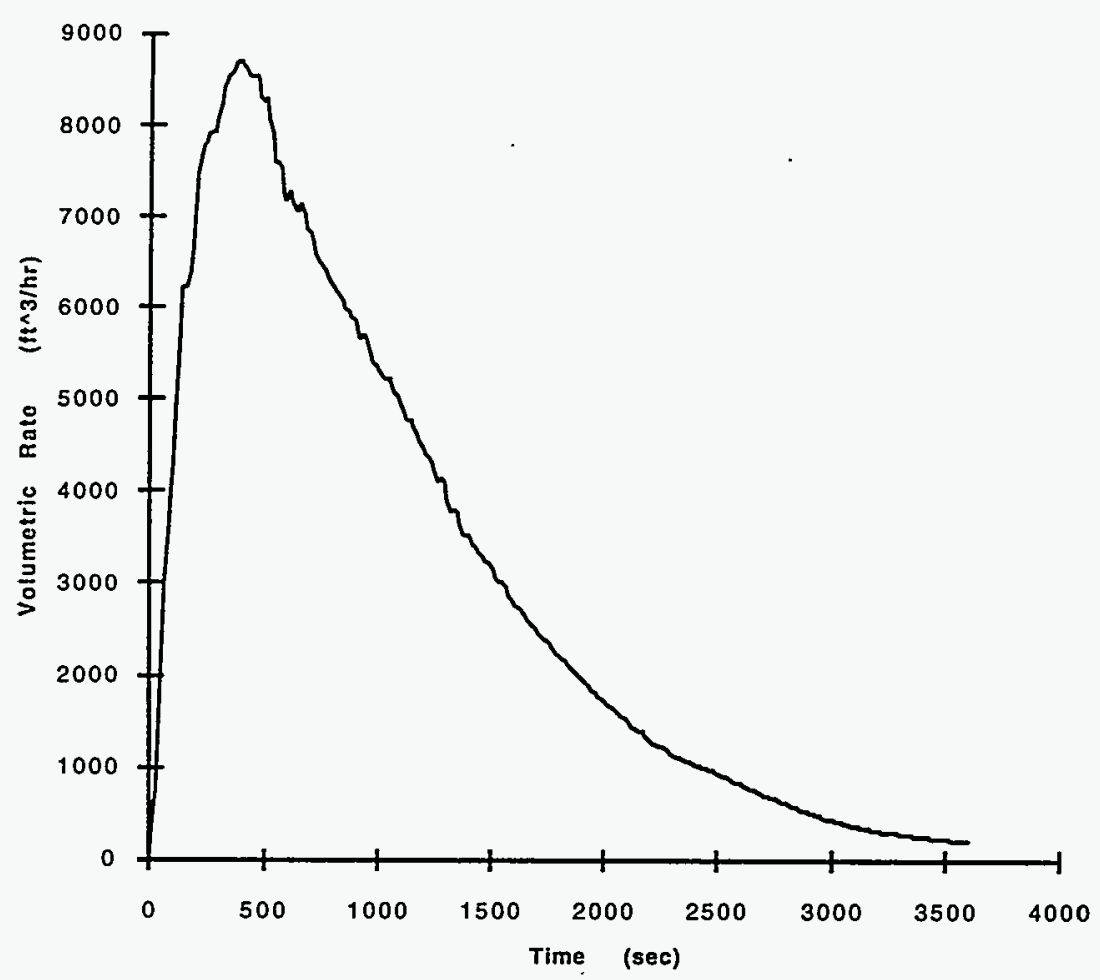

Figure E.12. Gas Release History from Unmixed SY-103 Waste with Probe Sonification at 200 Second Intervals

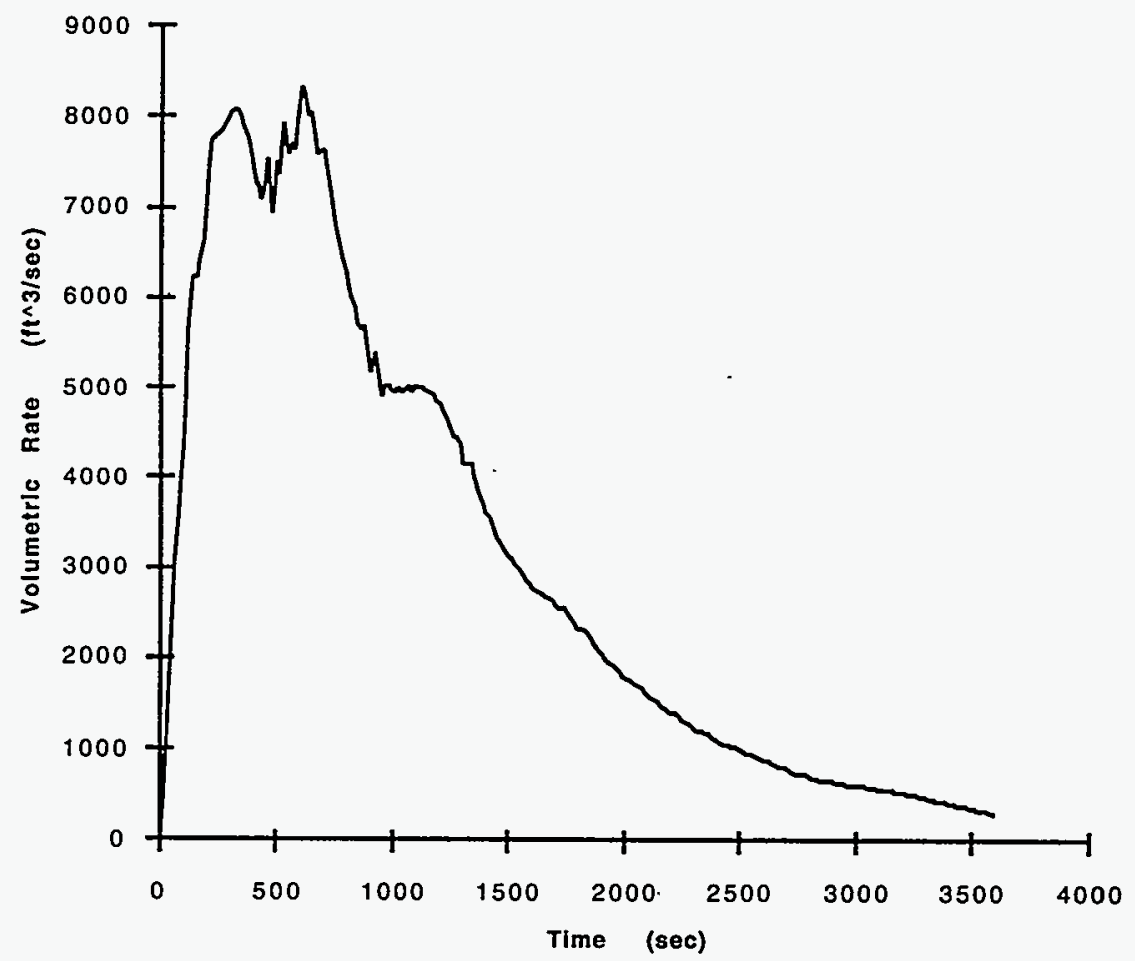

Figure E.13. Gas Release History from Unmixed SY-103 Waste with Probe Sonification at 400 Second Intervals 


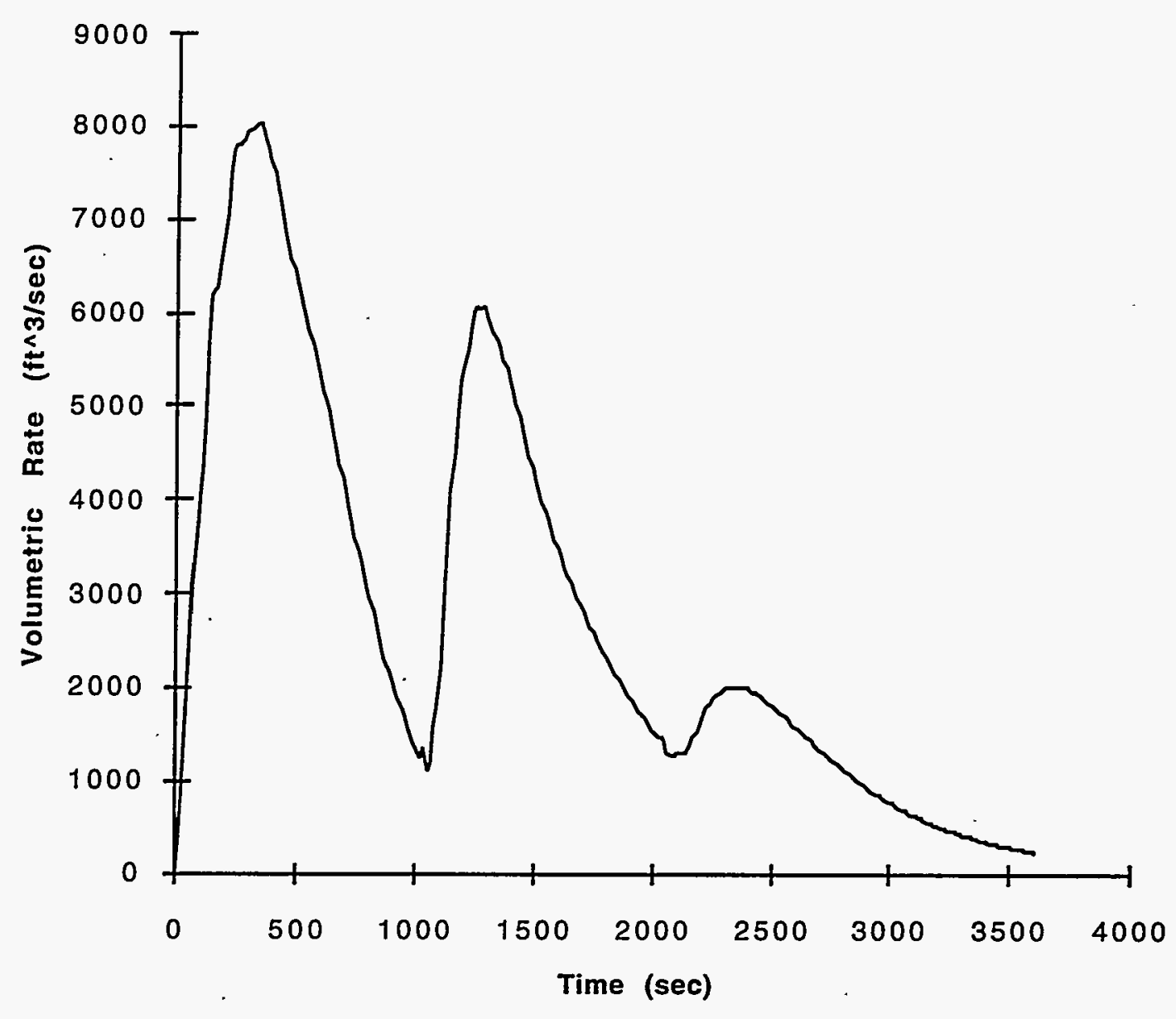

Figure E.14. Gas Release History fromUnmixed SY-103 Waste with Probe Sonification at 1000 Second Intervals

At the end of one hour, the convective motion has largely abated although there is a residual decaying circulation pattern (Figure E.15). The volume fraction for 1-mm bubbles at this time shows virtually all released (Figure E.16). The fraction distribution for $0.01-\mathrm{mm}$ bubbles (not shown) is comparatively unstratified. This may seem peculiar considering the convection history, but gas relative velocities for this bubble size are computed to be so small as to simply cause them to remain with the transported fluid. Again, the actual location of convective recirculation should be considered qualitative since the developing density stratification and resulting local convective patterns are tied to evolving particle settling and relative bubble motion.

\section{E.7. Summary and Observations}

Modeling, in which acoustic pressure waves are generated by a sonic probe, transmitted with attenuation by the bubbly medium possessing a yield strength, and cause yielding of that medium at regions of sufficient amplitude, has been coupled to a fluid dynamics calculation to investigate the spatial yielding of the fluid media and subsequent gas release. The method couples the sonification with the convective fluid TEMPEST mechanics to predict the flow, driven by bubble percolation or density stratification, which also transports bubbles. TEMPEST/ PROBE employs routines to compute the time dependent pressure wave propagation with dissipatory effects. The dissipation and local acoustical velocity are derived from theoretical expressions for bubbly media. 


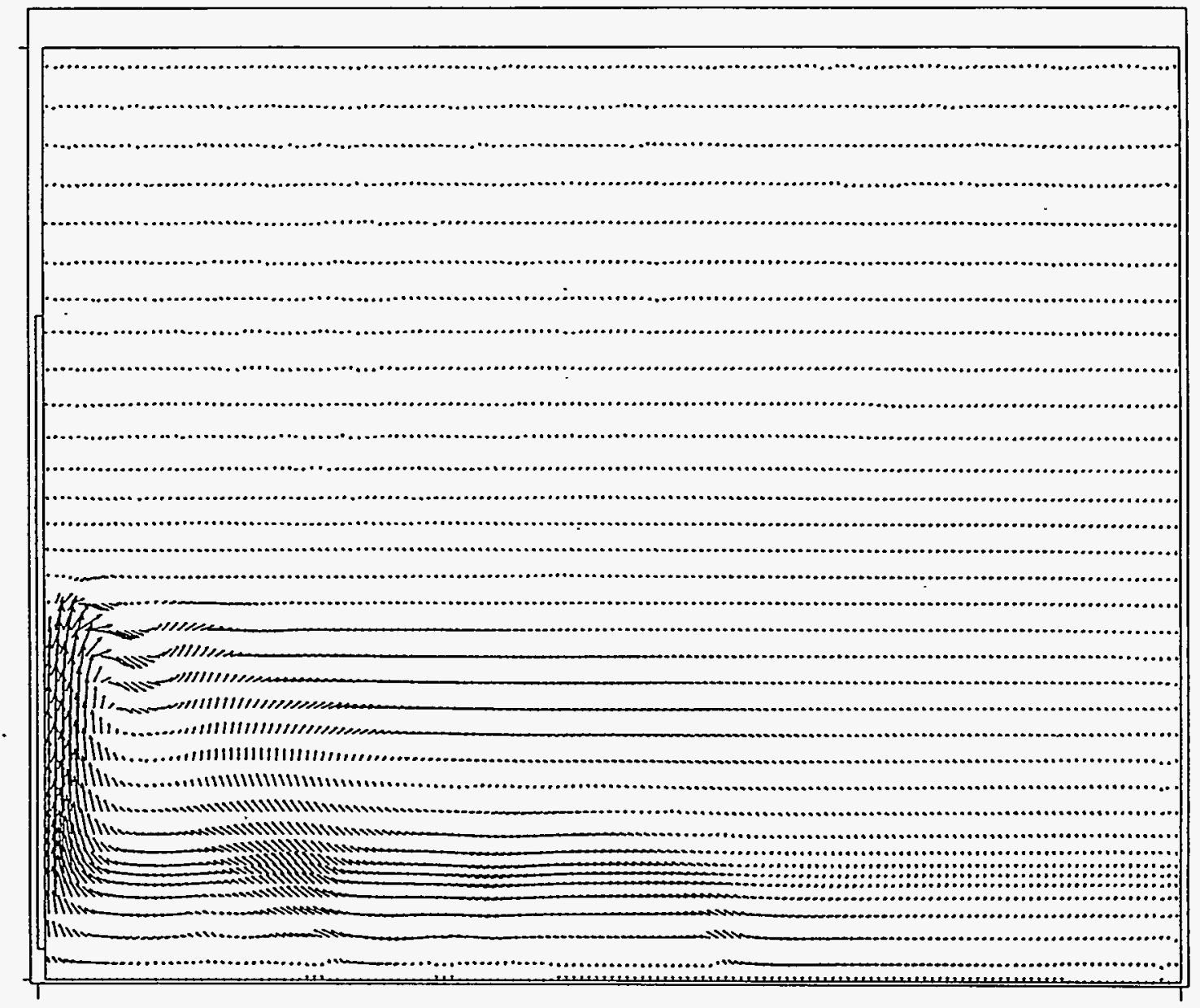

Figure E.15. Predicted Convective Velocities in Unmixed SY-103 Waste at 1 Hour with Probe Sonification at 200 Second Intervals 


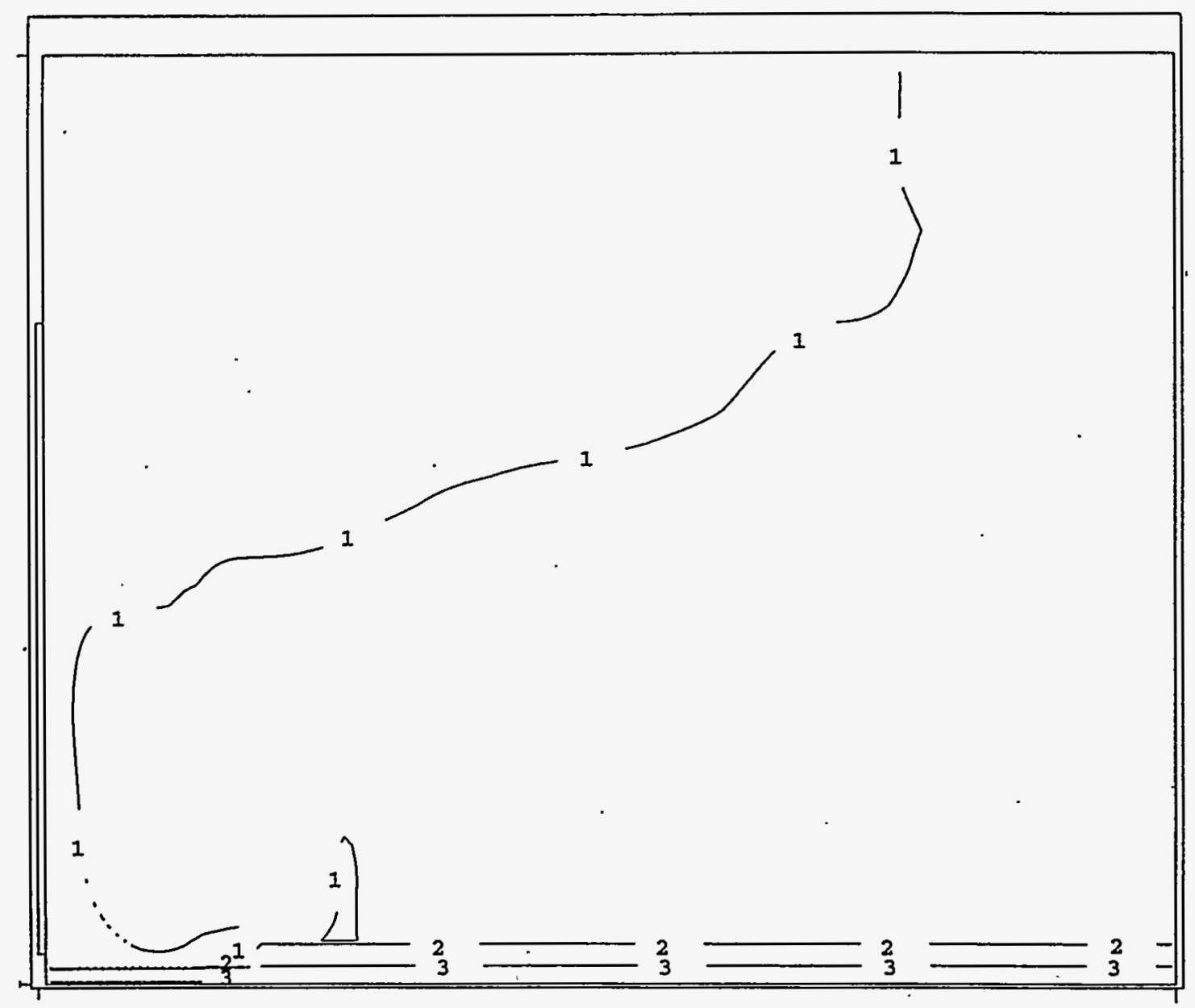

Figure E.16. Predicted Gas Volume Fraction from $1 \mathrm{~mm}$ Bubbles in Unmixed SY-103 Waste with Probe Sonification at 200 Second Intervals

A yield model is used to predict "unlocking" of the bubbles from the local media based on the relative amplitude of the pressure wave at a particular spatial position compared to yield strength. It does not enter into any sophisticated calculation for determining the probe operating period to yield the slurry; it is assumed that the simple accomplishment of sufficient pressure amplitude of the wave produces nonconvective slurry yielding.

The computational program is applied to a "mixed" and "aged" model of Tank 241-SY101 and a "unmixed" Tank 241-SY-103. All models are initiated from a stable hydrostatic condition. The probe is assumed to be located in the center of the tank, and axially symmetric simulations are employed. The "mixed" Tank 241-SY-101 model (reference model) assumes that there is no yield strength in the mixed slurry due to mixing pump operation, while the "aged" model assumes a yield strength of 1 psf. The mixed Tank 241-SY-101 employs two bubble sizes of 0.1 and $0.01 \mathrm{~mm}$ for a total gas volume fraction of $4 \%$. The aged model has two bubble sizes of 1 and $0.01 \mathrm{~mm}$ for a total gas volume fraction of $8 \%$. 
Analysis of the reference model (sonification is immaterial) results in no convective flow patterns for the transient period ( 1 hour). Bubbles simply percolate to the surface, with a rate reaching about $500 \mathrm{ft}^{3}$ per day $(\sim 20 \mathrm{ft} 3 / \mathrm{hr})$. The solid particle/gas bubble motion is so small that the time constant for any potential density stratification convection motion may be several hours or days. The present model, with the large number of cells in the radial direction and small Courant limit,(a) requires significant machine time to accomplish transients on the order of one hour.

The aged models of Tank 241-SY-101 and the unmixed model of SY-103 show much faster bubble release time constants. Both models exhibit mobile slurry density stratification due to bubble volume/particle mass fraction redistribution. Convective motion in the slurry and the convecting liquid are well developed 500 seconds into the transient. In the case of Tank 241-SY-101, where the entire slurry is yielded immediately, the repetitive use of the probe (computationally) has no effect. In the case of SY-103, where the slurry has a relative large yield strength, the general radial yielded penetration pattern expands with time and repetitive sonification. This leads to some parametric options with intermittent sonification.

Three intermittent probe sonification scenarios were analyzed for SY-103; a 200 second, a 400 second, and a 1000 second intermittent probe period. Below 200 seconds, there is no notable variation in the gas release rate history. The peak rate is predicted about $9,000 \mathrm{ft} 3 /$ hour at 500 seconds into the transient, decaying to some $250 \mathrm{ft} 3 /$ hour at the end of one hour. With longer periods of intermittency, the gas release rate history tends to exhibit periodic increases which track the sonification periods.

The accumulated gas release predicted for the "aged" Tank 241-SY-101 model is about $3,800 \mathrm{ft}^{3}$ at the end of one hour, mostly in the form of $1 \mathrm{~mm}$ gas bubble volume fraction. The accumulated gas release for the various SY-103 scenarios is about 3,000 ft 3 , again mostly in the form of $1 \mathrm{~mm}$ gas bubble volume fraction. Table E.5 tabulates the tank results.

Average convective vertical assent velocities are an order of magnitude greater than the bubble rise velocities, so that the dominating mechanism of gas release is via convective motion of the fluid in the tank rather than bubble percolation. The actual location and pattern of convective recirculation should be considered qualitative since the developing density stratification and resulting local convective patterns are tied to evolving particle settling and relative bubble motion, and azimuthal symmetry was also assumed. It arguably does not significantly impact the gas release time scale in that the convective motion is induced by the density stratification from Stokes's law for specie velocities which, together with tank size, result in convective fluid motion of the predicted scale and magnitude.

Table E.5. Tank Gas Modeling

\begin{tabular}{||l|l|l|l||}
\hline & $\begin{array}{l}\text { Tank 241-SY-101 } \\
\text { Mixed }\end{array}$ & $\begin{array}{l}\text { Tank 241-SY-101 } \\
\text { Aged }\end{array}$ & $\begin{array}{l}\text { SY-103 } \\
\text { Unmixed }\end{array}$ \\
\hline $\begin{array}{l}\text { Total Gas Vol - } \mathrm{ft}^{3} \\
(\mathrm{STP})\end{array}$ & $\sim 4,750$ & $\sim 9,500$ & $\sim 7,100$ \\
\hline $\begin{array}{l}\text { Peak Release Rate } \\
\mathrm{ft}^{3} / \mathrm{hr}\end{array}$ & $\sim 20$ & $\sim 9,000$ & $\sim 8,000$ \\
\hline $\begin{array}{l}\text { Accumulated Release } \\
\mathrm{ft}^{3}\end{array}$ & $\begin{array}{l}\sim 24 \\
(1 \mathrm{Hour})\end{array}$ & $\begin{array}{l}\sim 3,800 \\
(1 \mathrm{Hour})\end{array}$ & $\begin{array}{l}\sim 3,000 \\
(1 \mathrm{Hour})\end{array}$ \\
\hline \hline
\end{tabular}

(a) The Courant limit is the time step limit imposed on the transient analysis by the cell size and velocity. 


\section{E.8 References}

Allemann, R. T., Z. I. Antoniak, J. R. Friley, C. E. Haines, L. M. Liljegren, and S. Somasundaram. 1991. Collection and Analysis of Existing Data for Waste Tank Mechanistic Analysis. PNL-7658. Pacific Northwest Laboratory.

Allemann, R. T., T. M. Burke, D. A. Reynolds, and D. E. Simpson. 1993. Assessment of Gas Accumulation and Retention - Tank 241-SY-101. WHC-EP-0576, Westinghouse Hanford Company, Richland, Washington.

Chhabra, R. P. 1993. Bubbles, Drops, and Particles in Non-Newtonian Fluids. CRC Press, Cleveland, Ohio.

Fox, G. L., D. D. Stepnewski, and R. P. Anantatmula. 1993. Tank 241-ST-103 Hazard Assessment. WHC-SD-WM-SAR-061, Westinghouse Hanford Company, Richland, Washington.

Levy, S. and J. Wilkinson. 1976. The Component Element Method in Dynamics. McGraw Hill, New York.

Nakoryakov, V. E., B. G. Pokusaev, and I. R. Shreiber. 1993. Wave Propagation in Gas-Liquid Media. Institute of Thermophysics, Russian Academy of Sciences, Novosibirsk, Russian Federation.

Swanson Analysis Systems, Inc. ANSYS: Engineering Analysis System: Theoretical Manual V4.4. Houstan, Pennsylvania.

Trent, D.S., and L. L. Eyler. 1993. TEMPEST: A Computer Program for Three-Dimensional TimeDependent Computational Fluid Dynamics, Volume 1: Theory Manual (Version T, Mod 2). PNL-8857, Pacific Northwest Laboratory, Richland, Washington. 


\section{Appendix F \\ Effects Of Dilution On Volume Of \\ Potential Gas Releases}




\section{Appendix F}

\section{Effects Of Dilution On Volume Of Potential Gas Releases}

A gas release event (GRE) in a waste tank may be possible when enough gas accumulates in the sludge layer to make its density equal to that of the liquid above. The amount of gas released depends on the volume of sludge that participates, the volume of gas required to make the sludge neutrally buoyant and the hydrostatic pressure at which the gas is retained in the sludge. The gas volume depends on the ratio of liquid and sludge densities and the hydrostatic pressure is proportional to both the average depth of the sludge below the waste surface and the average density. All these factors are affected by dilution.

We can estimate the effect of dilution on the volume of gas released in a GRE with the standard neutral buoyancy model. Consider the tank schematic shown in Figure F.1 containing a total waste depth, L. Gas is held in the sludge layer of depth D with a supernatant liquid layer above. Addition of diluent increases the depth by $\mathrm{d}$ and dissolves solids to reduce the sludge depth by $\mathrm{y}$. The dissolved solids mix with the liquid layer and increase its density, partially offsetting the density reduction of diluent addition. A GRE is assumed to occur when the sludge density becomes equal to the liquid density.

The settled sludge contains liquid so that its solids volume fraction, $\phi$, is less than unity. Therefore, the sludge density depends on the liquid density as given by

$$
\rho_{\mathrm{SL}}=\phi \rho_{\mathrm{s} 0}+(1-\phi) \rho_{\mathrm{L}}
$$

where $\rho_{\mathrm{s} 0}$ is the density of the solids and $\rho_{\mathrm{L}}$ is that of the liquid. The solids fraction is assumed constant and can be determined by solving equation (F.1) and substituting densities measured at zero-dilution. The liquid density, after dilution assuming complete mixing, is approximately

$$
\rho_{L}=\frac{\rho_{d} d+\rho_{L 0}(L-\phi D)+\rho_{s 0} \phi y}{d+(L-\phi D)+\phi y}
$$

where $\rho_{d}$ is the diluent density and $\rho_{L 0}$ is the initial liquid density before dilution. The dissolution is related to the dilution ratio by an approximate curve fit to 101-SY dilution data (see Section 5.1).

$$
y / D=0.457(d / L)^{0.535}
$$

Using initial densities from the data with this expression for dissolution and a diluent density of 1.06 g/cc yields the density variations shown in Figure F.2. The gas fraction required to make the sludge neutrally buoyant is given by

$$
\alpha_{\mathrm{NB}}=1-\frac{\rho_{\mathrm{L}}}{\rho_{\mathrm{SL}}}
$$

where the liquid and sludge densities are defined by Equations (F.1) and (F.2), respectively. The volume of gas at neutral buoyancy depends on the volume of gas-retaining sludge left after dissolution and the gas fraction from (F.3). For a tank cross-sectional area A, the release is 


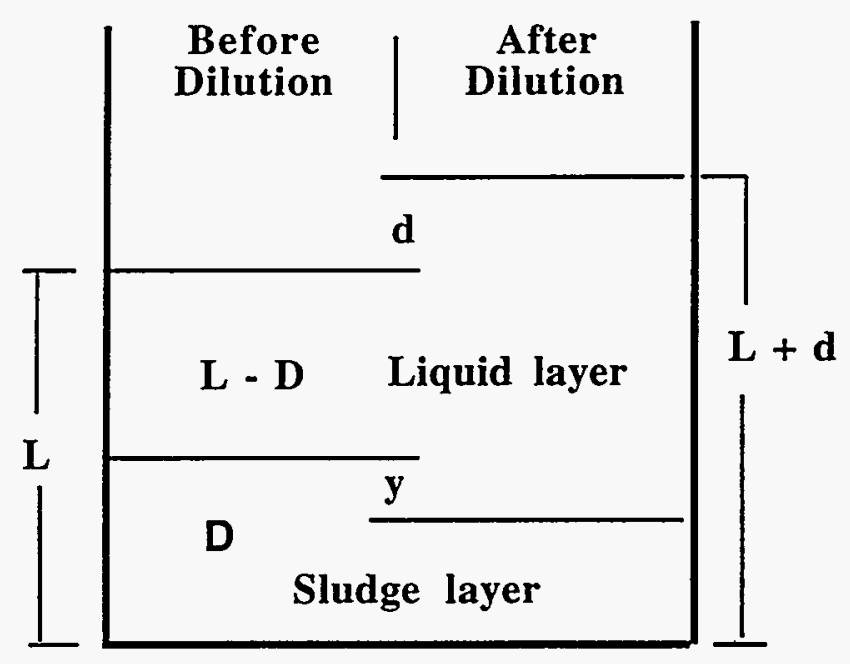

Figure F.1. In-Tank Dilution Schematic

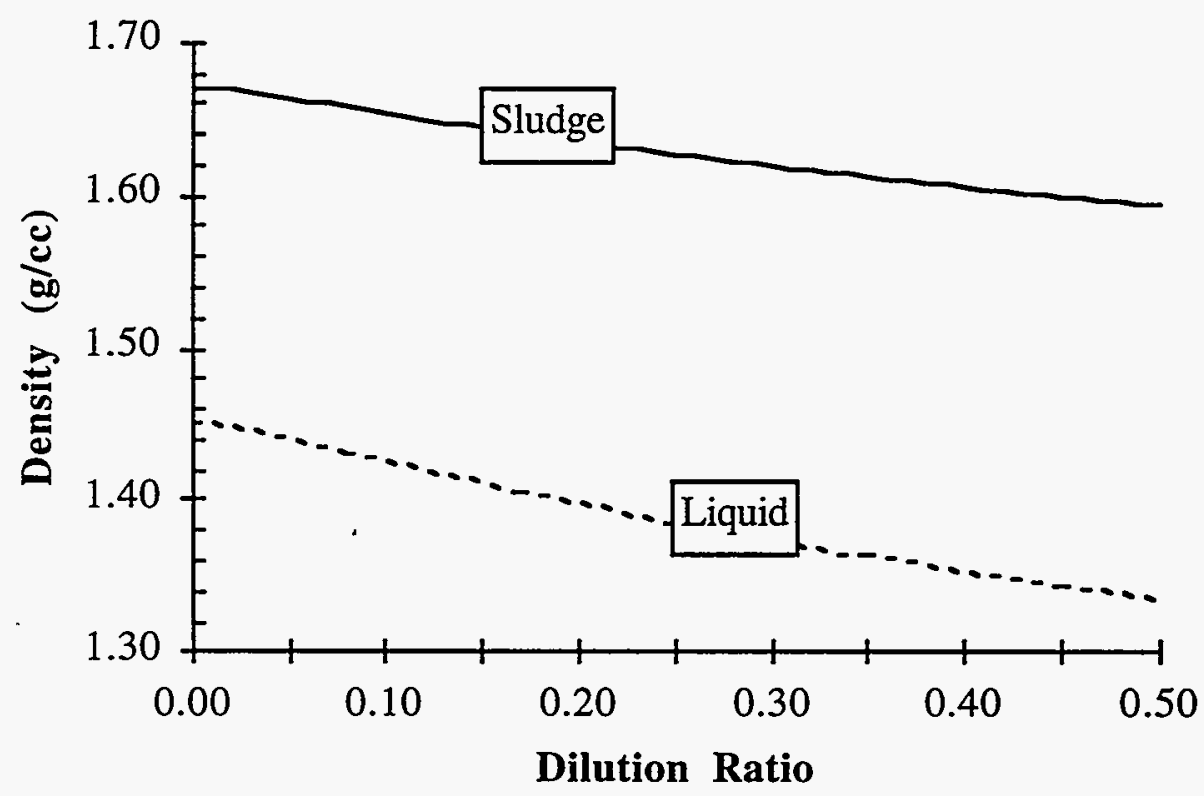

Figure F.2. Sludge and Liquid Density Versus Dilution Ratio. 


$$
\mathrm{V}_{\mathrm{GAS}}=\frac{\alpha_{\mathrm{NB}}}{1-\alpha_{\mathrm{NB}}} \mathrm{A}(\mathrm{D}-\mathrm{y})
$$

Assuming a GRE occurs at the neutral buoyancy point, the gas will rise to the surface, expanding by the ratio of its original hydrostatic pressure to ambient pressure. Gas is released to bring the sludge back to neutral buoyancy at the surface pressure. Because we are interested only in pressure and volume effects, the sludge yield strength is ignored. The gas release volume is given by

$$
\mathrm{V}_{\mathrm{REL}}=\mathrm{V}_{\mathrm{GAS}}\left(\frac{\mathrm{P}_{\mathrm{H}}}{\mathrm{P}_{0}}-1\right)
$$

The hydrostatic pressure at the average sludge depth is

$$
P_{H}=\left[\rho_{L}(d+L-D+y)+\frac{1}{2} \rho_{S L}(D-y)\right] g+P_{0}
$$

The ratio of the maximum potential gas release volume with and without dilution is given by combining (F.5), (F.4), and (F.3), and dividing by the gas release when $d=0$ to give

$$
\frac{\operatorname{GRE}_{\text {afler }}}{\operatorname{GRE}_{\text {before }}}=\frac{\left(\frac{\rho_{\mathrm{SL}}}{\rho_{\mathrm{L}}}-1\right)\left(1-\frac{\mathrm{y}}{\mathrm{D}}\right)\left(\frac{\mathrm{P}_{\mathrm{H}}}{\mathrm{P}_{0}}-1\right)}{\left(\frac{\rho_{\mathrm{SLO}}}{\rho_{\mathrm{LO}}}-1\right)\left(\frac{\mathrm{P}_{\mathrm{H} 0}}{\mathrm{P}_{0}}-1\right)}
$$

Figure F.3 shows the relative magnitude of the effect of increasing hydrostatic pressure, decreasing liquid density, and dissolution for a tank with waste properties of Tank 241-SY-101 according to (F.7). The effect of increasing hydrostatic pressure is clearly dominant.

Figure F.4 shows the overall sensitivity of gas release ratio (F.7) to dilution ratio. The slight initial decrease is an artifact of the steep slope of the curve fit approximating dissolution at the smallest dilutions. Otherwise, the increase in gas release ratio is not highly sensitive to dissolution. Addition of a low-density liquid to a tank generally tends to increase gas release volume. 


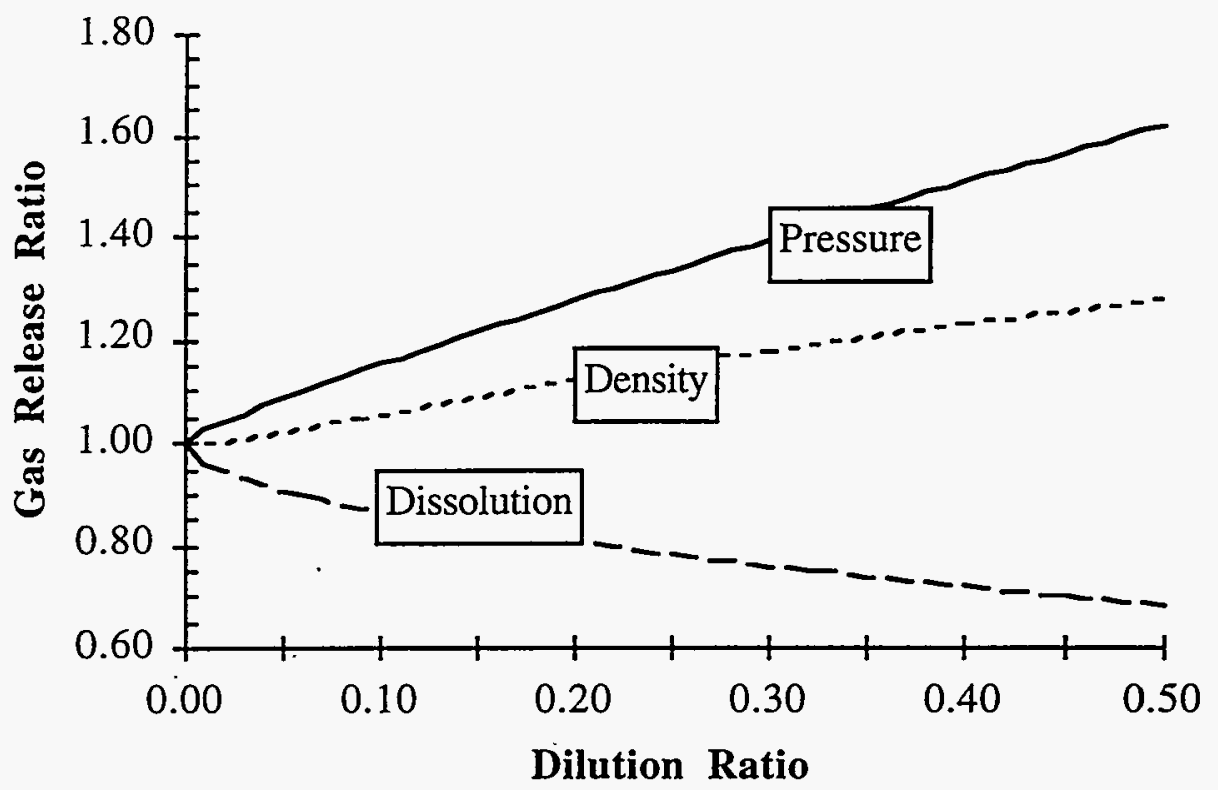

Figure F.3. Relative Magnitude of Pressure, Density, and Dissolution Effects

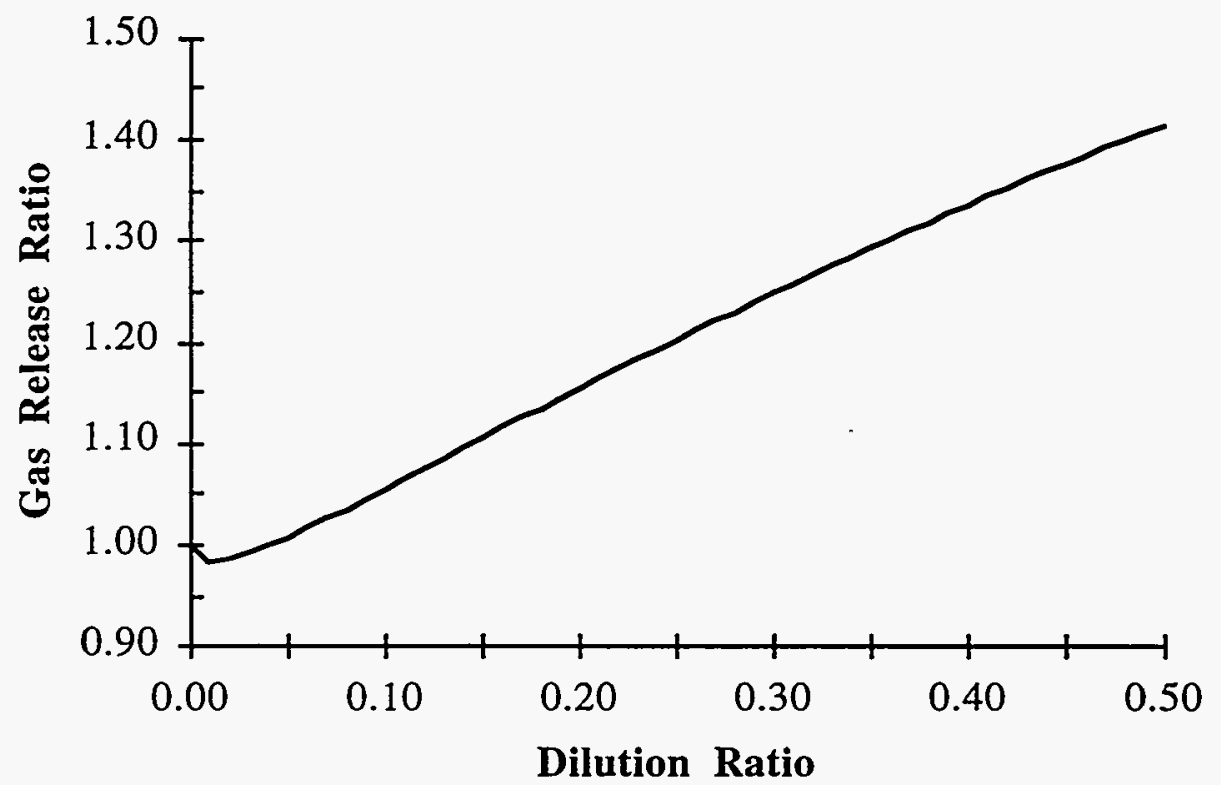

Figure F.4. Gas Release Ratio versus Dilution Ratio. 


\section{Appendix G}

\section{Analysis Of Potential Gas Releases \\ After Transfer Of Waste From Tank 241-SY-101 To 101-SN}




\section{Appendix G}

\section{Analysis Of Potential Gas Releases After Transfer Of Waste From Tank 241-SY-101 To 101-Sn}

To estimate the mitigating effects of diluting the Tank 241-SY-101 slurry with $2 \mathrm{M} \mathrm{NaOH}$, and of transferring the diluted slurry to Tank 101-SN, the effects of dilution on the properties of the slurry must be known. The solids content of the slurry is the key parameter for estimating viscosity, density, and other properties of importance. Both the "undissolved solids" (filterable solids) and the "dissolved solids" (solute in the filtrate) affect the gas-retention capacity of slurry and must be considered.

The goal of this appendix is to estimate the solids content and the amount and density of slurry in Tanks $241-S Y-101$ and 101-SN so that slurry properties and in-tank gas retention can be calculated. Such estimates depend on knowing the relationship between dilution and dissolution. Section 5.1 of this report describes the derivation from data of the functional relationship between the amount of diluent added to slurry and the amount of solids that remain in the slurry after dilution and dissolution. That correlation is used in what follows.

Section G.1 describes the information that had to be developed to support mass balance calculations, and Section G.2 describes the mass balances themselves. The results of the mass balances are used to estimate settled sludge and waste heights (Section G.3) and gas retention and release (Section G.4). Section (G.5) presents the results.

\section{G.1 Supporting Information}

First, the tank mass balances required the determination of what solids and solutes are present in the undiluted and diluted slurries. Tingey et al. performed a dilution/heating study which provided the densities of the filtered solids and filtrate and the weight fraction of filtered solids in the diluted slurry over a range of temperatures and dilutions(a). In all cases non-convective layer slurry was used, with $2 \mathrm{M} \mathrm{NaOH}$ as the diluent -- as proposed for the dilution and transfer process for Tank 241-SY101. Some of these measurements were repeated with more complete centrifugal separation (Bredt 1994) and used to correct the Tingey et al. data for liquid retained in the "filtered solids" and solids in the "filtrate". The correction process is described in Section 5.1 and the results of the correction are shown in Figure 5.9; the figure demonstrates that the two sets of experiments can be reconciled. .

Second, the relation between dilution and dissolution of the solids had to be found. Figure 5.10 in Section 5.1 shows the correlation that was generated from the Tingey et al. and Bredt(b) data. The fraction of solids remaining after a certain amount of dilution is expressed in terms of the dilution factor, the volume of diluent added per volume of original undiluted slurry. The dissolution function at $50^{\circ} \mathrm{C}$ is given in Equation G.1:

$$
f=0.457 D^{0.535}
$$

(a) Tingey, J. M., P. R. Bredt, and E. H. Shade 1994. The Effects of Heating and Dilution on the Rheological and Physical Properties of Tank 241-SY-101 Waste. Draft Report, Pacific Northwest Laboratory, Richland, Washington

(b) Bredt, P. R. 1994. "101-SY Dilution Studies." Technical Memorandum from P. R. Bredt to C. W. Stewart. July 26, 1994. Pacific Northwest Laboratory, Richland, Washington. 
where $\mathrm{f}=$ fraction of original solids that remain

$\mathrm{D}=$ volume of $2 \mathrm{M} \mathrm{NaOH}$ diluent per volume of pre-dilution slurry

Third, a relation between the density and the solute ("dissolved solids") concentration in the liquid was needed because both the final waste height and the gas retention depend on liquid density. The Tingey et al.and Bredt experiments did not measure the concentration of solute in the filtrate; therefore a complete characterization of the slurry requires that the "dissolved solids" concentration be approximated from other data.

A clue to the relationship of the solution density and the solution concentration was found in Reynolds and Herting (1984), which documented analyses on simulated defense tank solutions and slurries. The study contained density data for high-concentration solutions containing sodium hydroxide, nitrate, nitrite, and aluminate. To help predict densities for low-concentration ranges as well, density data for solutions of sodium hydroxide, nitrate, and nitrite were taken from Perry and Chilton (1973) and added to the database. The composite database, including both highconcentration and low-concentration density and concentration data, was correlated. A resulting density correlation was

$$
\begin{aligned}
& \rho=1.0013+1.0054 \mathrm{w}_{\mathrm{d}}-0.0007123 \mathrm{~T}+3.640 \times 10^{-6} \mathrm{~T}^{2} \\
& \text { where } \mathrm{w}_{\mathrm{d}}=\text { concentration (weight fraction of solute, all components together) } \\
& \mathrm{T}=\text { temperature }\left({ }^{\circ} \mathrm{C}\right) \\
& \text { Correlation } \mathrm{r}^{2}=0.950 ; \text { standard error }=0.054 \mathrm{~g} / \mathrm{cc} ; \text { maximum error }=10.5 \%
\end{aligned}
$$

The density database contains 347 data points total, comprising the following ranges of data:

- $\quad$ Reynolds and Herting (1984): temperature ranging from $60^{\circ} \mathrm{C}$ to $100^{\circ} \mathrm{C}$; hydroxide from 5.0 to 11.5 molal; nitrate from 3.0 to 12.0 molal; nitrate from 3.7 to 14.5 molal; aluminate from 1.0 to 3.0 molal; multi-component solution.

- Perry and Chilton (1973): sodium hydroxide from 0 to 25 molal, 0 to $100^{\circ} \mathrm{C}$; sodium nitrate from 0 to 9.6 molal, 0 to $100^{\circ} \mathrm{C}$; sodium nitrite from 0 to 3.6 molal, $15^{\circ} \mathrm{C}$; single-component solutions.

\section{G.2 Mass Balances}

During the transfer and mitigation process, the jet-mixed slurry from Tank 241-SY-101 is added to $2 \mathrm{M} \mathrm{NaOH}$ and then pumped to Tank 101-SN. Using mass balances to calculate the waste and sludge heights and properties requires some basic assumptions. It is assumed that the 241-SY101 contents are (from the top down) a light crust, a slurry layer mixed by the jets, and an effectively immobile sludge layer. All of the material removed from 241-SY-101 is taken from the slurry layer, and the crust is assumed not to dissolve (though the solids in the slurry and sludge layers can both dissolve). It is also assumed that Tank 101-SN starts out empty.

The solids content of the mixed slurry layer has not been measured and therefore must be estimated from the known heights of the mixed layer and the immobile sludge layer and from the masses of solids in the convecting and nonconvecting layers before jet mixing was started. Before jet mixing began, the depths of the several layers in Tank 241-SY-101 were

$h_{\mathrm{up}}=220$ inches; the depth of the nonconvecting layer at the bottom, with gas absent

$\mathrm{h}_{\mathrm{cp}}=144$ inches; the depth of the convecting layer

$h_{\mathrm{tp}}=36$ inches; the depth of the crust 
and in these layers, the densities and solids fractions were(a)

$$
\begin{aligned}
\rho_{\mathrm{f}}= & 1.45 \mathrm{~g} / \mathrm{cc} ; \text { the } 50^{\circ} \mathrm{C} \text { filtrate density from Window } \mathrm{C} \\
\rho_{\mathrm{s}} & =2.2 \mathrm{~g} / \mathrm{cc} \text {; the average } 50^{\circ} \mathrm{C} \text { filtered solids density from Window } \mathrm{C} \\
\mathrm{w}_{\text {usp }}= & 0.43 ; \text { the weight fraction of undissolved solids in the } 50^{\circ} \mathrm{C} \text { nonconvecting layer } \\
& \text { from Window } \mathrm{C}
\end{aligned}
$$

Before jet mixing, the bulk densities of the non-convecting and convecting layers were, respectively,

$$
\begin{aligned}
& \rho_{u b}=\frac{\rho_{s} \rho_{f}}{\rho_{s}+w_{u s p}\left(\rho_{f}-\rho_{s}\right)}=1.67 \\
& \rho_{c b}=\frac{\rho_{s} \rho_{f}}{\rho_{s}+w_{c s p}\left(\rho_{f}-\rho_{s}\right)}=1.45
\end{aligned}
$$

and the fully-settled volume fraction of undissolved solids in the sludge was

$$
v_{u s p}=\frac{\rho_{u b}-\rho_{f}}{\rho_{s}-\rho_{f}}=0.34
$$

Under the present mixed conditions, the crust depth is unchanged and the mixed and sludge layer depths are

$\mathrm{h}_{\mathrm{u} 0}=40$ inches; depth of the immobile sludge layer on the bottom

$\mathrm{h}_{\mathrm{c} 0}=324$ inches; depth of the mixed layer; the depths of the sludge and mixed layers add to 364 inches, as did the depths of the convecting and nonconvecting layers before jet mixing

It is assumed that the immobile sludge has the same undissolved solids weight fraction as the nonconvecting layer that existed before mixing, and that the liquid and solids densities and solute concentration are also the same as in the pre-mixing period. Then, by mass balance arguments, the weight fraction of undissolved solids in the mixed layer and the bulk density of the mixed layer are

$$
\begin{aligned}
& w_{c s 0}=\frac{\left(h_{u p} \rho_{u b} w_{u s p}+h_{c p} \rho_{c b} w_{c s p}-h_{u 0} \rho_{u b} w_{u s p}\right)}{\left(h_{u p} \rho_{u b}+h_{c p} \rho_{c b}-h_{u 0} \rho_{u b}\right)}=0.25 \\
& \rho_{c b 0}=\frac{\rho_{s} \rho_{f}}{\rho_{s}+w_{c s 0}\left(\rho_{f}-\rho_{s}\right)}=1.57 \mathrm{~g} / \mathrm{cc}
\end{aligned}
$$

For the purpose of estimating sludge heights in the two tanks after dilution, dissolution, and transfer, the process is assumed to behave as follows. First, a volume of the mixed layer in Tank 241SY-101 is withdrawn, diluted with $2 \mathrm{M} \mathrm{NaOH}$ at $\mathrm{D}_{1}$ parts by volume of diluent to 1 part by volume of

(a) Bredt, P. R. 1994. "101-SY Dilution Studies." Technical Memorandum from P. R. Bredt to C. W. Stewart. July 26, 1994. Pacific Northwest Laboratory, Richland, Washington. 
mixed layer, and put in Tank SN-101. Then the waste remaining in Tank 241-SY-101 is diluted with $\mathrm{D}_{2}$ parts by volume of caustic to 1 part volume of tank waste. Dilution of the waste in 241-SY-101 takes place only if its liquid level (height excluding the crust) falls below what is needed for pump suction, about 280 inches. The 241-SY-101 dilution is assumed to affect only the mixed layer and its associated undissolved solids. No solids from the crust or sludge layers are treated as being dissolved; this approach which should overestimate the 241-SY-101 sludge depth and gas retention.

Define the remaining parameters:

$A_{1}=636000$ inches; plan-view area of Tank 241-SY-101

$A_{2}=636000$ inches; plan-view area of Tank 101-SN solids,

Solving the solids and water mass balances for Tank 101-SN is straightforward. For the total solids from

(undissolved solids from 241-SY-101) + (dissolved solids from 241-SY-101) + (dissolved

$\mathrm{NaOH})=($ undissolved solids in 101-SN) + (dissolved solids in 101-SN)

$A_{1} h_{r} \rho_{c b 0} w_{c s 0}+A_{1} h_{r} \rho_{c b 0}\left(1-w_{c s 0}\right) w_{u d 0}+D_{2} A_{1} h_{r} \rho_{d} w_{d d}=$

$\mathrm{A}_{2} \mathrm{~h}_{2} \rho_{\mathrm{cb} 2} \mathrm{w}_{\mathrm{cs} 2}+\mathrm{A}_{2} \mathrm{~h}_{2} \rho_{\mathrm{cb} 2}\left(1-\mathrm{w}_{\mathrm{cs} 2}\right) \mathrm{w}_{\mathrm{cd} 2}$

where $h_{r}=$ the depth (inches) of the mixed layer removed from Tank 241-SY-101

$\mathrm{h}_{2}=$ the final depth (inches) of slurry in Tank 101-SN

$\rho_{\mathrm{cb} 2}=$ the bulk density of the slurry in Tank 101-SN

$\mathrm{w}_{\mathrm{cs} 2}=$ the weight fraction of undissolved solids in the Tank 101-SN slurry

$\mathrm{w}_{\mathrm{cd} 2}=$ the weight fraction of solute in the Tank 101-SN liquid solved are

The unknowns in Equation (G.7) are $h_{2}, \rho_{c b 2}, w_{c s 2}$, and $w_{c d 2}$. The remaining equations to be dissolved solids balance:

$$
f_{2} A_{1} h_{r} \rho_{c b 0} w_{c s 0}+A_{1} h_{r} \rho_{c b 0}\left(1-w_{c s 0}\right) w_{u d 0}+D_{2} A_{1} h_{r} \rho_{d} w_{d d}=A_{2} h_{2} \rho_{c b 2}\left(1-w_{c s 2}\right) w_{c d 2}
$$

water balance:

$$
A_{1} h_{r} \rho_{c b 0}\left(1-w_{c s 0}\right)\left(1-w_{u d 0}\right)+D_{2} A_{1} h_{r} \rho_{d}\left(1-w_{d d}\right)=A_{2} h_{2} \rho_{c b 2}\left(1-w_{c s 2}\right)\left(1-w_{c d 2}\right)
$$

where $f_{2}=$ the fraction of original solids that dissolve in the diluent, per Equation

$$
\text { (G.1) }
$$

and where

$$
\rho_{c b 2}=\frac{\rho_{s} \rho_{f 2}}{\rho_{s}+w_{c s 2}\left(\rho_{f 2}-\rho_{s}\right)}
$$

and the 101-SN liquid density $\rho_{\mathrm{f} 2}$ is a function (Equation (G.2)) of the 101-SN solute concentration $\mathrm{w}_{\mathrm{cd} 2}$.

These four equations in four unknowns can be rearranged into forms that do not require iterative solution:

$$
w_{c s 2}=\frac{h_{r} \rho_{c b 0} w_{c s 0}\left(1-f_{2}\right)}{h_{r} \rho_{c b 0}+D_{2} h_{r} \rho_{d}}
$$




$$
\begin{aligned}
& w_{c d 2}=\frac{h_{r} \rho_{c b 0} w_{c s 0} f_{2}+h_{r} \rho_{c b 0}\left(1-w_{c s 0}\right) w_{c d 0}+D_{2} h_{r} \rho_{d} w_{d d}}{h_{r} \rho_{c b 0} w_{c s 0} f_{2}+h_{r} \rho_{c b 0}\left(1-w_{c s 0}\right)+D_{2} h_{r} \rho_{d}} \\
& \rho_{c b 2}=\frac{\rho_{s} \rho_{f 2}}{\rho_{s}+w_{c s 2}\left(\rho_{f 2}-\rho_{s}\right)} \\
& h_{2}=\frac{A_{1} h_{r} \rho_{c b 0} w_{c s 0}+A_{1} h_{r} \rho_{c b 0}\left(1-w_{c s 0}\right) w_{c d 0}+D_{2} h_{r} \rho_{d} w_{d d}}{A_{2} \rho_{c b 2} w_{c s 2}+A_{2} \rho_{c b 2}\left(1-w_{c s 2}\right) w_{c d 2}}
\end{aligned}
$$

Similar mass balances can be used for the Tank 241-SY-101 estimation; however, here the solution must be iterative because of the minimum liquid waste height $\left(h_{\min }\right)$ requirement, which makes the 241-SY-101 waste height a known and the dilution factor $D_{1}$ an unknown. $D_{1}$ is a nonlinear function of solute concentration and so must be solved for by successive approximation.

If $\left(h_{w 0}+h_{c 0}-h_{r}\right) \geq h_{\min }$ then

$$
\begin{aligned}
\mathrm{D}_{1} & =0 \\
\mathrm{w}_{\mathrm{csl}} & =\mathrm{w}_{\mathrm{cs} 0} \\
\mathrm{w}_{\mathrm{cdl}} & =\mathrm{w}_{\mathrm{cd} 0}
\end{aligned}
$$

Otherwise, dilution is needed in 241-SY-101 and iteration must be used to solve the equations

$$
\begin{gathered}
w_{c s l}=\frac{\left(\left(h_{c 0}-h_{r}\right) \rho_{c b 0} w_{c s 0}+h_{u 0} \rho_{u b} w_{u s p}\right)\left(1-f_{l}\right)}{\left(h_{c 0}-h_{r}\right) \rho_{c b 0}+h_{u 0} \rho_{u b}+D_{1}\left(h_{t p}+h_{u 0}+h_{c 0}-h_{r}\right) \rho_{d}} \\
w_{c d l}=\frac{\left(h_{c 0}-h_{r}\right) \rho_{c b 0}\left(w_{c s 0} f_{1}+\left(1-w_{c s 0}\right) w_{c d 0}\right)+h_{u 0} \rho_{u b}\left(w_{u s p} f_{1}+\left(1-w_{u s p}\right) w_{c d 0}\right)+D_{1}\left(h_{t p}+h_{u 0}+h_{c 0}-h_{r}\right) \rho_{d} w_{d d}}{\left(h_{c 0}-h_{r}\right) \rho_{c b 0}\left(w_{c s 0} f_{l}+\left(1-w_{c s 0}\right)\right)+h_{u 0} \rho_{u b}\left(w_{u s p} f_{1}+\left(1-w_{u s p}\right)\right)+D_{1}\left(h_{t p}+h_{u 0}+h_{c 0}-h_{r}\right) \rho_{d}}
\end{gathered}
$$

$$
\begin{aligned}
& \rho_{c b l}=\frac{\rho_{s} \rho_{f l}}{\rho_{s}+w_{c s l}\left(\rho_{f l}-\rho_{s}\right)} \\
& D_{1}=\frac{\rho_{c b l} h_{\min }-\rho_{c b 0}\left(h_{c 0}-h_{r}\right)-\rho_{u b} h_{u 0}}{\left(h_{t p}+h_{u 0}+h_{c 0}-h_{r}\right) \rho_{d}}
\end{aligned}
$$

where $D_{1}=$ the volume of diluent added to $241-S Y-101$ per unit volume of total waste in 241-SY-101 after transfer to 101-SN; the crust is included in the waste volume for the purpose of estimating $D_{1}$

$\rho_{\mathrm{cbl}}=$ the bulk density of the mixed layer in 241-SY-101 after adding diluent

$\mathrm{w}_{\mathrm{csI}}=$ the weight fraction of undissolved solids in the Tank 241-SY-101 slurry

$\mathrm{w}_{c d 1}=$ the weight fraction of solute in the Tank 241-SY-101 liquid

$\mathrm{f}_{1}=$ the fraction of original solids that dissolve in the diluent, per Equation (G.1)

and the 241-SY-101 liquid density $\rho_{\mathrm{f} 1}$ is a function (Equation (G.2)) of the 241-SY-101 solute concentration $\mathrm{w}_{\mathrm{cd} 1}$. 


\section{G.3 Sludge Layers}

With the "mixed layer" solids concentrations and the layer depths having been calculated from Equations (G.8) through (G.20), the next step is to find the depth of the sludge layers that would result from settling after mixing stops. In both tanks, the remaining solids are assumed to settle to the same packed volume fraction ( $v_{u s p}$ ) as in the original 241-SY-101 sludge. In Tank 101$\mathrm{SN}$, which contains no pre-existing immobile sludge layer, the settled sludge layer depth $\mathrm{h}_{2 \mathrm{~s}}$ (in inches) and associated quantities are

$$
\begin{aligned}
& w_{u s 2}=\frac{\rho_{s} v_{u s p}}{\rho_{s} v_{u s p}+\rho_{f 2}\left(1-v_{u s p}\right)} \\
& h_{2 s}=\frac{h_{2}\left(\rho_{c b 2} w_{c s 2}-\rho_{c b f 2} w_{c s f}\right)}{\left(\rho_{u s 2} w_{u s 2}-\rho_{c b 52} w_{c s f}\right)} \\
& \rho_{c b f 2}=\frac{\rho_{s} \rho_{f 2}}{\rho_{s}+w_{c s f}\left(\rho_{f 2}-\rho_{s}\right)} \\
& \rho_{u s 2}=\frac{\rho_{s} \rho_{f 2}}{\rho_{s}+w_{u s 2}\left(\rho_{f 2}-\rho_{s}\right)}
\end{aligned}
$$

where $\quad \mathrm{w}_{\mathrm{csf}}=$ the unremovable solids fraction in the supernatant after settling has finished; the suspended fine particles; for a conservative (high end) estimate of gas retention, assume $\mathrm{w}_{\mathrm{csf}}$ is 0

$\rho_{\mathrm{cbf} 2}=$ the supernatant bulk density in 101-SN, including the fines (if any)

$\mathrm{w}_{\mathrm{us} 2}=$ the solids weight fraction in the settled sludge

$\rho_{\text {us } 2}=$ the bulk density of the settled sludge, which is assumed to settle to the same volume fraction $v_{u s p}$ as the original sludge in 241-SY-101

In Tank 241-SY-101, the total settled sludge depth $h_{1 s}$ (in inches) and associated quantities are

$$
\begin{aligned}
& w_{u s l}=\frac{\rho_{s} v_{u s p}}{\rho_{s} v_{u s p}+\rho_{f 1}\left(1-v_{u s p}\right)} \\
& h_{1 s}=\frac{h_{\min }\left(\rho_{c b l} w_{c s l}-\rho_{c b f 1} w_{c s f}\right)}{\left(\rho_{u s 1} w_{u s l}-\rho_{c b f 1} w_{c s f}\right)} \\
& \rho_{c b f 1}=\frac{\rho_{s} \rho_{f 1}}{\rho_{s}+w_{c s f}\left(\rho_{f 1}-\rho_{s}\right)} \\
& \rho_{u s 1}=\frac{\rho_{s} \rho_{f 1}}{\rho_{s}+w_{u s l}\left(\rho_{f 1}-\rho_{s}\right)}
\end{aligned}
$$

where $\rho_{\mathrm{cbf} 1}=$ the supernatant bulk density in 241-SY-101, including the fines (if any)

$\mathrm{w}_{\text {usl }}=$ the solids weight fraction in the settled sludge

$\rho_{\text {usI }}=$ the bulk density of the settled sludge in 241-SY-101

The depths and densities in Equations (G.21) through (G.28) are valid for gas-free sludge. 


\section{G.4 Gas Retention and Release}

Next, the gas retention in and release from the two tanks need to be estimated. Assume that the gas that is generated in the sludge is retained up to the point of neutral buoyancy, at which point the gas-containing sludge has the same density as the supernatant above it. Then the volume fractions of gas in the neutrally buoyant sludge in the tanks are

$$
\begin{aligned}
& \alpha_{1}=\frac{\rho_{\mathrm{us} 1}-\rho_{\mathrm{cbf} 1}}{\rho_{\mathrm{us} 1}} \\
& \alpha_{2}=\frac{\rho_{\mathrm{us} 2}-\rho_{\mathrm{cbf} 2}}{\rho_{\mathrm{us} 2}}
\end{aligned}
$$

where $\quad \alpha_{1}=$ void fraction in the sludge in 241-SY-101

$\alpha_{2}=$ void fraction in the sludge in 101-SN

The gas in the voids increases linearly in density from the top to the bottom of the sludge layer, as a result of the variation of local hydrostatic head. The average gas pressure and density in the sludge occurs halfway down into the sludge layer. These average conditions can be used to estimate the total gas in the sludge.

Of the gas in the voids, the only portion released is that which at ambient pressure (at the top of the waste) exceeds the amount required for local neutral buoyancy of the sludge. And of the gas released, only part is hydrogen, the gas that is the major safety concern in the release. The expression for the volume of hydrogen released from each tank during an event is

$$
\begin{aligned}
& V_{\mathrm{H} 1}=\frac{f_{\mathrm{H}} \alpha_{1} A_{1} h_{1 s}}{1-\alpha_{1}} \frac{g\left(h_{t p} \rho_{t}+\left(h_{1}-h_{1 s}\right) \rho_{c b f 1}+0.5 h_{1 s} \rho_{u s 1}\right)}{P_{0}} \\
& V_{H 2}=\frac{f_{H} \alpha_{2} A_{2} h_{2 s}}{1-\alpha_{2}} \frac{g\left(\left(h_{2}-h_{2 s}\right) \rho_{c b f 2}+0.5 h_{2 s} \rho_{u s 2}\right)}{P_{0}}
\end{aligned}
$$

where $\mathrm{V}_{\mathrm{H} 1}=$ the volume/event of hydrogen released in Tank 241-SY-101

$\mathrm{V}_{\mathrm{H} 2}=$ the volume/event of hydrogen released in Tank 101-SN

$f_{\mathrm{H}}=$ fraction of the gas generation that is hydrogen; set to 0.3

$\rho_{\mathrm{t}}=$ bulk density of the crust; set to $1.3 \mathrm{~g} / \mathrm{cc}$

$\mathrm{P}_{0}=$ ambient (dome space) pressure; set to $1 \mathrm{~atm}$ (in consistent units)

are

The maximum waste depths in the tanks (with gas retained to the point of neutral buoyancy)

$$
\begin{aligned}
& h_{\mathrm{TG} 1}=h_{\min }+h_{\mathrm{tp}}+\mathrm{h}_{1 \mathrm{~s}} \frac{\alpha_{2}}{1-\alpha_{2}} \\
& \mathrm{~h}_{\mathrm{TG} 2}=\mathrm{h}_{2}+\mathrm{h}_{2 \mathrm{~s}} \frac{\alpha_{2}}{1-\alpha_{2}}
\end{aligned}
$$

where $\mathrm{h}_{\mathrm{TG}}=$ the total waste height, including gas, in Tank 241-SY-101 (inches)

$\mathrm{h}_{\mathrm{TG} 2}=$ the total waste height, including gas, in Tank 101-SN (inches) 
The maximum depths attained (as calculated by Equations (G.33) and (G.34)) must not exceed an $h_{\max }$ of 422 inches, the level of the "lip" in both Tank 241-SY-101 and Tank 101-SN. This serves as a limit on tank fill in whichever tank reaches $h_{\max }$ first.

A value for the dome volume is needed in order to estimate the average hydrogen concentration in the dome space just after a release (assumed instantaneous). The plan-view area of each tank is $6.36 \times 10^{5} \mathrm{in}^{2}$, and the volume of dome space above the 422 -inch-high lip is $33,000 \mathrm{ft}^{2}$, or $5.7 \times 10^{7} \mathrm{in}^{2}$. This volume corresponds to an additional 90 inches of height, if the additional volume is taken as cylindrical. The assumption that the dome volume is cylindrical is accurate for calculating volume displaced by sludge or gas, though not for calculating sludge rise heights above 422 inches. Thus, assuming that the released gas displaces the dome atmosphere rather than mixing with it and being diluted, the hydrogen concentrations in the domes of the two tanks after release are

$$
\begin{array}{ll}
\mathrm{c}_{\mathrm{H} 1}=\frac{\mathrm{V}_{\mathrm{H} 1}}{\left(512-\mathrm{h}_{\mathrm{TG} 1}\right) \mathrm{A}_{1}} & \left(\text { a maximum value of } \mathrm{f}_{\mathrm{H}}\right) \\
\left.\mathrm{c}_{\mathrm{H} 2}=\frac{\mathrm{V}_{\mathrm{H} 2}}{\left(512-\mathrm{h}_{\mathrm{TG} 2}\right) \mathrm{A}_{2}} \quad \text { (a maximum value of } \mathrm{f}_{\mathrm{H}}\right)
\end{array}
$$

Note that Equations (G.35) and (G.36) overestimate the hydrogen concentrations by ignoring mixing and ventilation.

\section{G.5 Results}

Figure G.1 shows the maximum post-rollover hydrogen concentration in the dome space of either tank. Under current conditions (zero transfer, zero dilution), the maximum hydrogen concentration is calculated to be $14.0 \mathrm{vol} \%$. In the lower part of the figure, Tank 241-SY-101 contains the maximum concentration -- hence the insensitivity to the amount of dilution of the transferred slurry (which only affects 101-SN). At higher transferred volumes and dilution factors (the top right part of the figure), Tank 101-SN controls the hydrogen concentration. When about half the waste has been transferred from 241-SY-101 to 101-SN, hydrogen concentrations that are less than the lower flammable limit can be attained at low dilution ratios.

Figure G.2 depicts the maximum total gas volume released from either tank at rollover, divided by the amount of gas estimated as being released from 241-SY-101 under present conditions. Not surprisingly, this release volume ratio behaves in much the same manner as the hydrogen concentration. The post-transfer gas releases are minimum when about half the waste has been transferred from 241-SY-101 to 101-SN.

Figure G.3 shows the amount of new waste volume generated, expressed as a fraction of the original waste volume in Tank 241-SY-101. The minimum values of waste generation can be found only near zero transfer and zero dilution, as is to be expected.

\section{G.6 References}

Herting, D. L. 1992. "Laboratory Characterization of Samples Taken in May 1991 from Hanford Waste Tank 241-SY-101." WHC-SD-WM-DTR-024, Rev. 0-A, Westinghouse Hanford Company, Richland, Washington.

Perry, R. H., and C. H. Chilton. 1973. Chemical Engineers' Handbook, 5th Ed. McGraw-Hill Book Company, New York. 
Reynolds, D. A, and D. L. Herting. 1984. Solubilities of Sodium Nitrate, Sodium Nitrite, and Sodium Aluminate in Simulated Nuclear Waste. RHO-RE-ST-14P, Rockwell Hanford Operations, Richland, Washington. 


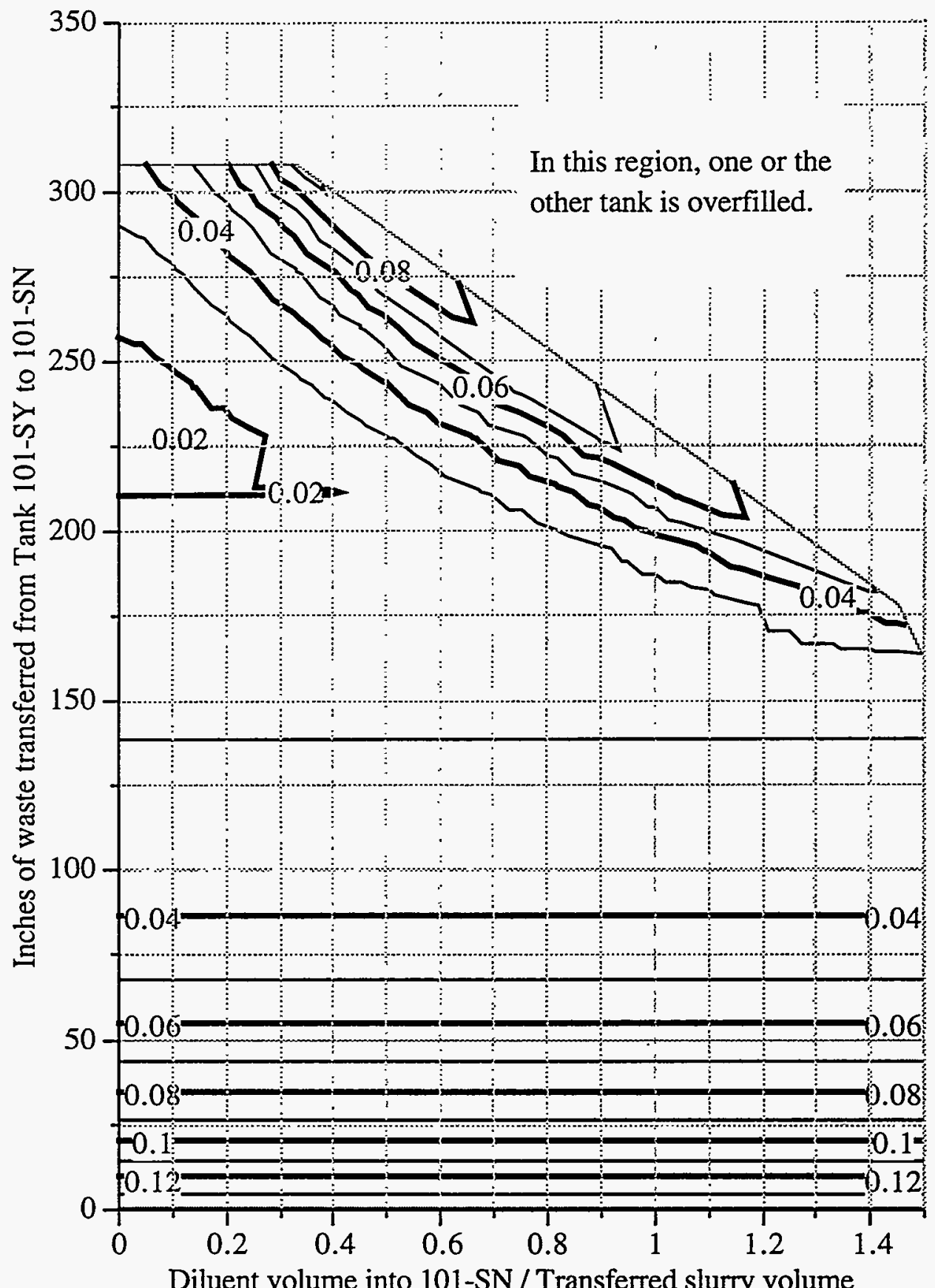

Diluent volume into 101-SN / Transferred slurry volume

Figure G.1. Maximum Hydrogen Concentration (volume fraction) Predicted for Either Tank's Dome Space After Transfer and Dilution 


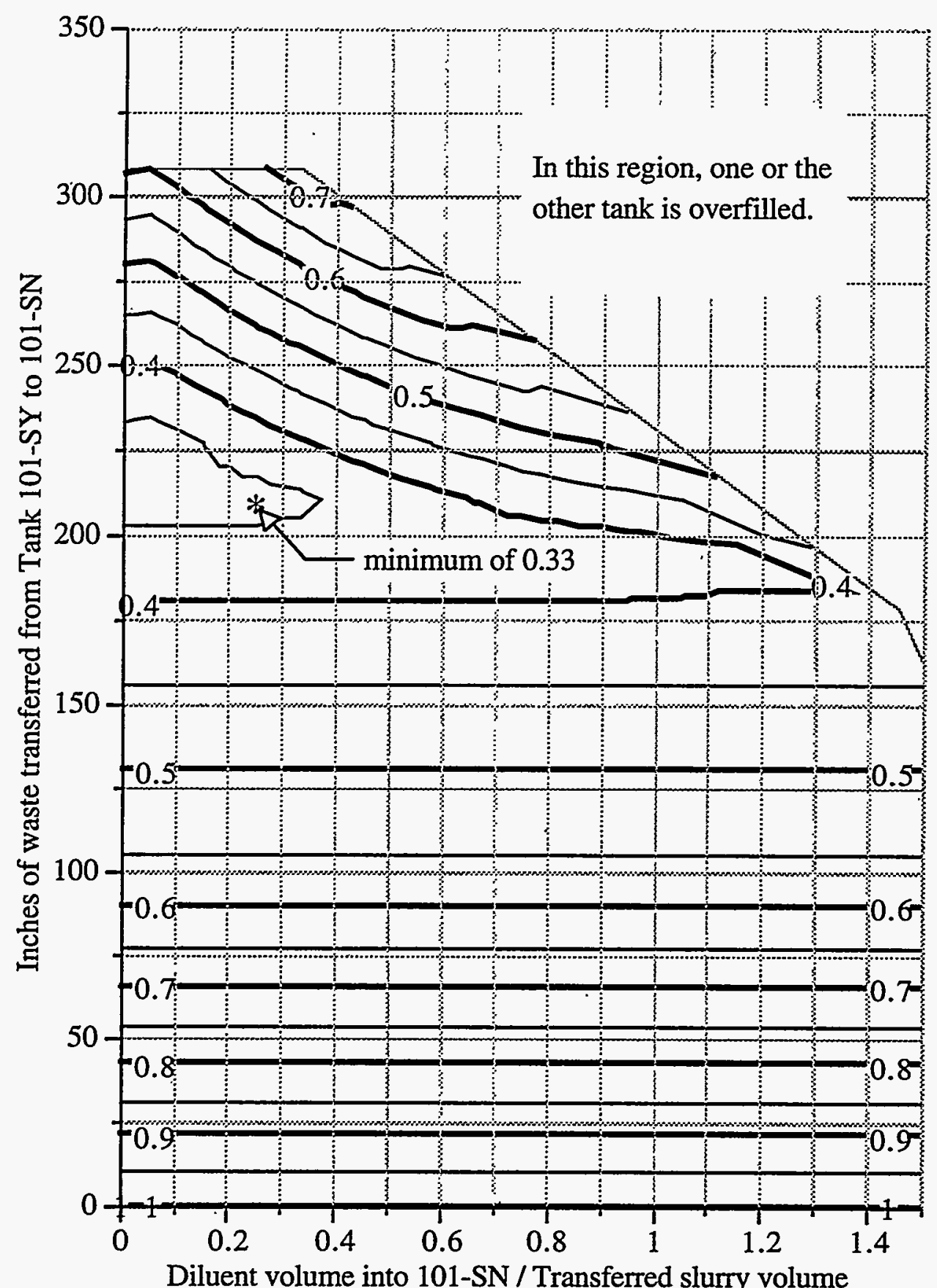

Figure G.2. Maximum Ratio of GasRelease Volume (after to before) Predicted for Either Tank as a Result of Transfer and Dilution 


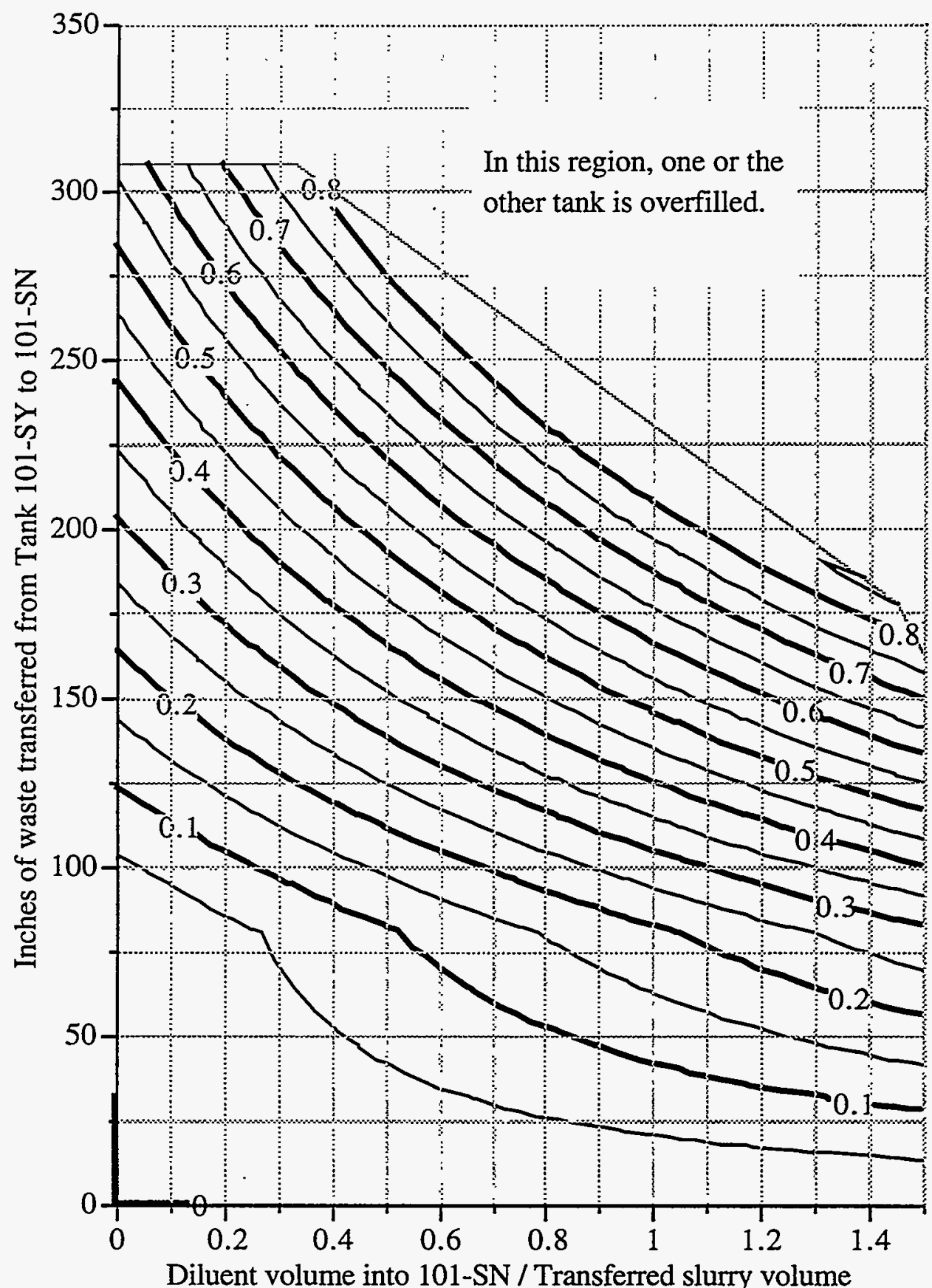

Figure G.3. Amount of Additional Waste Volume Generated by Transfer and Dilution Expressed as a Fraction of Original 101-SY Waste Volume 


\section{Distribution}

No. of

Copies

Offsite

12 DOE Office of Scientific and Technical Information

C. S. Abrams

1987 Virginia

Idaho Falls, ID 83404

E. C. Ashby

225 North Avenue

Boggs Chemistry Building

Georgia Institute of Technology

Atlanta, GA 30332

N. W. Bibler

Westinghouse Savannah River Co.

Building 773A, Room B132

Box 616

Aiken, SC 29802

D. Campbell

102 Windham Road

Oak Ridge, TN 37830

F. N. Carlson

6965 North, 5th West

Idaho Falls, ID 83401

E. D. Collins

Oak Ridge National Laboratory

P.O. Box 2008

7930, MS-6385

Oak Ridge, TN 37831-6385

Morton Corn

Room 6010

School of Hygiene and Public Health

John Hopkins University

615 N. Wolf Street

Baltimore, MD 21205
No. of

Copies

M. First

Harvard School of Public Health

665 Huntington Avenue

Boston, MA 02115

Charles W. Forsberg

Oak Ridge National Laboratory

P.O. Box 2008, MS-6495

Oak Ridge, TN 37831-6495

E. P. Horwitz

Chemistry Department

Argonne National Laboratory

9700 Cass Avenue

Argonne, IL 60439-4831

Billy C. Hudson

202 Northridge Ct.

Lindsborg, KS 67456

M. S. Kazimi

Massachusetts Institute of Technology

Department of Nuclear Engineering

77 Massachusetts Avenue

Cambridge, MA 02139

J. L. Kovach

Nuclear Consulting Services, Inc.

P.O. Box 29151

Columbus, OH 43229-0151

B. R. Kowalski

Chemistry Department, BG-10

University of Washington

Seattle, WA 98195

Thomas S. Kress

Oak Ridge National Laboratory

P.O. Box 2009, MS-8088

Oak Ridge, TN 37831-8088

Distr.1 
No of

Copies

Thomas E. Larson

Los Alamos National Laboratory

MS-P915, DX-DO

P.O. Box 1663

Los Alamos, NM 87545

4 Los Alamos National Laboratory

P.O. Box 1663

Los Alamos, NM 87545

Attn: L. H. Sullivan, K557

J. R. White, K555

W. L. Kubic, K557

K. Pasamehmetoglu, K555

D. Meisel

Chemistry Department

Argonne National Laboratory

9700 Cass Avenue

Argonne, IL 60439-4831

T. E. Larson

Los Alamos National Laboratory

MS-P915, DX-DO

P.O. Box 1663

Los Alamos, NM 87545

D. T. Oakley

Waste Policy Institute

Suite 600

555 Quince Orchard Road

Gaithersburg, MD 20878

Don Orth

124 Vivion Drive

Aiken, South Carolina 29803

F. L. Parker

Vanderbilt University

P.O. Box 1596, Station B

Nashville, TN 37235

D. Pepson

U.S. Department of Energy

Trevion II Building, EM-35

Washington, D.C. 20585-0002
No of

Copies

G. E. Schmauch

Air Products and Chemicals, Inc.

7201 Hamilton Boulevard

Allentown, PA 18195-1501

Scott E. Slezak

Sandia National Laboratory

Org. 6471/MS 0741

P.O. Box 5800

Albuquerque, NM 87185-0744

Dana Powers

Sandia National Laboratory

Dept. 6404/MS-0744

P.O. Box 5800

Albuquerque, NM 87815-0744

W. J. Thomson

Dept. of Chemical Engineering

Washington State University

Pullman, WA 99164

J. Tseng

U.S. Department of Energy

Trevion II Building, EM-35

Washington, D.C. 20585-0002
A. S. Veletsos
5211 Paisley
Houston, TX 77096

Onsite

16 DOE Richland Operations Office

D. H. Alexander

S7-51

S. T. Burnum

S7-53

R. F. Christensen

S7-54

R. E. Gerton

S7-54

J. M. Gray (10)

S7-54

G. W. Rosenwald

S7-54

Y. G. Noorani 
No of

Copies

39 Westinghouse Hanford Company

W. T. Alumkal

S7-85

H. Babad

R. E. Bauer

S7-30

G. T. Bear

T. R. Benegas

L. E. Efferding

R. L. Fritz

M. N. Hall

C. E. Hanson

D. L. Herting

J. R. Jewett

G. D. Johnson

N. W. Kirch

L. S. Krogsrud

D. C. Larsen

J. W. Lentsch (10)

R. M. Marusich

N. G. McDuffie

M. A. Payne

J. C. Person

D. A. Reynolds

C. A. Rieck

R. C. Roal

G. J. Rust

C. P. Shaw

D. D. Stepnewski

J. D. Thomson

J. E. VanBeek

G. F. Vargo

E. D. Waters
No of

Copies

47 Pacific Northwest Laboratory

J. M. Alzheimer K5-22

W. J. Apley $\quad$ S7-71

Z. I. Antoniak K7-15

R. M. Bean P8-08

S. Q. Bennett K7-90

P. R. Bredt P7-25

J. W. Brothers K5-22

W. D. Chvala K5-08

J. B. Colson K5-10

E. J Eschbach K7-15

W. B. Gregory K7-22

J. D. Hudson K7-15

B. M. Johnson K1-78

D. L. Lessor K7-15

L. A. Mahoney K7-15

T. E. Michener K7-15

F. E. Panisko P8-34

M. R. Powell P7-19

L. M. Peurrung P7-41

K. P. Recknagle K7-15

H. C. Reid K7-15

L. A. Schienbein K5-20

P. A. Scott P7-43

C. L. Shepard K5-25

C. W. Stewart (15) K7-15

J. M. Tingey P7-25

D. S. Trent K7-15

Publishing Coordination

Technical Report Files (5) 